JORGE LUIZ DE BRITO JUNIOR

\title{
INTERFACE ENTRE A PROTEÇÃO À PROPRIEDADE INTELECTUAL E O DIREITO DE CONCORRÊNCIA NO BRASIL
}

Dissertação de Mestrado

Orientador: Professor Associado Dr. José Maria Arruda de Andrade

UNIVERSIDADE DE SÃO PAULO

FACULDADE DE DIREITO

São Paulo-SP

2015 
JORGE LUIZ DE BRITO JUNIOR

\section{INTERFACE ENTRE A PROTEÇÃO À PROPRIEDADE INTELECTUAL E O DIREITO DE CONCORRÊNCIA NO BRASIL}

Dissertação apresentada a Banca Examinadora do Programa de Pós-Graduação em Direito, da Faculdade de Direito da Universidade de São Paulo, como exigência parcial para obtenção do título de Mestre em Direito, na área de concentração Direito Econômico, Financeiro e Tributário, sob a orientação do Professor Associado Dr. José Maria Arruda de Andrade

UNIVERSIDADE DE SÃO PAULO

FACULDADE DE DIREITO

São Paulo-SP 
Data de defesa:

Resultado:

BANCA EXAMINADORA:

Prof. Assoc. Dr. José Maria Arruda de Andrade

Universidade de São Paulo

Prof. Dr.

Universidade de São Paulo

Prof. Dr.

Universidade

Faculdade de Direito da Universidade de São Paulo

São Paulo/SP

Ano de Depósito: 2015 


\section{Dedico este trabalho}

À Ana Paula, minha esposa, pelo amor e cuidado com os quais ela me abençoa todos os dias, sem os quais a minha carreira seria não apenas mais difícil, como também um exercício frio e sem sentido 


\section{AGRADECIMENTOS}

Por trás de todo trabalho, por simples que seja, há uma história de vida, pessoas que marcam nosso caminho e que nos ajudam a compreender melhor não apenas o Direito, como, também, a vida. De fato, este trabalho não teria sido remotamente possível sem algumas pessoas, pelas quais sou imensamente grato a Deus acima de tudo. De modo que, sem nenhum receio de me alongar excessivamente, passo aos agradecimentos.

Agradeço aos meus pais primeiramente, pelo incentivo e investimento em minha educação e ao meu irmão, Pedro Luiz, pela amizade e "torcida" de sempre.

Agradeço à minha esposa Ana Paula, por toda paciência e apoio. Nada em minha vida teria a mesma alegria, a mesma cor, se não fosse pelo prazer de chegar em casa e dividir cada uma das pequenas conquistas do meu dia com você. Schumpeter era conhecido por desencorajar seus alunos quando o assunto era casamento. Bem, em nosso trabalho, vemos que, apesar de brilhante, ele não estava certo em tudo...

Agradeço ao Daniel Gelcer, Mestre e futuro Doutor em Direito, amigo na melhor (ou única) acepção do termo. Agradeço pelas tantas conversas que me ajudaram a amadurecer um projeto acadêmico, pelas palavras de encorajamento e ânimo, por ter praticamente me aberto as portas da pós-graduação, ao introduzir meu projeto ao Professor José Maria, de quem somos co-orientandos. Como um irmão mais novo, pude acompanhá-lo em toda sua jornada acadêmica e aprender com suas escolhas e experiências. Agradeço, também, pela auxílio na revisão da dissertação.

Agradeço, imensamente, pela orientação e, principalmente, pela oportunidade de conviver com o Professor José Maria. O desenvolvimento de meu tema em muito deve à sua segunda viagem, como Visiting Researcher, ao Max Planck Institute, München, em meados de 2011. Trata-se do maior e mais influente instituto em questões envolvendo a Propriedade Intelectual e a Concorrência na Europa. Foi graças a este contato que primeiro tive acesso ao trabalho de Josef Drexl, autor cuja obra foi de grande importância, sobretudo em minhas primeiras impressões sobre o tema.

O Zé, como ele próprio se deixa ser chamado pelos seus orientandos, me ensinou, acima de tudo, pelo exemplo, pela sua energia criativa, espírito crítico e rigor acadêmico. Considerome realmente afortunado por tê-lo acompanhado de perto enquanto escrevia a sua tese de Livre Docência (a "Economização do Direito Concorrencial") - aprovada com as mais distintas notas por gabaritada banca de qualificação. Foi um privilégio tê-lo observado na 
reconstrução, nesta obra, das várias escolas de pensamento - sejam elas filosóficas, jurídicas ou econômicas - sem nunca recorrer a simplificações e sempre buscando identificar as dicotomias, os antagonismos, as implicações e os marcos teóricos de cada sistema de pensamento.

Agradeço, também, aos Professores Luis Fernando Massoneto e Alessandro Octaviani, pelos preciosos comentários e conselhos na minha banca de Qualificação. Ao Professor Octaviani sou particularmente grato por ter disponibilizado a sua sempre atenciosa secretária, que facilitou imensamente a minha pesquisa dos casos mais importantes em que o Conselheiro Octaviani havia proferido votos.

Agradeço, também, ao Tilmann Quarch, pesquisador do Instituto Max Planck, que auxiliou no acesso à doutrina alemã utilizada, especialmente, os textos clássicos de Fritz Machlup sobre a Propriedade Intelectual e os Comentários à GWB, também fornecendo importantes esclarecimentos sobre o estado atual da discussão na Europa.

Agradeço ao Gerd Müller pelo auxílio na tradução do material em alemão.

Agradeço ao amigo Bruno Nunes Medeiro, economista da FEA/USP e amigo de longa data, desde que estudávamos na Escola Técnica Federal no final da década de 1990 e que foi muito importante para minha melhor compreensão sobre os temas econômicos.

Agradeço aos sócios do escritório em que trabalho, Fernando Gaia, Enio Zaha e Alexandre Tróia, pelos muitos exemplos de profissionalismo e excelência e por terem me proporcionado a oportunidade de um intercâmbio profissional com duração de três meses em uma firma de advocacia em Salt, Lake City, Estados Unidos durante o período em que escrevia o Mestrado - o que muito contribuiu para uma melhor compreensão do Direito Norte-Americano, bem como para um profundo amadurecimento profissional e pessoal. Agradeço ao constitucionalista Michael Anderson, amigo que fiz em Salt Lake City e com quem pude desfrutar de esclarecedores bate-papos sobre momentos importantes da histórica jurisprudencial americana.

Agradeço, ainda, a colegas como Georgios Theodoros e Maurício Barros, pelas importantes contribuições para meu desenvolvimento em matéria de textos jurídicos em inglês. O Maurício, a quem também pude acompanhar em sua banca de doutorado nesta Faculdade, foi sempre um grande incentivador da minha produção acadêmica. Agradeço a outros tantos amigos de firma, que mesmo sem terem se envolvido diretamente, dividiram momentos bons e ruins comigo nessa fase: Sandrya Valmana, Alessandro Calaf, Jorge Facure, Lívia Maciel, Aline Aun, Eduardo Bartkevicius, Cícero 
Coppola, Daniela Zicatti, Paulo Henrique Gomes de Oliveira, Isabela Pesoti, meus companheiros de time de futebol da Gaia (o melhor time do mundo) e tantos outros.

Finalmente, agradeço ao amigo Ian Pratt pela revisão cuidadosa do Abstract.

Jorge Luiz de Brito Junior

São Paulo, 5 de janeiro de 2015. 
"Dream - not making dreams your master Think - not making thoughts your aim With Crowds, keep your virtue With Kings - nor lose the common touch" (Rudyard Kipling) 


\section{RESUMO}

Embora os direitos de Propriedade Intelectual (PI) sejam supostamente instituídos de forma a fomentar a inovação e o bem-estar em longo prazo, seu uso pode ensejar comportamentos oportunistas e abusivos - como os Artigos 8.2 e 40 do TRIPS expressamente admitem. Sempre que tal tipo de comportamento afetar a concorrência em determinado mercado - excluindo concorrentes, impondo barreiras à entrada, prejudicando consumidores por meio de aumento de preços ou redução da oferta - o Direito de Concorrência será chamado a intervir. Considerando tais questões, o objetivo desse trabalho é identificar um quadro de trabalho brasileiro para tratar de questões envolvendo questões de Direito de Concorrência relacionadas à Propriedade Intelectual. O autor buscou delinear os conceitos de "uso abusivo de direitos de Propriedade Intelectual", "Dominação de Mercado" por meio de uso da Propriedade Intelectual e de "abuso de posição dominante", considerando o novo quadro regulatório introduzido pela Lei $12.259 / 2001$.

PALAVRAS-CHAVE: Propriedade Intelectual, Direito de Concorrência, Escola de Chicago, Abordagens Pós-Chicago, Joseph Schumpeter, More Economic Approach, Fusões e Aquisições de Bens Intangíveis, Cláusulas Anticoncorrenciais em Contratos de Transferência de Tecnologia, Acordos de Licenciamento Cruzado (Patent Pools), Padronização, Abuso na Fixação de Royalties, Recusa a Licenciar, Patent Trolls e Sham Litigation, Mercados Secundários, Direito Concorrencial brasileiro 


\begin{abstract}
While intellectual property (IP) rights are usually claimed to be designed to foster innovation and welfare in the long run, their use may give rise to opportunistic, abusive behavior - as Articles 8.2 and 40 of TRIPS openly admit. Whenever such sort of behavior affects competition in a given market - whether by dislodging competitors, imposing barriers to entry, harming costumers, raising prices or reducing output - competition law is called to intervene. Considering these issues, the purpose of this paper is to identify a Brazilian legal framework for dealing with IP related competition issues. The author sought to draw the legal concepts of "abusive of IP rights", "market domination" and “abuse of dominant position” considering the new regulatory framework introduced by Law 12.259/2011.
\end{abstract}

KEY-WORDS: Intellectual Property, Competition Law, Chicago School, Post-Chicago Approaches, Joseph Schumpeter, More Economic Approach, Mergers and Acquisitions of Intangible Assets, Anticompetitive Licensing Terms, Cross-Licensing Agreements (Patent Pools), Standardization, Royalties Fixing Abuses, Refusal to license, Patent Trolls and Sham Litigation, Downstream Markets, Brazilian Competition Law 


\section{SUMÁRIO}

Capítulo 1 - Historia das Ideias sobre a Propriedade Intelectual e aS PRIMEIRAS TENSÕES COM A CONCORRÊNCIA .......................................................................14

1.1. DisseminaÇão Dos Regimes de Patente ATÉ 1850 .................................................. 16

1.2. O Movimento Anti-Patentes no Século XiX e Seu Declínio................................19

1.3. O Embate entre Protecionistas e DefEnsores do Livre-ComÉrCiO..................25

1.3.1. TEORIAS DA PROPRIEDADE SOBRE IDEIAS, FUNDADAS NO DiREITO NATURAL E NO

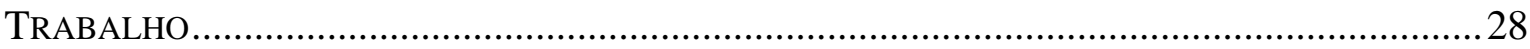

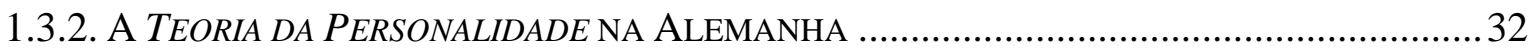

1.3.3. TEORIAS SOBRE O EstímUlo À INOVAÇÃo E À DivUlgaÇÃo do CONHECIMENTO ......37

1.4. CONCLUSÕES PARCIAIS SOBRE A RECONSTRUÇão HistóRICA DAS TEORIAS PARA JUSTIFICAR A PROPRIEDADE INTELECTUAL..................................................................... 39

1.5. TEORIAS ECONÔMICAS PARA JustificAR a Propriedade INTELECTUAL No SÉculo XX 41

1.5.1. AntECEDENTES: O VALOR EConÔMICO SubJetivo do ConHECIMENTO......................41

1.5.2. FundAMENTAÇÃO ECONÔMICA DA PROPRIEDADE ……………………………….....4

1.5.3. EXTENSÃo DA FUNDAMENTAÇÃo ECONÔMICA DA PROPRIEDADE SOBRE BENS

TANGÍVEIS À "PROPRIEDADE” SOBRE BENS INTELECTUAIS ..................................................46

1.5.4. CRíticas À EXTENSÃo dOS Fundamentos EConômicos dA PropriedAde TANGível

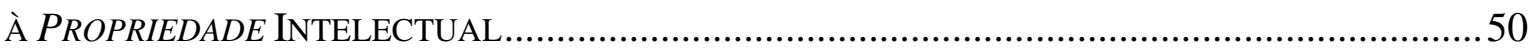

1.5.5. CONSEQUÊNCIAS ECONÔMICAS DE UMA "SUPERPROTEÇÃO" PRIVADA DA INFORMAÇÃO

1.5.6. Conclusões Parciais Sobre a ANÁlise EConômica da Propriedade

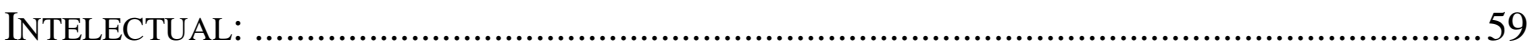

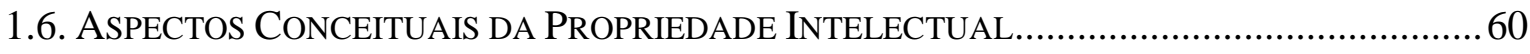

1.6.1. DivisÃo TRADICIONAL ENTRE PROPRIEDADE INDUSTRIAL E PROPRIEDADE LITERÁRIA

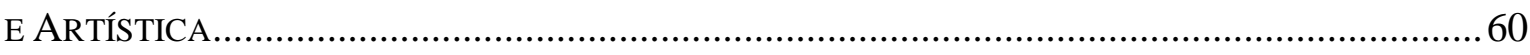

1.6.2. Crise da DivisÃo Tradicional entre Propriedade Industrial e ArTística.....64 1.6.3. Conclusão sobre as EsPécies de Propriedade InTELECtual. DelimitaÇÃo de ESCOPO DO TRABALHO

CAPítulo 2 - Histórico das InTERFACES ENTRE DireIto ANTITRUSTE (DireITO Concorrencial) E a Propriedade InTELECTUAL

2.1. O AdVENTO Do SHERMAN Act (1890) E PRINCIPAIS IDEIAS ECONÔMICAS SOBRE A CONCORRÊNCIA NOS EUA

2.1.1. As Duas Primeiras Décadas do Antitruste: PrevalênCia da Propriedade INTELECTUAL 
2.1.3. NÃO APLICAÇÃO DO SHERMAN ACT EM CASOS ENVOLVENDO A PI ............................. 80

2.1.4. A SeÇão 3 do Clayton Act E os Casos envolvendo Tying ARRANGEMENTS ........85

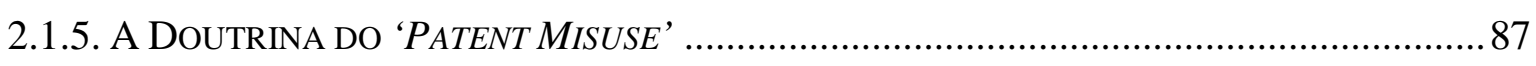

2.1.5. AplicaÇÃo do Antitruste - PresunÇão de Poder de Mercado E os "Nine-Nos"

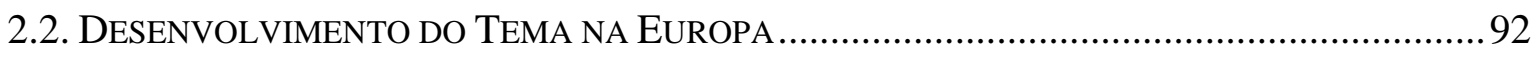

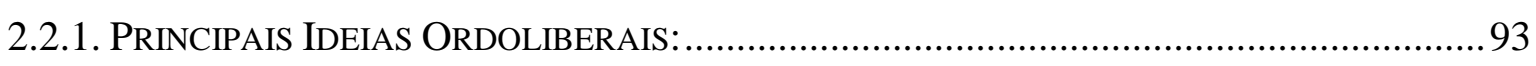

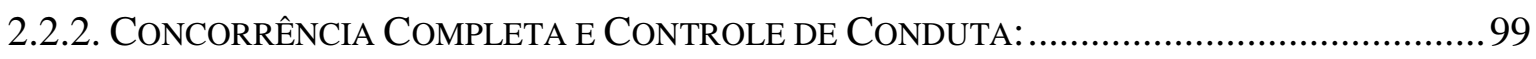

2.2.3. Propriedade Intelectual e a TeOria do "Estímulo e Proteção ao INVESTIMENTO". 100

2.2.4. RESUMO DA INFLUÊNCIA DAS IDEIAS ORDOLIBERAIS NA RELAÇÃO ENTRE DIREITO

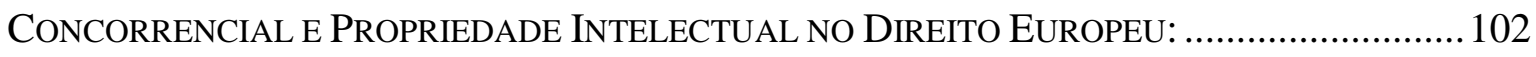

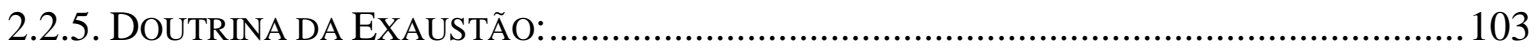

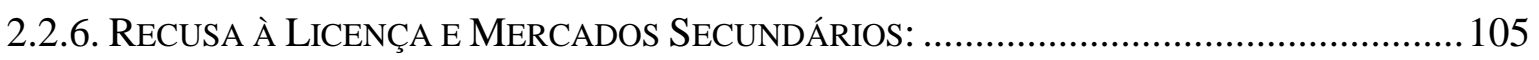

2.3. A Escola de Chicago e os Conceitos de EFiciênCia Produtiva E EFiciencia DinamiCA. AMERICANIZAÇÃo do DiREITO EUROPEU (MORE ECONOMIC APPROACH) ?..... 108

Capítulo 3 - O Debate sobre a InTerface entre a Propriedade Intelectual e o Direito de CoNCORRÊNCIA NO SÉCULO XXI: NovOS DESAFIOS TRAZIDOS PELOS

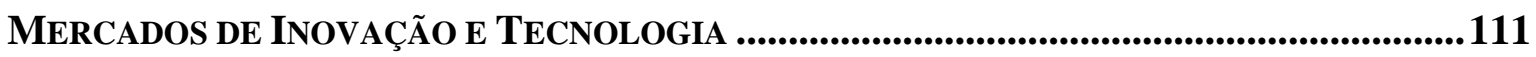

3.1. INTRODUÇÃO: DESENVOLVIMENTOS NA TEORIA ECONÔMICA PÓS-CHICAGO E IMPACTO PARA O DEBATE SOBRE CONCORRÊNCIA E PROPRIEDADE INTELECTUAL .............................111

3.2. A CRESCENTE IMPORTÂNCIA DA INOVAÇÃo TECNOLÓGICA PARA O DEBATE ATUAL SOBRE PROPRIEDADE INTELECTUAL E CONCORRÊNCIA …............................................... 117

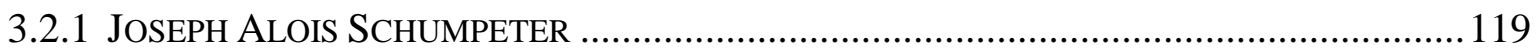

3.2.2 A DiCOTOMIA SCHUMPETER X ARROW: MONOPÓLIOS SÃO MAIS PROPENSOS A

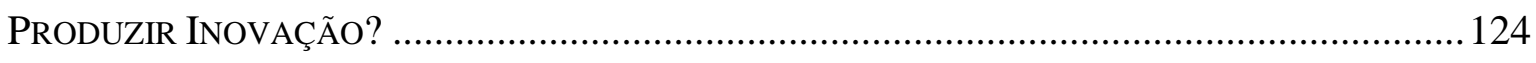

3.2.3. EFICIÊNCIA DinÂMICA E MERCADOS DE TECNOLOGIA E INOVAÇÃO.......................... 130

3.2.4. AnÁlise Dinâmica no ConteXto de Controle de Atos de ConcentraÇÃo

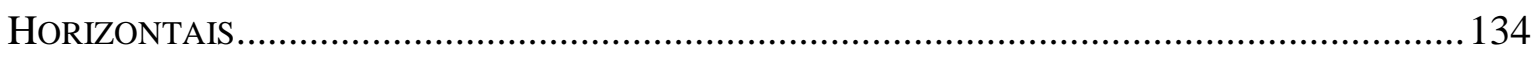

3.3. CARACTERÍsticas dA “Nova ECONOMIA” E BARREIRAS À ENTRADA ......................... 138

3.3.1. DeVe-Se Aplicar uma “TeOria da Decisão” na ANÁlise de Condutas Com POTENCIAL IMPACTO SOBRE A INOVAÇÃO TECNOLÓGICA? ................................................. 144

3.4. ILUSTRAÇÕES dOS ENCONTROS ENTRE PROPRIEDADE INTELECTUAL E ANTITRUSTE ... 147

3.4.1. FusÕES E AQUISIÇÕES DE ATIVOS INTELECTUAIS .................................................. 147 


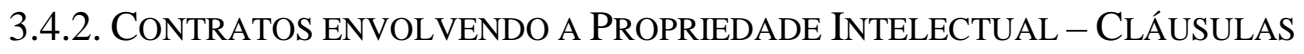

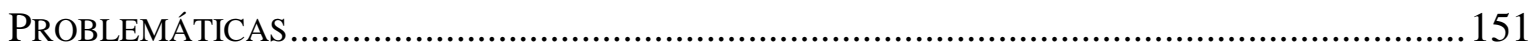

3.4.2.1. LiCEnCIAMENTo CruZado (Patent PoOLS) E PAdronizaÇão:............................. 156

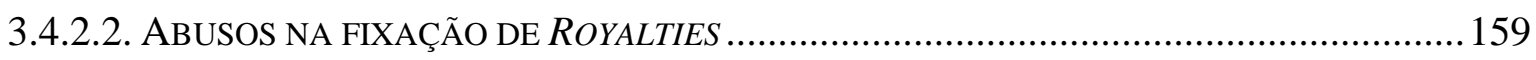

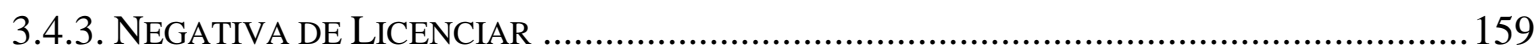

3.4.4. OUtras Figuras Anticoncorrenciais EnVOLVENdo a Propriedade

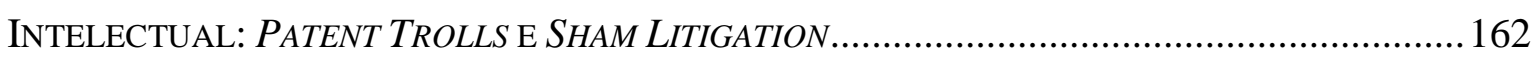

3.5 ASPECTOS CONCORRENCIAIS DO LICENCIAMENTO INTERNACIONAL DE TECNOLOGIA - O

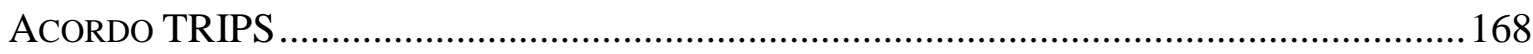

Capítulo 4 - Dos Rumos Atuais do Debate no Direito Brasileiro: AvanÇos E

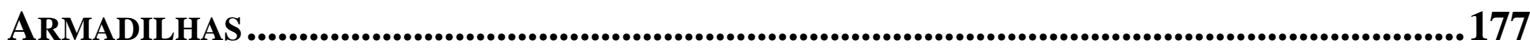

4.1. INTRODUÇÃO: A PROPRIEDADE INTELECTUAL NO CONTEXTO SiSTEMÁtiCO DA ORDEM ECONÔMICA BRASILEIRA.....................................................................................................................177

4.2. QUADRO DE TRABALHO DA LEGISLAÇÃo BRASILEIRA QUANTO À INTERFACE ENTRE PROPRIEDADE INTELECTUAL E ANTITRUSTE NO PERÍODO ANTERIOR À LEI No 12.529/2011.

4.2.1. O Caso das Autopeças de Reposição COMO UM CASO-Limite do QuAdRo dE TRABALHO BRASILEIRO QUANTO À INTERFACE ENTRE A PROPRIEDADE INTELECTUAL E O DIREITO DE CONCORRÊNCIA.

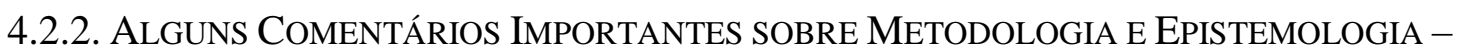
PAPEl DA ECONOMIA NAS DiscuSSÕES ENVOLVENDO DiREITO DA CONCORRÊNCIA.

Algumas ARMAdilHas A SEREM EvitAdas.

4.2.3. O CASO DAS PEÇAS DE REPOSIÇÃO COMO MARCO DIVISÓRIO NA JURISPRUDÊNCIA BRASILEIRA E DE IMPORTANTES MODIFICAÇÕES INTRODUZIDAS NO ORDENAMENTO JURÍDICO (LEI N $12.529 / 2011)$...............................................................................................................191

4.2.4. A QUESTÃo do PODER NOS MERCADOS SECUNDÁRIOS ................................................198

4.2.5. Meios Ilícitos de Conquista de Poder de Mercado ou Posição Dominante, POR MEIO DE EXERCÍCIO (ABUSIVO) DA PROPRIEDADE INTELECTUAL...................................202

4.2.6. Conclusão Parcial: Uma Tentativa de ConceituaÇão das Figuras do Abuso de Direitos de Propriedade Intelectual, Dominação de Mercados E Abuso de PosiçÃo DOMINANTE, CONSIDERANDO O NOVO QUADRO DE TRABALHO INTRODUZIDO PELA LEI No $12.529 / 2011$

4.3. Controle Antitruste sobre Contratos de Fornecimento/LicenCiamento de TECNOLOGIA - OUTRAS ARMAdILHAS 


\title{
Capítulo 1 - Historia das Ideias sobre a Propriedade InTElectual e as Primeiras Tensões COM a CONCORRÊNCIA
}

\begin{abstract}
"The arguments for patents, formulated in these terms and opposed and defended during the controversy of the nineteenth century, are still used today whenever the patent system is debated. Indeed, little, if anything, has been said for or against the patent system in the twentieth century that was not said equally well in the nineteenth" [MACHLUP e PENROSE] ${ }^{1}$
\end{abstract}

Diversas justificativas, tanto morais como econômicas, têm sido apresentadas para suportar a proteção conferida pela Propriedade Intelectual.

Nesse campo, defensores da Propriedade Intelectual costumam fazer uso do argumento retórico de que a sua proteção visaria conceder estímulos para a continuidade de investimentos em pesquisa e inovação. Não raro, este argumento é suscitado em discussões envolvendo a Propriedade Intelectual, especialmente quando o foco da discussão se volta para o real interesse público da proteção em um caso concreto em que altos valores da sociedade, como a saúde pública, por exemplo, estão em jogo ${ }^{2}$.

O apelo a este tipo de argumento é de uma estratégia retórica óbvia: ao invés de se defender o direito das empresas de obterem lucros exorbitantes de seus investimentos em Pesquisa e Desenvolvimento (P\&D) versus o interesse da população em obter acesso a medicamentos vitais, a lógica é invertida, ou seja: passa-se a defender maiores investimentos em saúde pública no longo prazo, o que diminui a resistência natural quanto à posição defendida pelas empresas (que, por sinal, em se tratando do setor farmacêutico, invariavelmente, consistem em grandes corporações).

Outras justificativas são igualmente frequentes, como os estigmas da pirataria e da quebra de patentes.

\footnotetext{
${ }^{1}$ Machlup, Fritz; Penrose, Edith , "The patent controversy in the nineteeth century" - The Journal of Economic History. Vol. X. n. I. 1950, pgs. 1-29

2 "A recusa da Suprema Corte indiana em defender a patente sobre o Gleevec, a droga contra o câncer de sucesso desenvolvida pelo gigante farmacêutico suiço Novartis, é uma boa notícia para muitos dos que sofrem de câncer na Índia. Se outros países em desenvolvimento seguirem o exemplo da Índia, será uma boa notícia em outros lugares, também: mais dinheiro poderia ser dedicado a outras necessidades, talvez. combatendo a Aids, proporcionando educação, ou fazendo investimentos que permitam o crescimento e a redução da pobreza. Esta é a proposta inicial do artigo assinado por Joseph E. Stiglitz e Arjun Jayadev para o veículo Project Syndicate. Mas a decisão indiana também significa menos dinheiro para grandes empresas farmacêuticas multinacionais. Não surpreendentemente, isso conduziu a uma resposta exagerada deles $e$ seus lobistas: a decisão, eles alegam, destrói o incentivo para inovar, e pode vir a ser um duro golpe para a saúde pública a nível mundial”. (http://www.jb.com.br/internacional/noticias/2013/04/09/a-prudente-quebrade-patentes-na-india/ - Jornal do $\quad$ Brasil - 09/04/2013
} http://www.jb.com.br/internacional/noticias/2013/04/09/a-prudente-quebra-de-patentes-na-india/) 
Novamente aqui, a força retórica do argumento é evidente, pois defender o contrário significa se colocar na difícil posição de defender a tolerância ao roubo - o que significa uma ofensa à moral.

Em ambos os casos, os argumentos se mostram como verdadeiros lugares comuns, expressões virais empregadas frequentemente em discussões, mas que não se mostram tão indiscutíveis quando submetidas a criticismo.

Não se têm notícias de que alguma multinacional do setor farmacêutico tenha cortado investimentos em P\&D, ou que se tenha retirado de um mercado, após, por exemplo, sofrer um revés nos tribunais em um caso envolvendo a negativa da tentativa de estender, indevidamente, a validade de uma patente, por meio de alterações insignificantes no medicamento já existente - como decidiu a Corte indiana na notícia acima citada. Tampouco o mito do inventor como um desbravador abnegado e altruísta e não alguém subordinado a uma grande empresa pode ser considerado como regra na realidade atual ${ }^{3}$. Não obstante, a noção de que os investimentos em inovação dependem exclusivamente do nível de proteção conferido à PI - e que, no limite, os incentivos seriam reduzidos a zero caso a proteção não fosse assegurada - parece ser aceita como verdade insofismável, sem que se procure recorrer aos dados objetivos da realidade.

A naturalidade com que se faz uso de tais argumentos em discussões envolvendo a Propriedade Intelectual desperta a necessidade de uma maior investigação sobre a sua raiz histórica.

Como sugere FRITZ MACHLUP ${ }^{4}$, ao contrário do que se poderia imaginar, os argumentos com os quais normalmente nos deparamos em discussões sobre os supostos

\footnotetext{
3 “(...) notwithstanding the mithology of the inventor in the garage, today most inventing goes on in business firms whose principal motive is profit. Even much of the innovation that occurs in unviversities has profitable licensing as a goal. The same thing is true in copyright. Indeed, and distressingly, the artist, author, and composer have almost become invisible in copyright litigation. The principal interest holders are publishers, movie or music producers or other media companies - and the motives are almost always financial" (Bohannan, Christina and HovenkamP, Herbert J., "Creation Without Restraint: Promoting Liberty and Rivalry in Innovation”, Oxford University Press, December 2011; U Iowa Legal Studies Research Paper. Disponível em SSRN: http://ssrn.com/abstract=2125277)

${ }^{4}$ MACHLUP, economista austríaco que migrou para os Estados Unidos em 1933, fugido do nazismo, estudou na Universidade de Viena na década de 1920, tendo sido aluno de LUDWIG VON MISES e FRIEDRICH HAYEK. Suas duas maiores áreas de trabalho foram a organização industrial e a economia monetária, mas também dedicou-se por toda a carreira ao estudo do método em economia e do papel dos tipos-ideais presentes nas premissas da teoria econômica (GoDIN, Benoît, "The Knowledge Economy: Fritz Machlup's Construction of a Synthetic Concept" - Disponível em http://www.csiic.ca/PDF/Godin_37.pdf). Pode-se identificar, em sua obra, os antecedentes de HAYEK, em suas críticas à racionalidade perfeita e à simetria de informações. MACHLUP consagrou a expressão "economia do conhecimento", em seu importante livro "The Production and Distribution of Knowledge" (1962). O autor foi um grande estudioso e crítico do sistema da Propriedade Intelectual, tendo, inclusive, produzido um estudo a pedido do Subcomitê de Patentes, Marcas e Copyrights, como parte de seus estudos do sistema de patentes norte-americano conduzidos nos termos das Resoluções
} 
benefícios do sistema de proteção à Propriedade Intelectual são mais antigos do que normalmente se supõe, remontando ao período em que o reconhecimento da Propriedade Intelectual se disseminou largamente entre as nações europeias, o que ocorreu no Século XIX.

MACHLUP, que participou ativamente no comitê do Senado Americano dedicado à reforma do sistema de patentes no final da década de 1950, elaborou juntamente com a economista EDITH PENROSE um detalhado retrato das discussões travadas neste período ${ }^{5}$. Acompanharemos estes autores na reconstrução dessa decisiva passagem para história da Propriedade Intelectual em geral e para as relações ente este sistema e a concorrência em particular ${ }^{6}$.

\subsection{Disseminação dos Regimes de Patente até 1850}

Costuma-se referir ao desenvolvimento das concessões na Inglaterra, sob Elizabeth e James I, como o início da história moderna das patentes. Durante esse período, a política da Coroa de concessão de privilégios de monopólio sob a prerrogativa legal culminou com o Statute of Monopolies of 1623, que anulou todas as patentes e monopólios anteriormente concedidos pela Coroa, estabelecendo que apenas seriam válidos os monopólios a partir de então concedidos, desde que recaíssem sobre invenções inteiramente novas.

do Senado 55 e 236, do $85^{\circ}$ Congresso ("An Economic Review of the Patent System" - 1958), Tal estudo se debruça sobre uma "inconsistência econômica básica": "In a free-enterprise economy dedicated to competition, we have chosen, not only, to tolerate but to encourage individual limited islands of monopoly in the form of patents" (cf. prefácio de Joseph C. O'Mahoney, Chairman, Subcomittee on Patents Trademarks and Copyrights, Comittee on the Judiciary, United States Senate, June, 30, 1958).

${ }^{5}$ Os autores escreveram com o objetivo de afastar as opiniões então insurgentes nos Estados Unidos, no sentido de que a posição crítica às patentes seria uma ideia completamente inédita e refratária à propriedade privada Eles citam, a esse respeito, HAROLD G. FOX, que escreveu uma "história do monopólio das patentes". Em sua obra, FOX afirmava que "nunca antes, até aquela época, havia existido um criticismo daquela espécie quanto ao privilégio exclusivo", atribuindo a suposta atitude nova a "caçadores de bruxas modernos", "famintos aspirantes ao ofício público" e, em resumo, aos "inimigos de toda espécie de propriedade privada".

${ }^{6}$ Nosso relato neste capítulo é centrado na história das ideias sobre a Propriedade Intelectual e sua relação com a concorrência, relação esta que teve importantes turning points no Século XIX. Nosso relato seguirá de perto a FRITZ MACHLUP, primeiramente, pela riqueza de detalhes fornecida por esse autor, que reúne mais de cento e sessenta citações literais e referências, incluíndo documentos oficiais do governo americano, documentos oficiais internacionais, decisões judiciais, livros, artigos, relatórios e discursos (ver "An Economic Review of the Patent System", Study of the Subcommitee on Patents, Trademarks, and Copyrights of the Comittee on the Judiciary United States Senate, Eighty-Fifth Congress, Second Session - Pursuant Senate Resolution 236 - Study No 15, Washington, Government Printing Office, 1958). Para relatos alternativos disponíveis, ver: CHRISTINE MACLEOD ("Patents and Indusgtrialization: An Historical Overview of the British Case, 1624-1907") e DutTON, H.I, “The Patent System and Inventive Activity during the Industrial Revolution”, Manchester University Press, 1984, ambos citados em nossa Bibliografia. O trabalho destes últimos autores, no entanto, se debruça quase que exclusivamente sobre o caso inglês. 
Com o Statute, o sistema de patentes alcançou um desenvolvimento formal que não existiu em nenhum outro lugar até muito mais tarde ${ }^{7}$.

O Statute of Monopolies, de fato, abarcou a primeira lei de patentes de uma nação moderna, a qual derivou diretamente do sistema de privilégios reais. Mas um sistema de patentes bastante desenvolvido já havia existido em Veneza, no Século XV, e a prática de conceder monopólios aos inventores era seguida em muitas partes da Europa ocidental e central nos séculos XVI e XVII ${ }^{8}$.

Entretanto, a par da expressão em forma de um sistema estatutário, o sistema de patentes não foi uma criação eminentemente inglesa, tendo se desenvolvido simultaneamente em vários países, embora não no mesmo ritmo. Praticamente em toda a parte na Europa, privilégios eram concedidos aos inventores, ou, mais precisamente, aos artesãos e empreendedores. Eles consistiam em apenas uma dentre as várias espécies dos privilégios, cartas régias, franquias, licenças e regulamentos então conferidos pela Coroa ou pelos governos locais, dentro do quadro mercantilista ${ }^{9}$.

Se o Statute of Monopolies foi chamado de Magna Carta dos direitos de inventores, não foi porque ele originou a proteção em si, mas - principalmente - porque ele estabeleceu um princípio segundo o qual apenas um legítimo e primeiro inventor poderia obter um monopólio de patente.

HA-JOON CHANG retrata que este regime de concessão de monopólios foi utilizado pelos Tudor, especialmente Henrique VII e Elizabeth I, como meios de desenvolver as manufaturas de lã na Inglaterra ${ }^{10}$. No Século XVIII, a proteção às patentes se inseria em um quadro político de protecionismo as empresas manufatureiras inglesas, o qual culminaria com a revolução industrial e uma hegemonia tecnológica da Inglaterra sobre as outras nações ${ }^{11}$.

\footnotetext{
${ }^{7}$ MACHLUP, Fritz; PENROSE, Edith , in "The patent controversy in the nineteeth century" - The Journal of Economic History. Vol. X. n. I. 1950, pgs. 1-29

${ }^{8}$ MAChlup, Fritz; PENROSE, Edith , "The patent controversy in the nineteeth century" - The Journal of Economic History. Vol. X. n. I. 1950, pgs. 1-29

${ }^{9}$ MaChluP, Fritz; Penrose, Edith , "The patent controversy in the nineteeth century" - The Journal of Economic History. Vol. X. n. I. 1950, pgs. 1-29.

10 "No livro [A Plan of the English Commerce, 1728] Robert Dafoe descreve como os Tudor, especialmente Henrique VII e Elizabeth I, usaram o protecionismo, os subsídios, a distribuição de direitos de monpólio, a espionagem industrial financiada pelo governo e outros meios de intervenção do governo para desenvolver a indústria de manufaturas de lã na Inglaterra, a indústria de alta tecnologia da Europa naquela épooca”. (ChANG, Ha-Joo - "Maus Samaritanos - O Mito do Livre-Comércio - A história secreta do capitalismo, Rio de Janeiro, Elsevier, 2009)

11 “Em 1721, a reforma da lei mercantil introduzida pelo Primeiro Ministro britânico, Robert Walpole, significou uma dramática mudança de foco nas políticas industriais e comerciais do Reino. A legislação de 1721 e as mudanças que se seguiram incluíam: (i) redução ou mesmo remoção de tarifas sobre a importação
} 
Ao final do Século XVIII, três dos mais importantes países no mundo possuíam sistemas estatutários de patentes (Inglaterra, Estados Unidos e França).

Nos Estados Unidos, a declaração de independência, movida por um espírito iluminista e liberal, conduziu à aprovação de uma constituição política fortemente inspirada por estes valores em 1787, a qual conferiu ao Congresso poderes para "promover o Progresso da Ciência e das Artes úteis (useful arts)”, assegurando por um tempo limitado a autores e inventores o direito exclusivo sobre seus respectivos escritos e descobertas.

O Congresso americano instituiu, em 1790, a primeira lei de patentes inspirada por uma ideologia moderna, a qual reconhecia o direito dos inventores de explorar suas invenções pelo prazo de quatorze anos. A legislação pode ser considerada revolucionária, pois exigia a análise por um órgão administrativo pré-constituído, o qual verificaria os requisitos e viabilizaria a divulgação do conhecimento. Além disso, permitia a impugnação da concessão da patente e previa a sanção pela sua violação ${ }^{12}$.

$\mathrm{Na}$ França, a Assembleia Constitucional também aprovou uma lei de patentes em 1793. Como consequência, os inventores poderiam obter, por questão de direito, meramente de facto na Inglaterra ${ }^{13}$, mas de jure na França e nos Estados Unidos, proteção de patentes contra a concorrência na exploração de seus inventos ${ }^{14}$.

\footnotetext{
de matérias-primas usadas nos produtos ingleses; (ii) subsídios às matérias-primas importadas para produtos exportados; (iii) abolição de tarifas sobre a maioria das exportações; (iv) aumento das tarifas sobre bens manufaturados importados; (v) subsídios às exportações foram estendidas a novos itens, como produtos de seda e pólvora, ao passo que os subsídios já existentes sobre lonas e açúcar refinado foram aumentados; (vi) regulação sobre os produtos manufaturados, especialmente produtos têxteis, evitando que produtores inescrupulosos pudessem causar dano à imagem dos produtos britânicos em mercados estrangeiros. Após a revolução industrial na segunda metade do século XVII, a Inglaterra começou a ampliar sua liderança tecnológica sobre os outros países, movimento que se estendeu até meados do Século XIX" (CHANG, Ha-Joon "Kicking Away the Ladder - An Unofficial History of Capitalism, Especially in Britain and the United States", Challenge, 2002, Vol. 45, Issues - tradução livre).

${ }^{12}$ FrANCESCHELli, Remo. "Trattato di Diritto Industriale. Parte Generale, volume primo, Milano, Dott. A. Giuffré Editore, 1961, pg. 381.

13 "Before 1852, there was no dedicated patent office, but only a tortuous route through the royal bureaucracy laid down by the Clerks Act (1535) for all grants of the crown under the great seal. An applicant's petition for "letters patent" was refereed to one of the crown's law officers (Attorney or Solicitor General), who as required to check that the patent would not contervene the Statute of Monopolies - or harme the royal interest, for example, by reducing the revenue from excise duties. There was no formal examination for novelty or utility, and very few applications were refused. Yet, the applicant still had to negotiate a bureaucratic maze: his patent would not be enrolled until he had accumulated an expansive series of seals and signatures, waiting on officials, paying fees and favours at every stage (...). This time-consuming process added to the cost, especially for anyone not resident in London. One Manchester inventor's diary shows him spending six months there during 1722-3. To secure a patent for England and Wales cost approximately $£ 100$, to extend it to Scotland and Ireland, another $£ 200-250$ (plus more time and effort). A patent agent' services, which the system's growing complexity (especially the specification) made ingreasingly desireable, added a further $£ 40$ to $£ 100$. It was an enormous expense when a skilled worker earned about $£ 1$ to $£ 2$ per week". Charles Dickens famously lampooned this bureaucratic excrescence in this "Poor Man's Tale of a
} 
Até a metade do século XIX, o sistema de patentes, na acepção de um sistema de proteção dos inventores regulamentado por uma lei estatutária, se disseminaria em vários países. Leis de patentes foram editadas na Áustria em 1810, Rússia em 1812, Prússia em 1815, Bélgica e Países Baixos em 1817, Espanha em 1820, Bavária em 1825, Sardenha em 1826, Estado do Vaticano em 1833, Suécia em 1834, Würtemberg, em 1836, Portugal em 1837, e Saxônia, em $1843^{15}$.

\subsection{O Movimento Anti-Patentes no Século XIX e Seu Declínio}

Duzentos anos após advento do Statute of Monopolies, na Inglaterra, a lei de patentes ainda não havia passado por nenhuma proposta de revisão ou emenda no parlamento $^{16}$.

Foi por volta de 1827 que, pela primeira vez, o assunto de uma reforma do sistema de patentes começou a chamar a atenção da legislatura, principalmente por conta de reclamações de que o procedimento para obter uma patente seria caro, confuso e incerto. Vários grupos, então, se formaram na tentativa de obter uma lei mais favorável aos inventores e uma agitação considerável criou-se no Parlamento e na imprensa ${ }^{17}$.

Isso provocou um contra-ataque, não da parte daqueles que eram favoráveis à lei então vigente, mas, sim, daqueles que desejavam ver o sistema de patentes abolido por completo. No último flanco estavam a influente Economist, o vice-presidente do Board of Trade, alguns inventores notáveis da época, membros do Parlamento e representantes de distritos manufatureiros, tais como Manchester e Liverpool ${ }^{18}$.

Comitês selecionados do Parlamento e comissões reais investigaram o funcionamento do sistema de patentes entre 1851 e 1852, entre 1862 e 1865, e, novamente, entre 1869 e 1972.

Patent" and Little Doorrit. The poor man afforded his patent only through that common Victorian literary device of a chance inheritance". (MACLEOD, Christine, "Patents and Industrialization: An Historical Overview of the British Case, 1624-1907”, Department of History, University of Bristol,UK, June, 2010)

${ }^{14}$ MACHLUP, Fritz; PENROSE, Edith, "The patent controversy in the nineteeth century" - The Journal of Economic History. Vol. X. n. I. 1950, pgs. 1-29

${ }^{15}$ MaChluP, Fritz; PENROSE, Edith, "The patent controversy in the nineteeth century" - The Journal of Economic History. Vol. X. n. I. 1950, pgs. 1-29

${ }^{16}$ Hulme, E. Wyndham, "The History of the Patent System under the Prerrogative and at Commom Law", Law Quartely Review, XII (1896), 141 (apud, MACHLUP, Fritz; PENROSE, Edith , "The patent controversy in the nineteeth century", op. Cit.)

${ }^{17}$ MACHLUP, Fritz; PENROSE, Edith, "The patent controversy in the nineteeth century" - The Journal of Economic History. Vol. X. n. I. 1950, pgs. 1-29

${ }^{18}$ Machlup, Fritz; Penrose, Edith , "The patent controversy in the nineteeth century" - The Journal of Economic History. Vol. X. n. I. 1950, pgs. 1-29 
Alguns dos testemunhos prestados perante tais comissões foram tão danosos à reputação do sistema de patentes que os líderes estadistas nas duas casas do Parlamento propuseram a completa abolição da proteção ${ }^{19}$.

Um projeto de reforma, redigido com base no relatório da comissão de 1872, previa uma redução da proteção de patentes para sete anos, um exame mais estrito dos depósitos de patentes, multas para as patentes não utilizadas depois de dois anos e licenças compulsórias para todas as patentes. O projeto passou pela Câmara dos Lordes ${ }^{20}$.

$\mathrm{Na}$ Alemanha, um forte movimento contra as patentes de invenção iniciou-se como uma reação, não apenas às demandas por parte dos defensores das patentes por um fortalecimento da proteção nos estados alemães individuais, mas, também, contra a adoção de uma legislação uniforme em todos os estados membros da União Aduaneira $\left(\right.$ Zollverein $\left.^{21}\right)$. Nos ataques contra o regime protecionista das patentes, argumentos de livre-comércio eram mais frequentes na Alemanha do que ocorria na Inglaterra e os economistas eram quase unânimes quanto à condenação do sistema ${ }^{22}$.

\footnotetext{
${ }^{19}$ Um escritor americano, em artigo publicado na "Revue de Droit International et de législation comparée", I (1869), 311, retratou a impressão que a "l'Angleterre paraît s'acheminer vers une abolition compléte de ce systéme". Ele acrescentou que os Estados Unidos jamais se permitiriam ficar atrás de outras nações "em uma questão de liberdade"; e que se outros países tomassem a liderança na abolição do sistema de patentes, os Estados Unidos, certamente, seguiriam tal movimento (cf. MACHLUP e PENROSE, op. Cit). Vemos, aqui, que a ideia de manutenção de privilégios sobre invenções não foi aceita de forma tão simples pelas revoluções liberais quanto se possa imaginar. Ao contrário, foi com resistência e sob forte criticismo que tais privilégios foram mantidos, podendo-se registrar várias vozes em contrário. Nos Estados Unidos, por exemplo, é fato conhecido que THOMAS JEFFERSON defendia, senão a abolição total do sistema de patentes, um "alto grau de patentabilidade", que reservaria a proteção apenas a contribuições muito substanciais ao progresso e à ciência. JEFFERSON, que estava na França durante a Convenção Constitucional no verão de 1787, não desempenhou nenhum papel na redação da Constituição, mas prontamente respondeu à adoção da cláusula de Propriedade Intelectual com uma proposta pelo seu afastamento e instituição, em seu lugar, de uma carta de direitos que teria proibido quaisquer espécies de "monopólios", incluindo aqueles por um período limitado que teriam o pretenso objetivo de estimular o "engenho". Essa sugestão foi rejeitada pelos redatores do Bill of Rights no Congresso, juntamente com a segunda proposta de JEFFERSON, por um nono artigo na Constituição, o qual permitiria monopólios limitados para produções literárias e invenções (Cf. BURCHFEL, Kenneth J., "Revising the "Original" Patent Clause: Pseudohistory in Constitucional Construction", In Harvard Law Review, Volume 2, Spring Issue, 1989, pg. 163).

${ }^{20}$ MAChluP, Fritz; PENROSE, Edith , "The patent controversy in the nineteeth century" - The Journal of Economic History. Vol. X. n. I. 1950, pgs. 1-29

${ }^{21}$ PRINCE-SMITH, John "Ueber Patente für Erfindungen", Vierteliahrschrift für Volkswirthschaft und Kulturgeschichte, Erster Jahrgang (1863), III, 150. Também GROTHE, Herman "Das Patentgesetz für das Deutsche Reich" (Berlin, 1877), p. 7 (apud, MACHLUP, Fritz; PENROSE, Edith , op. Cit.)

${ }^{22} \mathrm{Na}$ reunião anual do Kongress deutscher Volkswirthe, sediada em Dresden, Setembro de 1863, a seguinte resolução foi adotada "por uma maioria acahapante": "Considerando que as patentes mais atravancam do que estimulam o progresso das invenções; que elas impedem o pronto uso generalizado de invenções úteis; que, no balanço geral, elas causam mais danos do que benefícios aos próprios inventores e, assim, são uma forma altamente enganosa de indenização; o Congresso de Economistas Alemães resolve que patentes de invenção são uma afronta ao bem-estar comum" - "Bericht über die Verhandlungen des sechsten Kongresses deutscher Volkswirthe zu Dresden am 14, 15, 16 und 17. September," vierteljahschrift für Volkswirthschaft und Kulturgeschichte, Erster Jahrgaang (1863), III, 221. (apud, MACHLUP, Fritz; PENROSE, Edith , op. Cit., tradução livre)
} 
Deve se ter em mente, aqui, o quadro peculiar de uma industrialização tardia na Alemanha, que não alcançaria o seu desenvolvimento industrial até o final do Século XIX. $\mathrm{Na}$ ciência econômica, o cenário nacional alemão era marcado pela Escola Histórica de Economia, liderada por Gustav SchMOLER. Para se resumir o pensamento dessa escola, pode-se afirmar que ela era crítica ao pensamento clássico dos autores britânicos, como AdAm Smith e StUART MiLl. Os Históricos buscavam uma ciência econômica que refletisse a realidade alemã e não se baseasse em um método puramente dedutivo. GUSTAV SCHMOLER protagonizou, com CARL MENGER, um debate sobre a importância da teoria na ciência econômica (a disputa sobre o método) ${ }^{23}$.

Associações comerciais e câmaras de comércio apresentaram relatórios recomendando a reforma ou abolição das leis de patentes. O debate ganhou lugar em livros, panfletos, jornais e na imprensa diária; em várias sociedades de advogados, engenheiros, economistas e nas legislaturas. Por outro lado, engenheiros, inventores e potenciais inventores, industrialistas com interesse em patentes, advogados de patentes e outros que lucravam a partir das leis de patentes figuravam entre os ferrenhos defensores do sistema ${ }^{24}$.

Depois de anos de discussão pública, o governo da Prússia decidiu opor-se à adoção de uma lei de patentes pela Federação Alemã do Norte e, em Dezembro de 1868, o Chanceler Bismarck anunciou suas objeções ao princípio de proteção de patentes ${ }^{25}$.

A Suíça era o único país industrializado na Europa que havia deixado de adotar um sistema de patentes até aquela época. Vários abaixo-assinados submetidos ao governo, urgindo a instituição de um sistema de patentes, haviam sido rejeitados. Com base em uma declaração emitida por membros do corpo docente do Instituto de Tecnonlogia de Zürich, o governo continuava a refutar os pedidos de adoção de um sistema de patentes. Tendo rejeitado propostas anteriores em 1849, 1851, 1854 e no início de 1863, a legislatura em Dezembro de 1863 ratificou sua rejeição ao sistema de patentes, com uma referência ao fato de que "economistas políticos da maior competência" haviam declarado que o

\footnotetext{
23 "In particular, the German historical school argued that each 'volk' had its own behavioral characteristics, as did each era, and that these should be the focus of economic thought and research rather than the search for universally-valid principles. In this view, the economist's primary task was to understand the history and evolution of economic conduct for a specific group at a particular time. The perspective was radically empiricist, rejecting the deductive methods of classical economics as irrelevant to real life". (GERBER, David J., "Law and Competition in Twentieth Century Europe - Protecting Prometheus", Oxford, 1998, pg. 30)

${ }^{24}$ MACHLUP, Fritz; PENROSE, Edith, "The patent controversy in the nineteeth century" - The Journal of Economic History. Vol. X. n. I. 1950, pgs. 1-29.

${ }^{25}$ MAChlup, Fritz; PenRose, Edith "'The patent controversy in the nineteeth century" - The Journal of Economic History. Vol. X. n. I. 1950, pgs. 1-29
} 
princípio da proteção de patentes era "pernicioso e indefensável” ("verderblich un verwerflich") ${ }^{26}$.

$\mathrm{Na}$ Holanda, o movimento antipatentes era ainda mais relacionado ao movimento de livre-comércio do que em qualquer outro país. Isso não significa que a controvérsia era apenas ideológica. De fato, as principais questões se centravam sobre a operacionalidade de leis de patentes e sobre as dificuldades de reformá-las de modo satisfatório a todas as partes interessadas. O debate terminou com uma vitória dos abolicionistas: em Julho de 1869 , a lei de patentes foi rejeitada ${ }^{27}$.

Em resumo, até o final da década de 1860, a causa das patentes parecia totalmente perdida. Mas os defensores do sistema de patentes organizaram uma poderosa contraofensiva, com uma agressiva propaganda em favor das patentes entre os anos de 1867 e 1877.

Novas sociedades de proteção de patentes foram formadas, resoluções enviadas à imprensa diária, palestrantes discursavam perante as organizações comerciais e profissionais, enxurradas de panfletos e folhetos lançados, artigos divulgados em jornais do comércio e reproduzidos nos jornais diários, concursos públicos ofereciam prêmios aos melhores trabalhos em defesa do sistema de patentes, abaixo-assinados eram submetidos aos governos e legislaturas, reuniões internacionais eram marcadas e compromissos eram firmados com grupos inclinados a apoiar reformas liberais ao regime de patentes ${ }^{28}$.

Tal esforço, sem dúvidas, foi exitoso em reverter a maré contrária à Propriedade Intelectual. O repentino desaparecimento do movimento antipatente depois de 1873 pode se relacionar ao enfraquecimento do movimento pelo livre-comércio na Europa, em consequência da forte depressão naqueles anos. A ideia de proteção às patentes retomou fôlego quando, depois da crise de 1873, os protecionistas triunfaram sobre os defensores do livre-comércio. Segundo MAChlup e Penrose, esta seria a real razão pela qual o movimento contrário às patentes teria arrefecido ${ }^{29}$. Escrevendo na década de 1980, FRIEDRICH-KARL BEIER, contestou essa ideia, ao defender que a real razão do êxito final do

\footnotetext{
${ }^{26}$ Offizielles Bundesblatt, Jahrgang (1864), II, 510-11), apud MACHLUP, Fritz; PENROSE, Edith , (op. Cit.)

${ }^{27}$ MACHLUP, Fritz; PENROSE, Edith , "The patent controversy in the nineteeth century" - The Journal of Economic History. Vol. X. n. I. 1950, pgs. 1-29.

${ }^{28}$ MACHLUP, Fritz; PENROSE, Edith , "The patent controversy in the nineteeth century" - The Journal of Economic History. Vol. X. n. I. 1950.pgs. 1-29.

${ }^{29}$ MACHLUP, Fritz; PENROSE, Edith , "The patent controversy in the nineteeth century" - The Journal of Economic History. Vol. X. n. I. 1950.pgs. 1-29.
} 
movimento pró-patentes se deveu ao fato de que os opositores do regime patentes jamais lograram demonstrar que a proteção desestimularia as inovações tecnológicas ${ }^{30}$.

Embora MACHLUP e PENROSE atribuam este fato somente à crise e ao descrédito do livre-comércio, entendemos que este arrefecimento do movimento contrário à proteção das patentes está, também, relacionado ao fato de que, ao final do Século XIX, os países que haviam sido, até então, resistentes à adoção do sistema - como no caso da Alemanha alcançaram a fronteira tecnológica ${ }^{31}$.

Não chega a ser surpreendente que os mesmos países que, outrora em uma condição de subdesenvolvimento, se mostravam críticos do sistema de patentes, passassem a se tornar defensores do mesmo sistema, na medida em que superavam tal estágio de atraso tecnológico $^{32}$ e 33 .

\footnotetext{
${ }^{30}$ BEIER, Friedrich Karl argumenta que: "In most countries, patent protection was introduced only after very intensive debate about its advantages and drawbacks, and a careful balancing of arguments for and against the protection, as, for example, in England, the United States, France, Germany, Switzerland and the Netherlands. The patent statutes have always had a difficult birth. Should we now say that lawmakers of (presently) more than 100 countries have all so fundamentally erred about the suitability of the patent system for the promotion of technical and economic progress? And why did they not subsequently correct this alleged error in the light of newly acquired knowledge? Why did the countries, after basic political, social and economic upheavals such as the French Revolution, the Declaration of the Independence of the United States, the introduction of freedom of business and trade in the European countries, the Russian Revolution, the introduction of the socialist political and economic order in the countries of Eastern Europe, and the rise to independence of former colonies, not abolish the protection of inventions? Why did they rather maintain it or immediately adopt a new form of protection for inventions, even in those cases where the prior system of protection of inventions was no longer acceptable and all the prior legislation had, in any event, been thrown overboard? The force of these legislative facts has in my view more weight than even the most cogent criticism of economists as long as they cannot submit sufficient evidence that the patent system does not fulfil a useful function in promoting technological innovation. This, however, they have been unable to do thus far. Fritz Machlup admitted this frankly at the end of his well-known study". ("The Significance of the Patent System for Technical, Economic and Social Progress" - disponível em http://beckonline.beck.de/default.aspx?printmanager=print\&VPATH=b)

${ }^{31}$ Convém ressaltar que os países viveram seus períodos de industrialização em diferentes épocas e graus de intensidade. Por exemplo, 1760: Inglaterra; 1800: Bélgica, França, EUA, Suíça, Escócia; 1860: Alemanha, Itália, Suécia, Áustria, Checoslováquia; a partir de 1900: o restante dos países industrializados (ARRUDA DE ANDRADE, José Maria, "Economização do Direito Concorrencial e Positivismo Jurídico: entre Teoria da Decisão e das Provas" - Tese de Livre Docência - FDUSP, 2012, São Paulo, pg. 22), e AvELÃs NunES, J. Antônio, Uma Introdução à Economia Política, São Paulo, Editora Quartier Latin, 2007, p. 176).

${ }^{32}$ ChANG, Ha-Joon descreve como os países que mais cedo se industrializaram, principalmente a Inglaterra e os Estados Unidos, "não só se valeram de uma política tarifária protecionista, como, também, estimulavam a aquisição de tecnologia estrangeira, às vezes, por meio de medidas ilegais, como o apoio à espionagem, contrabando de maquinário, e recusa a reconhecer patentes estrangeiras. Paralelamente, o desenvolvimento de tecnologia era encorajado por meio do financiamento à Pesquisa e Desenvolvimento, educação e treinamento. Outras medidas eram também tomadas para permitir a pronta atualização de tecnologias avançadas (por exemplo, o estabelecimento de "fábricas modelo", organização de exposições, concessão de livre importação de maquinário a empresas do setor privado). É importante notar que estas mesmas políticas são, atualmente, criticadas pelos mesmos países que as adotaram no passado, quando não tornadas explicitamente "ilegais" por meio de acordos bilaterais e multilaterais". (CHANG, Ha-Joon, "Kicking Away the Ladder - An Unofficial History of Capitalism, Especially in Britain and the United States", Challenge, 2002, Vol. 45, Issues)

33 "Uma soma de fatos como a anexação da Silésia, uma província industrial, a pesquisa e a espionagem de tecnologias mais avançadas e um forte sistema educacional, a permitir a formação de quadros no governo e
} 
De fato, se alguns escritores atribuíram a rápida industrialização da Inglaterra e dos Estados Unidos ao fato de que estas nações possuíam sistemas de patentes desenvolvidos do que se poderia inferir uma relação causal entre patentes e progresso ${ }^{34}$ - por outro lado, economistas alemães e suíços também relacionavam o progresso industrial experimentado em seus países à ausência de uma efetiva proteção de patentes ${ }^{35}{ }^{36}$.

Alguns autores admitiram expressamente que as patentes poderiam promover a inovação tecnológica em estágios iniciais do desenvolvimento industrial, mas, em níveis mais avançados, elas passariam a exercer uma influência negativa ${ }^{37}$.

Quaisquer que sejam as razões para tanto, a mudança de opinião é claramente evidenciada pelas ações das legislaturas nos vários países. Na Inglaterra, o Patent Bill de 1874, que havia passado na Câmara dos Lordes, foi retido na Câmara dos Comuns. Na Alemanha, uma lei uniforme de patentes para todo o Reich foi adotada em 1877.

na iniciativa privada, completam o cenário sobre a Alemanha em seu processo de industrialização tardia” (ARrudA DE ANDRADE, José Maria, "Economização do Direito Concorrencial e Positivismo Jurídico: entre Teoria da Decisão e das Provas", Tese de Livre Docência - FDUSP, 2012, São Paulo, pg. 67).

${ }^{34}$ Dentre os economistas que enxergaram tal relação positiva entre o sistema de patentes e o desenvolvimento industrial, citamos Douglas NoRTH. Christine MACleOD, entretanto, se opôs a tal conclusão. Para a autora, o sistema de patentes consistiria em uma forma de propriedade e um instrumento de concorrência cujo valor teria experimentado um crescimento em um momento em que o próprio capitalismo industrial estava em um momento de ascensão. A autora sugere, inclusive, que a relação seria inversa, ou seja: a industrialização promoveu o sistema de patentes. Mais do que isso, as características específicas do sistema de patentes britânico foram moldadas pelas circunstâncias de seu desenvolvimento: uma sociedade oligárquica produziu um sistema de patentes oligárquico. A maioria dos inventores do século XVIII eram ou completamente ignorantes sobre a existência do sistema de patentes, ou não lhes era conveniente adquirir uma patente em razão dos altos custos". (MACLEOD, Christine, "Patents and Industrialization: An Historical Overview of the British Case, 1624-1907”, Department of History, University of Bristol, UK, June, 2010)

35 "German Industry undoubtedly owes its present prosperous condition also to the fact that only a few patents have been granted in Germany(...)” - BÖHMERT, Die Erfindungspatente, pg. 48, BÖHMERT also suggested that England developed industrially in spite of her patent system but less than she would have without it. - ibid, p. (apud, MACHLUP, Fritz; PENROSE, Edith ,op. Cit.).

${ }^{36} \mathrm{O}$ historiador econômico ECKHARD HÖFFNER dedicou uma obra à tese de que a disseminação da leitura em nível nacional e o sucesso da Alemanha em seu projeto de industrialização estão diretamente relacionados à ausência de uma proteção aos direitos autorais, e que o efeito oposto teria se verificado na Inglaterra, que permaneceu estagnada. Ele chegou à surpreendente conclusão de que “(...) unlike neighboring England and France, Germany experienced an unparalleled explosion of knowledge in the 19th century. German authors during this period wrote ceaselessly. Around 14,000 new publications appeared in a single year in 1843. Measured against population numbers at the time, this reaches nearly today's level. And although novels were published as well, the majority of the works were academic papers. The situation in England was very different. For the period of the Enlightenment and bourgeois emancipation, we see deplorable progress in Great Britain," (...). Indeed, only 1,000 new works appeared annually in England at that time -- 10 times fewer than in Germany -- and this was not without consequences. (...) it was the chronically weak book market that caused England, the colonial power, to fritter away its head start within the span of a century, while the underdeveloped agrarian state of Germany caught up rapidly, becoming an equally developed industrial nation by 1900" (http://www.spiegel.de/international/zeitgeist/no-copyright-law-the-real-reasonfor-germany-s-industrial-expansion-a-710976.html)

${ }^{37}$ RENTZCH, Hermann, "Geistiges Eigenthum", Handwörterbuch der Volkswirtschaft, p. 634; also several British experts, whose opinions are criticzed in the Westminster Review, XXXVI (N.S.) (July, 1869), 125. (apud, MACHLUP, Fritz; PENROSE, Edith ,op. Cit.) 
A Suíça resistiu um pouco mais às pressões dos defensores de patentes. Em um referendo em 1882, a emenda constitucional exigida para adoção da legislação de patentes foi rejeitada, embora por apertada maioria. Um novo referendo permitiu à legislatura a aprovação da lei de patentes, após fortes pressões externas que associavam a falta de um sistema de patentes ao estigma da pirataria, acompanhadas de ameaças de sanções comerciais.

A Holanda foi o último bastião do livre comércio nas invenções: por quarenta e dois anos depois de 1869, não houve concessão de patentes. Somente em 1910 uma nova lei de patentes foi adotada, a qual entrou em vigor em $1912^{38}$.

\subsection{O Embate entre Protecionistas e Defensores do LiVRe-ComÉrCio}

Os economistas clássicos britânicos, no final do Século XVIII, aceitaram a tradicional filosofia expressa no Statute of Monopolies, de 1623: Os monopólios temporários na exploração de inovações deveriam estar isentos da repulsa aos monopólios em geral, por conta de seu especial caráter e função ${ }^{39}$.

Embora ADAM SMITH defendesse que os monopólios no comércio "desequilibravam em maior ou menor grau a natural distribuição das parcelas da sociedade”, e que eram “necessariamente danosos à sociedade em que reconhecidos”, ele reconhecia como uma exceção os monopólios temporários, conferidos ao inventor de uma nova máquina, com base na necessidade de recompensar os riscos e as despesas por ele $\operatorname{suportados}^{40}$. JEREMY BENTHAM foi além, ao afirmar que os privilégios conferidos aos inventores "nada tinham em comum com monopólios, tão justamente condenados ${ }^{41}$ ".

JOHN STUART MiLl afirmou categoricamente que "a condenação dos monopólios não deveria se estender às patentes”.

\footnotetext{
${ }^{38}$ MACHLUP, Fritz; PENROSE, Edith, "The patent controversy in the nineteeth century" - The Journal of Economic History. Vol. X. n. I. 1950.pgs. 1-29. "[A] Holanda (que tem as melhores credenciais de livrecomércio desde o século XIX) e a Suiça (até a primeira guerra mundial), que praticavam consistentemente o livre-comércio. (...) mesmo esses países não estão em conformidade com o ideal neo-liberal do século XX. A Holanda passou a aplicar a lei de patentes em 1817, mas a aboliu em 1869 e não a reintroduziu até 1912. Os suiços introduziram sua primeira lei de patentes em 1888, a qual produziu apenas invenções mecânicas. A lei geral de patentes na Suíça foi introduzida apenas em 1907". (CHANG, Ha-Joo, "Maus Samaritanos - O Mito do Livre-Comércio - A história secreta do capitalismo, Rio de Janeiro, Elsevier,2009)

${ }^{39}$ MachluP, Fritz; PEnRose, Edith, "The patent controversy in the nineteeth century" - The Journal of Economic History. Vol. X. n. I. 1950. 1-29.

${ }^{40}$ SMITH, Adam, "Inquiry Into the Nature and Causes of the Wealth of Nations", Canan Edition, B.IV. Ch. 7 "Of Colonies", Disponível em http://www.econlib.org/library/Smith/smWN.html)

${ }^{41}$ BenthAM, Jeremy, "Observations on Parts of the Declaration of Rights as Proposed by Citizen Sieyes", The Works of Jeremy Bentham, Vol. 2 (Judicial Procedure, Anarchical Fallacies, works on Taxation), 1843
} 
Em sua argumentação, MiLl faz uso da teoria utilitarista, ao defender a necessidade de se indenizar e recompensar os inventores pelo seu serviço de utilidade social. Ele faz um ataque virulento à tentativa de estabelecer aquilo que, em sua visão, seria um livre-roubo, sob o dissimulado pretexto de se defender o livre-comércio ${ }^{42}$.

A teoria presente nos autores britânicos clássicos era de cunho utilitarista. Conforme constataria JOHn MAYNARD KeYNES no início do século XX, no curso das importantes transformações sofridas no sistema capitalista desde o início do Século XVIII, as teorias utilitaristas, cujo fundamento estava na filosofia moral e na religião, conciliaram o egoísmo de Hume, o bem-estar social de BEnTHAm e até mesmo a teoria da evolução darwiniana para justificar a conclusão de que a busca da felicidade do indivíduo asseguraria a felicidade da coletividade.

Tais ideias legitimavam a busca pelos lucros e repudiavam - em geral - a intervenção estatal, tornando-se, assim, o fundamento teórico-filosófico da doutrina do laissez-faire f3. $^{43}$

Seguindo a mesma lógica, os ideais utilitaristas justificarão o reconhecimento do monopólio das patentes na atribuição de uma recompensa conferida ao indivíduo pela produção de bens que produziriam o bem-estar social - justificando a intervenção estatal para, em certa medida e visando ao bem-estar social, restringir o acesso do público a tais bens ${ }^{44}$.

\footnotetext{
42“"The condemnation of monopolies ought not to extend to patents, by which the originator of an improved process is allowed to enjoy, for a limited period, the exclusive privilege of using his own improvement. This is not making the commodity dear for his benefit, but merely postponing a part of the increased cheapness which the public owe to the inventor, in order to compensate and reward him for the service. That he ought to be both compensated and rewarded for it, will not be denied, and also that if all were at once allowed to avail themselves of his ingenuity, without having shared the labours or the expenses which he had to incur in bringing his idea into a practical shape, either such expenses and labours would be undergone by nobody except very opulent and very public-spirited persons, or the state must put a value on the service rendered by an inventor, and make him a pecuniary grant. (...) I have seen with real alarm several recent attempts, in quarters carrying some authority, to impugn the principle of patents altogether; attempts which, if practically successful, would enthrone free stealing under the prostituted name of free trade, and make the men of brains, still more than at present, the needy retainers and dependents of the men of money-bags" (StUART Mill, John, "Principles of Political Economy", Book V, Chapter X, Of Interferences of Government Grounded on Erroneous Theories, $7^{\text {th }}$ Edition, London, Longmans, Green and Co., 1909)

${ }^{43}$ KeYNES, J.M. "The End of Laissez-Faire". In: Essays in Pesuasion - CWJMK, Londres, Macnillan, 1972, v. IX, cap. IV-2, p. 272-94.

${ }^{44}$ FISHER aponta a teoria utilitarista como a primeira e mais popular das teorias fundamentais para justificar a proteção conferida aos autores e inventores: "The firt and most popular of the four employs the familiar utilitarian guideline that lawmakers' beacon when shaping property rights should be the maximization of net social welfare. Pursuit of that end in the context of intellectual property, it is generally thought, requires lawmakers to strike an optimal balance between, on one hand, the power of exclusive rights to stimulate the creation of inventions and works of art and, on the other, the partially offsetting tendency of such rights to curtail widespread public enjoyment of those creations". FISHER também traça um "link" entre a teoria utilitarista e as ideias dos economistas no Século XX, em especial, a autores vinculados à escola de Chicago e à Análise Econômica do direito: "A good example of scholarship in this vein is William Lande's and Richard
} 
Na França, JEAN BATPISTE SAY (1803) concordou com os escritores ingleses clássicos. "Quem poderia reclamar, razoavelmente, de um privilégio meramente aparente?”, ele indagou. "Tal privilégio não prejudica nem tampouco impede um ramo previamente conhecido da indústria. Os custos são pagos somente por aqueles que não se importam em suportá-los; suas necessidades (...) não são menos satisfeitas do que antes $^{45, "}$.

JEAN ChARLES LÉONARD DE SiMONDI (1836) discordava a esse respeito, pois, em seu ponto de vista: “O resultado de um privilégio concedido ao inventor é conferir a ele uma posição monopolista no mercado contra os outros produtores no país. Como consequência, os consumidores se beneficiam muito pouco da invenção, o inventor ganha muito, os outros produtores perdem, e seus empregados caem em desgraça”. Ele defendia que "todas as invenções fossem, imediatamente, tornadas públicas e sujeitas à imitação por todos os concorrentes”. Se isso fosse arrefecer o ímpeto dos inventores, este resultado seria mais desejável, em sua opinião ${ }^{46}$.

Em um outro extremo, MARCELLIN JOBARD, na Bélgica, defendia uma proteção perpétua às patentes, tendo escrito nada menos que quarenta e oito livros defendendo tal ideia, no período compreendido entre 1829 e 1852. Para ele, os indivíduos teriam um direito natural inalienável à disposição de si próprio e de seu trabalho. Para este direito, ele cunhara o termo monautopólio, significando um monopólio de si próprio. A concorrência, segundo ele, seria a causa da pobreza, sendo um de seus motes "Ne laissez pas tout faire, ne laissez pas tout passer" - e tarifas e patentes, institutos para restrição da concorrência, eram os mais importantes fatores do progresso 47 .

Esse antagonismo em que figuravam, de um lado, o protecionismo tarifário e de patentes, e, de outro, o livre-comércio (externo e interno), foi também enfrentado pela maioria dos economistas nas décadas seguintes (1860 e 1870).

Posner's essay on copyright law". (FISHER, Willian, in "Theories of Intellectual Property", disponível em http://www.law.harvard.edu/faculty/tfisher/iptheory.html)

${ }^{45}$ MACHLUP, Fritz; PeNROSE, Edith , "The patent controversy in the nineteeth century" - The Journal of Economic History. Vol. X. n. I. 1950.pgs. 1-29.

${ }^{46}$ Machlup, Fritz; PenRose, Edith "'The patent controversy in the nineteeth century" - The Journal of Economic History. Vol. X. n. I. 1950.pgs. 1-29.

${ }^{47}$ Machlup, Fritz; PenRose, Edith, "The patent controversy in the nineteeth century" - The Journal of Economic History. Vol. X. n. I. 1950.pgs. 1-29 
Entre os economistas franceses, MiCHEL CHEVALIER era provavelmente o mais enfático ao declarar que tanto o protecionismo tarifário como o de patentes "fundamentavam-se na mesma doutrina e resultavam nos mesmos abusos ${ }^{48, "}$.

\subsubsection{TeOrias da Propriedade Sobre Ideias, fundadas no Direito Natural e no Trabalho}

A força do movimento contrário aos privilégios e monopólios e a favor do comércio livre era tamanha na Europa do início do século XIX, que qualquer elemento de conexão do protecionismo de patentes com o protecionismo tarifário, e do monopólio de patentes com os privilégios de monopólios, em geral, pesaria a favor dos oponentes do sistema de patentes, e, em contrapartida, enfraqueceria o argumento favorável ao sistema ${ }^{49}$.

Era, assim, essencial, do ponto de vista estratégico, isolar as patentes das ideias de concessão de um monopólio e de um entrave ao livre-comércio.

$\mathrm{Na}$ França, a estratégia foi apresentar a proteção de patentes como derivada do direito natural, nos mesmos moldes da propriedade privada, bem como no direito natural que todo homem possuiria, de viver por seu trabalho.

Em contrapartida, do mesmo direito natural, derivaria o dever da sociedade de assegurar ao indivíduo um justo quinhão de seu trabalho, o interesse social de alcançar progresso industrial ao menor custo possível ${ }^{50}$.

Nesse sentido, desenvolveu-se a Teoria do Trabalho, segundo a qual subsiste um direito inerente do indivíduo aos frutos de seu esforço, ainda que tal esforço seja exercido sobre bens que não lhe pertencem, ou sobre bens comuns. Essas ideias, originadas dos escritos de JOHN LOCKE, são aplicadas para justificar uma Propriedade Intelectual, campo em que as matérias-primas pertinentes (fatos e conceitos) parecem, de algum modo, sujeitas a um domínio comum, sendo importante a contribuição do trabalhador para o valor dos produtos finais ${ }^{51}$.

\footnotetext{
${ }^{48}$ MAChluP, Fritz; PeNROSE, Edith , "The patent controversy in the nineteeth century" - The Journal of Economic History. Vol. X. n. I. 1950.pgs. 1-29.

${ }^{49}$ MACHLUP, Fritz; PENROSE, Edith , "The patent controversy in the nineteeth century" - The Journal of Economic History. Vol. X. n. I. 1950.pgs. 1-29.

${ }^{50}$ MAChluP, Fritz; PeNROSE, Edith , "The patent controversy in the nineteeth century" - The Journal of Economic History. Vol. X. n. I. 1950.pgs. 1-29.

51 FISHER, Willian, in "Theories of Intellectual Property", disponível em http://www.law.harvard.edu/faculty/tfisher/iptheory.html 
A noção de que o homem possuiria um direito natural sobre ideias foi expressamente incorporada pela Assembleia Constitucional Francesa em 1791. No preâmbulo da lei de patentes constava que "toda ideia nova, cuja realização ou desenvolvimento torna-se útil à sociedade pertence, primariamente, àquele que a concebeu. Haveria uma violação à verdadeira essência dos direitos do homem, se uma invenção industrial não fosse reconhecida como propriedade de seu criador $^{52, "}$

É importante que se tenha claro que a formulação de teorias com base no Direito Natural e a adoção do termo propriedade em si foi uma estratégia retórica adotada de forma deliberada. O CHEVALIER STANISLAS DE BOUFFLERS ${ }^{53}$, relator do projeto de lei de patentes submetido à Assembleia, sabia que o "espírito de seu tempo era totalmente inspirado pela liberdade e pela igualdade e contra privilégios e monopólios de todo gênero".

Assim, não havia nenhuma esperança de salvar a instituição dos privilégios de patentes, senão por meio de uma teoria que soasse aceitável. Assim, de acordo com o economista liberal alemão HERMANN RENTZSCH, de BoufFlers e seus aliados, em deliberada insinceridade, "construíram a teoria artificial de direitos de propriedade dos inventores”, como parte dos direitos do homem. De BOUfFLERS, obviamente, sabia que, como um privilégio de monopólio, as patentes de invenções teriam sido rejeitadas, e, ainda que aprovadas, teriam caído em descrédito com o público. Como direitos naturais de propriedade, eles seriam aceitos e respeitados. Essa análise do pensamento popular provouse correta $^{54}$.

A noção de propriedade privada sobre ideias desafiou juristas e filósofos, especialmente quando muitos escritores passaram a defender que não havia nenhuma diferença lógica fundamental entre a propriedade intelectual e a propriedade material.

\footnotetext{
${ }^{52}$ MACHLUP, Fritz; PENROSE, Edith ,"The patent controversy in the nineteeth century" - The Journal of Economic History. Vol. X. n. I. 1950.pgs. 1-29.

${ }^{53}$ O CHEVALIER DE BOUFFLERS é uma figura curiosa e sua centralidade neste debate reflete bem as várias contradições da sociedade francesa de então. Um nobre em meio à Revolução francesa. Um ex-seminarista que não chegou a concluir seus votos. Aventureiro, tornou-se cavaleiro da Ordem de Malta, o que tanto serviu à sua paixão pelas armas como à intenção de preservar os seus privilégios eclesiásticos. Suas expedições eram sempre intermediadas por retornos à boemia em Paris, onde se tornou famoso pelo seu talento na literatura, música e artes cênicas e plásticas. Foi destacado como governador do Senegal, então colônia francesa. Escritor e poeta (e, portanto, ele próprio, um autor), tornou-se um imortal da Academie Française - um símbolo do ancién regiem, e que fora fechada na Revolução. Quando retornou de sua missão no Senegal foi eleito como deputado pela nobreza de Nantes. O livro "The Cavalier de Boufflers - A Romance of the French Revolution" (WeBSTER, Nesta H., New York, E.P. Dutton and Company, 1916) é centrado no romance vivido por Boufflers e a Condessa de Sabran, tendo como pano de fundo os costumes as contradições políticas e filosóficas desta época.

${ }^{54}$ MACHLUP, Fritz; PENROSE, Edith "“The patent controversy in the nineteeth century" - The Journal of Economic History. Vol. X. n. I. 1950.pgs. 1-29
} 
Alguns avançaram a dizer que a propriedade do homem sobre ideias seria ainda mais sagrada do que aquela que recai sobre bens materiais ${ }^{55}$.

Os conceitos de propriedade e de produto intelectual foram cuidadosamente revistos por juristas, filósofos e economistas. Muitos se dispunham a defender que havia um claro direito do homem de deter controle exclusivo sobre sua nova ideia.

Restringir o comércio de produtos que incorporam a mesma ideia, entretanto, apesar de ser um uso possível do poder estatal, não aparecia como uma consequência lógica de se reconhecer direitos naturais de propriedade. Isso foi esclarecido por inúmeros juristas e economistas, os quais apontaram que os elementos lógicos do conceito de propriedade, tais como aplicados à propriedade material - quais sejam, ocupação, posse, controle, apropriação, restituição, e assim por diante - eram claramente inaplicáveis às ideias ou criações do intelecto ${ }^{56}$.

O economista francês CHARles CoQuelin, for exemplo, fala de "uma estranha confusão de ideias, a qual coloca no mesmo nível uma invenção (...) cuja característica peculiar é a possibilidade de disseminação através de várias mentes e a possibilidade de exploração em centenas de lugares ao mesmo tempo - com o objeto material, necessariamente circunscrito, o qual, por não admitir divisão, pode apenas ser possuído por uma pessoa, e cujo uso não pode ser explorado exceto no lugar em que se encontra ${ }^{57 \text { ". }}$

É digno de nota que também alguns economistas ingleses se mostraram críticos quanto ao conceito da Propriedade sobre ideias.

ROBERT MACFIE, então membro do Parlamento Britânico e um influente defensor do sistema de recompensas, foi um dos maiores representantes dessa posição contrária a um direito natural de propriedade. MACFIE defendeu que, se havia algum direito natural de propriedade sobre ideias, este implicaria apenas o direito do inventor de utilizar seu próprio invento. Entretanto, argumentava ele, era frequente o caso de o próprio inventor ver-se impedido de utilizar o seu invento, pois alguém já havia obtido uma patente sobre

\footnotetext{
${ }^{55}$ Esse foi um dos principais argumentos que STANISLAS DE BOUFFLER usou ao apresentar o projeto de lei de patentes à Assembléia Constitucional em Dezembro de 1790: "Se existe para o homem alguma propriedade genuína, ela recai sobre seu pensamento (...) a legitimidade da propriedade de alguém sobre a árvore que cresce em seu campo não se compara à legitimidade do autor sobre a ideia que brota de sua mente. Invenção, a fonte das artes, é também fonte de propriedade: ela é propriedade primária, ao passo que todas as demais espécies são apenas convencionais (...) (MACHLUP, Fritz; PENROSE, Edith , "The patent controversy in the nineteeth century", op. cit.)

${ }^{56}$ MaChluP, Fritz; PENROSE, Edith , "The patent controversy in the nineteeth century" - The Journal of Economic History. Vol. X. n. I. 1950, pgs. 1-29.

${ }^{57}$ CoQuelin, Charles "Brevets d'Invention”, Dictionaire de l'économie politique (Paris, 1873, p. 217, apud, MACHLUP, Fritz; PENROSE, Edith , (op. cit.)
} 
ele. Isso poderia acontecer até mesmo se a sua ideia fosse superior à ideia patenteada, mas considerada como uma mera versão daquela.

MACFIE apresentou uma proposta de um sistema de financiamento público em substituição às patentes, que contava com o apoio da revista Economist. No rescaldo dessa proposta, vários trabalhos econômicos se debruçaram sobre o sistema de recompensas em jornais, livros, panfletos e conferências ${ }^{58}$.

A principal crítica ao sistema de recompensas levantava a dificuldade intrínseca em sua administração, conforme expressou John Stuart MiLl. Para Mill, um sistema de patentes seria preferível, porque não deixaria nada para o poder discricionário de uma autoridade. Segundo ele, a recompensa conferida pela patente depende da utilidade da invenção, ou seja, quanto maior a utilidade, maior a recompensa ${ }^{59}$.

Alguns dos críticos da proposta de MACFIE alegavam a existência de um conflito de interesses, uma vez que MACFIE era presidente da Câmara de Comércio de Liverpool e um empresário do ramo açucareiro ${ }^{60}$. Essa constatação ajuda a lançar uma maior luz sobre quais eram os inimigos das patentes na Inglaterra ${ }^{61}$.

Embora tendo em conta que o suposto direito natural de propriedade sobre ideias era uma construção mais política do que jurídica - o que levantava o problema de um direito que não encontrava fundamento na história e no direito positivo, TULIO AsCARELLI, embora não tenha aderido ao termo, reconheceu o seu valor filosófico e jurídico. Em primeiro lugar, reconhece ASCARELLI que a argumentação com base em direitos naturais teria sido fundamental para combater os privilégios concedidos ao livre descrímen das autoridades ${ }^{62}$.

\footnotetext{
${ }^{58}$ Shavell, Steven e TANGUY Van Ypersele, "Rewards Versus Intellectual Property Rights", Journal oof Law and Economics , vol. XLIV, October, 2001 - disponpivel em http://law.harvard.edu - acesso em 09.12.2014.

${ }^{59}$ ShaVell, Steven e TANGUY Van Ypersele, "Rewards Versus Intellectual Property Rights", Journal oof Law and Economics , vol. XLIV, October, 2001 - disponpivel em http://law.harvard.edu - acesso em 09.12.2014.

${ }^{60}$ MAChlup, Fritz; Penrose, Edith, "The patent controversy in the nineteeth century" - The Journal of Economic History. Vol. X. n. I. 1950, pgs. 1-29

61 "No final das Guerras Napoleônicas, em 1815, quatro décadas após a publicação de "A riqueza das nações", os fabricantes ingleses estavam estabelecidos firmemente como os mais eficientes do mundo, exceto em algumas áreas limitadas em que países como a Bélgica e a Suiçca tinham liderança tecnológica. Os fabricantes ingleses perceberam corretamente que o livre mercado agora era de seu interesse e começaram a campanha por ele (dizendo que eles ficariam naturalmente felizes em restringir o comércio quando lhes conviesse, como os fabricantes de algodão fizeram quando houve a exportação de maquinário para a indústria têxtil que iria ajudar os concorrentes estrangeiros). (CHANG, Ha-Joo - "Maus Samaritanos - O Mito do Livre-Comércio - A história secreta do capitalismo, Rio de Janeiro, Elsevier, 2009)

62 "É ad uma giustificazione política, piutosto che a uma costruzine giuridica, Che fanno capo quanti all'uopo invocano i diritti Del lavouro, cosi in sostanza concependo Il diritto assluto all'utilzzazione della creazioni come Il premio dello stesso 'lavoro', dello stesso sforzo dell'atto della creazione. Prescindendo da
} 
Além disso, para ASCARELLI, o conceito de uma propriedade intelectual possuía vantagem sobre a ambígua tradição anglo-americana de um monopólio, por reforçar a objetividade do direito, que não se confundia com o meio físico em que as ideias se tornavam extrínsecas, e nem tampouco com um monopólio sobre determinado ramo de atividade $^{63}$.

Essa diferença de tradições se mostrará clara quando estivermos abordando os diferentes caminhos que as autoridades europeias e americanas percorreram na solução do conflito envolvendo a Propriedade Intelectual e o Direito Antitruste.

\subsubsection{A TEOria da Personalidade na Alemanha}

A ideia de uma Propriedade Intelectual sofreu especial resistência na Alemanha, cujo ambiente cultural era dominado pelo movimento do historicismo, hegemônico desde a última parte do século XVIII e durante a maior parte do século XIX, fazendo-se presente em várias áreas (filosofia, direito, arte, economia, história, ciência e filologia) ${ }^{64}$.

costruzioni piú generali che, come nella teoria di Locke o nel Bill of Rights della Virginia (1776), mirano a trovare nella rimunerazione di um lavoro compiuto la giustificazione ultima di ogni proprietá (e che perció por ravvisano Nei diritti assoluti in questione dei diritti reali) non sembra che la tesi ora sposta possa dirsi esatta. Su um terreno piú generale essa no fa che presentare um'istanza giunaturalista che - a parte Il grandíssimo valore che le si deve riconocere sul terreno storico quale arma che venne usata per far venir meno um sistema di privilégi discrezionalmente concessi dall'autoritá - há Il vizio i ogni istanza giunaturalista e cioé quello di postulare um diritto fuori della storia Del quale quello storicamente attuato non sarebbe che uno specchio". (ASCARELl, Tulio - Teoria Della Concorrenza e Dei Beni Immateriali Istituizioni di Diritto Industriale, Terza Edizione, Milano, Dott. A. Giuffre Editore, 1960 - Pg. 305)

63 "Il ricorso allo schema della proprietá per la configurazione di um diritto assoluto di utilizzazione di uma creazione intelletuale si riconduci cosi alla possibilitá di considerare la creazione intelletuale oggetivamente $e$ di individuarla in um bene immateriale la cui fattispecie costitutiva viene oggettivamente disciplinata l'attribuizione originaria del diritto (...) si volesse, come pur acutamente proposto di recente, abbandonare il ricorso alla proprietá e tornare a far capo al diritto di monopólio - inteso allora in relazione alla produzione di um prodotto e cioé quello nel quale se estrinseca la creazione intelletuale, azinché con riferimento a um genere di attivitá - si tornerebbe a dimenticare l'oggetivittá della creazione intelletuale e della sua differenza della cosa o dall'energia nella quale si estrinseca, perché punto di riferimento del diretto sarenbbe non piú direttamente la creazione intelletuale, ma l'esercizio di um'attivitá (...)"(AsCARELli, Tulio - Teoria Della Concorrenza e Dei Beni Immateriali - Istituizioni di Diritto Industriale, Terza Edizione, Milano, Dott. A. Giuffre Editore, 1960 - Pg. 319)

64 "Historicismo" (um termo empregado com diversas variantes de conteúdo) compreende ideologicamente, quer dizer, do ponto de vista filosófico e político, resumidamente, uma corrente "que promete retirar da história conclusões sobre problemas e respostas a questões para, com isso, [oferecer insumos] para que o ser humano entenda a si mesmo e sua posição em relação ao mundo”. Este pensamento histórico, que teve por base um entendimento particular de História, cuja origem reporta a segunda metade do século XVIII, pode ser caracterizado como processualização e dinamização da compreensão histórica. Com isso afirma-se que a noção de "História" foi modificada. Enquanto antes era compreendida como uma soma de tradições particulares, ela passa então a despontar como um processo contínuo". (EISFELD. Jens, "Sobre a Oposição entre o Pensamento Jusnaturalista e Histórico na primeira metade do Século XIX, exemplificada na Propriedade Intelectual", in, Revista Eletrônica do IBPI, Ano II, no 4, 2011, pg. 8). Para uma visão mais detalhada das características da Escola Histórica do Direito, WIEACKER, Frans, "História do Direito Privado Moderno, Lisboa: Calouste Gulbenkian, 1993. 
Segundo JENS EISFELD, a Escola Histórica do Direito impôs resistência à noção de uma Propriedade sobre ideias, o que dificultou a sistematização dogmática da Propriedade Intelectual. A resistência do historicismo, no entanto, não estava vinculada somente à tradição romanista seguida por esta escola - segundo a qual não havia fundamentos para uma propriedade sobre bens incorpóreos. A dificuldade estava relacionada à identificação da Propriedade Intelectual com o pensamento jusnaturalista, que era rival da Escola Histórica no Século XIX ${ }^{65}$.

A divergência surgia em razão de fatores filosóficos e políticos. Do ponto de vista filosófico, a discordância entre as escolas era valorativa. Em resumo, a Escola Histórica defendia que o Direito Positivo emanaria de uma conjugação do espírito divino e do espírito do povo (volksgeist) ${ }^{66}$.

Os históricos eram avessos à busca de valores abstratos, que não encontrassem fundamento no direito positivo - cuja perfeição, e isenção de lacunas, eram tidas por pressupostos ${ }^{67}$. No campo político, a Escola Histórica mostrava-se conservadora e refratária aos ideais iluministas e liberais da Revolução Francesa.

Para EISFELD, "a ideia de propriedade intelectual estava intimamente ligada à teoria jusnaturalista de explicação do direito e à teoria jusnaturalista dos princípios e, nesse sentido, ela [a ideia] repartia com aquelas [teorias] sua mensagem política” 68.

A resistência à Propriedade Intelectual também era forte entre os economistas alemães. JOHN PRINCE-SMITH, o principal defensor do livre comércio entre os economistas

\footnotetext{
${ }^{65}$ EISFELD. Jens, "Sobre a Oposição entre o Pensamento Jusnaturalista e Histórico na primeira metade do Século XIX, exemplificada na Propriedade Intelectual”, In Revista Eletrônica do IBPI, Ano II, n 4, 2011 , pg. 8

${ }^{66}$ Há que se ter claro, porém, que, conquanto o mote da escola histórica fosse um Direito calcado na história de um povo, ambos os termos (história e povo) possuíam significado bem peculiar à Escola Histórica: “Outro ponto que deve ser reforçado é o fato de o elemento histórico dessa escola não poder ser confundido com o que se entende hoje por História. Trata-se, antes, de um complemento empírico posiivo do tratamento filosófico (sistemático), para que o direito possa se desenvlver como uma ciência. $O$ direito seria um produto cultural global, uma tradição espiritual, e não um fruto histórico em seu sentido de força social material. (...) Aliás, a própria noção de povo na obra desse jurista [Savigny] constitui antes um conceito cultural ideal ("a comunidade espiritual e cultural ligada por uma cultura comum") do que uma realidade política e social da nação”. (ARRUDA DE ANDRADE, José Maria, "Interpretação da Norma Tributária”, MP Editora, São Paulo, 2006, pg. 44)

67 “Enquanto o pensamento jusnaturalista buscava solucionar um problema político ou jurídico ao lançar mão de uma realidade independente da razão, o pensamento histórico entendia ser ilegítimo esse procedimento e, em contrapartida, confiava na racionalidade do Ser, ou seja, no caso da Escola Histórica do Direito, na racionalidade de valoração do Direito Positivo". (EISFELD. Jens, "Sobre a Oposição entre o Pensamento Jusnaturalista e Histórico na primeira metade do Século XIX, exemplificada na Propriedade Intelectual", In Revista Eletrônica do IBPI, Ano II, nº 4, 2011, pg. 8)

${ }^{68}$ EISFELD. Jens, "Sobre a Oposição entre o Pensamento Jusnaturalista e Histórico na primeira metade do Século XIX, exemplificada na Propriedade Intelectual”, In Revista Eletrônica do IBPI, Ano II, nº 4, 2011 , pg. 38.
} 
alemães ${ }^{69}$, opinou que "qualquer pleito pela proteção da propriedade privada é uma demanda pela intervenção estatal, que deveria ser ditada, exclusivamente, pelo bem-estar social. Em relação à propriedade sobre coisas, o bem-estar comum está firmemente estabelecido. Qual seria, a esse respeito, a situação da "propriedade intelectual” $e$, sobretudo, das patentes de invenção?",70. Segundo ele, as patentes seriam "danosas ao progresso da produção e ao bem comum e, assim, ilegítimas à luz do princípio do direito de propriedade".

Em resposta, a Escola do Direito Natural, por sua vez, desenvolveu uma teoria da personalidade, segundo a qual o homem deveria ser o proprietário do produto de seu intelecto.

Esse direito de personalidade conferiria ao homem o direito de livre realização, isto é, um direito de uso irrestrito de sua liberdade, que só era restringido pelo mesmo direito reconhecido a todos os outros homens. O direito de personalidade era o direito à liberdade e, portanto, a fonte de direito dos outros direitos originários e do Direito Natural como um todo. A teoria da personalidade influenciou o conceito de propriedade, cuja referência à personalidade individual possibilitou uma extensão à produção intelectual.

Influenciada pelo direito de personalidade, a teoria da propriedade do Direito Natural forneceu uma justificativa para legitimação teórica da Propriedade Intelectual ${ }^{71}$.

O recurso a uma teoria da personalidade foi a tentativa de se utilizar de uma terminologia familiar à tradição romanista da Escola Histórica - tendo em vista que o Direito Romano já reconhecia um direito de personalidade, que estava vinculado ao status. Tal direito, no entanto, não produzia nenhum conteúdo material independente e era geralmente equiparado com a capacidade jurídica do ser humano.

Influenciada pelo direito de personalidade, a teoria da propriedade do jovem Direito Natural forneceu a legitimação teórica da Propriedade Intelectual, o que não significa dizer que não continuou a haver resistência da escola histórica. FRIEDRICH KARL VON SAVIGNY,

\footnotetext{
${ }^{69}$ As barreiras tarifárias impostas pela Zollverein acabavam criando insatisfações, sobretudo, nas cidades portuárias mercantes (leia-se, liberais) da Prússia. Os proponentes do livre comércio na Alemanha formaram um movimento denominado como "Manchesterismo". JOHN PRINCE-SMITH, nascido em Londres, mas radicado em Hamburgo, se identificava com esse movimento.

${ }^{70}$ apud, MACHLUP, Fritz; PENROSE, Edith , (op. cit.)

${ }^{71}$ EISFELD. Jens, "Sobre a Oposição entre o Pensamento Jusnaturalista e Histórico na primeira metade do Século XIX, exemplificada na Propriedade Intelectual”, in, Revista Eletrônica do IBPI, Ano II, nº 4, 2011, pg. 37
} 
por exemplo, rejeitou, conjuntamente, com a noção de um direito originário de personalidade, também a teoria da Propriedade Intelectual ${ }^{72}$.

Mesmo em um período em que a resistência às patentes já havia arrefecido, os principais autores alemães continuaram evitando o recurso à aproximação da propriedade que recai sobre bens imateriais daquela convencional, embora, em alguns casos, passassem a reconhecer o seu conteúdo patrimonial. JOSEF KOHLER, por exemplo, veio a reconhecer o caráter patrimonial do direito conferido aos autores e inventores, porém, adotou a terminologia direitos sobre bens imateriais.

Conforme ressalta JOÃO DA GAMA CERQUEIRA ${ }^{73}$ :

"Uma dessas correntes, conquanto negue ao direito de autor os atributos da propriedade, considera-o, todavia, como direito patrimonial. De acordo com esta doutrina, o instituto do direito de autor possui caráter exclusivamente patrimonial, porque, como indicam as suas origens históricas, surgiu com o fim de garantir os interesses patrimoniais dos escritores; em segundo lugar, porque as regras principais contidas na lei destinam-se a tutelar a faculdade exclusiva de reprodução da obra, mediante a qual o autor assegura para si os proveitos econômicos de sua criação. O caráter patrimonial mais se evidencia na transmissibilidade deste direito, a que são estranhos os direitos pessoais do autor. KOHLER, que é um dos principais autores desta teoria, reconhece que, ao autor, competem outros direitos de natureza não patrimonial, mas pessoal, que denomina "individualrecht". Mas em sua opinião, estes direitos não fazem parte do conteúdo do direito de autor, pertencendo a outra esfera do direito, se bem que concorram para a proteção da obra".

Outros autores, dentre os quais OTTO VON GIERKE - identificado com a escola histórica continuaram contestando o caráter patrimonial do direito, atribuindo-lhe natureza puramente pessoal. Esta teoria deriva, diretamente, da teoria da personalidade, conforme GAMA CERQUEIRA ${ }^{74}$ :

"Alguns autores filiados a esta doutrina consideram o direito de autor como direito da personalidade (KANT, BLUNTSCHLI, NEUSTETEL); outros, como direitos sobre a própria pessoa (LANGE, ORLOF, DAHN). LANGE E ORLOF têm o direito de autor como afirmação do próprio eu; DAHN o considera como faculdade de dispor das próprias forças e de exteriorizar a própria personalidade. Para BLUNTCHLI, o direito de autor constitui a mais alta exteriorização da sua personalidade; e a publicação da obra, sem o seu consentimento, importa em dispor de seu nome, da sua honra, e em violação do exercício de sua liberdade pessoal.

${ }^{72}$ EISFELD. Jens, "Sobre a Oposição entre o Pensamento Jusnaturalista e Histórico na primeira metade do Século XIX, exemplificada na Propriedade Intelectual", in, Revista Eletrônica do IBPI, Ano II, n 4, 2011, pg. 38

${ }^{73}$ Gama CerqueIRA, João da, "Tratado da Propriedade Industrial, 2 2 Edição Revista e Atualizada, Vol. 1, Revista dos Tribunais, 1946, pg. 88

${ }^{74}$ Gama CerqueIra, João da, "Tratado da Propriedade Industrial, 2 2 Edição Revista e Atualizada, Vol. 1, Revista dos Tribunais, pg. 88 
GIERKE, finalmente, vê nas obras intelectuais não só depois de criadas, como, também, depois de publicadas, um direito de personalidade, uma faculdade que não se distingue da atividade criadora do indivíduo, de modo que o direito do autor encontra seu fundamento na personalidade e tem com objeto uma parte integrante da esfera própria da personalidade".

A Teoria da Personalidade foi importante para a concepção de um direito moral do criador da obra, o qual não se exauriria completamente após a sua divulgação e sua colocação no comércio $^{75}$.

Em período contemporâneo, houve tentativas de harmonizar as teorias baseadas na personalidade e aquelas baseadas no aspecto patrimonial. NEWTON SILVEIRA, por exemplo, defende que o direito de personalidade se manifestaria de modo absoluto antes da publicação da obra, sendo que, após ela, tal direito se manifestaria em maior ou menor grau, na medida em que a obra contenha elementos que refletem a personalidade do autor (seu nome, imagem, seu estilo, etc. $)^{76}$.

De modo geral, no entanto, pode-se dizer que o ardil político de equiparar a propriedade sobre ideias à propriedade material, que havia sido exitoso na França, fracassou na Alemanha - e isso, diga-se, mesmo quando a resistência às patentes já havia fenecido $^{77}$. Tal fez com que, durante o terceiro quarto do Século XIX, os defensores da Propriedade Intelectual se voltassem à construção de novos argumentos.

\footnotetext{
${ }^{75}$ Segundo FISHER, a Teoria da Personalidade, derivada das ideias de KANT e HEGEL, defende que a proteção da Propriedade Intelectual atenderia a algumas necessidades humanas fundamentais. A partir deste ponto de vista, os direitos de Propriedade Intelectual poderiam ser justificados tanto por afastar a apropriação e modificação de artefatos por meio dos quais os autores e artistas teriam expressado a suas vontades (atividade central à sua personalidade) como pelo fato de que eles criariam condições econômicas e sociais para a atividade intelectual criativa, que, por sua vez, seria fundamental para o florescimento humano. (FISHER, Willian, in "Theories of Intellectual Property", disponível em http://www.law.harvard.edu/faculty/tfisher/iptheory.html). HuGHES deriva, a partir da Filosofia do Direito de Hegel, as seguintes vigas mestras com respeito à apropriada formação de um sistema de Propriedade Intelectual: “(a) Deve-se conferir maior proteção legal aos frutos de atividades intelectuais altamente expressivas, como romances literários, do que os frutos de atividades menos expressivas, como uma pesquisa genética. (b) A persona do homem - sua imagem pública, incluindo características físicas, maneirismos e história" - seria um importante "receptáculo de sua personalidade", razão pela qual mereceria uma proteção legal mais generosa, a despeito do fato de que tais características não derivariam do trabalho. (c) deve-se permitir que os autores e inventores granjeiem respeito, honra, admiração e dinheiro pela venda ou distribuição de cópias de seus trabalhos, mas não se deve permitir que eles permitam a outros a mutilação ou mal uso de seus trabalhos". (HugHes, Justin, In "The Philosophy of Intellectual Property", Georgetown Law Journal, December, 1988)

${ }^{76}$ SILVEIRA, Newton. "Direito de autor no desenho industrial". 1. ed. São Paulo: Revista dos Tribunais, 1982 p. 76

${ }^{77}$ Um dos defensores das patentes na Alemanha escreveu, em 1877 (ano em que a lei de patentes foi aprovada): "It's interesting to observe that the advocates of the patent system in Germany, correctly understanting that this theoretical and sophistic debate [about so-called 'property on ideas'], was absolutely sterile, did not go so much into this question and, if so, only to refute the crassest absurdities in the theorizing of anti-patent people" - GROTHE, Das Patentgesetz, p.4). As a matter of fact, the chief draftsmen of the German patent law emphasized that that "property rights are... inseparably linked with material things" (Blitzer, F., Vorschläge für ein deutsches Patentgesetz (Stuttgart,1864), p. 122
} 


\subsubsection{TEORIAS SOBRE O EsTímUlo À INOVAÇão E À DIVUlgaÇão do CONHECIMENTO}

$\mathrm{Na}$ tentativa de se criar um argumento alternativo ao recurso à propriedade privada, os defensores de patentes desenvolveram a tese de que era necessário se recompensar os autores e inventores por seu serviço socialmente relevante, o que encontrava amparo em um argumento moral, de conferir-lhe uma justa recompensa.

No campo filosófico, esta teoria se apoiava na ideia de um contrato tácito entre o inventor e a sociedade. Tratar-se-ia, assim, de um direito de obrigação. Note-se que, no caminho que até aqui percorremos na reconstrução das principais teorias para justificar a proteção aos autores e inventores, esgotaram-se todas as categorias de direitos então conhecidas pelo Direito Romano (direitos reais, pessoais e de obrigação ${ }^{78}$ ).

Tampouco essa ideia era isenta de críticas, a maior parte delas, baseando-se no fato de que - no limite - todas as invenções emanavam da própria sociedade.

Nesse sentido, é de se citar a posição de JOHN LEWIS RICARDO, sobrinho do autor clássico DAVID RICARDO: “Aproximadamente todas as invenções dependem menos do indivíduo do que do progresso da sociedade como um todo", não havendo, portanto "nenhuma necessidade de recompensar o indivíduo pela sorte de ser o primeiro a se deparar com a invenção ${ }^{79, "}$

Outros autores aceitavam a ideia de um direito à recompensa, porém, defendiam que esta recompensa viria sem nenhuma necessidade de intervenção. Se o inventor estivesse realmente à frente dos outros, a sua exploração econômica no intervalo de tempo entre o advento da invenção e a sua disseminação, por meio da imitação, asseguraria a recompensa.

\footnotetext{
${ }^{78}$ Logo, porém, levantaram-se as primeiras dúvidas sobre os fundamentos dessa doutrina, segundo a qual o direito de autor consistia num direito de obrigação, oriundo de contrato tácito entre a sociedade e o indivíduo. Outros autores, entretanto, aos quais repugnava considerar tais direitos como de propriedade ou colocá-los como direitos de obrigação, criaram terceira escola, classificando os direitos do autor como direito pessoal. Exauria-se, assim, a clássica divisão do Direito romano, que distribuía todos os direitos do indivíduo nas três categorias dos direitos: reais, de obrigações e pessoais." (GAMA CERQUEIRA, João da, "Tratado da Propriedade Industrial”, $2^{a}$ Edição Revista e Atualizada, Vol. 1, Revista dos Tribunais, 1946, pg. 78)

79 "Nearly all useful inventions depend less on any individual than on the progress of society. A want is felt...., ingenuity is directed to supply it; and the consequence is, that a great number of suggestions or inventions of a similar kind come to light. The ideas of men (...) are set in the motion by exactly the same circumstances. So we find continually a great number of similar patents taken out about the same time. Thus, the want suggests the invention, and though the State should not reward him who might be lucky enough to be the first to hit on the thing required, the want growing from society, and not from the individual or from the Government, would most certainly produce the required means of gratifying it (...)" - The economist, July, 26, 1851, p. 812 .
} 
A esse respeito, uma diferença essencial, contudo, existiria entre os autores e inventores. Albert SCHÄFFle, um dos autores que avançou esta tese, reconhecia que a proteção seria importante no que se refere aos livros, por exemplo, mas não para a indústria. Isso se devia ao fato de que a contrafação de livros seria mais barata e rápida, permitindo que a imitação se desse praticamente sem nenhum intervalo ${ }^{80}$.

Essa teoria, que considerava as vantagens do primeiro ingressante em um mercado, granjeou grande respeito. Porém, em uma época em que se acreditava em uma concorrência quase perfeita, a alegação contrária, de que os lucros cessariam muito depressa era bastante plausível.

O único aparente consenso era de que era socialmente desejável que novas invenções fossem introduzidas e que o Estado deveria induzir o comportamento inovador. Entretanto, era altamente discutível que o sistema de patentes consistia na forma mais adequada de promover esse objetivo.

Conforme já comentamos anteriormente, as alegações de que a proteção conferira um suporte ao desenvolvimento industrial precoce na Inglaterra eram repelidas pelo fato de que outros países, notadamente a Alemanha, terem alcançado desenvolvimento industrial sem contar com um sistema de proteção autoral e às patentes ${ }^{81}$.

Por outro lado, era também altamente discutível que o sistema de patentes seria a forma de recompensa menos custosa para a sociedade. STUART MILL afirmara que nenhum outro método mostrara-se menos custoso. Entretanto, os relatórios das comissões do Parlamento inglês mostravam o oposto, ou seja, os sistemas de patentes se mostravam excessivamente custosos.

O sacrifício da produção, pelo sistema de patentes, era um fator a ser considerado. Porém, havia outros: o custo burocrático de administrar o sistema, os custos com os litígios, e os custos de se permitir o poder monopolista de certas empresas - poder este que, muitas vezes, excedia o escopo da proteção. Além disso, este argumento baseava-se na presunção de que o inventor e o detentor dos direitos seriam a mesma pessoa, o que, simplesmente, não coincidia com a realidade na maioria dos casos.

\footnotetext{
${ }^{80}$ SCHAFFLE, Die nationalokonomische Theorie, p. 141, apud, MACHLUP, Fritz; PENROSE, Edith , (op. cit.)

${ }^{81}$ É bem verdade, porém, que o desenvolvimento industrial alemão teve um fator peculiar e decisivo: a participação intensiva do Estado nas indústrias-chave. Tal característica, aliada a um investimento massivo em educação e a uma política de proteção e uso gorvernamental dos cartéis e monopólios, bem como a direção da indústria para objetivos militares, criaram um círculo virtuoso que marcou o desenvolvimento alemão. (cf. ARRUdA DE ANDRADE, José Maria, "Economização do Direito Concorrencial e Positivismo Jurídico: entre Teoria da Decisão e das Provas" - Tese de Livre Docência - FDUSP, 2012, São Paulo - pg. 67). Logo, a despeito de a Alemanha não ter se valido de um regime de Propriedade Intelectual nacional, a indústria funcionava sob um regime de quase monopólio.
} 
Um editorial da Economist publicado à época (1851, p. 114-115) reflete bem as sérias discordâncias quanto ao real estímulo concedido pela proteção ao espírito criativo da sociedade:

"The privileges granted to inventors by patent laws are prohibition on other men, and the history of invention accordingly teems with accounts of trifling improvements patented, that have put a stop, for a long period, to other similar and much greater improvements. It teems also with accounts of improvements carried into effect the instant some patents had expired. The privileges have stifled more inventions than they have promoted, and have caused more brilliant schemes to be put aside than the want of them could ever have induced men to counceal. Every patent is a prohibition against improvements in a particular direction, except by the patentee, for a certain number of years; and, however, beneficial that may be to him who receives the privilege, the community cannot be beneficied by it (...) On all inventors it is especially a prohibition to exercise their faculties, and in proportion as they are more numerous than one, it is an impediment to the general advancement, with which it is the duty of the Legislature no to interfere and which the claimers of privileges pretend at least to have at heart".

Um argumento suplementar seria a necessidade de se estimular a divulgação do conhecimento, por meio das patentes. Entretanto, o argumento contrário, neste caso, seria o de que, na prática, o sistema criaria um incentivo apenas para a divulgação daquelas invenções que, dificilmente, pudessem ser mantidas em segredo - as quais, não raro, seriam as menos úteis à sociedade.

\subsection{Conclusões parciais sobre a Reconstrução Histórica das TeOrias para Justificar a Propriedade InTElectual}

O relato acima demonstra que, ao contrário do que se poderia supor, as tensões entre a proteção à Propriedade Intelectual e a concorrência existem desde a disseminação da concepção mais moderna e liberal desse sistema, tendo tal conflito moldado os diferentes regimes de patentes.

Também nos ajuda a discernir duas linhas de tradição básicas, sendo que a primeira, de origem francesa, acarreta a objetividade do bem jurídico protegido, ao passo que a segunda (anglo-americana), é ambígua (pois o termo monopólio poderia significar o monopólio sobre a ideia, sobre o meio físico que a tornava extrínseca, e, ainda, sobre um determinado ramo de atividade, inclusive, um mercado). Essas diferenças, como já dissemos, serão ressaltadas quando estivermos analisando as diferentes abordagens quanto ao conflito envolvendo a Propriedade Intelectual e o Antitruste. 
O retrato histórico dos embates entre defensores do livre-comércio e protecionistas também ajuda a ilustrar como o tema da Propriedade Intelectual está indissociavelmente relacionado ao comércio internacional, não chegando a surpreender que a primeira tentativa de internacionalização tenha ocorrido já ao final do século XIX, em 1883, com a Convenção de Paris - período em que os países outrora resistentes à proteção já haviam se industrializado ou se encontravam em vias de atingir a fronteira tecnológica.

CAliXto SAlomão FILHO também registra que a proteção às patentes, no Século XIX, estava associada ao protecionismo comercial, sendo que tal decorreria, na opinião do autor, de um resquício do corporativismo típico do antigo regime. Um dos objetivos da Convenção de Paris, segundo o autor, seria a criação de um sistema que permitisse o reconhecimento internacional das patentes:

"Durante todo o século XIX, o grande problema, ainda resquício do sistema corporativo, é do reconhecimento das patentes estrangeiras. O sistema exclusivamente nacional de direito industrial faz com que os importadores nacionais possem a registrar as patentes como "brevet d'importation". A visão corporativa, antes limitada às corporações de ofício, agora transforma-se em um corporativismo nacional.

O crescimento do comércio mundial obviamente não pode conviver com um tal desestímulo. Daí uma das principais razões para a celebração da Convenção de Paris em 1883, criando um sistema internacional de reconhecimento de patentes ${ }^{82,}$.

Finalmente, os principais argumentos no debate envolvendo Propriedade Intelectual e livre comércio no Século XIX serão retomados no debate sobre Direito Concorrencial e a Propriedade Intelectual ao longo do Século XX, o que poderá ser facilmente notado ${ }^{83}$.

\footnotetext{
${ }^{82}$ Salomão Filho, Calixto, "Direito Industrial, Direito Concorrencial e Interesse Público", Revista de Direito Público da Economia, Belo Horizonte, Ano 2, nº 7, 2004, pg. 29

83 "The third line of attack comes from many distinguished antitrust advocates, who are at home exclusively in the west Washington, Berlin and Brussels. In contrast to their socialist colleagues and some ministers of technology, they are staunch promoters of the free market system and opposed, therefore, to all direct government intervention in the market. Nevertheless, they are among the severest critics of the patent system. What disturbs them is the alleged anticompetitive effect of patent monopolies. They consider these monopolies as alien to a system of free competition, and are willing to accept them only reluctantly as a statutory exception which is to be strictly delimited. While they have nothing against technical progress as a condition for economic growth, they view the exclusive patent right with unallayed suspicion since, as they say, it unduly limits competition, gives rise to misuses, favors the acquisition of economic power, and, last but not least, because of its territorial nature, constitutes an excellent instrument for international trade regulation and market division. This last element naturally plays a special role in the ambit of the European Common Market. Under the catchword "free movement of goods," it determines the practice of the Commission of the European Communities, and to a certain extent, also the decisions of the European Court of Justice" (BEIER, Friedrich-Karl, in "The Significance of the Patent System for Technical, Economic and Social Progress" - disponível em http://beck-online.beck.de/default.aspx?printmanager=print\&VPATH=b)
} 


\subsection{TEORIAS ECONÔMICAS PARA JUSTIFICAR A PROPRIEDAdE INTELECTUAL No SÉCULO XX}

\subsubsection{ANTECEDENTES: O VALOR ECONÔMICO SUbJETIVo do CONHECIMENTO}

Nos itens anteriores, nos valemos, em grande parte, do relato de MACHLUP e PENROSE sobre o conflito de ideias sobre a Propriedade Intelectual no século XVIII e a reconstrução das principais teorias econômicas e jurídicas.

Anteriormente, já referimos ao prestígio de MACHLUP, economista austríaco, nos Estados Unidos. A influência de autores austríacos à ciência econômica no país é conhecida, podendo-se referir a nomes como Ludwig VON MiSES, FrIEDRICH HAYeK que foram professores de MACHLUP em Viena - e JOSEPH SCHUMPETER ${ }^{84}$.

HAYEK, em particular, era um crítico da premissa neoclássica de informação perfeita. Para HAYEK, "if we possess all the relevant information, if we can start out from a given system of preferences and if we command complete knowledge of available means, the problem which remains is purely one of logic ${ }^{~} 85$.

Consequentemente, HAYEK via o conhecimento não como um dado conferido igualmente a todos na sociedade (premissa neoclássica), mas sim, como um dos recursos escassos que compunham o problema básico alocativo da ciência econômica ${ }^{86}$ :

"Knowledge is never for the whole society given. Social knowledge is "dispersed bits of incomplete and frequently contradictory knowledge which all the separate individuals possess. The economic problem of society is thus not merely a problem of how to allocate given resources (...). It is rather a problem of how to secure the best use of resources known to any of the members of society (...). To put it briefly, it is a problem of the utilization of knowledge not

\footnotetext{
${ }^{84}$ Este último autor, frequentemente citado em discussões envolvendo a relação entre a Propriedade Intelectual e a concorrência, não pode ser enquadrado na chamada "Escola Austríaca de Economia". SCHUMPETER, ao menos no início de sua carreira, com o pensamento neoclássico. Seu primeiro livro foi um tratado teórico, que teve a finalidade de defender o valor da teoria na Alemanha (lembrar, aqui, da "Disputa sobre o método" travada entre a escola histórica e os neoclássicos, como CARL MENGER - que fora mestre de SCHUMPETER). Porém, ao longo de sua obra, distanciou-se, metodologicamente, dos neoclássicos, ao defender a importância do elemento histórico, sem, contudo, abandonar o valor da teoria).

${ }^{85}$ HAYEK, Friedrich, "The Use of Knowledge in Society”, American Economic Review, 1945, XXXV, No. 4., pg 519-530, disponível em http://www.econlib.org/library/Essays/hykKnw1.html

${ }^{86}$ É de se ressaltar que HAYEK não concordava com a premissa neo-clássica de "equilíbrio": "equilibrium is not an (optimal) outcome (or state), but a process (activity) - the coordination of individuals' plans and actions. In this process, individuals learn from the experience and acquire knowledge about things, events and others that help them to act. In this sense, the system of prices plays the role of a signal; prices direct attention: "the whole reason for employing the price mechanism is to tell individuals that they are doing, or can do, has for some reason for which they are not responsible become less or more demanded" (...) The prices system is a mechanism for communicating information”.
} 
given to anyone in its totality”. "Any approach, such as that of mathematical economics with its simultaneous equations, which in effect starts from the assumption that people's knowledge corresponds with the objective facts of the situation, systematically leaves out what is our main task to explain ${ }^{87, "}$

Portanto, a ideia de conhecimento subjetivo ${ }^{88}$, como um dos recursos da sociedade, foi uma contribuição da escola austríaca. O problema de cálculo desse conhecimento começou, então, a despertar novos estudos econômicos.

KenNeth J. ARROw produziu um texto seminal, no qual enfrentou o problema de alocação dos recursos destinados a promover as invenções, termo tomado pelo autor de forma ampla (i.e., como produção de conhecimento) ${ }^{89}$.

ARROW analisou a hipótese de que a competição perfeita conduziria à alocação ótima de recursos, inclusive, no que se refere aos recursos destinados a promover a produção de conhecimento (invenção). ARROW apontou três causas pelas quais a concorrência perfeita não poderia atingir uma alocação de recursos ótima no que se refere às invenções: indivisibilidades, não-apropriabilidade e incerteza $a^{90}$. Analisaremos as ideias de ARROW em maiores detalhes em Capítulo oportuno, em que se fará uma contraposição entre SCHUMPETER e ARROW, e as consequências deste contraponto para as análises antitruste envolvendo a Propriedade Intelectual.

Por ora, basta-nos constatar que, entre as décadas de 1950 e 1960, vários estudos econômicos importantes estavam sendo desenvolvidos sobre o tema do conhecimento, sendo que, a par das diferenças de abordagem teórica, todos eles tinham como ponto em comum o desafio da premissa neoclássica de conhecimento objetivo ${ }^{91}$.

\footnotetext{
${ }^{87}$ GodIN, Benôit, “The Knowledge Economy: Fritz Machlup's Construction of a Synthetic Concept”, Project on the History and Sociology of STI Statistics, Working Paper $n^{\circ} 37,2008$, disponível em www.csiic.ca

88 "In real life, no one has perfect information, but they have the capacity and skill to find information. This knowledge has nothing to do with a pure logic of choice, but is knowledge relevant to actions and plans. This kind of knowledge, unfortunately for mathematical economists, "cannot enter into statiscs": it is mostly subjective. To what extent, thus asked Hayek, "does formal economic analysis convey any knowledge about what happens in the real world”. (GoDIN, Benôit, "The Knowledge Economy: Fritz Machlup's Construction of a Synthetic Concept", Project on the History and Sociology of STI Statistics, Working Paper n⿳ 37, 2008, disponível em www.csiic.ca)

${ }^{89}$ ARROW, Kenneth "Economic Welfare and the Allocation of Resources", in "The Rate and Direction of Inventive Activity: Economic and Social Factors", Princeton University Press, 1962, pg. 609, disponível em: http://www.nber.org/chapters/c2144.pdf

${ }^{90}$ ARrow, Kenneth, "Economic Welfare and the Allocation of Resources for Invention", in "The Rate and Direction of Inventive Activity: Economic and Social Factors, Universities-National Bureau, UMI, ISBN: 087014-304-2, 1962, pg. 609-626.

${ }^{91}$ GodIN, Benôit, "The Knowledge Economy: Fritz Machlup's Construction of a Synthetic Concept”, Project on the History and Sociology of STI Statistics, Working Paper $n^{\circ} 37,2008$, disponível em www.csiic.ca
} 
MACHLUP avançou nesta ideia, ao desenvolver uma teoria que visava analisar a produção e a distribuição do conhecimento ${ }^{92}$.

A partir de sua teoria, MACHLUP desenvolveu uma metodologia para medir o conhecimento, a qual se baseou na ciência das finanças públicas. Ele concentrou-se em estimar os custos e vendas de produtos e serviços relacionados ao conhecimento, tendo coletado dados estatísticos de diversas fontes públicas e privadas.

MACHLUP, então, chegou à estimativa de que a economia do conhecimento valeria U\$ 136,4 milhões, ou 29\% do PIB americano em 1958, bem como que tal economia havia crescido a uma taxa de 8,8\% ao ano no período entre 1947 e 1958, e gerava empregos que representavam 26,9\% da renda nacional. Foi em seu livro Production and Distribution of Knowledge (1962), que o autor cunhou primeiro a expressão Economia do Conhecimento.

O método de MACHLUP, embora tenha tido importância política, não foi bem aceito pelos economistas, principalmente, por ter se baseado em um método empírico, e não em uma função matemática, como defendia a visão mais ortodoxa (que partia de uma função que decompunha o PIB em capital e trabalho, ficando o residual atribuído à ciência e tecnologia). Tal, naturalmente, havia sido uma opção consciente do autor, que rejeitou o método matemático como uma construção abstrata, que apenas media a relação entre insumos e produção, não estabelecendo nenhuma relação de causalidade.

Porém, é de se registrar a importância de sua obra para uma análise econômica do conhecimento.

\footnotetext{
${ }^{92}$ Primeiramente, o autor se valeu de um amplo conceito de conhecimento, científico e leigo. A segunda ideia avançada foi analisar a produção e distribuição do conhecimento. Para MACHLUP, a informação seria conhecimento apenas se comunicada e utilizada (teoria da comunicação). Assim, MACHLUP operacionalizou seu conceito de conhecimento como sendo composto de quatro elementos: educação, P\&D, comunicação e informação. Para analisar a produção do conhecimento (R\&D), MACHLUP utilizou-se de uma definição mais ampla de educação (que, para ele, não se limitava apenas à educação formal, mas toda espécie de treinamento: igreja, forças armadas, televisão, etc.). MACHLUP redefiniu o conceito corrente de P\&D, tal como utilizado à época pela US National Science Foundation (que a definia como "a quantia básica de pesquisa, pesquisa aplicada e desenvolvimento). Em lugar desse conceito, ele definiu o conceito como um processo de quatro estágios que culminaria em inovação (termo evitado pelo autor). Ao assim definir o conceito, MACHLUP se distanciou de um conceito histórico de inovação e se apegou a um conceito econômico, que estava atrelado à comercialização da invenção pelas empresas. O terceiro componente da operacionalização seria a mídia, a qual ele considerava um grande leque de veículos (livros, periódicos, jornais, fotografia, fonografia, televisão, etc.) O último elemento seria a informação em si, composta de serviços de informação e máquinas de informação (tecnologias).
} 


\subsubsection{Fundamentação ECONÔMICA da Propriedade}

Na década de 1960, surgiram, nos Estados Unidos, diversas abordagens econômicas que - a despeito de suas diferenças entre si - buscavam analisar não apenas a teoria marginalista de formação de preços, mas também as instituições que o formam e condicionam. A esse grupo de estudos, costuma-se denominar Nova Economia Institucional.

É importante ressaltar que não se trata de uma escola econômica, uma vez que as abordagens teóricas e orientações políticas entre os autores eram muito diversas, porém, de uma maneira geral, se mostravam críticos à teoria neoclássica, seja para aperfeiçoá-la (OLIVER E. WilliAMSON), seja para substituí-la, seja para retornar à economia clássica (RONALD COASE). Também se verifica uma maior preocupação com o comportamento dos agentes do que com as estruturas de mercado $^{93}$.

Destaca-se o texto de COASE, The Problem of Social Cost (1960). Este texto foi dedicado a analisar o problema das ações das empresas que provocam prejuízos a outros (em termos econômicos, externalidades - como no típico exemplo de uma fábrica que produz emissões de fumaça prejudiciais às pessoas que habitam áreas vizinhas).

A solução neoclássica para este problema (com base no autor neoclássico ARTHUR CECIL PIGOU) seria a responsabilização do proprietário da fábrica pela emissão dos gases, ou a imposição de um tributo na proporção da poluição produzida. Essas alternativas foram consideradas como equivocadas por COASE.

Em uma breve síntese do raciocínio proposto por COASE, o que teria de ser decidido é se os ganhos sociais da cessação da poluição trariam seriam maiores do que as perdas originadas pela paralisação da atividade que produz o dano. Para COASE, os Tribunais fariam este tipo de análise com frequência, porém, a delimitação do direito [i.e., pelos tribunais] também dependeria da previsão legal de ilegalidade da conduta. Assim, a solução convencional dos economistas demandaria uma ação estatal, que, no entanto, poderia se revelar por demais condescendente com os responsáveis pelos danos.

A solução ideal para COASE seria o tratamento de todos os fatores de produção como direitos de propriedade bem delimitados.

O exercício de tais direitos ao uso de fatores de produção (digamos, o "direito de poluir"), na ausência de outros custos, poderia ser transacionado no mercado, sem

\footnotetext{
93 ARruda DE ANDRADE, José Maria, in "Economização do Direito Concorrencial e Positivismo Jurídico: entre Teoria da Decisão e das Provas” - Tese de Livre Docência - FDUSP, 2012, São Paulo.
} 
necessidade de intervenção estatal ${ }^{94}$. Em resumo, em um mundo com direitos de propriedade bem definidos e baixos custos de transação, os direitos sempre seriam atribuídos aos agentes que mais os valorassem, produzindo, assim, uma alocação eficiente (Teorema de COASE).

Um determinado ramo da escola de Chicago, então hegemônica - principalmente, os autores que representavam esta escola de pensamento no campo jurídico (isto é, autores do Law and Economics) - utilizou-se desta teoria para fundamentar, economicamente, a propriedade privada em geral - a qual teria o efeito de internalizar as externalidades, fazendo o proprietário ser responsabilizado pelas suas próprias ações sobre o bem.

Essa argumentação concebia a propriedade como a solução ao que se denomina de Tragedy of Commons (ou, a tragédia dos baldios, termo tornado famoso em um artigo de GARRET HARDIN para a revista Science).

É importante perceber que este ramo do Law and Economics valeu-se de uma forma forte do Teorema de COASE, ao entender que as transações eficientes sempre aconteceriam - isto é, que os bens sempre iriam para as mãos mais produtivas - o que, em nenhum momento, foi proposto por COASE ${ }^{95}$.

Conforme MARK LEMLEY ${ }^{96}$ :

"Further support for the externality-reducing function of property law comes from those who apply a strong form of the COASE theorem. If one assumes that efficient transactions will always occur, it doesn't particularly matter who gets the property entitlement, as they will simply sell or rent the property to the most productive user. Thus, one of the significant risks of

\footnotetext{
94 "In fact it would be true under any system of law. A system in which the rights of individuals were unlimited would be one in which there were no rights to acquire. If factors of production are thought of as rights, it becomes easier to understand that the right to do something which has a harmful effect (such as the creation of smoke, noise, smells, etc.) is also a factor of production. Just as we may use a piece of land in such a way as to prevent someone else from crossing it, or parking his car, or building his house upon it, so we may use it in such a way as to deny him a view or quiet or unpolluted air. The cost of exercising a right (of using a factor of production) is always the loss which is suffered elsewhere in consequence of the exercise of that right-the inability to cross land, to park a car, to build a house, to enjoy a view. to have peace and quiet or to breathe clean air. It would clearly be desirable if the only actions performed were those in which what was gained was worth more than what was lost. But in choosing between social arrangements within the context of which individual decisions are made, we have to bear in mind that a change in the existing system which will lead to an improvement in some decisions may well lead to a worsening of others. Furthermore we have to take into account the costs involved in operating the various social arrangements (whether it be the working of a market or of a government department) as well as the costs involved in moving to a new system. In devising and choosing between social arrangements we should have regard for the total effect. This, above all, is the change in approach which I am advocating".(COASE, Ronald H. "The Problem of Social Cost", Journal of Law and Economics, Vol. 3, 1960, The University of Chicago Press)

${ }^{95}$ LeMLEY, Mark, "Property, Intellectual Property, and Free Riding", in Texas Law Review, vol. 83, 20042005, pg. 1031-1075

${ }^{96}$ LEMLEY, Mark, "Property, Intellectual Property, and Free Riding", in Texas Law Review, vol. 83, 20042005, pg. 1031-1075
} 
assigning property rights - that the property will be mismanaged because it falls into the wrong hands - disappears, at least in theory.

COASE himself never really believed this; he set up the zero transactions costs model to make a point. But the idea has taken on a life of its own, and is generally attributed to him".

HAROLD DEMSETZ, também da Escola de Chicago, expressamente usou essa teoria em sua análise econômica da propriedade privada ${ }^{97} . \mathrm{O}$ autor estendeu, automaticamente, o mesmo raciocínio à Propriedade Intelectual, sem, no entanto, um maior aprofundamento dos argumentos ${ }^{98}$. Essa extensão dos fundamentos econômicos da Propriedade Convencional para a Propriedade Intelectual revelou grande apelo retórico no âmbito judicial, trazendo consequências importantes para a interpretação dos limites conferidos pela proteção conferida pela Propriedade Intelectual.

\subsubsection{Extensão da Fundamentação Econômica da Propriedade sobre bens TANGÍVEIS À PROPRIEDADE SOBRE BENS INTELECTUAIS}

A lição extraída da propriedade privada parecia indicar que, via de regra, com direitos de Propriedade Intelectual delimitados, as transações sempre seriam eficientes - ou seja, um proprietário sempre teria estímulos para licenciar um direito, sempre que o valor social da inovação fosse superior ao valor da propriedade privada.

Outra consequência prática da extensão da racionalidade econômica da Propriedade Privada para a dita Propriedade Intelectual foi uma excessiva preocupação com o freeriding.

Se a demarcação de direitos de propriedade era a forma de internalizar as externalidades negativas, e fazer com que os bens ficassem com quem mais os valorasse, qualquer um se beneficiasse de investimento alheio estaria incorrendo em free-riding.

\footnotetext{
97 "In his classic work on the economics of property rights, Harold Demsetz argued that property rights are valuable in a society because they limit the creation of uncompensated externalities. In a world without transactions costs, Demsetz argued, the creation of a clear property right will internalize the costs and benefits of an activity in the owner, and permit the sale of that right to others who may value it more.23 Once transactions costs are taken into account, Demsetz believed that the creation or alteration of property rights could be explained by asking whether the social gains from internalizing an externality exceeded the costs of doing so" (LemLeY, Mark, "Property, Intellectual Property, and Free Riding", in Texas Law Review, vol. 83, 2004-2005, pg. 1031-1075)

98 "Demsetz himself devoted less than a paragraph to intellectual property, concluding that it was "closely analogous" to his land examples and that "the relevant variables are identical." (LEMLEY, Mark A., "Property, Intellectual Property, and Free Riding." Standford Law School, Working Paper No. 291, August 2004).
} 
E, se o proprietário fosse desestimulado a investir em sua propriedade por conta do free-riding, então, a eficiência do sistema dependeria da eliminação de tal aproveitamento por terceiros de investimento alheio (free-riding).

MARK LEMLEY é preciso ao identificar que esta ideia era puramente retórica, não tendo nenhum fundamento nas regras do Commom Law, mas sim, em uma visão econômica bastante particular dos direitos de propriedade. $\mathrm{O}$ autor também acrescenta que a retórica saiu do controle, criando uma verdadeira obsessão das cortes e doutrinadores com o free riding ${ }^{99}$ :

"The rise of property rhetoric in intellectual property cases is closely identified not with common law property rules in general, but with a particular economic view of property rights.(...)

The shift begins with simple rhetoric - talking about intellectual property rights as aspects of a broader system of property. But its implications go far beyond that. The temptation to move from rhetoric to rationale seems almost irresistible. Courts and commentators adoptexplicitly or implicitly - the economic logic of real property in the context of intellectual property cases. This leads them to an almost obsessive preoccupation with identifying and rooting out that great evil of the modern economic world -free riding".

Os tribunais americanos, de fato, passaram a decidir casos envolvendo Propriedade Intelectual com fundamento exclusivo na existência ou não de free-riding. Sem nos aprofundar na análise dos casos neste momento, nos valemos, novamente, do relato de LEMLEY quanto ao uso abusivo do estigma do free-riding pelas cortes:

"Courts applying the property theory of intellectual property are seeking out and eliminating uses of a right they perceive to be free riding. Some treat copying as free riding. They justify property-like protection for trademarks on the basis that it will avoid free riding. They find innovative uses of trademarks by non-competitors to be free riding because they make money by "trading on the goodwill" of the trademark owner. They debate the proper role of patent law's doctrine of equivalents in terms of whether it permits free riding. They permit the imposition of a private intellectual property-like restriction that would otherwise violate the antitrust laws on the grounds that the restriction is necessary to prevent free riding on data created by the restrictor. The database protection bill pending in Congress at this writing expressly conditions liability on loss occasioned by "the ability of other parties to free ride on the efforts of the plaintiff." Courts have defined the elements of the quasi-intellectual property tort of misappropriation by reference to whether the defendant is free riding on the plaintiff's

\footnotetext{
${ }^{99}$ LEMLEY, Mark A., "Property, Intellectual Property, and Free Riding.” Standford Law School, Working Paper No. 291, August 2004.
} 
information. Even the courts that reject intellectual property claims do so because they cannot find evidence of free riding ${ }^{100}$.

Em resumo: aquilo que seria apenas uma analogia recaiu em exagero. A adoção desta teoria no Direito americano levou a uma expansão dramática dos direitos de Propriedade Intelectual:

"By virtually any measure, intellectual property rights have expanded dramatically in the last three decades. Terms of protection are longer, the number of things that are copyrightable has increased, it is easier to qualify for copyright protection, copyright owners have broader rights to control uses of their works, and penalties are harsher. In addition, Congress has created entirely new rights. These changes are directly tied to the reconceptualization of patents, copyrights and trademarks as a form of property. Even some of the most careful scholars of intellectual property economics have suggested that copyrights should be perpetual, relying on the economic theory of private property".

Herbert HOVEnKAMP E CRistina Bohannan pontuam que o tratamento da proteção como propriedade foi, de certa forma, mais benéfico em relação à tradição anglosaxônica de tratá-la como monopólio, uma vez que a propriedade raramente conferiria um poder de mercado substancial. Entretanto, os autores concordam que a mudança de analogia acarretou uma indesejável expansão da proteção:

"In the mid-twentieth century patents were commonly regarded as species of monopoly. Antitrust cases in particular often spoke of the "patent monopoly". Today we generally view patents less as monopoly and more as a type of property. In some ways this has been a good development, because patents rarely confer substantial market power. They behave more like simple property rights, with "boundary-based" rather than "market based" power to exclude. For example, a farmer has the power to exclude trespassers from his corn patch, but this does not give him any power at all to charge more than the market price for either corn or

\footnotetext{
${ }^{100}$ LEMLEY dá conta do crescimento exponencial das menções aos termos "Intellectual Property" e "freeriding" em decisões proferidas pelos Tribunais Federais americanos:

"Years Instances of Term "Intellectual Property"

$1993-2003(3,863)$

$1983-1993(1,510)$

1973-1983 (555)

1963-1973(327)

$1953-1963(303)$

1943-1953(201)

Years Instances of Term "Free Rider" or "Free Riding"

1993-2003 (243)

$1983-1993(232)$

1973-1983 (87)

1963-1973(20)

$1953-1963(26)$

1943-1953 (3)"

(Lemley, Mark A., "Property, Intellectual Property, and Free Riding". Standford Law School, Working Paper No. 291, August 2004)
} 
farmland. The same thing is true for most patents. Nevertheless this makeover in our conception of patent has also contributed to some of patent law's less desirable expansions ${ }^{101}$ ".

Os autores também ressaltam as falhas da analogia com a propriedade tangível:

"Significantly, the "propertization" of patent law has not been attended by other requirements that traditionally apply to property rights. One principle of property law is that claimants have the obligation to articulate clear boundaries of ownership, with the penalty for ambiguity falling on the claimant and often being loss of title. Another is that property owners must communicate timely and effective notice of their claims because the cost of giving notice is typically much lower than the cost of searching. As James Bessen and Mike Meurer so thoughtfully pointed out in Patent Failure, patent law remains an area where we call something property without seriously requiring it to behave like property. The amount of overprotection and wasted resources that results is enourmous. These are largely problems that the patent system must confront for itself, and antitrust has relatively little place. The same thing is true of the copyright system".

É interessante notar que já ASCARELLI havia advertido que a analogia com a propriedade tangível - uma produção liberal - conquanto tenha colaborado para a ruína de um sistema odioso de privilégios, acabou, no mundo moderno, por promover uma cultura totalmente contrária aos ideais liberais originais: isto é, um individualismo exacerbado, calcado na atribuição de um direito de propriedade exercido contra a sociedade.

Essa excessiva privatização, além de não se justificar com a premissa de que todo o conhecimento emana, em certa medida, da sociedade, contribuiria - inclusive - para um enrijecimento da economia ${ }^{102}$.

No início do capítulo, vimos que o uso do termo propriedade foi uma estratégia retórica da revolução francesa, a fim de evitar a associação da proteção com os monopólios e privilégios do antigo regime. No Século XX, nos deparamos novamente com a mesma analogia, desta vez, revestida de uma fundamentação econômica de um ramo específico da escola de Chicago (o que, por sinal, chega a ser surpreendente, considerado que a tradição jurídica americana sequer concebia a proteção como uma propriedade).

\footnotetext{
${ }^{101}$ HovenKAmP, Herbert e BoHANNAN, Cristina in "Creation without Restraint - Promoting Liberty and Rivalry in Innovation", Oxford University Press, pg. 15

102 "Nel mondo moderno, questa premessa acquista poi una portata opposta a quel liberalismo al quale deve la sua origine, perché essa si traduce nella rinvedicazione di un'esclusiva su qualunque risultato intellettuale, che in linea di fatto, funzionerebbe a favore dei grandi imprenditori nelle cui mani si concentrano le creazioni intellettuali e agirebbe nel senso di un irrigidimento dell'economia; essa si ispira all'immagine di un individuo isolato e quasi in posizzione di aprioristico contrasto con la societá, pituttosto che a quella di un individuo in societá, individuo le cui conquiste intellettuali sono insieme frutto della cultura acquisita, ció che suole essere dimenticato all'orgogliosa rivendicazione di esclusiva su qualunque creazione intellettuale che il singolo possa raggiungere”. (ASCARELLI, Tulio - Teoria Della Concorrenza e Dei Beni Immateriali - Istituizioni di Diritto Industriale, Terza Edizione, Milano, Dott. A. Giuffre Editore, 1960 - Pg. 305)
} 


\subsubsection{Críticas à Extensão dos Fundamentos Econômicos da Propriedade TANGível À Propriedade INTELECTUAL}

É importante ressaltar que esta visão econômica da Propriedade Intelectual como Propriedade é bastante particular, tendo sido rejeitada por autores importantes, como HAYEK, que foi enfático em sua refutação, ao afirmar que "a slavish application [to intellectual property] of the concept of property as it has been developed for material things has done a great deal to foster the growth of monopoly. . . [D]rastic reforms may be required if competition is to be made to work ${ }^{103}$."

O próprio Richard Posner, um dos maiores expoentes do Law and Economics, rejeitou prontamente tal doutrina.

De fato, o caso da Propriedade Intelectual difere da Propriedade convencional, pois esta última está mais relacionada com o problema de internalizar externalidades positivas, do que com o problema das externalidades negativas. Ou seja, o argumento, no caso da Propriedade Intelectual, reside em se evitar que efeitos positivos do investimento se propaguem para outros.

No caso da Propriedade privada sobre bens materiais, as externalidades positivas também estão presentes em muitas situações, porém, isto não costuma gerar preocupações na sociedade.

Se eu reformo a fachada da minha casa, e o melhor aspecto dela passa a beneficiar a vizinhança, eu não posso exigir uma compensação por esta externalidade positiva criada. Se eu planto flores em meu jardim, e os passantes podem apreciá-lo ao passar pela calçada, igualmente, eu não poderia pleitear uma compensação, nem tampouco poderia chamar isso de free-riding (embora, nos dois exemplos, se trate de externalidades positivas).

É fato que existem exceções, em que as externalidades positivas têm relevância para a propriedade privada. Pensemos, por exemplo, no caso de uma rodovia pública, em que, como contraprestação pela sua construção, o governo concede a uma empresa o direito de sua exploração econômica, por meio de cobrança de um pedágio. Isso implica que aquela empresa particular terá o direito de excluir outros do que seria, naturalmente, um recurso público. Outro exemplo é o caso de construção de um shopping center, o qual pode acarretar valorização imobiliária para os moradores vizinhos.

\footnotetext{
${ }^{103}$ HAYEK, Friedrich A., in "Individualism and Economic Order", The University of Chicago Press (1948), disponível em http://mises.org/sites/default/files/Individualism\%20and\%20Economic\%20Order 4.pdf acesso em 14.12.2014.
} 
O ponto crítico é que, mesmo no caso de tais exceções, o investimento em propriedade tangível não depende da internalização de todas as externalidades positivas. No exemplo do shopping, o fato de haver externalidades positivas não compensadas, resultantes da valorização imobiliária de áreas circunvizinhas, não afetará a decisão sobre o investimento. $\mathrm{O}$ que o investidor espera é capturar benefícios bastantes de seu investimento de modo a que ele possa se tornar lucrativo. O benefício excedente resultante será dissipado - pelo mercado, se o recurso é negociado em uma economia concorrencial, ou pela regulação de preços pelo governo (no caso dos pedágios, por exemplo).

$\mathrm{O}$ caso das externalidades na propriedade privada é, portanto, assimétrico. $\mathrm{O}$ modelo só exige a internalização das externalidades negativas apenas em um nível em que os custos de transação criados excedam a externalidade (uma vez que as externalidades negativas afetarão a decisão sobre investimento).

Embora o problema de investimentos gerarem efeitos positivos a terceiros (i.e., externalidades positivas) não seja sempre visto em economia como um problema social, pelas razões demonstradas acima, é importante salientar, no entanto, que alguns autores brasileiros proeminentes fazem referência à importância de se combater o free-riding como um dos fundamentos do sistema de Propriedade Intelectual. Veja-se, por exemplo, CAliXto SAlomão FILHO, para quem a Propriedade Intelectual "impedindo o free-riding, ou seja, o aproveitamento por parte daquele que não investiu na pesquisa dos resultados dela advindos, estimula a pesquisa e o desenvolvimento individual. A repressão ao freeriding encontra, portanto, um fundamento eminentemente concorrencial ${ }^{104}$,"

Para MARK LEMLEY, no entanto, a teoria econômica não exigiria a internalização de todas as externalidades positivas, mas apenas a apreensão de benefícios em nível capaz de permitir a recuperação dos investimentos.

Aqui, um esclarecimento se faz necessário, apenas para dizer que a recuperação dos investimentos não pode ser uma garantia da teoria econômica, senão uma mera potencialidade (em outras palavras, a recuperação do investimento deve ser possível). Em uma economia de mercado, o risco é inerente, e não há que se falar em garantia dos investimentos, mas sim, de uma expectativa razoável de recuperação de investimentos e de

\footnotetext{
${ }^{104}$ SAlOMÃo FILHO, Calixto, in "Direito Industrial, Direito Concorrencial e Interesse Público", Revista de Direito Público da Economia, Belo Horizonte, ano 2, n. 7, 2004, pg. 29.
} 
lucros. Não está claro, na frase de LEMLEY, qual seria o alcance de sua afirmação, mas se ela for tomada na primeira acepção, discordamos dessa ideia ${ }^{105}$.

Em matéria de Propriedade Intelectual, ao contrário da Propriedade tangível, praticamente todas as externalidades são positivas. Portanto, o que se denomina Tragedy of Commons em matéria de bens tangíveis é praticamente uma comédia em se tratando da informação.

Essa diferença básica se deve ao fato de que a Tragedy of Commons se relaciona à escassez natural dos bens corpóreos - o que não se verifica quanto à informação, que, uma vez publicada, torna-se praticamente ubíqua. Precisamente por conta da característica de não-rivalidade, a informação não apresenta nenhum risco de uma Tragedy of Commons.

Copiar informação, em verdade, multiplica os recursos disponíveis. A cópia, vista dessa maneira, apenas cria externalidades positivas não compensadas - as quais não levantam muitas preocupações, como vimos acima, quando descrevemos a análise econômica da propriedade privada.

De fato, um dos objetivos da Propriedade Intelectual é, inclusive, promover as externalidades positivas. A Propriedade Intelectual atua dessa forma ao estimular que ideias que, do contrário, permaneceriam em segredo, sejam amplamente disseminadas ${ }^{106}$. Em outras palavras, a disseminação do conhecimento (e a irradiação, na sociedade, dos efeitos positivos, daí resultantes) é, também, uma das finalidades do sistema.

\footnotetext{
${ }^{105}$ Em um outro trecho, porém, LEMLEY se exprime em termos mais precisos em nossa opinião: "In a private market economy, individuals will not generally invest in invention or creation, unless the expected return from doing so exceeds the cost of doing so - that is, unless they can reasonably expect to make a profit from the endeavor". (LEMLEY, Mark A., "Property, Intellectual Property, and Free Riding". Standford Law School, Working Paper No. 291, August 2004). Como havíamos referido anteriormente, já STUART MILL, ao discutir a proposta de criação de um sistema de recompensas em substituição ao sistema de patentes, afirmou que o sistema de patentes seria preferível por não conferir nenhuma discricionariedade às autoridades públicas quanto ao montante da recompensa, pois este é um julgamento feito pela sociedade por meio do mecanismo de mercado. Se a invenção for considerada útil, o mercado lhe atribuirá maior valor. Ou seja, a patente não confere uma garantia de retorno de investimentos, uma vez que o "prêmio" pela invenção será conferido pelo mercado. No Brasil, KARIN GraU-KUNTZ tem, sistematicamente, combatido a ideia da Propriedade Intelectual como garantia de retorno de investimentos, de forma imune aos riscos normais do mercado (GRAU-KUNTZ, Karin. A interface da propriedade intelectual com o direito antitruste, publicado na plataforma do IBPI - Instituto Brasileiro de Propriedade Intelectual www.ibpibrasil.org), especificamente no endereço http://www.ibpibrasil.org/40693/64901.html).

106 "Moreover, in a world without patents, inventive activity would be biased toward inventions that could be kept secret, in just the same way that an absence of property rights in physical goods would bias production towards things that involve minimum preparatory investment" (POSNER, Richard A. In "Economic Analysis of Law, $4^{a}$ Ed., Boston: Litle-Brown, 1992, p. 38)
} 
LEMLEY extrai, de um precedente das cortes, um exemplo de mal uso da analogia da Propriedade Privada, ao citar um caso em que se entendeu que o réu havia cometido uma infração ao acessar o protocolo WHOIS de um site na internet $^{107}$.

No caso em questão (Register.com v. Verio), a corte entendeu que o réu, ao acessar as informações, havia agido como quem "apanha uma maçã de uma árvore que cresceu na propriedade do autor".

No entanto, ao contrário da analogia com a propriedade tangível, o autor não fora privado de nenhum bem. "Apanhar uma maçã" parece uma conduta negativa, porque presume que se trata de um bem rival, cujo consumo priva o proprietário de algo. A simples mudança da analogia para "espiar" o terreno do vizinho mudaria todo o juízo de valores no qual se baseou a interpretação.

Tratar a informação como propriedade privada tangível nos induz a imaginar o uso da informação como uma usurpação de bem alheio (i.e., free-riding) - e, portanto, como algo que deveria ser proibido, inclusive por afrontar à moral.

Para LeMLEY, a justificação básica da Propriedade Intelectual advém de algo que seria apenas um problema secundário da propriedade tangível: o risco de que os criadores não terão lucros suficientes para recuperar seus custos.

A produção de qualquer bem envolve investimentos na forma de custos fixos, que devem ser feitos antes da produção, e custos variáveis ou marginais, que são incorridos cada vez que uma nova unidade é produzida.

Para a maioria dos bens tangíveis, um preço alto o bastante para cobrir os custos marginais de produzir unidades adicionais do bem, acrescido de um lucro razoável, é suficiente para gerar lucros a partir de investimentos em capital fixo.

Nesse aspecto, a informação difere dos bens tangíveis, porque o custo marginal de reproduzi-la é baixíssimo. Os custos fixos de produzir a informação variam de indústria para indústria, ao passo que os custos marginais são muito baixos. Em todas as situações, a razão entre custos fixos e custos marginais é muito maior do que em qualquer outra espécie de bens. Esta é a característica essencial da chamada Nova Economia ${ }^{108}$.

\footnotetext{
107 O "WHOIS" é um protocolo específico que permite a consulta de informações de contato e DNS ("Domain Name System") de uma entidade na internet, isto é, de um domínio, um endereço IP ou um Sistema Autônomo. Esse sistema (WHOIS) permite o acesso a três tipos de contato de uma entidade: Contato Administrativo (Admin Contact), Contato Técnico (Technical Contact) e Contato de Cobrança (Registrant Contact). Esses contatos são informações de responsabilidade do provedor de internet, que as nomeia de acordo com as políticas internas de sua rede.

108 "Tais empresas [i.e., da chamada "Nova Economia”] caracterizam-se por manter altos custos fixos em $P \& D$, ao passo que os custos marginais (i.e., os custos para produção de uma unidade adicional) são
} 
Consideradas essas características, se não houvesse proteção da Propriedade Intelectual, os concorrentes do inventor estariam em uma situação claramente mais vantajosa, porque eles seriam capazes de lucrar cobrando, pelos bens reproduzidos, apenas um preço superior aos seus custos marginais, sem ter arcado com os custos fixos de produção dos bens. Em contrapartida, o proprietário, que suportou os custos fixos de produção do bem, estaria em uma situação desprivilegiada, pois apenas poderia cobrar um preço superior aos seus custos fixos - preço este que não seria competitivo.

O resultado, com base na teoria econômica, é que haveria uma falta de incentivos para produção de bens intelectuais. O objetivo da Propriedade Intelectual, visto sob esta ótica, é criar uma escassez que não existe naturalmente, a fim de incentivar os investimentos em inovação.

Esse incentivo, diga-se, deve ser suficiente para criar uma expectativa razoável de recuperação de custos fixos e de uma taxa de lucro (por incentivo suficiente entende-se como um nível abaixo de um controle perfeito).

Como conclui LEMLEY, "the critical difference is that intellectual property law is justified only in ensuring that creators are able to charge a sufficiently high price to ensure a profit sufficient to recoup their fixed expenses. (...) Sufficient incentive, as Larry Lessig reminds us, is something less than perfect control. Economic theory offers no justification for awarding creators anything beyond what is necessary to recover their average fixed costs" 109 .

\subsubsection{CONSEQuênCIAS ECONÔMICAS DE UMA SUPERPRoteção PRIVADA DA INFORMAÇÃOO}

Finalmente, observa-se que uma excessiva proteção de direitos de propriedade distorce os mercados, por afastar a regra geral de livre concorrência. Assim, criam-se ineficiências estáticas na forma de pesos mortos.

Além disso, uma proteção excessiva à PI interfere com a habilidade de outros inovadores atuarem, e, portanto, criam ineficiências estáticas. Em terceiro, incentiva-se um

próximos a zero, permitindo uma economia de escala. Com este cenário, os custos médios diminuem na medida em que a produtividade aumenta. Esta situação é descrita pelos economistas como "monopólio natural” (LITAN, Robert E., in "Antitrust and the New Economy", University of Pittsburgh, Law Review, v. 62, n. 3, Spring 2001, pg. 249).

${ }^{109}$ LEMLEY, Mark A., in "Property, Intellectual Property, and Free Riding". Standford Law School, Working Paper No. 291, August 2004 
comportamento oportunista (rent-seeking), que é socialmente dispendioso, e mesmo um superinvestimento em P\&D, que - na opinião de LEMLEY - poderia criar um subinvestimento em outras áreas produtivas ${ }^{110}$.

Parafraseando a citação de ISAAC NEWTON ("Se enxerguei longe, é porque estive apoiado nos ombros de gigantes”), CARL SHAPIRO se refere à verdadeira pirâmide sobre a qual os pesquisadores têm que se apoiar para produzir inovação. Para escalar essa pirâmide, o pesquisador precisa obter permissão para a pessoa que, antes dele, colocou um tijolo no patamar inferior (o que, na analogia, consiste no pagamento de royalties ou taxas).

Embora reconheça que tais entraves cresceriam na medida em que se avança no processo inovador (isto é, conforme se avança de "P" para "D”, isto é, da Pesquisa Básica para o Desenvolvimento - sendo insignificantes em "P" e crescentes em "D"), o autor reconhece que uma excessiva proteção conferida à Propriedade Intelectual, acompanhada pela necessidade de se negociar royalties com uma infinidade de proprietários, teria como resultado último um desestímulo à inovação.

O autor alude a este elevado número de patentes como Patent Thickets (que pode ser traduzido por "emaranhado de patentes"):

"Today, most basic and applied researchers are effectively standing on top of a huge pyramid, not just on one set of shoulders. Of course, a pyramid can rise to far greater heights than could any one person, especially if the foundation is strong and broad. But what happens if, in order to scale the pyramid and place a new block on the top, a researcher must gain the permission of each person who previously placed a block in the pyramid, perhaps paying a royalty or tax to gain such persmission? Would this system of intellectual property rights slow down the construction of the pyramit or limit its height?

Clearly, pyramid building, namely, research and development $(R \& D)$, is taking place at an impressive pace today, so there is no great cause for alarm, especially in the area of basic research where the "royalty" is often (but not always) nothing more than a citation. As we move from pure $R$ to applied $R$ and ultimately to $D$, however, one can fairly ask whether our legal and commercial institutions are in fact properly designed to promote rather than discourage the creation of products and services that draw on many stands of innovation and thus potentially require licences from multiple patent holders. To complete the analogy, blocking patents play the role of the pyramid's building blocks.

Mixing metaphors, thoughtful observers are increasingly expressing concerns that our patent (and copyright) system is in fact creating a patent thicket, a dense web of overlapping

\footnotetext{
${ }^{110}$ Importante observar que a "teoria da propriedade" não serve para fundamentar direitos sobre marcas e publicidade, por exemplo. Tais direitos devem buscar sua fundamentação econômica em outras teorias , como a redução de custos de busca, a necessidade de se evitar confusão entre concorrentes, entre outras.
} 
intellectual property rights that a company must hack its way through in order to actually comercialize new technology. With cumulative innovation and multiple blocking patents, stronger patent rights can have the perverse effect of stiffling, no encouraging, innovation ${ }^{111}$ ".

Também HovenKAmp e BoHANnAN ressaltam que a expansão da Propriedade Intelectual contribui para o aumento dos custos de inovação, atravancando o ritmo da inovação, dado que o processo inovador, em alguns mercados, depende de um trabalhar sobre terreno alheio. Portanto, o sistema de Propriedade Intelectual, ao conferir direitos para além do que seria necessário para criar incentivos para inovação, acaba por elevar demasiadamente os custos de pesquisa de terceiros, atravancando o processo de contínua inovação. Tais custos, que são impostos sobre a sociedade, não possuem nenhuma contrapartida por parte dos proprietários ${ }^{112}$.

Os autores também destacam o problema da captura do legislador por interesses especiais de grupos específicos, como um fator causador da excessiva proteção conferida à PI e, em última análise, da imposição de um freio ao processo inovador. Para eles, "Clearly Congress is stuck. Over the past few decades it has tended to listen only to right holders and not users, and innovation suffers. One important result of legislative capture in copyright infringement, particularly where derivative works and fair use are concerned $^{113,}$.

Em artigo famoso, Michael Heller e Rebecca S. Eisenberg, escrevendo vinte anos após The Tragedy of Commons (Hardin, 1968), falam de uma Tragedy of Anticommons - referindo-se, especificamente, à transição, nos Estados Unidos, da Pesquisa e Desenvolvimento em biomedicina, de um regime financiado por recursos públicos, para um regime privatizado - e às consequências que tal mudança poderia produzir para o processo contínuo de inovação ${ }^{114}$.

\footnotetext{
${ }^{111}$ SHAPIRO, Carl - "Navigating the Patent Thicket: Cross Licenses, Patent Pools, and Standard Setting, Univesity of California at Berkeley"

${ }^{112}$ HovenKamp, Herbert e BoHAnnan, Cristina in "Creation without Restraint - Promoting Liberty and Rivalry in Innovation", Oxford University Press, pg. 11

${ }^{113}$ HovenKAMP, Herbert e BOHANNAN, Cristina in "Creation without Restraint - Promoting Liberty and Rivalry in Innovation", Oxford University Press, pg. 18

114 "Like the transition to free markets in post-socialist economies, the privatization of biomedical research offers both promises and risks. It promises to spur private investment but risks creating a tragedy of the anticommons through a ploriferation of fragmented and overlapping intellectual property rights. An anticommons in biomedical research may be more likely to endure than in other areas of intellectual property because of the high transactions costs of bargaining, heterogeneous interests among ownersm, and cognitive biases of researchers. Privatization must be more carefully deployed if it is to serve the public goals of biomedical research. Policy-makers should seek to ensure coherent boundaries of upstream patentes and to minimize restrictive licensing practices that interfere with downstream product development. Otherwise, more up-stream rights may lead paradoxally to fewer useful products for improving human
} 
JANET HOPE bem expressou o que tal tragédia dos anticommons representa para os pesquisadores individuais no ramo de biotecnologia: anos de trabalho duro em pesquisa, e de financiamento público conseguido a duras penas, colocados, em última análise, sob a ameaça de um "beco sem saída" de negociações de licenças ${ }^{115}$.

Nos Estados Unidos, a partir da década de 1980, com a disseminação da tecnologia digital e da internet, vários movimentos, com fundamentos morais e teóricos diversos, surgem em crítica ao sistema da Propriedade Intelectual e à sua inadequação para regular as novas formas de produção de conhecimento então insurgentes.

LARry Lessig, Yochai Benkler, JAMEs Boyle, PAMEla SAMUELSON - entre outros autores - enxergaram na revolução tecnológica a abertura de novas oportunidades de produção não proprietárias de conhecimento, não baseadas no mercado ${ }^{116}$. Trata-se de um movimento de crítica a uma visão maximalista da Propriedade Intelectual, de repercussão internacional, sem importar - no entanto - em negação ao regime ${ }^{117}$.

Também é importante mencionar movimentos que pretenderam instituir formas colaborativas - commons-based-peer production - de produção e compartilhamento de informações, como o software livre (copyleft), idealizado por RICHARD STALLMAN ${ }^{118}$, ou o

health". (HELler, Michael e EISENBERG, Rebecca S. - "Can Patents Deter Innovation? The Anticommons in Biomedical Research”, Science, 1 May 1998, Vol. 280, no. 5364, pgs. 698-701)

115 Hope, Janet, "Biobazaar: The Open Source Revolution and Biotechnology", USA-UK, Harvard University Press, 2008

116 "The network information economy requires access to a core set of capabilities - existing information and culture, mechanical means to process, store and communicate new contributions and mixes, and the logical system necessary to connect them to each other. What nonmarket forms of production need is a core common infrastructure that anyone can use, irrespective of whether their production model is market based or not, proprietary or not" (BENKLER, Yochai, "The Wealth of Networks: How social production transforms markets and freedom. New Haven/London: Yale Univesity Press, 2006)

117 "Ressalte-se que, apesar de anti-maximalista, não se trata de um movimento abolicionista. Os discursos clássicos de fundamentação intelectual não são inteiramente abandonados, mas submetidos a uma tarefa de apresentação crítica, tendo-se em vista a elaboração de um regime menos unilateral quanto aos interesses protegidos e mais sensível à criação de um ambiente/infra-estrutura em que produção cultural possa ocorrer e fluir com um número menor de restrições. Além dos nomes já citados, podemos mencionar os de William W. Fisher, Julie E. Cohen, Eben Moglen, Mark Lemley, Jonathan Zittrain, Neil Weinstock Netanel, Mark Rose, Carol M. Rose, dentre outros, inclusive fora da área do direito, como é o caso de Siva Vaidhynathan. Internacionalmente, o movimento tem influenciado diretamente, ou encontrado sintonia em, obras de outros autores, como José de Oliveira Ascensão em Portugal, Peter Drahos na Austrália, Michael Geist no Canadá, Bernt Hugenholtz na Holanda, e Ronaldo Lemos no Brasil". (MIZUMAKI, Pedro Nicolletti, "Função Social da Propriedade Intelectual: Compartilhamento de Arquivos e Direitos Autorais na CF/88", Dissertação de Mestrado, Pontífica Universidade Católica de São Paulo, 2007)

118 "So, I looked for a way to stop that from happening. The method I came up with is called "copyleft". It's called copyleft because it's sort of like taking copyright and flipping it over. [Laughter] Legally, copyleft works based on copyright. We use the existing copyright law, but we use it to achieve a very different goal. Here's what we do. We say, "This program is copyrighted." And, of course, by default, that means it's prohibited to copy it, or distribute it, or modify it. But then we say, "You're authorized to distribute copies of this. You're authorized to modify it. You're authorized to distribute modified versions and extended versions. Change it any way you like." But there is a condition. And the condition, of course, is the reason why we go to all this trouble, so that we could put the condition in. The condition says: Whenever 
Open Source, de semelhantes propósitos - porém sem a mesma fundamentação ideológica $^{119}$.

De modo geral, os economistas divergem acerca do que seria um nível adequado de proteção. Certamente, porém, tal nível adequado de proteção variaria de acordo com o tipo de direitos de Propriedade Intelectual (por exemplo, direitos autorais e patentes), os ciclos de vida de cada produto, a velocidade com que se propagam imitações, e outras características específicas de cada mercado.

Por vezes, a discrepância entre a proteção legal e a realidade econômica torna-se, com o perdão do trocadilho, patente.

Basta tomar, por exemplo, o caso da proteção conferida ao software, a qual, no Direito Brasileiro, se dá sob a tutela conferida aos direitos autorais, com proteção estendida pelo prazo de cinquenta anos ${ }^{120}$.

É difícil imaginar uma justificativa econômica para tamanho nível de proteção, considerando a atual dinâmica do mercado de softwares, sobretudo, se observarmos a velocidade com que novos aplicativos são criados atualmente, e por qualquer pessoa que disponha de um computador e mínimos conhecimentos em programação.

Tais aplicativos são criados e vendidos, via internet, por meio de downloads feitos por meio de aparelhos móveis. Alguns desses aplicativos chegam ao ápice do sucesso,

you distribute anything that contains any piece of this program, that whole program must be distributed under these same terms, no more and no less. So you can change the program and distribute a modified version, but when you do, the people who get that from you must get the same freedom that you got from us. And not just for the parts of it -- the excerpts that you copied from our program - but also for the other parts of that program that they got from you. The whole of that program has to be free software for them". The freedoms to change and redistribute this program become inalienable. (STALLMAN, Richard, "Free Software: Freedom and Cooperation" (discurso), New York University in New York, New York on 29 May 2001)

119 "Anyway, there's even a group of people who focus on this particular benefit as the reason they give, the main reason they give, why users should be permitted to do these various things, and to have these freedoms. If you've been listening to me, you've noticed, you've seen that I, speaking for the free software movement, I talk about issues of ethics, and what kind of a society we want to live in, what makes for a good society, as well as practical, material benefits. They're both important. That's the free software movement. That other group of people -- which is called the open source movement -- they only cite the practical benefits. They deny that this is an issue of principle. They deny that people are entitled to the freedom to share with their neighbor and to see what the program's doing and change it if they don't like it. They say, however, that it's a useful thing to let people do that. So they go to companies and say to them, "You know, you might make more money if you let people do this." So, what you can see is that to some extent, they lead people in a similar direction, but for totally different, for fundamentally different, philosophical reasons". (STALLMAN, Richard, "Free Software: Freedom and Cooperation" (discurso), New York University in New York, New York on 29 May 2001)

${ }^{120}$ Lei 9.609/1998:

“Art. $2^{\circ} \mathrm{O}$ regime de proteção à propriedade intelectual de programa de computador é o conferido às obras literárias pela legislação de direitos autorais e conexos vigentes no País, observado o disposto nesta Lei. (...)

$\S 2^{\circ}$ Fica assegurada a tutela dos direitos relativos a programa de computador pelo prazo de cinqüenta anos, contados a partir de $1^{\circ}$ de janeiro do ano subseqüente ao da sua publicação ou, na ausência desta, da sua criação". 
levantando milhões de forma repentina, mas caem em ocaso em seguida, fazendo com que os altos lucros iniciais despenquem vertiginosamente, antes que as imitações possam ser

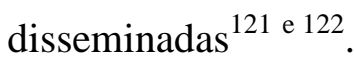

Seria muito difícil, porém, que a legislação atingisse um nível de detalhamento adequado a cada mercado, bem como que antecipasse todos os possíveis problemas que novos mercados possam suscitar.

Contudo, há que se ter em mente que, quanto maior a proteção conferida pela PI, menor o escopo do domínio público - que, por assim dizer, pertence à sociedade, constituindo-se de fonte primária de todas as inovações. Esse balanço deve ser considerado na elaboração de políticas de proteção à Propriedade Intelectual.

\subsubsection{Conclusões Parciais sobre a Análise Econômica da Propriedade} INTELECTUAL:

É aqui que chegamos àquela que, talvez, seja a conclusão mais importante deste tópico para a sequência do tema da dissertação.

Se atingir um adequado balanço entre proteção e domínio público é um difícil desafio para os policymakers - que atuam ex ante - o Direito Antitruste, atuando ex post, externamente ao sistema da Propriedade Intelectual e com viés publicista, passa a exercer um importante papel para que o adequado balanço entre domínio público e interesse privado, sempre que o exercício da Propriedade Intelectual se mostrar abusivo ${ }^{123}$.

\footnotetext{
121 “Os tropeços dos aplicativos precedentes podem ser compreendidos em números. Nos dois primeiros meses, o Draw Something (adquirido por 200 milhões pela empresa de jogos Zynga) conseguiu a adesão de mais de 36 milhões de usuários do Facebook, número que foi reduzido a apenas 9 milhões em dezembro de 2012, uma queda de 75\% em apenas sete meses. A Zynga, por sinal, sofre com a queda de acesso a esses games. Recentemente, mais de 100 funcionários foram demitidos, um escritório em Boston, nos Estados Unidos, foi fechado e onze jogos sociais foram descontinuados". (Revista Veja, 05/02/2013)

${ }^{122}$ Isso, aliás, serve para ilustrar a crise da "Teoria Utilitarista" na Nova Economia da Informação em Redes, pois resta fulminada a premissa de que apenas a proteção à Propriedade Intelectual asseguraria incentivos à criatividade. "It is increasingly evident that utilitarianism fails as a comprehensive theory of intellectual property, either descriptively or prescriptively. Intellectual property rights are expanding new rights. Meanwhile, rapid-fire technological advances and new forms of creative output, from advent of open source collaborative networks to garage garage bands, remix culture and the Internet itself, undermine utilitarian intellectual property law's very premise: that intellectual property law to the developing world through TRIPS and bilateral agreements has weakened the utilitarian understanding of intellectual property: intellectual property rights may not incentivize significant invention in poor nations that lack the infrastructure and resources required to create their own knowledge"). (SUNDER, Madhavi, "Playing With Fire", Journal of Gender, Race \& Justice, Vol. 4, No. 1, Fall 2000, disponível em: http://papers.ssrn.com/sol3/papers.cfm?abstract_id=279318)

123 "Problematically, the size of the public domain and the scope of IP protection are inversely related. Every grant of an IP right reduces the size of the public domain, and the broader the IP right the greater the reduction. IP policy must try to find a balance that maximizes the net gains that result from increased
} 


\subsection{Aspectos Conceituais da Propriedade Intelectual}

Ao longo de todo o Capítulo 1, procuramos fornecer fundamentos, históricos, filosóficos, econômicos e jurídicos da Propriedade Intelectual - fundamentos estes aos quais se reportará com frequência no decorrer da dissertação.

Essa última seção se destina a aspectos mais dogmáticos, a fim de que se possa diferenciar, corretamente, as variadas espécies da Propriedade Intelectual.

\subsubsection{Divisão Tradicional entre Propriedade Industrial e Propriedade LiteráRIA E ARTÍSTICA}

Para fins didáticos, costuma-se dividir, tradicionalmente, a Propriedade Intelectual em dois grandes grupos, considerando que o exercício da ação criativa humana pode ser exercida tanto no campo da estética (Propriedade Literária e Artística) como no campo da técnica (Propriedade Industrial) ${ }^{124}$.

Conforme Gama CerqueIRA:

"O primeiro grupo denomina-se, geralmente, propriedade literária, científica, artística, em oposição à propriedade industrial, que designa o segundo. Ambas sob a denominação genérica de 'propriedade industrial, que designa o segundo. Ambas, sob a denominação genérica de propriedade imaterial ou propriedade intelectual, constituem objeto do direito industrial, considerado como ramo autônomo da ciência jurídica”. Mas nos países em que o

exclusivity, minus the loss of social value from a diminished public domain. It must also account for the very considerable administrative and litigation costs of running the IP system as well as its propensity to make serious errors. Antitrust policy has an important role as well". (HOVENKAMP, Herbert e BOHANNAN, Cristina in "Creation without Restraint - Promoting Liberty and Rivalry in Innovation", Oxford University Press, December 2011; U Iowa Legal Studies Research Paper). No Brasil, SALOMÃo FILHO clama por uma revisitação ou "atualização" do Direito Industrial, com intuito de interpretá-lo como uma instituição que também visaria a preservar a instituição concorrência: "De tudo o que foi dito, a conclusão é direta. Não há que se falar em complementaridade entre direito industrial e direito concorrencial. Não se deve, tampouco, cogitar de derrogação das regras do direito concorrencial pelo direito industrial. O direito industrial é, ao contrário, um campo no qual os princípios concorrenciais têm particular aplicação. Ocorre que esses princípios são publicísticos, i.e., tendentes à proteção de difusão do conhecimento e não à proteção privada de concorrentes. Reconstruído com base em princípios concorrenciais institucionais, o direito industrial não apenas ganha novas hipóteses legais de incidência, como passa a ter uma disciplina muito mais abrangente e rígida a um só tempo". Segundo nos parece, o ponto comum entre a perspectiva do autor e a nossa neste trabalho é o reconhecimento de importância de aplicação do Direito Concorrencial (i.e., o "Direito Antitruste") ao Direito Industrial e, em particular, à Propriedade Intelectual, como forma de corrigir as distorções de uma excessiva privatização de bens intelectuais. (SAlomão FILHO, Calixto, in "Direito Industrial, Direito Concorrencial e Interesse Público", Revista de Direito Público da Economia, Belo Horizonte, ano 2, n. 7, 2004, pg. 29)

124 "O poder da inteligência do homem e a atividade de sua imaginação criadora manifestam-se no domínio das artes e das ciências, como no campo da técnica e das indústrias, em obras de vários gêneros, que encontram proteção na lei e constituem origem de variadas relações jurídicas". (GAMA CERQUEIRA, João da, “Tratado de Propriedade Industrial”, Vol. I, Rio de Janeiro, Revista Forense, 1946, p. 67) 
Direito Industrial não logrou alcançar autonomia didática, doutrinária ou legislativa, a propriedade imaterial é desdobrada em membra disjecta: a propriedade literária, científica e artística é estudada, geralmente, como parte do direito civil, ao passo que a propriedade industrial é considerada como capítulo do direito comercial ou, quando muito, como simples especialidade no quadro desse ramo do direito ${ }^{125}$ ",

Adiante-se que esta separação está em franca crise, pelos motivos que analisaremos mais adiante neste tópico. Entretanto, para meros fins de exposição, nos valeremos da costumeira divisão em um primeiro momento.

No campo da Propriedade Industrial, estão incluídos ${ }^{126}$ as patentes ${ }^{127}$, os modelos de utilidade $^{128}$, o desenho industrial ${ }^{129}$, as marcas ${ }^{130}$, as indicações geográficas ${ }^{131}$ e os segredos empresariais ${ }^{132}$.

${ }^{125}$ GAma CERQUeIRA, João da "Tratado de Propriedade Industrial, GAMA CERQUeIRA, João da Tratado de Propriedade Industrial, Vol. I, Rio de Janeiro, Revista Forense, 1946, pg. 70-71)

${ }^{126}$ A Convenção de Paris dispõe em seu Artigo I, 2o parágrafo, o seguinte: “A proteção da propriedade industrial tem por objetivo os privilégios de invenção, os modelos de utilidade, os desenhos e modelos industriais, as marcas de fábrica e de comércio, o nome comercial e as indicações de procedência ou denominações de origem, bem como a repressão da concorrência desleal".

127 "Uma patente, na sua formulação clássica, é um direito, conferido pelo Estado, que dá ao seu titular a exclusividade da exploração de uma tecnologia. Como contrapartida pelo acesso do público ao conhecimento dos pontos essenciais do invento, a lei dá ao titular da patente um direito limitado no tempo, no pressuposto de que é socialmente mais produtiva em tais condições a troca da exclusividade de fato (a do segredo da tecnologia) pela exclusividade temporária de direito”. (BARBOSA, Dênis Borges, "Introdução à Propriedade Intelectual”, pg. 295, disponível no portal do autor em http://www.denisbarbosa.addr.com/)

128 "[o] modelo de utilidade corresponde a uma forma nova de produto conhecido que resulta em melhor utilização." Assim, “os modelos de utilidade visam a melhorar o uso ou a utilidade dos produtos, dotando-os de maior eficiência ou comodidade em sua utilização, por meio de uma nova configuração." (SILVEIRA, Newton, Propriedade intelectual, $3^{\mathrm{a}}$ Ed., Ed. Barueri, Manole, 2005, pg. 7)

129 "Já os desenhos industriais se reduzem a objetos de caráter meramente ornamental, objetos de gosto, como se dizia no passado. A proteção, no caso, restringe-se à nova forma conferida ao produto, sem considerações de utilidade, podendo achar-se aplicada a um objeto útil ou não. Tal forma, entretanto, deve achar-se desvinculada da função técnica, isto é, não pode consistir em uma forma necessária para que o produto preencha a sua finalidade, hipótese em que se configuraria um modelo de utilidade” (SILVEIRA, Newton, "Propriedade intelectual", cit., p. 7.)

130 “marca é o sinal visualmente representado, que é configurado para o fim específico de distinguir a origem dos produtos e serviços. Símbolo voltado a um fim, sua existência fáctica depende da presença destes dois requisitos: capacidade de simbolizar e capacidade de indicar uma origem específica, sem confundir o destinatário do processo de comunicação em que se insere: o consumidor. Sua proteção jurídica depende de um fator a mais: a apropriabilidade, ou seja, a possibilidade de se tornar um símbolo exclusivo, ou legalmente unívoco, em face do objeto simbolizado". (BARBOSA, Dênis Borges, "Introdução à Propriedade Intelectual", pg. 700)

131 "Pelo art. 177, considera-se indicação de procedência o nome geográfico de país, cidade, região ou localidade de seu território, que se tenha tornado conhecido como centro de extração, produção ou fabricação de determinado produto ou de prestação de determinado serviço. Já denominação de origem é o nome geográfico de país, cidade, região ou localidade de seu território, que designe produto ou serviço cujas qualidades ou características se devam exclusiva ou essencialmente ao meio geográfico, incluídos fatores naturais e humanos". (BARBOSA, Dênis Borges, "Introdução à Propriedade Intelectual”, pg. 794)

132 “O art. 195 da Lei 9.279/96, como já mencionado no capítulo sobre concorrência desleal, considera crime o ato de quem divulga, explora ou utiliza-se, sem autorização, de conhecimentos, informações ou dados confidenciais, utilizáveis na indústria, comércio ou prestação de serviços, excluídos aqueles que sejam de conhecimento público ou que sejam evidentes para um técnico no assunto, a que teve acesso mediante relação contratual ou empregatícia, mesmo após o término do contrato; ou divulga, explora ou utiliza-se, 
No campo da Propriedade Literária e Artística, em teoria, se trata da proteção da forma (estética) de expressão de ideias (corpus mysticus), e não do meio mecânico em que a expressão é reproduzida (corpus mechanicus). Neste campo, se dá a proteção do direito autoral e direitos a ele $\operatorname{conexos}^{133}$. Entretanto, a tutela do software, como já aludido anteriormente, embora certamente mais relacionada ao aspecto funcionalidade do que ao aspecto estético, se dá, no Brasil, conforme o direito de autor.

Há, ainda, direitos sui generis, que não se enquadram nem no campo da Propriedade Industrial e nem no campo da Propriedade Literária e Artística, como o direito de Cultivares ${ }^{134}$ e de Circuitos Integrados ${ }^{135}$.

O quadro abaixo, tal como reproduzido por CláUdio R. BARBOSA ${ }^{136}$, resume, segundo uma concepção mais tradicional - leia-se - as espécies de direitos de Propriedade Intelectual e respectivos requisitos de proteção e campos de aplicação:

\begin{tabular}{|c|c|c|c|}
\hline $\begin{array}{c}\text { Direitos de Propriedade } \\
\text { Intelectual }\end{array}$ & Instrumentos de Proteção & Requisitos & Campo de Aplicação \\
\hline \multirow{3}{*}{ Propriedade Industrial } & Patentes & $\begin{array}{c}\text { Novidade, Atividade inventiva, } \\
\text { aplicação industrial }\end{array}$ & Indústria \\
\cline { 2 - 4 } & Modelos de Utilidade & $\begin{array}{c}\text { Novidade, ato inventivo, } \\
\text { aplicação industrial }\end{array}$ & Indústria \\
\hline
\end{tabular}

sem autorização, de conhecimentos ou informações a que se refere o inciso anterior, obtidos por meios ilícitos ou a que teve acesso mediante fraude". (BARBOSA, Dênis Borges, "Introdução à Propriedade Intelectual", pg. 640)

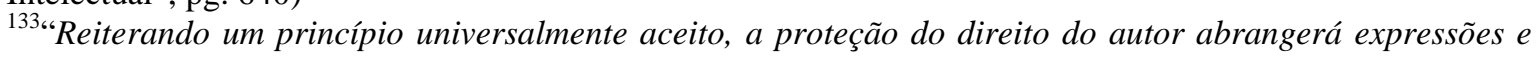
não ideias, procedimentos, métodos de operação ou conceitos matemáticos como tais. Para os programas de computador, em código fonte ou objeto, se reservará a proteção das obras literárias pela Convenção.Igualmente serão protegidas por direito autoral as bases de dados, legíveis por máquina ou em outra forma, nos casos em que, pela seleção ou da disposição de seu conteúdo, constituam criações intelectuais, deverão ser protegidas como tal. Essa proteção não se estenderá aos dados ou ao material em si, e não afetará qualquer direito autoral subsistente nesses dados ou material.(BARBOSA, Dênis Borges, "Introdução à Propriedade Intelectual", pg. 306)

134 “Após o aparecimento das técnicas de manipulação genética, tornou-se consideravelmente mais fácil o patenteamento dos objetos da biotecnologia, inclusive das variedades de plantas e animais. Antes de 1973, no entanto, apenas um número limitado de novas tecnologias do campo biológico atingiam os padrões mínimos de patenteabilidade - principalmente no que toca às novas variedades de plantas e animais. Tal limitação gerou a necessidade de criar, já há algum tempo, um sistema específico de proteção”. (BARBOSA, Dênis Borges, "Introdução à Propriedade Intelectual", pg. 306)

135 “De 1959 até 1981, a produção de circuitos integrados era exclusividade americana; a indústria desenvolvia-se bem e não pensava em propriedade intelectual. A entrada da indústria japonesa no mercado revolucionou as perspectivas do crescimento da oferta e inverteu a liderança de comercialização: em 1986, $47 \%$ do mercado mundial eram japoneses e 39\%, americanos 1064. Alguma coisa teria que ser feita para proteger a indústria americana de tais piratas. Mas o sistema de patentes não operava adequadamente na proteção dos circuitos integrados". (BARBOSA, Dênis Borges, "Introdução à Propriedade Intelectual", pg. 615)

${ }^{136}$ Baseado na publicação da ONU (1993) e OMPI (1994) por CARLOS A. PRIMO BRAGA - "Traded-Related Intellectual Property Issues: The Uruguay Round Agreement and its economic implications". P.383. In. "The Uruguay round and the developing economies/Edited by Will Martins, L. Alan Winters, New York: World Bank, 1995. 


\begin{tabular}{|c|c|c|c|}
\hline \multirow{4}{*}{} & Desenho Industrial & Novidade, caráter ornamental & Indústria, Serviços \\
\cline { 2 - 4 } & Marcas & $\begin{array}{c}\text { Sinais que identifiquem bens } \\
\text { ou serviços }\end{array}$ & $\begin{array}{c}\text { Agricultura, Indústria e } \\
\text { Serviços }\end{array}$ \\
\cline { 2 - 4 } & Indicação Geográfica & Sinais que identificam bens & Agricultura e Indústria \\
\cline { 2 - 4 } & Segredos Empresariais & $\begin{array}{c}\text { Informações comerciais e/ou } \\
\text { industriais confidenciais }\end{array}$ & $\begin{array}{c}\text { Agricultura, Indústria e } \\
\text { Serviços }\end{array}$ \\
\hline $\begin{array}{c}\text { Propriedade Literária e } \\
\text { Artística }\end{array}$ & Direito de Autor e Direitos \\
Conexos & Obras criativas e originais & Artes e Entretenimento \\
\hline \multirow{2}{*}{\begin{tabular}{c} 
Proteções Sui Generis \\
\cline { 2 - 4 }
\end{tabular}} & Direito de Cultivares & $\begin{array}{c}\text { Espécie com descritores } \\
\text { estáveis }\end{array}$ & Agricultura \\
\cline { 2 - 4 } & Circuitos Integrados & $\begin{array}{c}\text { Layout (Tridimensional) } \\
\text { Original }\end{array}$ & Indústria \\
\hline
\end{tabular}

A primeira diferença essencial que desponta entre os grupos Propriedade Industrial e Propriedade Literária e Artística é que a primeira tem como pressuposto um conceito de novidade, ao passo que, a segunda, trabalha com a ideia de originalidade.

Novidade é um conceito aferível objetivamente, consistindo em uma criação que não esteja compreendida no estado atual da técnica - assim considerado como o atual estoque de invenções já divulgadas por meio do sistema de patentes. É fundamental, para o conceito de novidade, que esta inovação não possa ser atingida com facilidade por qualquer técnico no assunto (conceito semelhante ao homem médio, ou seja, pessoa que esteja apta a trabalhar em um determinado ramo da técnica, e não o superdotado, fora de série).

Este conceito está atrelado às ideias fundamentais, já expostas anteriormente, de (i) que toda inovação se baseia, em parte, no trabalho do inventor, e, em parte, no suporte conferido pelo atual estágio de conhecimento da sociedade, e (ii) não se admite a apropriação daquilo que está em domínio público. ${ }^{137}$

A seu turno, a originalidade é um conceito subjetivo, atrelado ao ineditismo. Obras semelhantes, não afrontam o conceito de originalidade, a não ser que se passe a adentrar o campo da cópia servil pura e simples ${ }^{138}$.

${ }^{137}$ Este foi um dos primeiros limites reconhecidos pela Suprema Corte Americana à prerrogativa do
Congresso de estabelecer privilégios: "The Congress in the exercise of the patent power may not overreach
the restraints imposed by the stated constitutional purpose. Nor may it enlarge the patent monopoly without
regard to the innovation, advancement or social benefit ained thereby. Moreover, Congress may not
authorize the issuance of patents whose effects are to remove existent knowledge from the public domain, or
to restrict free access to materials already available, Innovation, advancement, and things which add to the
sum of useful knowledge are inherent requisites in a patent system which by constitutional command must
"promote the Progress of . . useful Arts." This is the standard expressed in the Constitution and it may not
be ignored". (Graham v. John Deere Co, 1966, apud BURCHFE, Kenneth J. in "Revising the Original Patent
clause: Pseudo History in Constitutional Construction", In Harvard Law Review, Volume 2, Spring Issue,
1989 , pg. 163)
138 "No direito autoral, é tipicamente objeto de proteção a obra, fruto de criação pessoal, ainda que seja
semelhante a outra, anterior, de outro autor. É certo que se distingue tais obras similares, mas criativas, da 


\subsubsection{Crise da Divisão Tradicional entre Propriedade Industrial e Artística}

Como estudado acima, o Direito Autoral tutela a forma de expressão, e não as ideias em si. Porém, esta linha demarcatória entre Propriedade Industrial e Manifestação Artística nem sempre é muito clara.

Basta observar que, no Brasil, o software - que está muito mais relacionado à indústria do que a uma forma de expressão artística - é tutelado pelo direito do autor. A suposta razão apontada para proteger os softwares sob o manto da proteção conferida aos autores é a de que o software consistiria em linguagem de programação, criptografada.

No entanto, DÊNIS BORGES BARBOSA retrata, com riqueza de detalhes, as pressões políticas internacionais que marcaram a adesão do Brasil à proteção autoral do software ${ }^{139}$.

Do ponto de vista prático, a proteção autoral acarreta duas consequências. A primeira delas, já abordada, refere-se ao extenso prazo de duração da proteção (cinquenta anos). A segunda refere-se ao fato de que, ao contrário das patentes, não há divulgação da informação ao público. Em outras palavras, os proprietários de softwares não são obrigados a conceder livre acesso ao código-fonte dos programas ${ }^{140}$.

No início do mercado de softwares, as empresas normalmente facultavam o livre acesso ao código-fonte, pois isso tornava seus sistemas mais atrativos aos consumidores. A tendência do mercado era a venda de hardwares, e não softwares.

cópia servil, que é indigna de proteção". (BARBOSA, Dênis Borges, "Introdução à Propriedade Intelectual", pg. 786)

139 "No meio do mais quente da discussão jurisprudencial a lei foi fruto de uma definição política pelo internacionalismo; alinhando-se com o disposto no Trade Act de 1974, o CONIN, em sua reunião de 26 de agosto de 1986, havia se manifestado pelo direito autoral como meio de proteger o software, em voto unânime dos representantes da União, contra a tendência de escolher outro regime de proteção”. (...)O episódio, em toda sua robustez anedótica, merece ser narrado aqui. Um dia antes o autor, juntamente com um ilustre servidor do Itamarati, posteriormente Ministro das Relações Exteriores, haviam participado de um seminário nacional sobre a questão, afirmando ambos que a adoção de um regime específico para o software era a solução acertada para o país. De volta a Brasília, o autor reunira-se com o Ministro da Indústria e Comércio, de quem era assessor junto ao CONIN, para aconselhar o voto, na reunião da manhã seguinte, pelo tertius genus - nem direito autoral, nem patente, ao que o ministro concordou. Na solene sessão da manhã de 26 de agosto, doze Ministros de Estado presentes, surge um ajudante de ordens do Presidente da República, com documento sigiloso, que repassa, sem entregar, a cada um dos titulares, no instante exato da votação. Ao iniciar-se a tomada de votos, o Ministro da Indústria e Comércio, para a surpresa absoluta do autor e dos representantes da empresa privada nacional, pronunciou-se pela adoção do direito autoral - o que resultou na Lei 7.646/87".

140 "Source COde: Computer programs or operating systems are originally written by a human being in a programming language. This is called the source code of the softwar. To be actually used by a computer, the program has to be translated by the computer from source code into the machine language that the computer understands and can execute. This translation process is referred to as compiling" (http://iet.ucdavis.edu/glossary.cfm) 
O crescimento da importância econômica do software levou a que grupos de pressão exigissem a proteção autoral ${ }^{141}$.

RONALD J. MANN ressalta que este movimento ocorreu em meados da década de 1960, devido à crescente complexidade dos softwares e a escassez de mão-de-obra para que cada empresa fizesse seu próprio software.

Coube à IBM, em 1968, a radical decisão de separar os seus softwares de seus hardwares. A época, os Estados Unidos possuíam cerca de 1800 empresas produtoras de softwares $^{142}$.

De todo modo, a questão de inclusão dos softwares na proteção autoral serve para demonstrar que as diferenças entre Propriedade Industrial e Propriedade Artística e Literária, outrora firmes, já não são tão estanques.

Esse movimento, no entanto, não é novo.

Desde a segunda metade do Século XIX e ao longo de todo o Século XX, ocorrem mudanças de paradigma importantes nas ciências naturais ${ }^{143}$.

Também no campo da arte, a partir de novos conceitos propostos primeira escola de design (a Staatliches Bauhauss, de WALTER GROPIUS, na Alemanha) nas primeiras décadas do Século XX, há uma importante mudança de paradigma, passando a produção artística a

\footnotetext{
${ }^{141}$ PAMELA SAMUELSON afirma que "IBM, for example, initially published interface specifications and provided customers with source code to make its computer systems more attractive to those customers" (The strange odyssey of software interfaces and intellectual property law, UC Berkeley Public Law Research Paper n. ${ }^{\circ} 1.323 .818,2008$, disponível em http://ssrn.com/abstract=1323818 p. 4).

142 "The industry is young. It generally is regarded as originating in the mid-1960s. The concept of the software product-a product designed by firm A and sold to firm B for use on firm B's computer-first originated because of the increasing complexity of software and a shortage of the labor needed for each hardware firm to make its own software. The most crucial event was IBM's decision in late 1968 to "unbundle" its software from its hardware. Sales of software products grew rapidly throughout the 1970s. By the 1980s, the United States had a large and well-developed corporate software products industry with more than 1,800 firms." (MANN, Ronald J., "Do Patents Facilitate Financing in the Software Industry?, In Texas law review", Vol. 83, n. ${ }^{\circ}$ 4, 2005, p. 968).

143 "Em seu livro, "A Teia da Vida”, FRITJOF CAPRA argumenta que a ciência contemporânea estaria passando de uma mudança de paradigma, de uma visão de mundo mecanicista, associada ao pensamento de NEWTON e DESCARTES, para uma visão holística ou ecológica. Para ele, esta mudança já teria inclusive transbordado do âmbito das ciências para o campo dos valores e práticas sociais, constituindo-se numa verdadeira transição de paradigmas sociais. Sua origem estaria na percepção de que os problemas com os quais nos deparamos nos últimos anos não podem ser compreendidos de modo habitual, tomados isoladamente de seu contexto mais amplo: "São problemas sistêmicos, o que significa que estão interligados e são interdependentes. Segundo o mesmo autor, essa mudança de paradigmas seria perceptível em várias disciplinas científicas, mas não ocorreria no mesmo ritmo e da mesma maneira em cada uma delas. Ela corresponderia à passagem para um pensamento sistêmico, que teria começado a ocorrer a partir dos anos 20 na biologia e, depois, em outras áreas. A noção do mundo concebido como uma máquina, um mecanismo, estaria dando lugar a um modo de pensar em termos de relações, conexões, contexto [Capra, 1998: 33-45]". (GAma CerqueIRA, Hugo E. da Gama , A Economia Evolucionista: Um Capítulo Sistêmico da Teoria Econômica", Belo Horizonte, UFMG/Cedeplar, $2000, \quad$ disponível em http://web.cedeplar.ufmg.br/cedeplar/site/pesquisas/td/TD\%20150.pdf)
} 
ser direcionada também para produção em massa (movimento que, ao fim e ao cabo, implicará em uma incorporação da arte pela indústria) ${ }^{144}$.

Tais importantes transformações contribuem em muito para uma maior diluição das fronteiras baseadas em divisões conceituais típicas do Século XIX. Essas mudanças de paradigmas têm um óbvio impacto nos conceitos das espécies de direitos albergados pela Propriedade Intelectual.

Com Cláudio R. Barbosa constatamos que, “atualmente, percebe-se que o desenvolvimento das novas atividades empresariais, científicas e culturais torna o quadro anterior inteiramente defasado, em espaços muito curtos, deixando sem sentido a classificação por ramos dos “direitos de propriedade intelectual”. Não é preciso muito esforço para entender que uma nova percepção da realidade modificou completamente a consistência do quadro anterior, que ora pode ser organizado pela função da proteção de cada instituto".

O autor propõe, então, um novo quadro, como segue:

Direitos de Propriedade Intelectual

\footnotetext{
${ }^{144}$ A Escola, fundada pelo arquiteto WALTER GROPIUS em 1919, baseava-se em uma crítica à separação entre os processos criativos e produtivos, a qual havia sido imposta pela revolução industrial. Durante a época em que HANNES MEYER era diretor da Bauhauss, a escola travou diálogo com o Círculo de Vienna, por meio de um ciclo de palestras de OtTo NeURATH, Herbert Feigl e RUdOlf CARnAP, em 1929 - este último, um amigo pessoal de Meyer, ambos tendo sido influenciados pela Neue Sachlichkeit (Nova Objetividade Alemã). Como influências do Círculo de Viena, destacamos a crítica à filosofia metafísica (implicitamente, criticavase HEIDEGGER, e sua visão existencialista fenomenológica, calcada na divisão entre o "ser" e o "ser no mundo", entre "intelecto e vida", entre "estética" e "função" - contrastar com em contraste com WITTGENSTEIN, o filósofo que "would bring words back from their metaphysical to they everyday use [PI§116]"), o que foi de encontro ao ideal da Bauhauss de promover uma maior proximidade entre arquitetura e ciência. Uma citação da palestra de CARNAP sobre "Ciência e Vida" exprime o espírito proposto: "I work in Science, you work in the creation of (visual) forms; both are just parties of one single life”. (HANS-JOACHIM dahms, Neue Sachlichkeit in the Architecture and Philosophy of the 1920's) e EDWARD MINAR, "Heidegger, Wittgenstein and Skepticism",
} (http://www.harvardphilosophy.com/issues/2001/Minar.pdf). 


Proteção Sui Generis Conhecimentos Tradicionais

Ainda conforme CLÁUDIO R. BARBOSA:

"O quadro acima, especialmente pela ausência de bordas definidas entre as áreas, reflete de forma explícita a situação conhecida pela doutrina de que a propriedade intelectual encontrase em grande e inequívoca mutação. Aliás, não se refere somente à falência da dicotomia entre a área civil e a comercial. Refere-se ainda ao surgimento de diversas novas espécies de bens intelectuais, e respectivos instrumentos de proteção. Estes novos objetos de proteção correspondem a um fenômeno que acompanha as modificações e evoluções dos produtos e serviços colocados em comércio, das empresas atuantes no cenário internacional, e como resultado, culmina na necessidade de criação de novas proteções "sui generis.A proteção das marcas tridimensionais, por exemplo, confunde-se com os desenhos industriais e com a proteção do direito autoral. As proteções às criações industriais na área de programas de computador implicam em conflitos com direitos autorais e patentes de invenção. A própria divisão entre o que é arte, o que é indústria, o que é orgânico, e inorgânico, o que é genética e o que é mero desenho de novas moléculas acaba cada vex mais se perdendo. Obviamente, os institutos jurídicos que deveriam proteger estas criações acabam também com suas fronteiras dissolvidas. Enfim, as modificações tecnológicas que presenciamos não nos autorizam a admitir que institutos jurídicos moldados no século XIX possam, perfeitamente, regulamentar toda a situação lançada pela constante evolução tecnológica".

\subsubsection{Conclusão sobre as Espécies de Propriedade Intelectual. Delimitação DE ESCOPO DO TRABALHO}

Tendo em vista tal cenário dinâmico, também, para efeito de definição do escopo do presente trabalho, não poderíamos analisar - por questão de espaço - todas as espécies de Propriedade Intelectual acima expostas, considerando que cada uma delas suscita diferentes problemas no que se refere à concorrência.

Para fins de delimitação do escopo, porém, nos dedicaremos ao grupo das criações industriais, pois, no que se refere às espécies aí alocadas, a associação a uma produção para fins de mercado - e, consequentemente, a relação com a concorrência - emerge de forma mais clara.

Quanto aos sinais distintivos, em especial quanto às marcas, deve ser reconhecido que tais direitos também se relacionam ao mercado e que, assim, deles também emanam efeitos concorrenciais. 
Some-se a isso os direitos sui generis que também têm um claro uso na indústria, como os circuitos integrados e, também, os cultivares - considerando-se a atual importância da agroindústria.

Entretanto, considerando que o campo das criações industriais é ainda muito vasto, ainda há necessidade de maior delimitação. Sendo assim, excluiremos do escopo os segredos industriais, porque, nesta categoria, não está presente o problema de um direito de exclusividade, potencial causador de preocupações concorrenciais. Tais direitos tutelam, em verdade, uma exigência de lealdade na competição. As informações sob segredo não estão protegidas de acesso dos concorrentes, porém, este acesso deve se dar por meios leais.

Em resumo, trataremos das patentes e modelos de utilidade, do desenho industrial, dos programas de computador, das marcas, dos circuitos integrados e das cultivares. 


\title{
Capítulo 2 - Histórico das Interfaces entre Direito Antitruste (Direito Concorrencial) e a Propriedade Intelectual
}

\begin{abstract}
"Legal rights are intellectual creations. They reflect the world view of the people who make and defend them. To know a culture's legal rights is to know something about the things its people believe are important ${ }^{145}$ ". [Herbert $\mathrm{J}$. Hovenkamp]
\end{abstract}

Se olharmos para a história do debate envolvendo concorrência e Propriedade Intelectual, veremos que - especificamente nos Estados Unidos - a dicotomia entre a Propriedade Intelectual e o Direito Antitruste pendeu, em alguns momentos, em favor da Propriedade Intelectual, e, em outros, em favor da concorrência - tendo alcançado extremos para os dois polos.

Como já adiantado, no que se refere à concorrência, tanto a legislação como a jurisprudência americanas foram influenciadas pelas diferentes teorias econômicas que foram prevalecendo ao longo do tempo - variando de acordo com abordagens mais evolucionárias ou mais intencionais. Ao se referir à livre concorrência, a referência pode ser à liberdade contra o intervencionismo estatal (abordagem evolucionária), ou contra o próprio poder de mercado (abordagem intencional) - sendo que a escola da Chicago se aproximava mais da primeira visão, ao passo que Harvard aproximou-se mais da segunda. Seguindo essas duas influências fundamentais, o Direito Antitruste americano foi desde a proibição per si (Harvard) a uma aplicação mais branda do Antitruste, com base na Rule of Reason (Chicago) ${ }^{146}$.

No plano jurídico, esse antagonismo também se refletiu entre dois desejos conflitantes: preservar a concorrência e garantir a máxima liberdade na exploração dos direitos individuais de propriedade. Nos momentos em que a Propriedade Intelectual prevaleceu sobre a Concorrência, o apelo retórico era maior aos Direitos Individuais à propriedade e à liberdade contratual, ao passo que, nos momentos em que se queria privilegiar a concorrência, a tendência era tratar a proteção dada à PI como um monopólio - contrário, portanto, aos princípios de uma economia de livre mercado.

\footnotetext{
${ }^{145}$ HovenKAmP, Herbert J. "The Political Economy of Substantive Due Process", 40 Stanford Law Review $379(1988)$

${ }^{146}$ GIOCOLI, Nicola, in "Competition vs. Property Rights: American Antitrust law, the Freiburg School and the early years of European competition policy", 2008, Online at http://mpra.ub.uni-muenchen.de/33807/
} 
Para os pensadores da escola de Freiburg - que, como veremos, influenciaram fortemente o Direito Concorrencial da atual União Europeia - as ambiguidades do Antitruste americano se deviam ao fato de que, naquele país, o Antitruste esteve totalmente descolado de uma constituição econômica.

Escrevendo em período contemporâneo, NiCOLA GIOCOLI torna esta crítica mais extensiva, ao afirmar que, sem uma definição clara dos princípios constitutivos por trás do Direito Concorrencial, qualquer legislação acabaria por se defrontar com a dicotomia entre concorrência e propriedade $e^{147}$.

No roteiro de estudos que se desenrolarão no Capítulo 2, é indispensável dedicar atenção ao desenvolvimento do tema nos Estados Unidos da América, que aparece com uma importância óbvia no debate - pois, como se sabe, a primeira legislação voltada a proteger a concorrência foi editada naquele país (o famoso Sherman Act, de 1890).

Depois, analisaremos a experiência europeia - marcada, como já dito, por uma influência de ideias ordoliberais, da escola de Freiburg, na Alemanha. É notório que ambos direitos influenciaram fortemente o nosso Direito Concorrencial.

Ao final dessa dissertação, procuraremos identificar um quadro de trabalho brasileiro para a solução dos eventuais conflitos envolvendo a Propriedade Intelectual e o Direito Concorrencial.

Não se tratará, porém, de um trabalho de Direito Comparado, pois o objetivo final pretendido não é comparar sistemas, mas - sim - contextualizar o influxo de argumentos jurídicos e econômicos de origem estrangeira que vêm aparecendo cada vez mais em trabalhos acadêmicos e em decisões proferidas pelos tribunais pátrios e pelo Sistema Brasileiro de Defesa da Concorrência - muitas vezes, a despeito de um exame mais criterioso de validade à luz do direito positivo brasileiro.

\footnotetext{
147 “. Ordoliberals defended and integrated view of economic policy, one where both kinds of principles should be taken into account. Indeed, Eucken explained the ambiguities of American antitrust with the failure to entered competition law within the broader framework of a specific economic constitution. We may reword this critique by saying that, absent a clear definition of the constitutive principles underlying it, any antitrust law is bound to generate policy decisions which would inevitably clash with side or the other of the "competition versus property rights" dichotomy". (GIOCOLI, Nicola, in "Competition vs. Property Rights: American Antitrust law, the Freiburg School and the early years of European competition policy", 2008, Online at http://mpra.ub.uni-muenchen.de/33807/)
} 


\subsection{O Advento do Sherman ACt (1890) e Principais Ideias Econômicas sobre a CONCORRÊNCIA NOS EUA}

O relato desenvolvido no Capítulo 1, centrado no Século XIX, tem, como pano de fundo, importantes transformações sofridas no sistema capitalista. Como se retratou ali, este período se inicia com a Inglaterra em meio à sua Revolução Industrial, tendo sido seguida por outros países que também alcançaram semelhante estágio de industrialização, porém, com diferentes ritmos e condições.

O período retratado coincide com o que se costuma chamar, para fins didáticos, de fase concorrencial do capitalismo liberal. Embora este termo traduza uma falsa ideia de homogeneidade, que não se verifica na realidade, retomaremos a ideia do fim capitalismo concorrencial liberal como uma mera ilustração, apenas para contextualizar o surgimento do Sherman Act.

Os Estados Unidos do início do Século XX haviam conhecido um processo de industrialização intensificado após a década de 1850, sobretudo, após a guerra de secessão, com a subsequente reconstrução do país durante as décadas de 1870 e 1890 - época esta conhecida como The Gilded Age (a era dourada) ${ }^{148}$.

Nesta fase, a economia americana conhece um período de forte concentração industrial que se iniciou durante a guerra, sobretudo, nos setores ferroviário, petroleiro, elétrico e de telégrafos.

Essa grande concentração - ao cabo de duas décadas - deu margem a abusos, que despertaram um clamor popular contra os grandes negócios. Destaca-se, sobretudo, o descontentamento por parte da classe dos agricultores, que se via fortemente prejudicada pela má administração dos trusts do setor ferroviário e pelo grande poder político que eles haviam alcançado. A insatisfação popular era tamanha que, nas eleições de 1888, ambos os partidos dominantes (Republicanos e Democratas) incluíram em seus programas eleitorais o compromisso de combate às restrições indevidas ao comércio e à concorrência. Tais pressões culminaram com a promulgação do Sherman Act, em 1890.

Um traço importantíssimo deste processo de forte concentração industrial vivido pela economia americana no período, e que - no entanto - é muitas vezes negligenciado

\footnotetext{
${ }^{148} \mathrm{O}$ termo foi ironicamente cunhado por MARK TWAIN e CHARLES DUdLEY WARNER, na obra "The Gilded Age: A Tale of Today", na qual satirizaram o que acreditavam ser uma sociedade marcada por vários problemas, escondidos por uma "camada fina de ouro".
} 
pelos relatos históricos correntes, é o papel pervasivo desempenhado pelos grandes bancos de investimento em Boston e Nova Iorque no surgimento dos trusts.

Efetivamente, por trás dos trusts industriais, havia aquilo que LOUIS BRANDEIS Juiz da Suprema Corte Americana entre 1916 e 1939 - denominaria anos mais tarde de oligarquia financeira - e que representava uma ameaça muito maior, não apenas à concorrência, mas, também, à própria democracia.

O controle da concorrência industrial pelos money trusts foi exposto pela comissão investigativa ocorrida no Congresso americano entre 1912 e 1913, após autorização obtida pelo congressista Arséne PUjo (the Pujo Comitee).

LOUIS BRANDEIS, que dedicou grande parte de sua carreira como advogado e Juiz ao combate aos grandes negócios, às economias de escala e ao consumo de massa - os quais considerava uma ameaça à liberdade e valores da cultura americana ${ }^{149}$ - compilou boa parte das conclusões a que chegou o comitê em sua obra “Other People's Money and How Banks Use It ${ }^{\text {"150 }}$.

O quadro retratado por BRANDEIS em sua obra destaca os três fatores principais que acarretaram a formação deste verdadeiro monopólio do crédito (Money Trust) - que encartava, também, um monopólio industrial, num esquema no qual os bancos de investimento eram os elementos dominantes, os bancos associados e seguradoras suas ferramentas e as ferrovias e corporações industriais seus objetos.

Primeiro, a consolidação de bancos de investimento por meio de combinações, que eram instrumentalizadas por controle acionário, trusts com poder de voto e diretorias cruzadas - que, na verdade, dissimulavam acordos de cavalheiros com o objetivo de eliminar a concorrência entre bancos de investimento.

Em segundo lugar, a consolidação das companhias ferroviárias em grandes conglomerados, que já não podiam ser operados e financiados de forma local - criando-se uma total dependência quanto aos grandes bancos de investimento associados.

Em terceiro lugar, pela expansão do papel dos bancos de investimento, que passaram, de um lado, a assumir papeis de diretoria em companhias férreas e industriais companhias estas que eram as emissoras de títulos e ações e, de outro, passaram também a controlar seguradoras, bancos comerciais e outros reservatórios de economias dos

\footnotetext{
${ }^{149}$ MCCRAw, ThOMAS K. Prophets of Regulation, Harvard University Press, 1984

${ }^{150}$ BRANDEIS, Louis D., "Other People's Money and How the Bankers Use It", New York, Frederick A. Stokes Company Publishers, 1913
} 
indivíduos - que, por sinal, vinham a ser os compradores dos mesmos títulos e ações emitidos pelas companhias que eram por eles (os bancos de investimentos) controladas.

Essas funções, que antes eram exercidas por pessoas diferentes, passaram a ser concentradas na figura dos bancos de investimento. É a partir dessa reunião de papéis nos bancos de investimento que o Money Trust foi construído e o grande poder financeiro e político por ele alcançado colocava em risco o sistema de Separação de Poderes arquitetado pela Constituição - e, em última análise, a própria democracia ${ }^{151}$.

Esta visão, propositalmente esquemática, contém os fatos mais importantes que marcaram o advento do Sherman Act. Dada a limitação do tema, não é nosso objetivo se aprofundar mais neste relato histórico.

Porém, é importante que se tenha em mente a existência, á época, de ceticismo por parte do mainstream econômico no país. Isso se devia a fato de que os economistas americanos não haviam desenvolvido, até então, uma teoria apropriada para justificar a concorrência.

151 "The dominant element in our financial oligarchy is the investment banker. Associated banks, trust companies and life insurance companies are his tools. Controlled railroads, public service and industrial corporations are his subjects. Though properly but middlemen, these bankers bestride as masters America's business world, so that practically no large enterprise can be undertaken successfully without their participation or approval. These bankers are, of course, able men possessed of large fortunes; but the most potent factor in their control of business is not the possession of extraordinary ability or huge wealth. The key to their power is Combination - concentration intensive and comprehensive - advancing on three distinct lines:

First: There is the obvious consolidation of banks and trust companies; the less obvious affiliations through stockholdings, voting trusts and interlocking directorates - of banking institutions which are not legally connected; and the joint transactions, gentlemen's agreements, and "banking ethics" which eliminate competition among the investment bankers.

Second: There is the consolidation of railroads into huge systems, the large combinations of public service corporations and the formation of industrial trusts, which, by making businesses so "big" that local, independent banking concerns cannot alone supply the necessary funds, has created dependence upon the associated New York bankers. But combination, however intensive, along these lines only, could not have produced the Money Trust - another and more potent factor of combination was added.

Third: Investment bankers, like J. P. Morgan \& Co., dealers in bonds, stocks and notes, encroached upon the functions of the three other classes of corporations with which their business brought them into contact. They became the directing power in railroads, public service and industrial companies through which our great business operations are conducted - the makers of bonds and stocks. They became the directing power in the life insurance companies, and other corporate reservoirs of the people's savings - the buyers of bonds and stocks. They became the directing power also in banks and trust companies - the depositaries of the quick capital of the county - the life blood of business, with which they and others carried on their operations. Thus four distinct functions, each essential to business. and each exercised, originall”, by a distinct set of men, became united in the investment banker. It is to this union of business functions that the existence of the Money Trust is mainly due. The development of our financial oligarchy followed, in this respect, lines with which the history of political despotism has familiarized us : - usurpation, proceeding by gradual encroachment rather than by violent acts; subtle and often long-concealed concentration of distinct functions, which are beneficent when separately administered, and dangerous only" when combined in the same persons. It was by processes such as these that Caesar Augustus became master of Rome. The makers of our own Constitution had in mind the dangers to our political liberty when they provided so carefully for the separation of governmental powers". (BRANDEIS, Louis D., "Other People's Money and How the Bankers Use It”, New York, Frederick A. Stokes Company Publishers, 1913) 
A crença predominante era de que a concorrência destruiria os setores marcados por enormes custos fixos, que só poderiam ser suportados por grandes empresas. Nesses setores, a concorrência conduziria as empresas à falência (ruinous competition) ${ }^{152}$.

\subsubsection{As Duas Primeiras Décadas do Antitruste: Prevalência da Propriedade} INTELECTUAL

A redação original do Sherman Act era ampla, abarcando previsão de que qualquer contrato que implicasse em uma restrição ao comércio, ou tentativa de monopolização seria considerado ilegal ${ }^{153}$. Esta previsão ampla fez com que o conflito entre as patentes reconhecidamente um monopólio na tradição americana ${ }^{154}$ - fosse suscitado já nas primeiras décadas de vigência do Sherman Act.

Conforme resume LEMLEY:"A simplistic assessment of this interaction might proceed as follows: IP rights are monopolies, and antitrust is designed to prevent

\footnotetext{
152 "In the marginalist conception of a perfectly competitive economy, prices are driven to marginal cost and the industry as a whole produces at the most efficient rate possible. While these conclusions largely tracked the much less technical formulations of "pure" competition in classical political economy, there was one important difference. The classicists generally believed that competition was the norm except when government intervened. By contrast, the initial impact of marginalist analysis was the belief that competition was exceptional. Fixed costs and scale economies dictated that firms could not price at the competitive level. Under the economic theories of the late nineteenth century and early twentieth centuries, such firms would be driven to overproduction and "ruinous competition" as prices would be forced so loww that they could not cover a firm's fixed-cost investments" (HOVENKAMP, Herbert J. "United States Competition Policy in Crisis: 1890-1955", Minessota Law Review, Vol. 94, pg. 311, 2009, U Iowa Legal Studies Research Paper No. 0832). Essas ideias seriam fortemente combatidas por JOHN MAURICE CLARK na virada do século XX. Para CLARK, "In the short run, firms might be driven to ruinous competition because their fixed costs are so high. However, in the long run excess plans will wear out and not be replaced and market equilibrium will be restored. John Maurice Clark's path-breaking book on fixed costs set the stage for theory that permitted equilibria to emerge even in industries subject to fixed costs. [...] Or as Schumpeter said in his critique of Joan Robinson, "the element of time must be got hold of in a much more efficient manner, if for no other reason because what people try to maximize is certainly gain over time" (HOVENMKAMP, Herbert J. idem).

153 "Every contract, combination in the form of trust or otherwise, or conspiracy, in restraint of trade or commerce among the several States, or with a foreign nation, is declared to be llegal. . . "Every person who shall monopolize, or attempt to monopolize, or combine or conspire with any other person or persons, to monopolize any part of the trade or commerce among the several States, or with foreign nations, shall be deemed guilty of a felony..." (LEMLEY, Mark "A New Balance Between IP and Antitrust", Southwestern Journal of Law and Trade in the Americas, Vol. 13, pg. 237, 2007, Standford Law and Economics Olin Working Paper No. 340)

${ }^{154}$ Também BURCHFEL comenta sobre a adoção da tradição inglesa do monopólio: “: "The English background suggests that under the intellectual property clause Congress might have the power to grant "'monopoly" rights, as in England, to those who merely imported rather than invented a useful article" (BURCHFIEL, Kenneth J, "Revising the 'Original' Patent Clause: Pseudohistory in Constitutional Construction", Vol. 2, Spring Issue, 1989).
} 
monopoly, so the two laws are in conflict. Indeed, on several occasion in U.S. history courts and scholars seem to have taken precisely this approach ${ }^{155, "}$.

Os primeiros encontros entre a Propriedade Intelectual e o recém-instituído Direito Antitruste envolveram casos em que o detentor de patentes tentava licenciar o seu direito sob condições que restringiam a fixação de preços, ou condicionavam o licenciamento à aquisição de outros produtos (espécie de venda casada).

Em um primeiro momento, que compreende as duas primeiras décadas do Sherman Act, as cortes americanas tenderam a afastar a aplicação do Antitruste, conferindo uma proteção ampla à Propriedade Intelectual.

À época, o judiciário americano era fortemente influenciado pela doutrina jurídica do Substantive Due Process ${ }^{156}$. Investigaremos mais profundamente as características dessa doutrina, pois - conforme procuraremos demonstrar - ela será central para compreensão do desenvolvimento da interface entre Propriedade Intelectual e Antitruste nos Estados Unidos.

\subsubsection{Doutrina do Substantive DUE Process}

A doutrina do Substantive due Process é rotulada como um período formalista na jurisprudência da Suprema Corte americana e em seu poder judiciário como um todo ${ }^{157}$.

\footnotetext{
${ }^{155}$ LEMLEY, Mark, “A New Balance Between Antitrust and IP” (op. cit.). O próprio Lemley cita vários precedentes na história americana em que a PI foi considerada como um monopólio, em contraste com o Antitruste: "See, e.g., United States v. Westinghouse Elec. Corp., 648 F.2d 642, 646 (9th Cir. 1981) ("[o]ne body of law creates and protects monopoly power while the other seeks to proscribe it."). Further back in history, the principle that patents (or indeed all IP rights) were "monopolies" of which antitrust law should be especially wary was taken for granted. See, e.g., Henry v. A.B. Dick Co., 224 U.S. 1, 27 (1912) (patent "is a true monopoly”); WILLIAM C. ROBINSON, THE LAW OF PATENTS FOR USEFUL INVENTIONS 67 (Boston, Little, Brown, and Co. 1890); Hon. Giles S. Rich, Are Letters Patent Grants of Monopoly?, 15 W. NEW ENG. L. REV. 239 (1993) (reviewing the history of the debate over whether patents are monopolies). For more detail, see also 1 HOVENKAMP ET AL., supra note 1, Ch. 4.

156 "Substantive Due Process" is the name of a doctrine which the United States Supreme Court and other American courts used from around 1885 until the Roosevelt Court-Packing crisis of 1937 to determine the constitutionality of regulatory legislation. Under this doctrine, the courts derived a test from the due process clause of the fourteenth amendment of the United States Constitution for evaluating the substantive effect of economic regulations such as wage and hour laws, product quality laws, licensing restrictions, restrictions on entry into business, and price regulation" (HOVENKAMP, Herbert J., "Political Economy of Substantive Due Process", op. cit.)

157 O formalismo americano tem sua origem na doutrina de LANGDELL. Tratava-se da tentativa epistemológica de estabelecer o direito como uma ciência como as demais, um sistema fechado, cujos únicos valores (internos) eram os precedentes passados das cortes: "Formalism was the rethoric of law in the late nineteenth century, particularly of private law. Lawyers beginning with LANGDELL or perhaps even earlier wanted the law to be seen as a self-contained system - a science whose "data" consisted entirely of earlier legal decisions - because they were obsessed with placing law on the same epistemological plane as the other sciences. But LANGDELL'S formalism was only a vision. It was never reality, and even formalism at its best (or
} 
Este formalismo era caracterizado pelo apego das cortes a uma determinada doutrina econômica - qual seja, o laissez-faire, nos moldes do classicismo britânico - em detrimento de outras doutrinas econômicas que estavam em franca ascensão no país, na virada do Século XIX para o Século XX.

Este período é marcado por vários debates políticos e econômicos nos EUA envolvendo temas sobre a regulação estatal, como a distribuição de renda e fixação de salários-mínimos e cargas horárias máximas aos trabalhadores ${ }^{158}$.

Em contrapartida, o apego das cortes à doutrina econômica do classicismo acarretou um grande descompasso entre as percepções do poder legislativo e do poder judiciário sobre o papel do Direito na distribuição de renda. Nesta época, vários estados editaram legislações para efeito de intervir no mercado em favor dos trabalhadores, proibir o trabalho infantil, estabelecer cargas horárias e mínimas condições de trabalho em certas indústrias, etc.

Tal ativismo era baseado nas crescentes críticas econômicas à doutrina do laissezfaire, por economistas como ChARLes Francis AdAMs JR., Richard T. ELy, EdwiN SEligman, e John R. COMMONS ${ }^{159}$. A Suprema Corte, no entanto, barrou boa parte desta iniciativa legislativa dos estados, com base na Décima Quarta emenda constitucional ${ }^{160}$.

wrost) never did what it said it did. (...) Substantive due process was a system of law based on an economic theory". (HovEnKAMP, Herbert J., "Political Economy of Substantive Due Process", op. cit.)

158 "Com o título de Primeiro Grande Movimento de Law and Economics, HeRBERT HovenKAMP estudou um grande grupo de pesquisas que abordaram, no final do Século XIX, vários temas jurídicos e econômicos. Esses autores não estavam tão comprometidos em erguer fortes fronteiras entre os estudos de economia (política), direito e ciências sociais. Assim como no caso do atual Law and Economics (1970-1980), o primeiro movimento também teve estudos voltados, inicialmente, a assuntos de regulação de certas atividades econômicas (preocupação com o transporte ferroviário, notadamente) e, após, de forma mais ampla, a restrições comerciais, direito do trabalho, direito penal, propriedade e contratos" (ARRUDA DE ANDRADE, José Maria, "Economização do Direito Concorrencial e Positivismo Jurídico”, pg. 30)

159 "In the late nineteenth century most judges were reluctant to recognize economic conflict explicitly as a justification for changing legal rules. This was not the case with the legislatures. By the turn of the century, a large gap had developed between judicial and legislative perceptions about the role of the law as a wealth distribution device. Many states had enacted legislation that intervened in the market on behalf o labor, regulating child labor, women's maximum hours, and hours or working conditions in certain industries. They had also enacted a host of licensing and regulatory restrictions that benefited establhished business at the expense of prospective entrants, although some of these regulations had health or safety justifications as well. Fierce attacks on classical laissez-faire economomic theory by economists such as CHARLES FRANCIS ADAMS JR., RICHARD T. ELY, EDWIN SELIGMAN, and JOHN R. COMMONS provided intellectual support for this legislative reform". (HovenKAMP, Herbert J., "Political Economy of Substantive Due Process", op. cit.)

${ }^{160}$ Este embate entre doutrinas econômicas progressistas - defendidas pelos Estados - e a posição mais conservadora então majoritariamente defendida pela Suprema Corte tem na figura LOUIS BRANDEIS uma interessante síntese - ou, talvez melhor dizendo, antítese. Como advogado, BRANDEIS defendeu vigorosamente o ativismo dos estados em matéria de regulação, o que lhe rendera a alcunha de "adgvogado do povo". Como Juiz da Suprema Corte, ele ficou conhecido como eterno "voto vencido" nestas mesmas questões, como bem relata MCCRAW: "In a period when the Court majority routinely overturned economic regulatory legislation as inconsistent with Fith or Fourteenth Amendment, Brandeis passionately opposed such activism. With single minded consistency, he took the position that judges must allow legislators wide 
Para melhor compreender a doutrina do Substantive due Process, é necessário analisar o fundamento maior dessa construção, que - como dito - encontrava-se na Décima Quarta emenda.

A Décima Quarta emenda foi promulgada após a guerra civil, estendendo a cidadania americana a todas as pessoas nascidas nos Estados Unidos (negros e imigrantes incluídos, portanto) ${ }^{161}$.

Conquanto esta emenda seja, normalmente, associada à questão da segregação racial - que era uma tensão presente naquele país, no contexto da guerra civil - ela contém, na verdade, uma cláusula de liberdade individual (liberdade contra intervenção dos estados, leia-se). Esta cláusula é dirigida a todos os cidadãos: "No state shall make or enforce any law which shall abridge the privileges or immunities of citizens of the United States; nor shall any state deprive any person of life, liberty, or property”.

Portanto, a questão da segregação racial não estava, na verdade, em foco na Décima Quarta emenda. As liberdades garantidas pela emenda eram liberdades civis e não raciais ${ }^{162}$. E as liberdades civis eram, claramente, liberdades econômicas (liberdade de contratar, liberdade de comprar e vender, de manter propriedade, etc. ${ }^{163}$.

latitude and freedom to experiment (He excepted only laws designed to limit civil liberties; there he threw off judicial restraint and voted to rule the legislation unconstitutional.) Always he appealed primarily to "the facts". Rapid industrialization, he argued, had produced unprecedent dislocations. If governments were denied the power to regulate industrial conditions, then the social fabric was going to split apart. Whether the case before the Court had to do with child labor, wages and hours, workmen's compensation or railroad regulation, Brandeis held that judges must not arrogate to themselves undue authority to overturn legislative action. Relying time and again on the same kind of sociological jurisprudence that he himself had pioneered as a trial lawyer, he pointed to actual economic conditions as affording legislators a reasonable and not arbitrary basis for passing regulatory laws". (McCRAW, Thomas, "Law: Louis D.Brandeis Reappraised, The American Scholar, Vol. 54, no 4, (Autumn 1985), pgs. 525-536)

161 "All persons born or naturalized in the United States, and subject to the jurisdiction thereof, are citizens of the United States and of the state wherein they reside. No state shall make or enforce any law which shall abridge the privileges or immunities of citizens of the United States; nor shall any state deprive any person of life, liberty, or property, without due process of law; nor deny to any person within its jurisdiction the equal protection of the laws".

${ }_{162}$ Que a igualdade reconhecida pela Décima Quarta emenda era civil e não racial tornou-se claro quando a Suprema Corte, em 1896, julgou constitucional a separação de vagões para brancos e negros, desde que os vagões fossem iguais (Plessy v. Ferguson), e isso, a despeito do Civil Rights Act de 1875: "Therefore, Be it enacted by the Senate and House of Representatives of the United States of America in Congress assembled, That all persons within the jurisdiction of the United States shall be entitled to the full and equal and enjoyment of the accommodations, advantages, facilities, and privileges of inns, public conveyances on land or water, theaters, and other places of public amusement; subject only to the conditions and limitations established by law, and applicable alike to citizens of every race and color, regardless of any previous condition of servitude". Essa doutrina do "iguais mas separados" permaneceu até 1954, quando a Suprema Corte determinou o fim da segregação nas escolas americanas (Brown v. Board of Education of Topeka).

163 "Congress did not have segregation in mind when it passed the Civil Rights Act of 1866, when it drafted the fourteenth amendment, or even a decade later, when, contemplating the end of Reconstruction, it drafted the Civil Rights Act of 1875, which was subsequently struck down by the Supreme court. Even Radical Republicans maintained a sharp distinction among "civil" rights, "political" rights, and "social" rights. The fourteenth amendment and the Civil Rights Act of 1866 were designed to protect civil and political 
A ideia de liberdades civis como liberdades econômicas encontra-se claramente presente no Civil Rights Act, de 1866. A Décima Quarta emenda, inclusive, fora promulgada para constitucionalizar esse ato:

"Be it enacted by the Senate and House of Representatives of the United States of America in Congress assembled, That all persons born in the United States and not subject to any foreign power, excluding Indians not taxed, are hereby declared to be citizens of the United States; and such citizens, of every race and color, without regard to any previous condition of slavery or involuntary servitude, except as a punishment for crime whereof the party shall have been duly convicted, shall have the same right, in every State and Territory in the United States, to make and enforce contracts, to sue, be parties, and give evidence, to inherit, purchase, lease, sell, hold, and convey real and personal property, and to full and equal benefit of all laws and proceedings for the security of person and property, as is enjoyed by white citizens, and shall be subject to like punishment, pains, and penalties, and to none other, any law, statute, ordinance, regulation, or custom, to the contrary notwithstanding".

De fato a Décima Quarta emenda incorporou uma ordem econômica na Constituição americana, ordem econômica essa na qual a intervenção estatal sobre privilégios e sobre a propriedade privada era excepcional (era uma ordem econômica não intervencionista - identificada com o laissez-faire, portanto).

À época que o Civil Rights Act, de 1866 e a Décima Quarta emenda passaram no Congresso, o laissez-faire da economia política clássica britânica ainda estava em voga nos Estados Unidos - embora, na Inglaterra, ele já tivesse passado por crises pouco mais de meio século antes. Apenas no início do Século XX, após duas décadas de intensos estudos econômicos, o classicismo britânico começou a entrar em ocaso também nos Estados Unidos.

Entretanto, a Suprema Corte e o judiciário americano como um todo permaneceram apegados a uma doutrina econômica superada por décadas.

Este grande embate, entre a teoria econômica do laissez-faire e as teorias econômicas então emergentes nos Estados Unidos, tornou-se evidente no enfrentamento, pelos tribunais, de políticas regulatórias de transferência de renda. Segundo a teoria clássica do laissez-faire, a intervenção estatal era indesejável a esse respeito, dadas as premissas de que, preservados os direitos de propriedade e a liberdade de contratar, a mão invisível do mercado asseguraria a maximização de riqueza ${ }^{164}$ e 165.

rights, but not social rights. And civil rights were fundamentally defined as economic rights" (HOVENKAMP, Herbert, "Political Economy of Substantive Due Process", op. cit.)

164 Àquela altura, entretanto, essas premissas clássicas do laissez-faire já haviam passado, desde o início do Século XIX, por duas grandes revoluções: uma utilitarista (BENTHAM, MALTHUS, RICARDO), e outra 
O primeiro motivo possível para o fato de a Suprema Corte ter se mantido por tanto tempo apegada à doutrina do laissez-faire é que, como já comentado, as então novas ideias sobre o capitalismo presentes na Inglaterra demoraram a penetrar nos Estados Unidos. As possíveis razões de tal descompasso se devem, principalmente, (1) ao fato de que tais críticas ao laissez-faire baseavam-se em um problema específico da Inglaterra - a escassez de terras - problema este que não existia nos Estados Unidos ${ }^{166}$; (2) os problemas sociais emanados da revolução industrial só se verificariam nos Estados Unidos tempos depois ${ }^{167}$.

marginalista (MENGER, JEVONS, E WALRAS). MALTHUS defendera que a população cresceria em progressão geométrica, ao passo que a produtividade das terras, que seguia uma progressão aritmética, seria limitada. Assim, existiria uma tendência de aumento da miséria no longo prazo. A teoria do aumento populacional, a princípio, justificaria uma não intervenção em favor dos pobres. MALTHUS, porém, seguindo uma influência do utilitarismo de BENTHAM, estava disposto a manipular os direitos de propriedade com a finalidade de melhorar o bem estar dos pobres, desde que o "preço" de tal intervenção não fosse muito alto. Os argumentos de MALTHus influenciaram, na Inglaterra, a aprovação da "Poor Law Reform Bill", de 1834. Posteriormemte, RICARDO elaborou uma teoria de land rents, segundo a qual a escassez de terras produtivas levaria a que, com o aumento populacional, os proprietários das melhores terras poderiam arrendá-las a preços monopolistas. Tal tendência ao monopólio, que demandaria intervenção estatal, consistia em mais uma falha na premissa básica do laissez-faire. (HovENKAMP, Herbet "Political Economy of Substantive due Process")

${ }^{165}$ Também a esse respeito, LEDA PAULANI: "Preocupado em conseguir, junto ao parlamento inglês, uma mudança na legislação que permitisse a abertura dos mercados da Inglaterra ao cereal importado, Ricardo vai argumentar que o crescimento da população e a conseqüente necessidade de uma quantidade crescente de alimentos faria com que fossem ocupadas terras cada vez menos férteis. Como o preço regulador do cereal seria dado pela produtividade do trabalho na pior terra, toda a diferença de produtividade existente nas faixas mais férteis seria embolsada como renda por seus proprietários. O valor cada vez maior dos cereais (dada a menor produtividade do trabalho a cada nova faixa de terra ocupada) implicaria salário cada vez maior e renda fundiária também cada vez maior, resultando assim no esmagamento dos lucros (profit squeeze)". E prossegue LEDA PAULANI: "Não é difícil perceber que, com esse tipo de argumento, o famoso economista inglês, apesar de ser ele próprio dono de terras, funcionava como porta-voz dos interesses da ascendente burguesia industrial contra os senhores de terra". (PAULANI, Leda, "Acumulação e Rentismo: resgatando a teoriada renda de Karl Marx para pensar o capitalismo, Paper, Rio de Janeiro, ANPEC, 2012)

166 "When the Progressives began to write, good land was still abundant. Monopoly profits were being earned, not from land, but from railroads, oil, and other forms of industrial development. As a result, America's Progressive Era economists, concerned about the effects of monopoly on wages and productivity, focuses their attention not on rents in land, but rather on industrial monopolies and trusts. For American Progressives, technology, rather than land, was the chief producer of rents and the attendant evils of subsistence wages and maldistribution of wealth. For example, Richard T. Ely, the most prominent Progressive economist, discussed rents at lenght in his book on property and contract. But he believed that the principal rent-producing engine was not land. Rather, it was large concentrations of capital. Ely identified railroads and telegraph companies as the types of property interests which were causing maldistribution of wealth in the United States. He did not so identify agricultural land. Most Progressives shared Ely's view. In fact, in the literature of both the Granger Movement and the Progressive Era, the farmer was the victim, rather than the cause, of monopoly. Neither farmers nor the owners of agricultural land were ever depicted in American political economy as the rent-stealing monsters that they were in Ricardo's England" (HovENKAMP, Hebert, "Political Economy of Substantive Due Process"). É interessante observar que, mesmo quando as críticas ao laissez-faire passam a fazer parte do cenário do debate americano ao final do Século XIX, elas são incorporadas com a consideração das diferenças entre os cenários dos dois países. Enquanto a preocupação quanto aos monopólios era associada aos proprietários de terras na Inglaterra (RICARDO) - pois, diferentemente do capital e da tecnologia, as terras não poderiam ser "duplicadas" - a percepção do problema era totalmente diferente por parte dos americanos, que o identificaram com o capital e a tecnologia. Nos Estados Unidos, os proprietários de terras eram as grandes vítimas da concentração 
Outra razão para as cortes terem se mantido fiéis ao discurso econômico do laissez-faire se deve à moral protestante dos juízes - que se identificavam, em geral, com os setores mais conservadores da sociedade. Essa moral se coadunava com o mesmo tipo de filosofia moral presente em ADAM SMITH: o realismo escocês ${ }^{168}$.

A teoria moral de SMITH incluía: (1) o conceito Lockeano de que cada pessoa tem um direito natural ao seu próprio trabalho - um direito que não pode ser removido pelo Estado; e (2) a noção Lockeana de que o valor seria uma função do trabalho alocado em algo, mais do que a sua demanda ou a utilidade marginal que produz. Logo, uma vez que cada pessoa tem um direito natural ao seu próprio trabalho, haveria também um direito natural à sua propriedade.

SMITH também aderira à teoria do preço natural, e acreditava que o direito natural da propriedade incluiria um direito ao seu preço (ele rejeitara a doutrina presente em HoBBES, de que o preço é justo apenas porque produto de barganha voluntária).

Ao mesmo tempo, SMITH acreditava que o mercado quase sempre produziria o preço natural. O resultado é que, para SMITH, a determinação individual do preço era um direito inerente ao proprietário, o que encontrava fundamento em justificativas econômicas e morais.

\subsubsection{Não APLICAÇÃo do SHERMAN ACT EM CASOS ENVOLVENDO A PI}

Como já dito, os primeiros casos envolvendo a Propriedade Intelectual e o Direito Antitruste versaram sobre a tentativa dos detentores de patentes de condicionar o seu licenciamento à fixação de determinado preço de venda, ou à tentativa de condicionar o licenciamento à exclusividade no fornecimento de certos bens.

De forma consistente com a doutrina do Substantive Due Process, a Suprema Corte americana tendeu a conferir total e irrestrita proteção ao direito de propriedade, bem como à liberdade contratual (direito de livremente fixar preços).

\footnotetext{
econômica, ao passo que os industriais (capitalistas) eram os grandes "vilões" (vide, por exemplo, a questão do conflito entre proprietários de terra e os trusts do setor ferroviário).

167 "Just as the revolutions in theory ocurred much earlier in Britain than in America, so too did the legislative response. Parliament passed the English Factory Acts in the 1830 and 1840, while widespread legislative regulation of wages and working conditions did not develop 1880s and after. Britain faced a restive labor force beginning in the 1830s; American capitalists faced the same threat beginning in the 1880s and 1890s. Most significantly, Britain reached the limits of its agricultural productivity and faced the prospect of imports and the tilling of inferior land early in the nineteenth century. America contained a great abundance of tillable land throughout the nineteenth century and does so even to the present". (HovenKAMP, Herbert J. "Political Economy of Substantive Due Process", op. cit.).

${ }^{168}$ Não confundir com o realismo jurídico norte-americano.
} 
Nesse sentido, Joshua NEWBERG e WiLlard K. TOM ${ }^{169}$ :

"In the first twenty years after the enactment of the Sherman Act in 1890, antitrust was no match for intellectual property in the perceived "conflict" between the two bodies of law. When faced with competition law challenges to the exercise of intellectual property rights, courts tended to resolve disputes by deferring to the prerrogatives of the intellectual property holder. This deference was substantially based on an understanding that intellectual property rights constitute "private property" with regard to which the owner is entitled to nearly unfettered discretion. The intellectual property owner's discretion extended, for the most part, to licensing restraints, which, when infrequently challenged, typically fell within the expansive protections of the late nineteenth and early twentieth century doctrine of "freedom of contract $^{170 ",}$.

Essas ideias podem ser encontradas no julgamento do caso Bement v. National Harrow Co. pela Suprema Corte americana (1902).

Neste caso, uma proprietária de patentes (National Harrow Co.) havia entrado em litígio com várias outras empresas, sob alegação de violação de direitos sobre os itens que compunham um determinado produto (um tipo de suporte flutuante de jardim). Tais litígios terminaram em acordos e os fabricantes licenciados acabaram por ceder todas as suas patentes à National Harrow, em troca de ações da empresa e de uma licença para produzir, usar e vender os produtos protegidos pelas patentes. $\mathrm{O}$ pool cresceu rapidamente, chegando a vinte e duas empresas, alcançando noventa por cento de todas as vendas do mercado em questão.

Duas condições em tais contratos despertam particular atenção: (1) os fabricantes licenciados eram obrigados a aderir a um preço uniforme para venda dos produtos fabricados; e (2) os fabricantes eram obrigados a utilizar somente tecnologia fornecida pelo pool. Quando a National Harrow processou Bement - um dos membros do pool - por vender abaixo dos preços avençados, em violação à licença, o réu alegou, em sua defesa, que o contrato era ilícito por violação ao Sherman $A c t^{171}$.

\footnotetext{
${ }^{169}$ NewBerg, Joshua A. e TOM, Willard K "Antitrust and Intellectual Property - From Separate Spheres to One Unified Field”, in “Antitrust Law Journal, n 66”, 1997, pg. 169.

${ }^{170}$ Aqui, algumas observações se fazem necessárias quanto à menção, feita pelos autores, no sentido de que a Propriedade Intelectual, nesse período, era considerada como análoga à propriedade privada (leiase:propriedade "tangível"). Primeiramente, confirma-se o que já havíamos afirmado antes, ou seja: o recurso à analogia da propriedade privada serviu para que se conferisse primazia desse direito sobre a concorrência.a despeito da tradição anglo-americana de interpretá-la como um monopólio. É de se notar que, mesmo quando a Suprema Corte fazia menção à expressão "monopólio", o recurso retórico à analogia da propriedade continuava a ser empregado. Por vezes, se fazia menção ao monopólio como "objeto de direito" - ou seja, tratava-se de "propriedade sobre um monopólio".

${ }^{171}$ NeWBERG, Joshua A. e ToM, Willard K "Antitrust and Intellectual Property - From Separate Spheres to One Unified Field”, in “Antitrust Law Journal, n 66”, 1997, pg. 169.
} 
A Suprema Corte, ao analisar o argumento, foi clara ao firmar que as patentes eram de propriedade do autor e que, portanto, haveria pleno direito de pré-fixar os preços como condição para o licenciamento. O principal fundamento era que as patentes confeririam um monopólio (nas palavras da Corte, o autor seria o proprietário de um monopólio - owner of a monopoly):

"This brings us to a consideration of the terms of the license contracts, for the purpose of determining whether they violate the act of Congress. The first important and most material fact in considering this question is that the agreements concern articles protected by letters patent of the government of the United States. The plaintiff, according to the finding of the referee, was at the time when these licenses were executed the absolute owner of the letters patent relating to the float spring tooth harrow business. It was therefore the owner of a monopoly recognized by the Constitution and by the statutes of Congress. An owner of a patent has the right to sell it or to keep it; to manufacture the article himself or to license others to manufacture it; to sell such article himself or to authorize others to sell it ${ }^{\prime 172}$.

De forma coerente com a doutrina do Substantive due Process, a liberdade de contratar e de firmar preços foi afirmada de forma quase absoluta - inclusive, a despeito de os contratos servirem para manter um monopólio, ou fixar preços:

"These cases are cited in the opinion of the court in the case of Heaton-Peninsular ButtonFastener Co. v. Eureka Specialty Company, supra. Notwithstanding these exceptions, the general rule is absolute freedom in the use or sale of rights under the patent laws of the United States. The very object of these laws is monopoly, and the rule is, with few exceptions, that any conditions which are not in their very nature illegal with regard to this kind of property, imposed by the patentee and agreed to by the licensee for the right to manufacture or use or sell the article will be upheld by the courts. The fact that the conditions in the contracts keep up the monopoly or fix prices does not render them illegal.(...)”.

Importante observar que a Suprema Corte reconheceu que os contratos em questão importariam em restrição ao comércio e que os precedentes estabeleciam, à época, que qualquer restrição - razoável ou não - implicaria em ofensa ao Sherman Act $^{173}$.

Porém, no caso, a violação ao Sherman Act foi afastada, sob fundamento de que prevenir este tipo de restrição ao comércio, imposta por patentes concedidas pelo governo, não teria sido o intento dos legisladores do Sherman Act:

\footnotetext{
${ }^{172}$ A Suprema Corte ponderou sobre alguns precedentes, em que o monopólio de patentes havia sido relevado em razão de motivos de política pública - todas essas exceções, no entanto, se referiam a casos em que a produção do bem patenteado era proibida pelas leis estaduais, dentro de sua competência de legislar sobre assuntos de interesse local (por questões de segurança, por exemplo)

${ }^{173}$ À época, a Suprema Corte não havia firmado a "Rule of Reason", o que somente aconteceria em 1911, em Standard Oil Co. of N.J. v. United States, 221 U.S. 1 (1911).
} 
"The contention that they do not affect interstate commerce is not correct. We think the licenses do, by their terms and by their plain meaning, refer to, include, and provide for interstate as well as other commerce. The contract called Exhibit B provides for the manufacture at Lansing, Michigan, and for the sale of the articles there made in territory lying south and west of Virginia and West Virginia and Pennsylvania, and the referee finds that a number of harrows have been sold under that contract. The contracts plainly look to the sale, and they also determine the price of the article sold, throughout the United States, as sell as to the manufacture in the State of Michigan. As these contracts do therefore include interstate commerce within their provisions, we are brought back to the question whether the agreement between these parties with relation to these patented articles is valid within the act of Congress. It is true that it has been held by this Court that the act included any restraint of commerce, whether reasonable or unreasonable.(...) But that statute clearly does not refer to that kind of a restraint of interstate commerce which may arise from reasonable and legal conditions imposed upon the assignee or licensee of a patent by the owner thereof, restricting the terms upon which the article may be used and the price to be demanded thereof. Such a construction of the act, we have no doubt, was never contemplated by its framers".

Entendimento semelhante predominou na jurisprudência americana nas duas primeiras décadas de vigência do Sherman $A c t^{174}$.

A atitude dos juízes em relação ao Substantive due Process mudou mais tarde, na época em que as doutrinas econômicas hegemônicas também haviam se alterado, nos anos 1920 e $1930^{175}$.

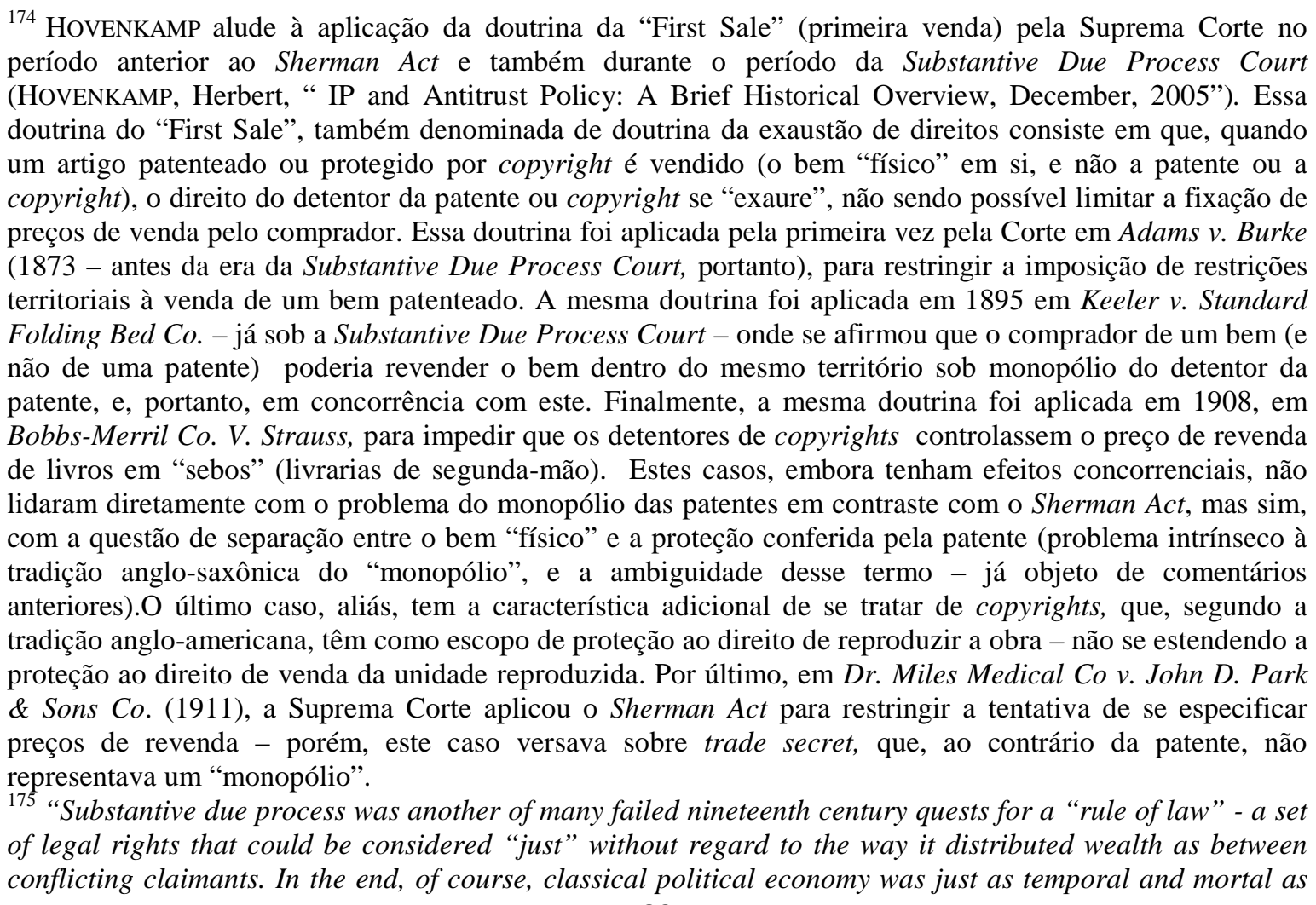


O que é realmente importante sublinhar é o fato de a Constituição americana ter incorporado, na Décima Quarta emenda, uma ordem econômica não intervencionista (i.e., a ordem econômica do laissez-faire). Tal fato conduziu a que, sempre que se decidia tratar os direitos intelectuais como propriedade, havia uma tendência maior a se conferir primazia a tal direito individual sobre o Antitruste, quando ambos estavam em conflito. Mesmo porque, como já dito, o Antitruste americano é descolado de princípios constitucionais bem definidos.

Mais do que isso: nem mesmo a própria livre concorrência está prevista expressamente na Constituição americana, como princípio a suportar a legislação antitruste $^{176}$.

É de se sublinhar: a doutrina econômica subjacente à Constituição americana era de que a preservação da liberdade contratual e direitos de propriedade bem definidos conduziria à livre concorrência.

A consequência prática é que o papel da livre concorrência sempre acabou sendo influenciado pela política - seja por meio do ativismo legislativo, seja por meio do ativismo judicial. A seu turno, ambas as espécies de ativismo foram influenciadas pelas teorias econômicas que foram prevalecendo no curso do Século XX.

Isso, como antecipamos, é fundamental para entender as várias fases da interface entre Propriedade Intelectual e Antitruste nos Estados Unidos.

substantive due process itself. Judicial attitudes toward substantive due process changed when the prevailing economic doctrine changed, in the 1920s and 1930s". (HOVENKAMP, Herbet "Political Economy of Substantive due Process")

${ }^{176}$ De fato, somente em 1904 - mais de duas décadas após a edição do Sherman Act - é que a Suprema Corte reconheceu o princípio de que a livre concorrência era o mecanismo mais desejável de alocação de recursos, e que essa ideia teria sido implicitamente reconhecida pelo Congresso, ao aprovar o Sherman Act. GIOCOLI ressalta que, neste julgamento, a Suprema Corte foi influenciada pela evolução da teoria econômica nas duas décadas seguintes ao Sherman Act: "It was up to the Supreme Court to define more precisely the boundaries of the Sherman Act. In Northern Securities (1904), the Court formulated what Martin (2007a, 13-14) has called "the principle of competition", namely, the idea that with the Sherman Act the Congress had acknowledged that free competition was the most desirable mechanism for resource allocation in society. The principle's immediate implication is that anything directly interfering with the free working of competitive markets must be considered a restraint of trade and thereby be declared per se illegal. As the canonical narrative goes, the Court's view mirrored the big progress achieved by theoretical economics during the two decades after the Act's approval. In short, those economists who in 1890 were unready to contribute to the legislative process because of their lack of a sound theory of competition and allocative efficiency, did have such a theory in the early years of the new century and could therefore influence the Supreme Court's views". (GIOCOLI, Nicola, "Competition vs. Property Rights: American Antitrust law, the Freiburg School and the early years of European competition policy, 2008, Online at http://mpra.ub.unimuenchen.de/33807/) 


\subsubsection{A SeÇão 3 do Clayton ACt e OS Casos envolvendo Tying ARRANGEMENTS}

No período da Substantive Due Process Court, a Suprema Corte americana fora fortemente marcada por uma doutrina econômica baseada no já à época ultrapassado laissez-faire, típico do classicismo inglês - o que foi, então, objeto de fortes críticas por parte dos economistas americanos, que já haviam superado essa teoria ${ }^{177}$.

Já no início do Século XX, economistas como JOHN BATES ClARK haviam concluído que a potencial concorrência não era suficiente para frear o comportamento monopolista, sendo indispensável a ação estatal para tanto. Mais tarde, essas ideias influenciariam, diretamente, a aprovação, em 1914, do Federal Trade Comission Act e do Clayton Act, que definia algumas condutas como anticompetitivas - tais como, por exemplo, discriminação de preços, tying arrangements e contratos de exclusividade, entre outras $^{178}$.

Os casos envolvendo tying arrangements foram um dos maiores palcos da discussão envolvendo Propriedade Intelectual e política concorrencial nos Estados Unidos. De um lado, a alegação dos detentores de patentes era de que sua liberdade econômica de capitalizar sobre as invenções deveria ser protegida ao máximo - o que incluiria conjugar outros bens não protegidos pelas patentes. De outro, estava a preocupação de que tal

\footnotetext{
177 "In 1912, when Harvard economist A.N. HOLLCOMBE criticized the judicial record in wage-and-hour cases, he placed blame on "the manning of our courts with a set of judges whose economic training was received mainly from the so-called classical school of political economists". (...) "the effect of such judicial interpretation has been to read into the constitution a doctrine that is nowhere expressed therein, namely, the doctrine of freedom of contract". (HovENKAMP, Herbet "Political Economy of Substantive due Process", op. cit.)

178 "A crucial role was played once more by John Bates Clark who, in a famous 1911 testimony in Congress and then in the second edition of The Control of Trusts (1912; written in collaboration with his son, John Maurice), partially reneged his early views and concluded that, since potential competition could no longer be trusted as an effective check to monopoly behavior, it was up to the lawmaker to actively promote actual competition. This should be done by preventing big firms from interfering with their rivals' ability to compete, i.e., by either prohibiting or regulating all forms of anti-competitive behavior. Clark also added that, whenever no such interference existed, it should be left to the free play of market forces to determine success and failure in the marketplace. The standard narrative highlights the economists' influence in the process leading to the 1914 approval of the Clayton and FTC Acts. Indeed, Clark's suggestion that some business behaviors be listed as illegal was accepted: the Clayton Act contains an explicit prohibition of price discrimination (\$2), tying, exclusive dealing and requirement contracts (\$3), and merges carried out by financial manipulations (so-called covert mergers: \$7).13 Even more remarkably, with the Clayton Act Congress embraced a more specific notion of competition and antitrust - specifically, a conduct-based notion. The goal of antitrust became defending competitive behavior by either limiting or prohibiting all kinds of anti-competitive conduct". (GIOCOLI, Nicola "Competition vs. Property Rights: American Antitrust law, the Freiburg School and the early years of European competition policy, 2008, Online at http://mpra.ub.uni-muenchen.de/33807/")
} 
conjugação implicaria uma indevida extensão do monopólio de patentes para além dos limites legais ${ }^{179}$.

A tendência inicial da Suprema Corte foi validar tais tentativas de estender a proteção conferida pelas patentes a outros bens, por meio do direito contratual. Um caso emblemático foi Henry v. A.B. Dick (1912). Neste caso, a Suprema Corte enfrentou a tentativa de A.B. Dick - proprietária de várias patentes sobre uma máquina de mimeógrafo para escritórios - de condicionar o seu licenciamento ao uso exclusivo de papel, tinta e outros itens produzidos pela empresa. A Suprema Corte entendeu que havia uma violação indireta às patentes (contributory infringement) por parte do réu (Henry), que havia vendido alguns dos itens com prévio conhecimento de que eles seriam utilizados por um comprador em violação à restrição contida na licença ${ }^{180}$.

O fundamento da decisão foi de que o Sherman Act não se aplicaria, uma vez que a restrição contida na licença não era proibida pelo Patent Act. Por outro lado: "arguments based on suggestions of public policy not recognized in the patent Law are not relevant".

O Congresso americano não ficou satisfeito com essa decisão e, dois anos depois, a seção 3 do Clayton Act - que enumera e proíbe uma série de tipos de acordos - foi $\operatorname{aprovada}^{181}$.

Em 1917, a Suprema Corte revisou o entendimento firmado em Henry, ao julgar o caso Motion Picture Patents Co. (MPPC), que versava sobre uma tecnologia desenvolvida por Thomas Edison, que detinha patentes sobre rodas dentadas e filme perfurado. Tais itens melhoravam, consideravelmente, o desempenho da projeção de filmes.

Os detentores dos direitos sobre essa tecnologia haviam logrado controlar toda a indústria cinematográfica, por meio de recusa à venda de câmeras patenteadas. Quando câmeras concorrentes começaram a surgir no mercado, os proprietários das patentes ingressaram com diversas ações, as quais resultariam em um acordo e na criação da Motion Picture Patentes Company em 1909.

\footnotetext{
${ }^{179}$ HovenKAMP, Herbert "IP and Antitrust Policy: A Brief Historical Overview", in U Iowa Legal Studies, Research Paper No 05-31, December, 2005

${ }^{180}$ A violação seria “indireta" porque não havia violação às patentes em si. A alegação de violação estava no uso de itens vinculados, contratualmente, às patentes, mas que não eram itens protegidos.

181 “Clayton Act, $\$ 3^{\circ}$ : “'tying' and 'exclusive dealing', two vertical practices by which a supplier limits the range of products that its dealers can sell, although tying law has been expanded into other contexts as well". (HovenKAMP, Herbert, "The Antitrust Enterprise: Principle and Execution -Cambridge, Massachusetts; Harvard University Press, 2008, pg. 20-22)
} 
Esta empresa, então, obteve um contrato de fornecimento exclusivo de filmes com a Kodak e também incluiu nas licenças de seus projetores a restrição de que somente seus próprios filmes poderiam ser rodados em suas máquinas.

Finalmente, a MPCC organizou a General Film Company, que adquiriu toda a rede de distribuição, então formada por pequenas empresas que compravam os filmes de seus produtores e, então, os licenciavam para as salas de projeção.

A General Film Company recusava-se a licenciar filmes para as salas de projeção que se utilizavam de equipamento produzido por outras empresas, ou que exibiam filmes de outros produtores. A MPPC também vetava atores e atrizes que haviam trabalhado para outras empresas. A estrutura era vertical e também horizontal, porque a própria MPPC era um consórcio de empresas que, de outro modo, estariam concorrendo entre si.

A Suprema Corte decidiu que, uma vez que os filmes não eram parte do direito assegurado pela patente sobre a máquina, não haveria possibilidade jurídica de se alegar que o licenciado violara a restrição. A Corte viu os detentores da patente como "de fato, estendendo o escopo de seu monopólio, ao restringir o uso dos materiais necessários nesta operação, os quais, no entanto, não eram parte da invenção patenteada”.

Essa decisão - note-se - foi totalmente baseada na Lei de Patentes, e não no $§ 3^{\circ}$ do Clayton Act.

Muito embora a Suprema Corte tenha, neste caso, modificado o entendimento anteriormente firmado em Henry, a relutância em se aplicar o antitruste era, ainda, muito grande - e isso, mesmo após a alteração introduzida no Clayton Act (Seção 3).

A decisão da Suprema Corte em Motion Pictures se baseou nos limites do monopólio de patentes, não no antitruste - e isso, mesmo quando o histórico legislativo da Seção 3 havia visado, expressamente, às atividades da General Film Company.

Esse entendimento originado no caso MPPC deu origem àquilo que, mais tarde, se tornaria a doutrina do patent misuse - que considera ilegal qualquer tentativa de tying arrangements - a despeito de quaisquer considerações sobre poder de mercado.

\subsubsection{A DOUTRINA do Patent Misuse}

As duas décadas que se seguiram à criação da Federal Trade Comission (FCT) são reconhecidas como um período em que se negligenciou a aplicação do antitruste. 
Nessa época, que coincide com o período que se seguiu à Primeira Guerra Mundial, os economistas americanos tenderam a apoiar uma visão mais paternalista do Estado para com os grandes negócios, nos moldes do que - à época - se praticava na Alemanha. Essa tendência se refletiu, novamente, em uma visão negativa da concorrência e em uma aplicação laxa do antitruste ${ }^{182}$.

Porém, em 1935, há uma nova guinada, em meio ao então governo RoOSEVELT, em direção a uma aplicação mais rigorosa do antitruste. Essa mudança também se deveu a uma mudança de paradigma entre os economistas americanos, que tornaram a enxergar a preservação da livre concorrência como chave para a prosperidade econômica ${ }^{183}$. Esse movimento foi fortemente influenciado pela ESCOLA DE HARVARD, e a teoria baseada no trinômio Estrutura-Conduta-Performance então em voga ${ }^{184}$.

A Suprema Corte, então aparelhada por Roosevelt, passa a proceder a uma completa e sistemática revisão da jurisprudência do período da Substantive Due Process Court $^{185}$.

\footnotetext{
${ }^{182}$ Giocoli, Nicola "Competition vs. Property Rights: American Antitrust law, the Freiburg School and the early years of European competition policy, 2008, Online at http://mpra.ub.uni-muenchen.de/33807/"

183 "In 1935, the Supreme Court canceled the NIRA. This event marked a dramatic shift in Roosevelt administration's approach to economic matters (so-called Second New Deal). The new agenda included the rehabilitation of competition as the key for economic prosperity, as testified by the 1938 appointment of Thurman Arnold as head of the Department of Justice antitrust division with a clear mandate to pursue an aggressive antitrust policy (Mayhew 1998, 197). The swing was capped by the Supreme Court's effective revitalization of the Sherman Act via the introduction of new per se prohibitions in rulings such as Interstate Circuit (1939) and Socony Vacuum (1940). In short, starting from the mid-1930s a favorable combination of events led to the resurgence of antitrust in the US, thereby opening an era of aggressive contrast gainst monopolization and restraints of trade that was to last until the 1970s". (GIOCOLI, Nicola "Competition vs. Property Rights: American Antitrust law, the Freiburg School and the early years of European competition policy, 2008, Online at http://mpra.ub.uni-muenchen.de/33807/')

184 "Once again, it is easy to remark that the 1930s were the very same years when new models of imperfect and monopolistic competition were proposed and, above all, the new structure-conduct performance (SCP) approach was developed in Edward Mason's Harvard seminar. As is well known, the SCP approach - which predicted anticompetitive outcomes as an inevitable consequence of non-perfectly competitive market structures - was to dominate industrial economics from the late 1930s to the early 1970s" (GIOCOLI, Nicola "Competition vs. Property Rights: American Antitrust law, the Freiburg School and the early years of European competition policy, 2008, Online at http://mpra.ub.uni-muenchen.de/33807/")

${ }^{185}$ Neste período, por exemplo, a Suprema Corte julgou constitucional o Fair Labor Standards Act, que compreendia uma parte importante da política do New Deal (salário mínimo e cargas máximas de trabalho em todas as indústrias que produzissem bens destinados ao comércio interestadual, por exemplo). Neste caso (Darby Lumber Co.v. United States, 1941), a Suprema Corte reverteu, expressamente, várias decisões do período da Substantive due Process Court - notadamente, o caso Hammer v. Dagenhard (1918). Outra decisão que serve para demonstrar a clara mudança de orientação da Suprema Corte rumo a um maior intervencionismo - próprio da política progressista do New Deal - e, consequentemente, a uma interpretação mais restrita das liberdades individuais foi a decisão da Suprema Corte quanto ao direito fundamental de não depor contra si próprio (Quinta Emenda). A Suprema Corte restringiu a aplicação deste princípio em United States v. White (1944), estendendo-o somente para indivíduos, e não para organizações. No sentido de crítica à reinterpretação de liberdades em razão da nova ordem constitucional do New Deal, ver POPE, James Gray, "The Thirteenth Amendment Versus the Commerce Clause: Labor and the Shaping of American Constitutional Order, 1921-1950.
} 
Foi exatamente neste período (em Motion Salt Co vs. G.S. Suppiger Co., 1942) que a Suprema Corte, pela primeira vez, afastou uma ação de violação direta de patentes, sob fundamento de Patent Misuse ${ }^{186}$.

No caso, o autor (Morton Salt Co.) alegou violação de uma patente de uma máquina de depósito de sal que havia sido licenciada para o réu (G.S. Suppinger). A licença conferida pela Morton exigia que os licenciados utilizassem apenas tabletes de sal produzidos pela empresa. A Morton, portanto, estava se valendo da patente para restringir a concorrência no mercado de um item que não estava dentro do escopo do privilégio da patente. A Suprema Corte, todavia, afastou a alegação de violação por entender que o autor estava usando a patente de forma contrária ao interesse público.

A peculiaridade deste caso em relação ao caso MPPC é que, no caso Morton Salt Co., o réu havia, de fato, fabricado uma máquina que violava frontalmente à patente do autor.

Porém, ao constatar que o autor estava se valendo de uma conduta tida por ilícita per se (tying arrangement), a Suprema Corte afastou, automaticamente, a alegação de violação, por argumentos de política pública ${ }^{187}$. Essa doutrina ficou conhecida como unclean hands ("mãos impuras"), ou seja, o detentor da patente não poderia invocar a proteção quando o seu próprio comportamento era ilícito.

É importante observar que, embora não tenha fundamentado a sua decisão no antitruste, a principal motivação da Suprema Corte foi, expressamente, a concorrência no mercado secundário de sal - e isso, a despeito da existência de qualquer elemento a demonstrar que a conduta do autor havia, de fato, importado em prejuízo ao réu no caso concreto $^{188}$.

\footnotetext{
${ }^{186}$ A despeito de certo dissenso entre os estudiosos sobre o surgimento da doutrina do patent misuse, é fato que ela não veio a ser aplicada pela Suprema Corte para afastar a alegação de violação direta aos direitos de patentes antes da década de 1940. Todos os casos em que a doutrina fora utilizada antes disso - como, por exemplo, o caso Motion Pictures - eram casos de violação indireta de patentes (contributory infringement).

187 "The grant to the inventor of the special privilege of a patent monopoly carries out a public policy adopted by the Constitution and laws of the United States, "to promote the Progress of Science and useful Arts, by securing for limited Times to ... Inventors the exclusive Right ... " to their new and useful" inventions. United States Constitution, Art.I, $\S 8$, cl. 8, 35 U.S.C. $\$ 31$. But the public policy which includes inventions within the granted monopoly excludes from it all that is not embraced in the invention. It equally forbids the use of the patent to secure an exclusive right or limited monopoly not granted by the Patent Office and which it is contrary to public policy to grant. (...)".

188 "Nothing turns on the fact that petitioner also competes with respondent in the sale of tablets. (...) It is the adverse effect upon the public interest of a successful infringement suit in conjunction with the patentee's course of conduct which disqualifies him to maintain the suit, regardless of whether the particular [infringer] has suffered from the misuse of the patent".
} 
Nesse precedente, vemos que a Suprema Corte reconheceu um interesse público implícito na patent clause na Constituição americana (art. $8^{\circ}$ ). Segundo esta interpretação, tudo que não estivesse abrangido pela invenção estaria automaticamente excluído do monopólio de patentes. A aplicação da doutrina do patent misuse excluiu a aplicação direta do antitruste neste primeiro momento ${ }^{189}$.

\subsubsection{Aplicação do Antitruste - Presunção de Poder de Mercado e os Nine-} NoS

Na década de 1940, a Suprema Corte começou a aplicar o antitruste diretamente em casos envolvendo tying arrangements, embora a doutrina do patent misuse tenha continuado a desempenhar um papel importante ${ }^{190}$.

No caso Mercoid II (1943), a Suprema Corte afirmou que a tentativa de controlar a concorrência sobre bens não patenteados violaria o antitruste: "The legality of any attempt to bring unpattented goods within the protection of the patent is measured by the antitrust laws not by the patent law ... [T] he effort here made to control competition in this unpatented device plainly violates the antitrust laws (...)”.

A despeito da aplicação direta do antitruste, não houve nenhuma discussão de poder de Mercado ou sobre autonomia dos produtos - dois elementos que se tornariam essenciais na análise moderna de tying agreements.

A partir de 1947, com a decisão em International Salt, a Suprema Corte passou a declarar tying agreements como ilícitos de per se à luz do antitruste, sempre que (i) houvesse efetivo poder de restringir a venda no mercado secundário; e que (ii) as vendas do produto conjugado fossem significativas. Mais: presumia-se o poder de restrição nos casos em que o produto principal era patenteado. Essa presunção foi objeto de duras críticas e até mesmo ridicularizada ${ }^{191}$.

A despeito de tal aplicação agressiva do antitruste, a doutrina do misuse continuou a ser aplicada, como forma de tornar a repressão aos patent ties ainda mais ampla.

\footnotetext{
${ }^{189}$ HovenKAMP, Herbert, "IP and Antitrust Policy: A Brief Historical Overview", in U Iowa Legal Studies, Research Paper No 05-31, December, 2005

${ }^{190}$ HovenKAMP, Herbert, "IP and Antitrust Policy: A Brief Historical Overview", in U Iowa Legal Studies, Research Paper No 05-31, December, 2005

${ }^{191}$ HovenKAMP, Herbert, "IP and Antitrust Policy: A Brief Historical Overview", in U Iowa Legal Studies, Research Paper Nº5-31, December, 2005
} 
Sempre que se lograsse demonstrar que o detentor da patente havia tentado estender a proteção para alcançar bens não patenteados se estaria no campo do misuse. $\mathrm{O}$ argumento era apresentado como um argumento de defesa possível contra uma alegação de violação de patentes. Se, além disso, ficasse confirmado que teria havido restrição no mercado secundário de produto cujas vendas fossem significativas, aplicava-se o antitruste, cuja consequência prática era uma indenização por perdas e danos.

Como, em se tratando de tying arrangements envolvendo patentes, o poder de mercado era presumido, a disciplina se mostrava bastante rígida e agressiva. Em 1952, o Congresso revisou o Patent Act, a fim de tornar mais restrita a doutrina do patent misuse. Esse período marcou um breve momento de fortalecimento da Propriedade Intelectual.

As décadas de 1960 e 1970, no entanto, marcam um período de aplicação agressiva do antitruste em face dos direitos de propriedade intelectual. A Suprema Corte estava em meio à chamada Era de Warren (1953-1969) ${ }^{192}$, marcada por um forte ativismo judicial. Nesse período, a Suprema Corte, influenciada pela ideologia do New Deal, estava mais inclinada a ver as patentes como inerentemente anticompetitivas e a interpretar as leis de antitruste de forma expansiva.

Além disso, a Antitrust Division of the Department of Justice editou uma lista de nove práticas consideradas ilegais de per se, a despeito de quaisquer considerações sobre seus reais efeitos competitivos, nem tampouco quanto a outras possíveis justificativas ${ }^{193}$.

Mais tarde, em 1988 - já sob a influência da Escola de Chicago, então dominante a doutrina do Patent Misuse seria reformada novamente (Patent Misuse Reform Act), para

\footnotetext{
192“WARREN joined the Court in 1954 all the justices had been appointed by FRANKLIN D. ROOSEVELT or TRUMAN, and all were committed New Deal liberals. They disagreed about the role that the courts should play in achieving liberal goals. The Court was split between two warring factions. FELIX FRANKFURTER and ROBERT H. JACKSON led one faction, which insisted upon judicial self-restraint and insisted courts should defer to the policymaking prerogatives of the White House and Congress. HUGO BLACK and WILLIAM O. DOUGLAS led the opposing faction that agreed the court should defer to Congress in matters of economic policy, but felt the judicial agenda had been transformed from questions of property rights to those of individual liberties, and in this area courts should play a more central role. WARREN'S belief that the judiciary must seek to do justice, placed him with the latter group, although he did not have a solid majority until after Frankfurter's retirement in 1962" (BELKNAP, Michael R. The Supreme Court under Earl Warren, 1953-1969, University of South Carolina Press, April, 2005, pgs. 13-14)

193 “1) Royalties not reasonably related to sales of the patented product; 2) restraints on licensee's commerce outside de scope of the patent (tie-outs); 3) requiring the licensee to purchase unpatented materials from the licensor (tie-ins); 4) Mandatory package licensing; 5) Requiring the license to assign to the patentee patents that may be issued to the licensee after the licensing arrangement is executed (exclusive grantbacks); 6) Licensee veto power over grant of further licenses; 7) Restraints on sales of patented products made with patented process; 8) Post-sale restraints on resale; and 9) Setting minimum prices on resale of the patented products.
} 
efeito de praticamente unificar as doutrinas do patent misuse e do antitruste, ao se estabelecer que não haveria misuse sem comprovação de poder no mercado relevante ${ }^{194}$.

\subsection{DESENVOLVIMENTO DO TEMA NA EUROPA}

FRIEDRICH-KARL BeIER, então diretor do MAX Planck Institute for Foreign and International Patent, Copyright and Competition Law, escrevendo em 1980, apontou o movimento antitruste - tanto nos Estados Unidos como na Europa - como um dos principais focos de criticismo quanto ao sistema de patentes ${ }^{195}$.

Em seu texto, o autor destaca que, especialmente na Europa, as patentes foram vistas, a princípio, como um instrumento de regulação e divisão de mercados ${ }^{196}$ - ideia que, efetivamente, desempenhou um papel central no âmbito do Mercado Comum Europeu.

A retórica da livre circulação de bens foi, de fato, determinante para a prática da Comissão Europeia e, em certo grau, também para as decisões da Corte Europeia de Justiça.

Tais ideias possuem implicações bem claras quando se trata da relação entre Direito Concorrencial e Patentes. Como veremos mais adiante, em suas primeiras decisões, a Corte Europeia de Justiça tendeu a privilegiar a concorrência quando em conflito com a Propriedade Intelectual - especialmente, nos casos em que a PI era utilizada em estruturas verticais que restringiam a livre circulação de bens no mercado comum europeu.

\footnotetext{
194 "Bastante conhecida é a doutrina do patent misuse norte-americana que levou a doutrina e as cortes daquele país a concluírem, após muita controvérsia, que só se deve considerar configurado o mau uso da patente quando as regras do direito antitruste assim o indicarem. Por via dessa teoria, afirmou-se, em muitos casos julgados pelas cortes, a ilegalidade de práticas de venda casada que envolviam um produto patenteado. Foi utilizada, para isso, basicamente a noção e os requisitos da venda casada desenvolvidos em sede de aplicação do direito antitruste”. (CALIXTO SAlOMÃo FILHO, Direito Industrial, Direito concorrencial e Interesse Público - Revista de Direito Público da Economia, Belo Horizonte, ano 2, n. 7, 2.004, p. 29 e ss.)

195 BEIER, Friedrich-Karl, "The Significance of the Patent System for Technical, Economic and Social Progress" (http://beck-online.beck.de)

${ }^{196}$ Essas ideias estavam presentes em autores vinculados à Escola de Freiburg de Direito e Economia, tais como EUCKEN. "Grundsätze der Wirtschaftspolitik" 268, 269 (3rd ed., Tübingen, Zurich, 1960); id., "Die Wettbewerbsordnung und ihre Verwirklichung," 1949 Ordo II 40, 49; ROPKE, "Die Gesellschaftskrise der Gegenwart” 369 (5th ed” Erlenbach, Zürich, 1948); GATHER, "Reform der Patentgesetzgebung." 1949 Ordo II 270 et seq.; BÖHM, "Wettbewerb und Monopolkampf” n.1, at 63 (Cologne. Berlin. 1933) e GÜNTHER, “Das Gesetz gegen Wettbewerbsbeschränkungen,” Grur 1958575 .at 580 (patent protection does not correspond to the model of free competition); KRONSTEIN, "Das Recht der internationalen Kartelle" 172 et seq. (Berlin, 1967); BuXBAUM, "Restrictions Inherent in the Patent Monopoly: A Comparative Critique," 113 U.Pa.L.Rev. 633 (1965). Segundo KARL-FRIEDRICH BEIER: "The views of these authors are characterized, on the one hand, by the theory of competition from which they proceed, and their orientation to the model of "perfect competition" and. on the other hand, by their special emphasis on the use of patents for obtaining monopoly positions and for controlling of international markets". (BEIER, "The Significance of the Patent System for Technical, Economic and Social Progress", disponível em http://beck-online.beck.de)
} 
Para que se possa bem contextualizar tais pronunciamentos da Corte Europeia de Justiça é fundamental o contato com as ideias ordoliberais da Escola de Freiburg - as quais, por sinal, moldaram todo o Direito Concorrencial Europeu moderno até, pelo menos, a década de $1990^{197}$.

\subsubsection{PrinCiPAis IDEIAS ORdOLIBERAIS:}

Durante muito tempo, a narrativa convencional defendeu que os Direitos Concorrenciais alemão e europeu, que se desenvolveram após a Segunda Guerra Mundial, seriam uma mera decorrência da poderosa influência da Intervenção Militar NorteAmericana que se instaurou na Alemanha naquele período ${ }^{198}$.

No entanto, DAVID J. GERBER, frequentemente citado em discussões contemporâneas sobre o Direito Concorrencial europeu, oferece um relato que enfatiza a importância das ideias ordoliberais, cujas origens remontam ao período entre guerras, em que houve forte intercâmbio e disseminação do pensamento austríaco do final do Século $\mathrm{XIX}^{199}$.

\footnotetext{
${ }^{197}$ KORAH, Valentine, The Interface Between Intellectual Property and Antitrust: The European experience Antitrust Law Journal, Vol. 69, nº 3, 2002,, pgs. 801-839

${ }^{198}$ Essa teoria defende que, no que se refere à proibição de cartéis, trustes e práticas restritivas, a lei alemã teria refletido a tradição americana do Antitruste.A então nova abordagem teria ganho força durante a Guerra Fria, dada a necessidade de proteger a estrutura industrial, mas, ao mesmo tempo, criar um quadro institucional que impedisse uma nova ameaça da Alemanha aos seus vizinhos ocidentais. A solução encontrada, segundo essa teoria, teria sido importar e difundir, primeiro na Alemanha e, depois, na Europa - o modelo de antitruste americano, que - àquela altura (isto é, pós $2^{\mathrm{a}}$ Guerra Mundial) - era baseado em uma estrutura oligopolística, que tolerava empresas grandes o bastante para alcançar ganhos de escala e de eficiência tecnológica, mas que, ao mesmo tempo,impedia condutas anti-competitivas por meio de uma aplicação agressiva das leis antitruste. A combinação "oligopólio plus antitruste efetivamente captura a realidade da economia americana no pós-guerra, tal como moldada pela história econômica, de um lado, e, de outro, pelo trinômio Estrutura-Conduta-Performance empregado pela Suprema Corte na interpretação do direito concorrencial. (GIOCOLI, Nicola, "Competition vs. Property Rights: American Antitrust law, the Freiburg School and the early years of European competition policy", 2008, Online at http://mpra.ub.unimuenchen.de/33807/)

${ }^{199}$ Não é nossa pretensão fazer um relato detalhado dos antecedentes históricos do Direito Concorrencial europeu contemporâneo, mas o relato de DAVID J. GERBER pode ser organizado, esquematicamente, da seguinte forma: i) Grande Depressão e Crise do liberalismo ao final do Século XIX, período em que a Livre Concorrência foi "demonizada" e culpada dos males do capitalismo.ii) Primeiras Ideias Austríacas de Controle dos Cartéis (exigência de formalidade e controles administrativos).iii) Intercâmbio de Ideias no Entre Guerras, com a propagação das ideias austríacas para outros países europeus, notadamente, a Alemanha. A respeito do assunto: Além de Gerber,David J. ("Law and Competition in Twentieth Century Europe - Protecting Prometheus", Oxford University Press, 1998), Giocoli, Nicola, in "Competition vs. Property Rights: American Antitrust law, the Freiburg School and the early years of European competition policy", 2008, Online at http://mpra.ub.uni-muenchen.de/33807/), e, no Brasil, JOSÉ MARIA ARRUDA DE ANDRADE ("Economização do Direito Concorrencial e Positivismo Jurídico: Entre Teoria da Decisão e das Provas, 2012, Tese de Livre Docência).
} 
Efetivamente, os arts. 85 e 86 do Acordo da Comunidade Europeia (Tratado de Paris, 1957) lidam tanto com restrições privadas à concorrência no mercado comum, como com restrições governamentais. Assim, a União Europeia reconhece ambas as espécies de interferência - o que se caracteriza como uma inovação em relação ao antitruste americano. Essa inovação foi consistente com as ideias ordoliberais, reforçando, assim, o argumento de GERBER.

Além disso, a substituição da abordagem tradicional europeia baseada no abuso (termo que era tomado de forma muito solta, ao sabor dos interesses políticos) por uma abordagem mais proibitiva - o que costuma ser apontado como fruto da influência americana - também pode ser visto como um traço do ordoliberalismo.

Mas o ponto mais decisivo para se considerar a posição de GERBER como a mais acertada é a ausência, no Tratado de Roma, de um controle de fusões e atos de concentração. Essa previsão foi removida na passagem do Tratado da Comunidade Europeia de Aço e Carbono (1951) para o Tratado de Paris (1957) - o que se torna difícil de explicar levando-se em conta apenas a influência do antitruste americano - à época, dominado pela Escola de Harvard, focada no trinômio Estrutura-Conduta-Performance.

Assim, qualquer leitura da história do Direito Concorrencial que não leve em conta a influência das ideias ordoliberais recai em uma grave omissão.

O ordoliberalismo era uma escola de pensamento que estava de acordo com concepções liberais mais antigas, ao considerar a concorrência como necessária para uma sociedade próspera, livre e igualitária. Entretanto, seus membros também estavam convencidos de que esta sociedade somente seria alcançada se limitada por um quadro constitucional, arquitetado para proteger o processo competitivo de distorções e abusos, garantir a distribuição equânime dos benefícios do mercado e minimizar a intervenção governamental na economia. O intercâmbio entre argumentos jurídicos e econômicos era, de fato, típico da Escola de Freiburg de Direito e Economia, que fortemente influenciou o ordoliberalismo $^{200}$.

Os fundadores da escola de Freiburg eram um economista, WALTER EUCKEN, e dois advogados, HANs GRossoman-DoERTH e FrAnz BÖHM.

\footnotetext{
${ }^{200}$ GIOCOLI, Nicola, in "Competition vs. Property Rights: American Antitrust law, the Freiburg School and the early years of European competition policy”, 2008, Online at http://mpra.ub.uni-muenchen.de/33807/)
} 
Iniciando em meados de 1930, os três se tornaram líderes de um bem-definido grupo de acadêmicos que compartilhavam objetivos básicos comuns, e que constituíam um dos poucos centros de oposição intelectual ao regime nazista ${ }^{201}$.

A primeira e mais fundamental crença comum entre tais estudiosos era a de que o poder econômico privado havia sido a principal causa da desintegração política e econômica da Alemanha durante o período entre guerras ${ }^{202}$.

Quanto ao problema do método econômico, os ordoliberais eram críticos do liberalismo clássico, presente na Inglaterra, cuja insistência na teorização pura se tornara alienante e descolada da realidade política e social- sobretudo ao final do Século XIX. Por outro lado, eram também fortes críticos do historicismo alemão, que se focava nos fatos e era totalmente avesso à teorização.

Os ordoliberais, portanto, defendiam uma ciência econômica que se baseava em abstrações a partir dos dados históricos e sua organização em um sistema teórico - porém, a teoria deveria ser sempre derivada dos fatos e frequentemente submetida a testes empíricos $^{203}$.

Se, no campo da ciência econômica, os ordoliberais defendiam a integração entre história e teoria econômica, no campo jurídico advogavam um outro tipo de integração: entre Direito e Economia. Para EuCKEN, uma vez que o fenômeno econômico ocorria em um quadro normativo institucional, o conhecimento econômico não poderia estar dissociado do conhecimento jurídico. O sistema legal prevê regras para o jogo econômico e, portanto, os processos econômicos não podem ser bem compreendidos sem o conhecimento integrador de tais regras.

Para atingir tal integração, um conceito fundamental entre os ordoliberais era o pensamento em ordens (Denken in Ordnungen), conforme distinção traçada por EUCKEN, entre economia de transação e economia de administração centralizada.

\footnotetext{
201 "German neo-liberal ideas took shape in response to the political and social crises of the Weimar Republic and of Nazi Germany. The Failings of the 1920s led to the conquest of political power by the Nazis, and neo-liberal thinkers were dedicated to understanding - and avoiding - a recurrence of that fateful process. For them, the core of that process was the accumulation and misuse of power. Law had been degraded to a tool of political power, which, in turn, had been degraded to a tool of economic power". (GERBER,David J., "Law and Competition in Twentieth Century Europe - Protecting Prometheus", Oxford University Press, 1998, pg. 233)

${ }^{202}$ GERBER,David J., "Law and Competition in Twentieth Century Europe - Protecting Prometheus", Oxford University Press, 1998, pg. 235

${ }^{203}$ GERBER,David J., "Law and Competition in Twentieth Century Europe - Protecting Prometheus", Oxford University Press, 1998, pg. 243
} 
$\mathrm{Na}$ primeira, a atividade econômica seria dirigida por decisões livres e independentes de agentes privados, cada um guiado por seus próprios incentivos. Na segunda, os comandos governamentais organizariam a atividade econômica segundo critérios externos ao sistema econômico ${ }^{204}$.

Para EUCKEN e seus colegas, a essência da economia de transação era a concorrência, porque ela permitiria o efetivo funcionamento do sistema. Quanto mais concorrência, mais efetivamente o sistema funcionaria, gerando os benefícios econômicos e não econômicos desejados.

Porém, o termo concorrência não era tomado pelos ordoliberais em sentido comum, mas, sim, implicava uma forma específica de concorrência - denominada concorrência completa - segundo a qual nenhuma empresa em um mercado deteria poder de coerção sobre outras empresas atuando naquele mesmo mercado. Esse conceito é central no pensamento ordoliberal.

Os ordoliberais inovaram ao embasar sua análise do fenômeno econômico em um contexto político-jurídico, fazendo com que a interface entre o pensamento jurídico e econômico atingisse seu ápice criativo. Eles assim o fizeram ao adicionar uma dimensão constitucional à sua análise dos problemas econômicos. A constituição política de uma sociedade e as escolhas desta sociedade em aplicar o Direito para concretizar tal constituição - afirmavam os ordoliberais - deveriam estabelecer as características de seu sistema econômico.

Sistemas econômicos não aconteciam espontaneamente, mas sim, eram formados a partir do poder decisório político-jurídico. Tais escolhas fundamentais determinavam a constituição econômica de uma nação (Wirtschaftseverfassung) ${ }^{205}$.

De acordo os ordoliberais, e aqui as contribuições de FRANZ BÖHM foram particularmente influentes, uma constituição econômica é definida por "a comprehensive decision concerning the nature and form of the process of socioeconomic co-operation". É uma decisão política sobre o tipo de economia que uma sociedade almeja, da mesma forma em que uma constituição política representa o tipo de sistema político que uma sociedade almeja.

\footnotetext{
${ }^{204}$ GERBER,David J., "Law and Competition in Twentieth Century Europe - Protecting Prometheus", Oxford University Press, 1998, pg. 243

${ }^{205}$ GERBER,David J., "Law and Competition in Twentieth Century Europe - Protecting Prometheus", Oxford University Press, 1998, pg. 245
} 
Essa ideia torna-se central no pensamento ordoliberal, constituindo a crítica mais importante em relação ao liberalismo clássico. Se, para os liberais clássicos, a economia deveria estar divorciada do direito e da política, para os ordoliberais as características e sobretudo - a efetividade da economia dependiam de sua relação com os sistemas político e jurídico.

A escolha de uma constituição econômica, porém, somente poderia ser efetiva se o sistema jurídico fosse estruturado para implementar tal escolha constitucional. Caso a unidade política optasse pela economia de transação em sua constituição econômica, por exemplo, tal escolha demandaria que políticas governamentais fossem criadas para criar e manter este sistema. Isso é o que os ordoliberais chamavam Ordnungspolitik, e constituía a alma do programa por eles defendido. De acordo com esse conceito, as decisões governamentais individuais deveriam fluir a partir dos princípios incorporados na constituição econômica e estar restringidas pelos mesmos princípios.

Em caso de uma opção por uma economia de transação, por exemplo, a Ordnungspolitik demandaria que o sistema jurídico fosse configurado de forma a criar e manter condições de concorrência completa - a qual permitiria aquele tipo de sistema econômico funcionar de forma mais eficiente ${ }^{206}$.

Para os ordoliberais, isso significava que o conhecimento econômico deveria ser traduzido em linguagem normativa.

Conforme escreveria BöHM: "The body of doctrine of classical economic philosophy had to be translated from the language of economics into the language of legal science". A ideia era de que a ciência econômica descreveria as condições de concorrência completa e de que tal informação forneceria os parâmetros para a elaboração de decisões/opções jurídicas por parte do governo.

O governo, a seu turno, poderia agir somente para implementar as normas gerais ou leis que derivassem dos princípios de conduta econômica, não havendo discricionariedade para intervir na economia exceto com o propósito de concretizar tais princípios. O Estado deveria prover um nível básico de segurança jurídica, assegurando que o Direito fosse passível de ser conhecido e não sujeito à manipulação ${ }^{207}$.

\footnotetext{
${ }^{206}$ GERBER,David J., "Law and Competition in Twentieth Century Europe - Protecting Prometheus", Oxford University Press, 1998, pgs. 246-247

${ }^{207}$ GERBER,David J., "Law and Competition in Twentieth Century Europe - Protecting Prometheus", Oxford University Press, 1998, pg. 247
} 
Críticos poderiam levantar que esta proposta nada mais era do que a regulação estatal - e que, portanto, cedo ou tarde se depararia com os mesmos problemas. Para lidar com esta potencial crítica, os ordoliberais criaram um conceito de regulação indireta, segundo o qual o governo não deveria dirigir os processos da economia, mas apenas as suas formas. Sem a função ordenadora de uma constituição econômica, a economia seria sitiada por problemas de inconsistência e contradições internas ${ }^{208}$.

Porém, na visão ordoliberal, o mecanismo de mercado não era suficiente para a integração social, que somente poderia ser alcançada por meio da inserção da economia em um quadro legal bem definido, centrado no direito concorrencial ${ }^{209}$.

O conceito de regulação indireta era apoiado tanto por princípios constitutivos como por princípios regulatórios. Sua função era estabelecer a forma básica da economia. Para EUCKEN, eles incluiriam os princípios da estabilidade monetária, mercados abertos, propriedade privada, liberdade contratual, responsabilidade e consistência política.

Os princípios regulatórios derivariam dos princípios constitutivos e estariam por estes limitados. Porém, seriam mais específicos e serviriam para manter a efetividade dos princípios constitutivos. Os princípios do direito concorrencial, por exemplo, eram vistos como princípios regulatórios que derivavam primariamente dos postulados constitutivos de mercados abertos e liberdade contratual ${ }^{210}$.

Para alcançar suas metas, os ordoliberais advogavam um Estado forte, pois um Estado fraco poderia ser cooptado facilmente pelos interesses econômicos privados - como teria acontecido em Weimar.

Os ordoliberais estavam convencidos de que a economia precisava do Estado para protegê-la e eles depositaram toda a sua confiança na capacidade do processo legal para limitar o poder estatal ${ }^{211}$.

Os estudiosos de Freiburg vislumbravam uma sociedade na qual as instituições democráticas garantiriam que os indivíduos estivessem livres do poder governamental e

\footnotetext{
${ }^{208}$ Gerber,David J., "Law and Competition in Twentieth Century Europe - Protecting Prometheus", Oxford University Press, 1998, pg. 248

${ }^{209}$ GERBER,David J., "Law and Competition in Twentieth Century Europe - Protecting Prometheus", Oxford University Press, 1998, pg. 241

${ }^{210}$ Gerber,David J., "Law and Competition in Twentieth Century Europe - Protecting Prometheus", Oxford University Press, 1998, pg. 249

${ }^{211}$ GERBER,David J., "Law and Competition in Twentieth Century Europe - Protecting Prometheus", Oxford University Press, 1998, pg. 250
} 
privado. Para tanto, a discricionariedade dos governos deveria estar restrita por um quadro jurídico, ou constituição, capaz de prevenir condutas oportunistas (rent-seeking) ${ }^{212}$.

Por outro lado, o Poder Econômico privado deveria estar restrito pela concorrência. Conforme FRANZ BÖHM escreveria (1960): “concorrência não é, de nenhum modo, apenas um mecanismo de incentivo, mas, acima de tudo, um instrumento de expropriação de poder. O mais poderoso jamais criado na história ${ }^{213}$ ".

O Direito Concorrencial tornou-se a pedra fundamental do programa ordoliberal rumo a uma ordem de transação. A história ensinara os ordoliberais que a liberdade econômica tendia a ser autodestrutiva, porque as empresas privadas preferem a regulação privada (isto é, contratual) de atividades econômicas do que a concorrência e porque elas frequentemente atingem tais níveis de poder econômico que são capazes de simplesmente eliminar a concorrência ${ }^{214}$.

\subsubsection{ConcorrênCia Completa e Controle de Conduta}

O modelo de concorrência completa demandava que o Direito fosse usado para impedir a criação de poder monopolístico, abolir os monopólios existentes quando possível e, quando não, controlar a sua conduta.

Uma empresa ou grupo que tivesse poder sobre preço ou poder de prejudicar a performance de suas rivais era inconsistente com o padrão da concorrência completa. Essa proibição era dirigida, principalmente, contra cartéis e outros acordos entre concorrentes.

Quando a posição monopolista era alcançada por uma única empresa, os ordoliberais concordavam, em geral, que o Direito Concorrencial deveria prover meios para exigir que as empresas fossem destituídas de alguns componentes de suas operações, ou, de algum outro modo, que abandonassem sua posição monopolista - o que representava uma grande margem para intervenção sobre a propriedade privada, levantando grande controvérsia ${ }^{215}$.

\footnotetext{
${ }^{212}$ GIOCOLI, Nicola, in "Competition vs. Property Rights: American Antitrust law, the Freiburg School and the early years of European competition policy”, 2008, Online at http://mpra.ub.uni-muenchen.de/33807/

${ }^{212}$ GIOCOLI, Nicola, in "Competition vs. Property Rights: American Antitrust law, the Freiburg School and the early years of European competition policy", 2008, Online at http://mpra.ub.uni-muenchen.de/33807/

${ }^{213}$ GiOCOLI, Nicola, in "Competition vs. Property Rights: American Antitrust law, the Freiburg School and the early years of European competition policy", 2008, Online at http://mpra.ub.uni-muenchen.de/33807/

${ }^{214}$ GIOCOLI, Nicola, in "Competition vs. Property Rights: American Antitrust law, the Freiburg School and the early years of European competition policy", 2008, Online at http://mpra.ub.uni-muenchen.de/33807/

${ }^{215}$ GERBER,David J., "Law and Competition in Twentieth Century Europe - Protecting Prometheus", Oxford University Press, 1998, pg. 252.
} 
Em casos específicos, quando a posição monopolista estivesse baseada em direitos de propriedade reconhecidos legalmente - como no caso das patentes e copyrights - o Direito Concorrencial deveria prever um padrão de conduta para tais empresas, exigindo que elas se comportassem como se estivessem sujeitas à concorrência. Isto é, como se elas não detivessem tal poder econômico ${ }^{216}$.

FRANZ BÖHM e outros ordoliberais emprestaram uma distinção advinda da doutrina da concorrência desleal - entre concorrência de performance e concorrência impeditiva e o a tornaram central em seu novo conceito de direito concorrencial.

A concorrência de desempenho se harmonizava com o modelo concorrencial, pois, em condições de concorrência, a melhora em desempenho seria o único meio pelo qual uma empresa poderia aumentar seus lucros. Quando, porém, uma empresa usasse seu poder para impedir o desempenho de um concorrente - por exemplo, excluindo-o do mercado - isto interferiria sobre o processo concorrencial e assim o Estado deveria proibir tal conduta ${ }^{217}$.

Entre as condutas impeditivas estavam, por exemplo, preços predatórios, boicotes, créditos concedidos em razão da lealdade do consumidor a determinada empresa. BÖHM, em seus primeiros trabalhos, considerava todas estas condutas como anticoncorrenciais, pois uma empresa só poderia praticá-las se detivesse poder monopolístico ${ }^{218}$.

\subsubsection{Propriedade Intelectual e a teorias do estímulo e Proteção aO INVESTIMENTO}

Portanto, tem-se que, nos casos envolvendo direitos de Propriedade Intelectual, o Direito Alemão - que, como veremos, influenciou o Direito Europeu - tendeu a controlar a conduta das empresas detentoras de tais direitos, exigindo que estas atuassem como se estivessem sujeitas à concorrência. Foi sob esta influência que se desenvolveu, na Alemanha, uma teoria peculiar para justificar a Propriedade Intelectual.

Dissertando acerca das insuficiências teóricas das quatro teorias fundamentais surgidas para justificar a Propriedade Intelectual na Alemanha, CALIXTO SALOMÃo FILHO

\footnotetext{
${ }^{216}$ Gerber,David J., "Law and Competition in Twentieth Century Europe - Protecting Prometheus", Oxford University Press, 1998, pg. 250.

${ }^{217}$ GIOCOLI, Nicola, in "Competition vs. Property Rights: American Antitrust law, the Freiburg School and the early years of European competition policy", 2008, Online at http://mpra.ub.uni- muenchen.de/33807/

${ }^{218}$ GERBER,David J., "Law and Competition in Twentieth Century Europe - Protecting Prometheus", Oxford University Press, 1998, pg. 253
} 
aponta para o surgimento e fortalecimento de uma quinta teoria, centrada na necessidade de se estimular e proteger investimentos. Esta teoria, segundo o autor, seria preferível às demais, por ser menos centrada na proteção de direitos individuais e mais voltada à proteção do direito coletivo à Concorrência ${ }^{219}$.

Nesse sentido, é o comentário de ULLRICH HEINEMANN e IMMENGA MESTMÄCKER à Lei Antitruste alemã (Gesetz, gegen Wettbewerbsbeschränkungen - GWB $)^{220}$ :

"In der Tat verdecken ethische, naturrechtliche oder auch einfach wirtschaftspolitische Begründungen für die gesetzliche Schaffung von geistigem Eigentum, wenn sie aus Legitimationsgründen für Schutzrechtsverhalten zu berechtigten Funktionszwecken und als solche zu Rechtsanwendungsmaßstäben erhoben werden, nur die praktischen Ursachen der Schutzrechtsbegründung für Immaterialgüter, die sich aus deren ökonomischen Eigenschaften ableiten. Die Immaterialgüter des geistigen Eigentums nämlich, wie etwa die erfinderischen technischen Lehren, die dem Wissen Ausdruck verleihenden oder die Sinne ansprechenden Werke oder Muster und die die Kommunikation herstellenden Zeichen, stellen nichts anderes als verschiedene Formen von Information dar und weisen deshalb deren wirtschaftliche Besonderheiten auf: Sie sind risikoreich in der Hervorbringung, entziehen sich der natürlichen Aneignung,sind deshalb nicht ohne weiteres übertrag( und verwertbar, und sie unterliegen weder der Abnutzung noch dem Grundsatz der Rivalität der Nutzung. Sie bedürfen des "künstlichen" rechtlichen Schutzes, um überhaupt als Wirtschaftsgut, das am Markt bewertet werden kann, hervorzutreten. Ohne solche Bewertungsmöglichkeit, d. h. ohne die Möglichkeit, die Nutzung individuell durch Ausschluss Dritter zu erfassen, werden sie weder bedarfs( noch

219 “Comprova-o a discussão doutrinária havida na Alemanha a respeito dos fundamentos da concessão das patentes. Ali, ao invés das duas teses avançadas por ASCARELLI, fala-se em cinco possíveis justificativas para a concessão das patentes. Delas, as quatro primeiras procuram justificar a concessão da patente a partir de uma ideia de contraprestação e aí exatamente reside a sua fraqueza. São elas: a teoria do direito natural (Naturechtstheorie), a teoria contratual (Vertragstheorie), a teoria da recompensa (Belohnungstheorie), e a teoria do estímulo (Anspornungstheorie) - v. V. Emmerich in GWB Kommentar, München, Beck, 1992, sub $\$ 20$, Rdn 3-8, p. 635. A primeira delas traz a clássica explicação naturalista para os institutos jurídicos - o criador tem um direito natural ao patenteamento. A petição de princípio que lhe é incita dificulta qualquer crítica, a não ser aquela a seus pressupostos evidentemente individualistas, razão pela qual hoje ela praticamente não encontra seguidores. A segunda, teoria contratual, é aquela que vê na concessão da patente uma recompensa da comunidade a inventor pela publicização de sua descoberta. Aqui encontra-se o primeiro exemplo da ineficácia cumulada com insuficiência teórica antes referida. Como é sabido, as empresas tendem a preferir um segredo industrial, desde que como tal ele possa ser mantido indefinidamente, à publicação e utilização - temporária - de uma patente. Dessa forma, a recompensa oferecida pela teoria contratual é bastante ineficaz. Do ponto de vista teórico, a perspectiva continua sendo eminentemente individualística. A terceira, teoria do estímulo, é bastante semelhante à teoria contratual. Nesse caso a recompensa é pelo estímulo ao bem-estar individual proporcionado pela individual, as patentes tendem a ser de pouco valor. No mundo empresarial moderno, raramente é possível identificar o inventor, as invenções são via de regra obra coletiva, da organização empresarial. Desse modo, ganha força a quinta teoria, do estímulo ao investimento. Nessa vertente, a patente é vista como um incentivo concorrencial às empresas, uma proteção e um estímulo a seus investimentos. Assim configurada, ela pode ser concebida, como se verá mais adiante, como forma de proteger a instituição da concorrência". (CALIXTO SALOMÃO FILHO, Direito Industrial, Direito Concorrencial e Direito Público, Revista de Direito Público da Economia, Belo Horizonte, ano 2, n. 7, 2.004, p. 29 e SS)

${ }^{220}$ HEINEMANN, Ullrich, MESTMÄCKER, Immenga, "EU Wettbewerbsrecht 5. Auflage 2012 - Die Anwendung der Wettbewerbsregeln auf die Verwertung von Schutzrechten und sonst geschützten Kenntnissen”, Rn 22 
kostengerecht, ja u. U. überhaupt nicht im Wettbewerb hervorgebracht. Damit wird aber, entgegen einer verwirrenden und verbreiteten Terminologie, nun nicht der Rechtsschutz zum Ansporn für die Hervorbringung des Immaterialgutes oder zum Belohnungsmechanismus. Vielmehr ergeben sich solche Wirkungen allein aus dem Wettbewerb, in dem der immaterielle Schutzgegenstand kraft seiner rechtlichen Konstituierung als Wirtschaftsgut eingesetzt werden kann. Dieser Wettbewerb, nicht das Schutzrecht, entscheidet über die Investitionsanreize, d. h.über die erreichbare Nachfrage, über die unternehmerischen Gewinnziele und (möglichkeiten sowie eben über den Wert des geschützten, immateriell oder in Erzeugnissen verkörpert angebotenen Wissens am Markt. Das Schutzrecht vermittelt nur diese Anreize oder Chancen dadurch, dass es ihre individuell ausschließliche Wahrnehmung erlaubt. Es setzt diesen Wettbewerb voraus, stellt, weil es ohne ihn wert( und nutzlos ist, ein bloßes Mittel im Wettbewerb dar, eine Handlungsbefugnis, die wettbewerbsgerechtes, $d . h$. individuell gewinnmaximierendes Verhalten ermöglicht. Der Schutz wird für den, nicht vor dem Wettbewerb gewährt”.

Segundo a visão dos autores, a proteção conferida pela Propriedade Intelectual possui, como finalidade, proteger a concorrência - ao eliminar a possibilidade de uma concorrência desleal, calcada na captura de investimentos alheios - mas não deve ser enxergada como uma proteção contra a concorrência (direitos de proteção para proteger a concorrência e não para se proteger dela).

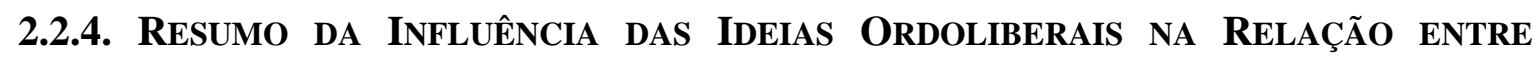 Direito Concorrencial e Propriedade Intelectual no Direito Europeu:}

Em resumo, o resultado final da influência ordoliberal sobre o Direito Concorrencial europeu foi a criação de um sistema que, embora ainda fiel aos fundamentos gerais ditados pela Escola de Freiburg, não era dirigido pelo ideal de concorrência completa, nem outro típico princípio constitutivo para uma economia de transação (digamos, a propriedade privada ou a liberdade de contrato), mas por uma variável exógena - embora ainda de natureza constitutiva - a qual consistia na meta de integração do mercado europeu.

Do ponto de vista prático, houve uma grande agressividade contra acordos que importavam em restrições verticais ao comércio, pois estes importavam em uma restrição mais evidente à circulação de bens entre os países do bloco.

Por outro lado, houve uma interpretação mais laxa no que se refere aos acordos horizontais, uma vez que estes poderiam colaborar para a criação de campeões 
continentais, ampliando a possibilidade de ganhos de escala e aumento da competitividade global.

Isso, como veremos, se refletiu na forma como a Comissão Europeia e a Corte Europeia de Justiça enfrentaram a dicotomia entre Propriedade Privada e Direito Concorrencial. Uma vez que havia um princípio constitucional claro a priorizar a meta de integração do mercado europeu, não houve grande dificuldade em conferir-lhe primazia sobre a liberdade contratual e os direitos de propriedade - inclusive, a Propriedade Intelectual - quando estes importavam em barreiras ao comércio entre países do bloco.

De fato, VALENTINE KORAH, procurando descrever, a leitores americanos, o tratamento conferido pela Comissão Europeia e a Corte Europeia de Justiça à relação entre Antitruste e Propriedade Intelectual até a década de 1990, referiu a uma suposta "hostilidade" quanto a direitos de propriedade.

Segundo a autora, por influência de ideias ordoliberais, tais direitos eram vistos como barreiras à entrada de novos competidores, bem como métodos de divisão do mercado comum que seriam contrários aos princípios básicos das Comunidades Europeias.

KORAH critica um suposto desrespeito do Direito Concorrencial europeu aos economistas e a falta de eleição da eficiência e do bem-estar dos consumidores dentre seus objetivos principais ${ }^{221}$. Essa perspectiva, no entanto, é claramente a do mainstream econômico (i.e., a Escola de Chicago) e que, portanto, diverge do pensamento da Escola de Freiburg que fortemente influenciou a interpretação das autoridades europeias.

De certa forma, a observação de KORAH ressalta que a jurisprudência europeia não aderiu a uma concepção expansionista da Propriedade Intelectual - o que, novamente, se deve à influência de Freiburg.

\subsubsection{DOUTRINA DA EXAUSTÃo:}

Antes de prosseguir, convém analisar, brevemente, o quadro de dispositivos do Tratado da Comunidade Europeia que se destinava a lidar com questões envolvendo Direito Concorrencial e Direitos de Propriedade.

\footnotetext{
221 "Another major difference between the European Community and United States is that in the early days of the Community there was considerable fear of patent monopolies which, under the influence of the ordoliberal school of economics in Freiburg, were perceived as barriers to entry. The need to avoid free riding and to encourage investment had limited influence on competition law until, with the creation of the merger task force in 1989, the competition department in the Comission of the EC began to respect economists more" (KORAH, Valentine, The Interface Between Intellectual Property and Antitrust: The European Experience - Antitrust Law Journal, Vol. 69, nº 3, 2002,, pgs. 801-839).
} 
O Artigo 81 (1) proibia acordos entre empresas que pudessem afetar o comércio entre estados membros e que tivessem o objetivo ou efeito de restringir a concorrência por serem inconsistentes com o objetivo de integração do mercado comum. Por sua vez, o Artigo 81 (3) previa exceções, que somente poderiam ser autorizadas pela Comissão, e o Artigo 81 (2) tornava nulos todos os acordos que violassem este artigo como um todo.

Por outro lado, o art. 295 (que, antigamente, era o art. 222) previa que “o Tratado não poderia, de nenhuma forma, prejudicar as regras de um Estado membro sobre o sistema de proteção da propriedade”.

Segundo KoraH, o fato de os países europeus contarem com direitos de Propriedade Intelectual locais fez com que tais direitos fossem percebidos como a isolar um Estado membro de outro, de forma contrária ao princípio fundamental do mercado único.

O mercado comum havia sido criado para permitir o livre movimento de bens, serviços, pessoas e capital. Consoante tal objetivo, a Corte Europeia de Justiça desenvolveu várias doutrinas para evitar o uso de direitos de Propriedade Intelectual como forma de repartir o mercado ${ }^{222}$.

Entretanto, já em meados da década de $1960^{223}$, a Corte Europeia de Justiça traçou uma distinção entre a existência, em si, de direitos de Propriedade Intelectual nacionais que não se sujeitaria ao Tratado - e o seu exercício, que estava sujeito ao tratado.

Tal distinção foi um artifício jurídico para que a Corte pudesse desenvolver a doutrina de exaustão de Direitos de Propriedade Intelectual: uma vez que um produto protegido tivesse sido disponibilizado, pelo detentor do direito de Propriedade Intelectual, ou com seu consentimento, em um mercado de um Estado membro, o direito de Propriedade Intelectual não poderia ser invocado para restringir a importação comercial do produto para outro Estado membro.

Esta primeira fase da jurisprudência da Corte Europeia levantou críticas por parte de economistas (leia-se, economistas mais identificados com o mainstream de então, i.e., a Escola de Chicago), tendo em vista que não havia consideração dos incentivos para manter investimentos em produção de novos bens intelectuais, mesmo em situações em que não era possível obter proteção no país de exportação ${ }^{224}$.

\footnotetext{
${ }^{222}$ KORAH, Valentine, The Interface Between Intellectual Property and Antitrust: The European Experience Antitrust Law Journal, Vol. 69, n 3, 2002, pgs. 801-839

${ }^{223}$ ECJ Establissements Consten S/A and Grundig Verkaufs GmbH v. Comission (1966)

${ }^{224}$ KORAH, Valentine, The Interface Between Intellectual Property and Antitrust: The European Experience Antitrust Law Journal, Vol. 69, nº 3, 2002, pgs. 801-839
} 


\subsubsection{RECUSA À LiCENÇA E MERCADOS SECUNDÁRIOS:}

A jurisprudência da Corte Europeia de Justiça tendeu a ler, no art. 82 do Tratado, uma obrigação geral de fornecer insumos a um concorrente no mercado secundário (downstream).

No julgamento do caso Commercial Solvents (1974), a Corte entendeu que havia abuso de posição dominante por parte da empresa Commercial Solvents, que era a única empresa com know-how para produzir ethambutol, principal matéria prima de uma droga usada para o tratamento de tuberculose. Zoja era uma das duas únicas produtoras de ethambutol no mercado comum, em concorrência com uma joint venture - Instituto - da qual a Commercial Solvents possuía metade das ações.

A Commercial Solvents havia decidido ingressar no mercado de produção de ethambutol e, como estratégia para excluir a concorrência, recusou-se a fornecer matérias primas para a Zoja. A Comissão Europeia entendeu que a Commercial Solvents havia abusado de sua posição dominante no mercado de ethambutol, ao cessar o fornecimento de matérias-primas à Zoja. A Corte Europeia de Justiça confirmou a decisão.

A partir deste caso, a doutrina europeia quanto ao dever de fornecer aos concorrentes se tornou mais ampla do que a doutrina das essential facilities desenvolvida nos Estados Unidos.

Qualquer recusa ao fornecimento por uma empresa dominante que importasse em exclusão de seus concorrentes de um mercado secundário era tratada como abuso de posição dominante ${ }^{225}$.

\footnotetext{
225 "The essential facilities doctrine is inspired by the leverage theory but presents certain specific characteristics. It is a legal doctrine framed by some early US decisions, which held that under specific circumstances, firms have affirmative duties to assist their competitors. Although never explicitly accepted by the US Supreme Court, the lower courts have set the conditions for the application of the doctrine as requiring from the plaintiff proof of the following four elements: (1) control of the essential facility by a monopolist; (2) a competitor's inability practically or reasonably to duplicate the essential facility; (3) the denial of the use of the facility by a competitor; (4) the feasibility of providing the facility. 124 The Supreme Court has recently marginalised the doctrine of essential facilities and it seems that the use of the doctrine of essential facilities in US law has fallen in desuetude. 125 Because the monopolist controls an essential facility (sometimes called bottleneck) he may be able to extend his monopoly power from "one stage of production to another". Under the essential facilities doctrine, a vertically integrated monopolist will be required to share some input in a vertically related market with someone operating downstream. This will only be the case if it is feasible for the monopolist to provide the facility, the competitor would be reasonably and practically unable to duplicate it and the denial of the use of the facility will deprive the competitor of an essential input, thus enabling the dominant firm to extend its monopoly power in a related market. In EU competition law, the Commission first used the concept of "essential facilities" in some decisions on interim measures involving the opening of port facilities to competition". (LIANOS, Ioannis e DREYFUSS, Rochele C., in "New Challenges in the Intersection of Intellectual Property Rights with Competition Law", CLES Working Paper Series - Faculty of Laws, UCL, 4/2013)
} 
Uma recusa a licenciar poderia ser abusiva se combinada com:

(1) recusa arbitrária a fornecer peças de reposição a empresas independentes no mercado de assistência técnica, (2) a cobrança excessiva por tais peças de reposição, ou (3) cessação de produção de peças de repoosição de um modelo particular quando houvesse muitos veículos daquele modelo ainda em uso $^{226}$.

Outro pronunciamento da Corte Europeia que se tornou emblemático da relação entre Propriedade Intelectual e Direito Concorrencial na Europa é o caso Magill (1995).

Em Magill, a Comissão adotou decisões contrárias a três emissoras de programas de TV na República da Irlanda e na Irlanda do Norte. Cada uma delas publicava seu próprio guia de programação, com uma semana de antecedência. As emissoras conferiam uma licença de copyright, gratuita ou mediante pagamento, aos jornais diários, licença esta que se limitava à publicação de guias com um dia de antecedência. Os jornais eram também autorizados a publicar destaques semanais.

Quando a Magill publicou uma única edição de um guia compreensivo para os programas das três emissoras, estas obtiveram liminares para prevenir a violação aos seus copyrights, bem como se negaram a licenciar os direitos 227 .

Em resposta a uma petição inicial da Magill, a Comissão entendeu que as três emissoras haviam abusado de uma posição dominante e determinaram a cessação desta conduta - o que foi confirmado pela Corte de Primeira Instância ${ }^{228}$.

No julgamento da apelação, a Corte Europeia de Justiça confirmou que, embora a propriedade intelectual não conferisse, de per si, uma posição dominante, as emissoras de televisão, no caso específico, detinham um monopólio de fato sobre a informação que era necessária à Magill. Elas eram a única fonte ${ }^{229}$.

Além disso, segundo entendeu a Corte Europeia de Justiça, a recusa em licenciar os direitos impedia o surgimento de um novo produto que as emissoras não ofereciam e para o qual havia uma constante demanda do consumidor, não haveria justificativas para a

\footnotetext{
${ }^{226}$ KORAH, Valentine, The Interface Between Intellectual Property and Antitrust: The European Experience Antitrust Law Journal, Vol. 69, n 3, 2002, pgs. 801-839

${ }^{227}$ KORAH, Valentine, The Interface Between Intellectual Property and Antitrust: The European Experience Antitrust Law Journal, Vol. 69, nº 3, 2002, pgs. 801-839

${ }^{228}$ KORAH, Valentine, The Interface Between Intellectual Property and Antitrust: The European Experience Antitrust Law Journal, Vol. 69, n 3, 2002, pgs. 801-839

${ }^{229}$ KORAH, Valentine, The Interface Between Intellectual Property and Antitrust: The European Experience Antitrust Law Journal, Vol. 69, nº 3, 2002, pgs. 801-839
} 
recusa e as emissoras haviam reservado para si próprias o mercado secundário de guias semanais de TV, ao excluir toda concorrência naquele mercado ${ }^{230}$.

Esse julgamento provocou grande debate, por implicar em uma possibilidade muito ampla do "dever de fornecer" aos concorrentes. A Corte Europeia de Justiça restringiu o escopo do precedente em Magill em julgamentos posteriores, já então sob novas influências econômicas.

No caso Bronner (1998), a Corte Europeia enfrentou a recusa ao licenciamento de um método de distribuição de jornais em todo território nacional, método este que era de propriedade da Mediaprint. Essa empresa também publicava um jornal e, por sinal, dominava aquele mercado.

Bronner, por outro lado, publicava um jornal que concorria com o publicado pela Mediaprint. Apesar de deter uma parcela relativamente pequena desse mercado, Bronner vinha experimentando um rápido crescimento e almejava acesso ao método de distribuição de jornais detido pela Mediaprint, para alcançar todo o mercado nacional. Quando a Mediaprint recusou-se a licenciar o método, Bronner alegou um abuso de posição dominante.

A Corte Europeia, no entanto, restringiu a aplicação da jurisprudência sobre dever de licenciar, ao entender que, no caso, o licenciamento não era indispensável para a atividade, pois havia métodos alternativos de distribuição, bem com nenhum impedimento a que Bronner desenvolvesse seu próprio método ${ }^{231}$.

Logo, a mera demonstração de posição dominante não seria suficiente. De acordo com o caso Bronner, o insumo recusado teria de ser indispensável. Além disso, a interpretação da Corte Europeia de Justiça implicou em uma análise prospectiva das condições de concorrência no mercado secundário - o que, talvez, tenha sido a maior inovação em relação à jurisprudência existente até então.

\footnotetext{
${ }^{230}$ KORAH, Valentine, The Interface Between Intellectual Property and Antitrust: The European Experience Antitrust Law Journal, Vol. 69, n 3, 2002, pgs. 801-839

${ }^{231}$ Bronner, [1998] ECR I- b7791
} 


\subsection{A Escola de Chicago e os Conceitos de Eficiência Produtiva e Eficiência DinÂMiCA. AMERICANIZAÇÃo do Direito Europeu (More ECONOMIC APPROACH)?}

$\mathrm{O}$ relato que se fez sobre a jurisprudência norte-americana, propositalmente, se desenrolou até meados da década de 1980 - quando, nos Estados Unidos, a Escola de Chicago alcançava seu apogeu em termos de influência política e jurisprudencial ${ }^{232}$.

Essa escola, de certo modo, venceu o embate teórico com a Escola de Harvard quanto aos objetivos do antitruste, em muito, graças ao sagaz argumento de ROBERT BoRK em sua crítica ao que chamou de Paradoxo do Antitruste. Após décadas de repressão antitruste em meio ao radicalismo da Era de Warren, BoRK apontou que o Antitruste havia recaído em um paradoxo, ao perseguir com rigor estruturas que, em verdade, ocasionariam o bem-estar do consumidor.

A forca do argumento de BORK residiu na identificação da eficiência produtiva com bem-estar do consumidor, bem como em sua identificação como o único objetivo do Sherman Act - a despeito do anacronismo, tendo em vista que tal conceito sequer estava disponível a época de introdução do Sherman Act.

Tal conceito eficiência produtiva foi, certamente, a grande inovação de Chicago, ao defender concentrações econômicas com base na necessidade de se preservar economias de escala, que, por sua vez, se justificariam com base em promessas de redistribuição dos ganhos em eficiência, fomentando, assim o bem-estar do consumidor ${ }^{233}$.

$\mathrm{Na}$ prática, o argumento consistiu em um recurso retórico poderoso para permitir aos empresários à apropriação desta parcela excedente obtida com os ganhos em produtividade. Tanto que, ao final de algumas décadas de larga aplicação destas ideias no campo judicial, ELEANOR FOX aponta aquilo que chamou de "Paradoxo da Eficiência": defesa de monopólios e oligopólios e supressão da inovação tecnológica ${ }^{234}$.

A influência das ideias de Chicago tem impacto sobre a discussão abordada em nosso trabalho em vários níveis. Primeiro, no que se refere aos casos envolvendo tying arrangements - que, a princípio, eram tratados sob a ótica dos limites conferidos pela

\footnotetext{
${ }^{232}$ ARRUdA DE ANDRADE, José Maria, “Economização do Direito Concorrencial e Positivismo Jurídico” (op. cit.), pg. 54.

${ }^{233}$ ARRUDA DE ANDRADE, José Maria, "Economização do Direito Concorrencial e Positivismo Jurídico”, pg. 63.

${ }^{234}$ FOX, Eleanor, "The Effiency Paradox", in "How Chicago Overshot the Mark: the effect of conservative economic analysis of U.S. Antitrust", organizado por Robert Pitofsky, p. 77-88, New York: Oxford University Press, USA, 2008.
} 
Propriedade Intelectual (Patent Misuse) e que passam a ser analisados sob a ótica dos efeitos em determinado mercado relevante.

Além disso, conforme já se chegou a mencionar no Capítulo 1, uma linha da Escola de Chicago passa a defender uma maior aproximação entre a Propriedade Intelectual e a Propriedade Tangível, o que levou a um aumento excessivo do escopo da proteção, bem como não aplicação do Direito Antitruste.

No caso da propriedade intelectual, o estigma do free riding consagrou a justificação econômica do “direito de alguém lucrar sobre seu próprio negócio" ocasionando uma grande expansão dos Direitos de Propriedade Intelectual, sob o pretexto de se proteger os investimentos na criação de novos bens, como já analisado no Capítulo 1.

Finalmente, com a crescente importância da inovação para o debate - graças a um retorno às teorias de JOSEPH ALOIS SCHUMPETER, que abordaremos com maiores detalhes no próximo Capítulo - surgem abordagens evolucionárias neo-Chicago que defenderão o afastamento de qualquer intervenção antitruste quando tal intervenção representar potenciais efeitos negativos sobre o processo de inovação - fonte primária de bem-estar, segundo a leitura que Chicago fará de SCHUMPETER ${ }^{235}$.

Porém, tais releituras neo-Chicago, frequentemente, desprezam fatores como barreiras à entrada, externalidades de rede e custos de mudança. Além disso, se a redistribuição dos ganhos em eficiência produtiva à sociedade já é algo difícil de se demonstrar na prática, os ganhos em eficiência futura, pela inovação (eficiência dinâmica), levantam dificuldades ainda maiores ${ }^{236}$.

\footnotetext{
235 "Proponents of this neo-Schumpeterian theory admit that refraining from intervention in the IP right has its costs, namely a loss in allocative efficiency and price competition. However, they recommend that competition law enforcers should refrain from interfering with the IP right because of potentially greater losses in dynamic efficiency(...) Recently Evans and Padilla, advocating a 'neo-Chicago approach', have brought more theoretical precision to this argument. The two authors, based on economic theory, assess the likelihood and costs of different kinds of errors policymakers may commit in combating unilateral restraints. They argue that the cost of condemning pro-competitive practices is higher than the costs of exonerating anti-competitive practices. It is clear from the outset that within a concept of dynamic competition that requires predictions about the consequences of any regulatory decision, but is unable to measure these consequences, the model developed by Evans and Padilla has to recommend that competition law enforcers refrain from any intervention in IP-related innovation markets.Hence, the neo-Schumpeterian concept can be brought down to the very simple conclusion: never interfere with intellectual property rights as you cannot measure the costs of such intervention!" (DREXL, Josef, "Is there a "more economic approach' to intellectual property and competition law?"- Research Handbook on Intellectual Property and Competition Law, Edgard Elgar Publishing Limited, UK, 2008)

236 "In the framework of an economic efficiency assessment, it would regularly be necessary to balance a loss in allocative efficiency (price competition) with gains in dynamic efficiency (innovation). This balancing approach appropriately describes the mechanism of the intellectual property right. The IPR excludes imitation and thereby price competition by a competitor who might well be better placed to produce the good or service in question. However, allowing imitation would negatively affect the incentive structure of the IP system. The question remains how such a balance should be struck given the fact that dynamic efficiency is
} 
De fato, as abordagens pós-Chicago, influenciarão fortemente o Direito Europeu a partir da década de 1980 e, sobretudo, do final da década de 1990, vários comentaristas apontando para um more economic approach por parte da Comissão Europeia e Corte Europeia de Justiça ${ }^{237}$.

No plano, dogmático, as mudanças implementadas se iniciaram com a regulação de acordos verticais (Regulamento Genérico $n^{0}$ 2790/1999), com a adoção do guia para aplicação do art. 81 (3) (atual art. 101 do Tratado sobre o Funcionamento da União Europeia - TFUE), com o regulamento sobre fusões de 2004 e com as guidelines para aplicação do art. 82 (EC) (atual art. 102 do TFUE).

De fato, a própria Comissão Europeia buscou uma maior aproximação entre a Europa e os Estados Unidos, conforme comentou o próprio então Comissário Mario Monti em $2004^{238}$.

No plano teórico, a reforma, de um modo geral, se revestiu em uma mudança de paradigma em direção à eficiência econômica - referência a eficiências compensatórias de eventuais concentrações ou posições dominantes. DAVID GERBER menciona, como fatores relevantes para o more economic approach, a própria globalização e a disputa de empresas europeias com empresas americanas e japonesas, além da busca por uma homogeinização institucional na União Europeia ${ }^{239}$.

impossible to measure" (DREXL, Josef, "Is there a 'more economic approach' to intellectual property and competition law?"- Research Handbook on Intellectual Property and Competition Law, Edgard Elgar Publishing Limited, UK, 2008)

${ }^{237}$ Por exemplo, Derclaye, Estelle (2004), 'The IMS Health Decision: A Triple Victory', World Competition, 27, 397, at 403; see also Eilmansberger, Thomas (2005), 'How to Distinguish Good From Bad Competition Under Article 82 EC: In Search of Clearer and More Coherent Standards for Anti-Competitive Abuses', C.M.L. Rev., 42, 129, at 159 (apud DREXL, Josef). "The leitmotiv of this reform, generally known as the 'more economic approach', has been described by former EC Competition Commissioner Mario Monti in the following words: 'In making this revision, we have shifted from a legalistic based approach to an interpretation of the rules based on sound economic principles". (DREXL, Josef, "Is there a "more economic approach' to intellectual property and competition law?"- Research Handbook on Intellectual Property and Competition Law, Edgard Elgar Publishing Limited, UK, 2008)

238 "This new framework should strengthen the soundness of our analysis of mergers and, at the same time, contribute significantly to enhance the transparency of our policy in this field. Incidentalluy, it is another example of the increasing convergence between EU and US competition policies" (MONTI, Mario, "EU Competition Policy After May 2004", Fordham Annual Conference on International Antitrust Law and Policy, New York, 24 October, 2003, Discurso/03/489).

${ }^{239}$ GERBER, David, "Global Competition - Law, Markets, and Globalization", Oxford University Press, 2010, pg. 187-204 


\title{
Capítulo 3 - O Debate sobre a Interface entre a Propriedade Intelectual e o Direito de Concorrência no Século XXI: Novos DESAFios TRAZIDOS PELOS MERCAdOS DE INOVAÇÃo E TECNOLOGIA
}

\begin{abstract}
"When at last will the day come when all will realize... that the ocean of facts has innumerable different aspects which call for innumerable different modes of approach". [Joseph Alois Schumpeter ${ }^{240}$ ]
\end{abstract}

\subsection{Introdução: Desenvolvimentos na Teoria Econômica Pós-Chicago E IMPACTO PARA O DEBATE SOBRE CONCORRÊNCIA E PROPRIEDADE INTELECTUAL}

Encerramos o Capítulo 2 tratando dos aportes da Escola de Chicago, cuja influência levou a uma mudança de paradigma no Antitruste, passando-se a centrar a discussão na eficiência. Não se deve perder de vista que tal conceito de eficiência se baseia em nem sempre garantidas promessas de partilhas de ganhos com os consumidores - não obstante a estratégia retórica adotada pela escola de Chicago insistir na total identificação de eficiência com o bem-estar do consumidor. Como também já foi objeto de comentários anteriores, a escola de Chicago gozou de grande influência política e jurisprudencial, sobretudo durante os anos $1980^{241}$.

Embora a aplicação estrita de alguns dos pressupostos mais normativos da Escola de Chicago tenha sido, já partir da década de 1980, objeto de críticas e revisões - tanto de dentro como de fora do modelo ${ }^{242}$ - duas de suas contribuições podem ser consideradas como ainda prevalentes: a ênfase em eficiências e na análise dos efeitos econômicos em

\footnotetext{
240 "Die 'Positive' Methode in der Nacionalokonomie” Deutsche Literaturseitung, xxxv, Jahrgang (1914), p. 2.101, apud, MACHLUP, Fritz, "Schumpeter's Economic Methodology", The Review of Economics and Statistics, Vol. 33, No. 2 (May, 1951), pgs. 145-151, Published by: The MIT Press

241 "The Chicago School enjoyed its heyday in the late 1970s as the Supreme Court began to uproot interventionist antitrust precedents from the 1950s and 1960s and to replace them with more permissive rules. Then, Ronald Reagan appointed Bill Baxter to head the Antitrust Division, and the antitrust agencies began to follow suit. Baxter was thoroughly Stanford - undergraduate, law degree, and law professor - and not Chicago, but it has become conventional to lump Baxter into the Chicago School. Under this direction the Justice Department veered away from interventionist stances on vertical restraints and mergers, monopolization, and even horizontal mergers. Reagan complemented Baxter's appointment by placing a conservative University of Virginia (but "Chicago School" nonetheless) economist, James Miller, to chair the Federal Trade Comission (FTC). Although slightly more interventionist policies would reemerge in the agencies during the Clinton Administration, Baxter and Miller's revolution set the agencies on a durable new path" (CRANE, Daniel A. "Chicago, Post-Chicago and Neo-Chicago". Review of How Chicago Overshot the Mark: The Effect of Conservative Economic Analysis on U.S. Antitrust, by R. Pitofsky, editor, U. Chi. L., Rev. 76, no 4, 2009: 1911-33)

${ }^{242}$ HovenKAMP, Herbert J., "Antitrust Policy After Chicago", University of Iowa Legal Studies Research Paper, 09-21, Maio/2009 - disponível em http://ssrn.com/abstract=1396788.
} 
determinado mercado relevante ${ }^{243}$. Essas duas características continuam a marcar o debate sobre o antitruste, tanto nos Estados Unidos como na Europa (atualmente, em meio a discussões sobre o more economic approach da Comissão Europeia - como visto no Capítulo anterior) ${ }^{244}$.

A própria Lei brasileira prevê a análise de eficiências compensatórias para justificar, excepcionalmente, atos de concentração. O Legislador brasileiro, entretanto, exigiu que, nestes casos, seja demonstrado que o ato restritivo da concorrência é estritamente necessário para que sejam alcançadas tais eficiências, bem como que sejam repassados aos consumidores parte relevante dos benefícios decorrentes ${ }^{245}$. Logo, observase que o Legislador não se rendeu à tese de Chicago, de que a eficiência se identificaria com o bem-estar do consumidor, constituindo-se em suposto objetivo maior do antitruste.

A Escola de Chicago baseou seus pressupostos em Teoremas de Impossibilidade, ou Teoremas de Legalidade per si - os quais recomendam uma não intervenção antitruste em boa parte das condutas e estruturas que a doutrina predominante até meados da década de 1970 considerava como inerentemente anticompetitivas ${ }^{246}$.

No campo dos acordos colusivos - apenas para citar um exemplo - a explicação clássica da Escola de Chicago (STIGLER) era de que esta não seria uma preocupação real, pois haveria dificuldades intrínsecas em se estabelecer tais acordos, mesmo em mercados concentrados $^{247}$.

Tais dificuldades adviriam da instabilidade inerente de tais acordos colusivos, pressuposta por Chicago, em vista da dificuldade de se identificar e reprimir uma possível violação - obstáculos estes que seriam ainda maiores em mercados nos quais as empresas

${ }^{243}$ KLEIN, Benjamin and LERNER, Andres V., “Introduction: The Economics Revolution in Antitrust Law”. In "Economics of Antitrust Law”, v. 1. p. ix-xliv, Cheltenham, Northampton: Edward Elgar Publishing, 2008 ${ }^{244}$ KLEIN, Benjamin and LERNER, Andres V., "Introduction: The Economics Revolution in Antitrust Law". In "Economics of Antitrust Law”, v. 1. p. ix-xliv, Cheltenham, Northampton: Edward Elgar Publishing, 2008 ${ }^{245}$ Lei no 12.529/2011:

"Art. 88. (...)

$\$ 5^{\circ}$ - Serão proibidos atos de concentração que impliquem eliminação da concorrência em parte substancial do mercado relevante, que possam criar ou reforçar uma posição dominante ou que possam resultar na dominação de mercado relevante de bens ou serviços, ressalvado o disposto no $\$ 6^{\circ}$ deste artigo.

$\S 6^{\circ}$ - Os atos a que se refere o $\$ 5^{\circ}$ deste artigo poderão ser autorizados, desde que sejam observados os limites estritamente necessários para atingir os seguintes objetivos:

I- Cumulada ou alternativamente:

a) Aumentar a produtividade ou a competitividade;

b) Melhorar a qualidade de bens ou serviços; ou

c) Propiciar a eficiência e o desenvolvimento tecnológico ou econômico; $e$

II - Sejam repassados aos consumidores parte relevante dos benefícios decorrentes” (destaques acrescidos).

${ }^{246}$ KLEIN, Benjamin and LERNER, Andres V., "Introduction: The Economics Revolution in Antitrust Law". In "Economics of Antitrust Law”, v. 1. p. ix-xliv, Cheltenham, Northampton: Edward Elgar Publishing, 2008

${ }^{247}$ KLEIN, Benjamin and LERNER, Andres V., "Introduction: The Economics Revolution in Antitrust Law". In "Economics of Antitrust Law”, v. 1. p. ix-xliv, Cheltenham, Northampton: Edward Elgar Publishing, 2008 
fornecem produtos diferenciados e a concorrência não é estritamente baseada em preço. Tais circunstâncias, segundo GEORGE STIGLER, afastariam totalmente os incentivos para colusão ${ }^{248}$.

Por outro lado, pesando contra uma preocupação excessiva quanto a mercados concentrados, havia a crença de que se deveriam levar em conta os fatores do lado da oferta (entrada e expansão dos concorrentes), bem como as eficiências resultantes de fusões (HAROLD DEMSETZ) ${ }^{249}$.

Estas ideias influenciaram fortemente as Merger Guidelines do Departamento de Justiça Americano de 1982, levando a um ambiente muito mais permissivo, à época, no que se refere a fusões nos Estados Unidos. Tais teoremas de impossibilidade também tiveram significativa influência sobre a jurisprudência ${ }^{250}$.

Se a teoria econômica que prevaleceu até meados da década de 1970 concluiu pela presunção de poder econômico e condenação, per si, de algumas práticas - vide, por exemplo, os nine nos do Departamento de Justiça dos Estados Unidos, tal como já abordado no Capítulo 2 - a escola de Chicago recaiu no outro extremo, ao considerar condutas como inerentemente inofensivas, como base em Teoremas de Impossibilidade tais como o proposto por STIGLER no que se refere aos acordos colusivos ${ }^{251}$.

No campo específico da relação entre concorrência e a propriedade intelectual, foi afastada, por exemplo, a presunção de poder de mercado em casos envolvendo tying arrangements (vendas casadas) ${ }^{252}$.

Os principais pontos de crítica quanto às ideias de Chicago residem em uma excessiva confiança em conceitos estáticos do mercado para lidar com situações empíricas em que apenas conceitos dinâmicos são capazes de explicar o comportamento ou os

\footnotetext{
${ }^{248}$ KLEIN, Benjamin and LERNER, Andres V., "Introduction: The Economics Revolution in Antitrust Law". In "Economics of Antitrust Law", v. 1. p. ix-xliv, Cheltenham, Northampton: Edward Elgar Publishing, 2008 ${ }^{249}$ KLEIN, Benjamin and LeRNER, Andres V., "Introduction: The Economics Revolution in Antitrust Law". In "Economics of Antitrust Law", v. 1. p. ix-xliv, Cheltenham, Northampton: Edward Elgar Publishing, 2008 ${ }^{250}$ Por exemplo, vide Brooke Group Ltd v Brown \& Williamson Tobaccoo Corp, 509 US 209, 227-30 (1993), no qual se sustentou que esquemas de preços predatórios seriam improváveis quando não há provas de cooperação entre empresas e Matsushita Eletric Industrial Co v Zenith Radio Corp, 475 US 574, 588-89 (1986), no sentido de que esquemas de preços predatórios não são plausíveis em geral, e que, no caso, a ausência de evidência de ganhos financeiros indicaria que não teria havido conspiração (CRANE, Daniel A. "Chicago, Post-Chicago and Neo-Chicago". Review of How Chicago Overshot the Mark: The Effect of Conservative Economic Analysis on U.S. Antitrust, by R. Pitofsky, editor, U. Chi. L., Rev. 76, n 4, 2009: 1911-33)

${ }^{251}$ PITOFSKY, R. "How Chicago Overshot the Mark: The Effect of Conservative Economic Analysis on U.S. Antitrust, by R. Pitofsky, editor, U. Chi. L., Rev. 76, nº 4, 2009: 1911-33

${ }^{252}$ Em Illinois Tool Works Inc v Independent Ink, Inc, 547 US 28, $42-43$ (2006), a Suprema Corte afastou a regra alcançada em Morton Salt Co v G.S. Suppiger Co, 314 US 488 (1942) - citado no Capítulo 2 -para fins de determinar que a condenação de tying arrangements, envolvendo produtos patenteados deve se basear em prova de poder no mercado, e não em mera presunção.
} 
resultados, além de sua falha em apreender o grau e os efeitos do comportamento estratégico sobre o bem-estar do consumidor ${ }^{253}$.

Contestando tais Teoremas de Impossibilidade, algumas das abordagens pósChicago desenvolverão, a partir da década de 1980, Modelos baseados na Teoria dos Jogos para descrever a interação oligopolística, considerando a interação dos concorrentes uns com os outros, repetidamente, ao longo do tempo.

Esta interação conduziria à adoção de estratégias complexas, nas quais as empresas podem mudar de comportamento de acordo com o resultado verificado em períodos anteriores. Uma vez que a interação repetitiva aumenta a capacidade das empresas de reprimir eventuais violações de acordos colusivos, tais modelos teóricos sugerem que as decisões individuais oportunistas - no sentido de desviar-se de um acordo de colusão poderiam ser mais custosas do que STIGLER havia suposto ${ }^{254}$.

Já a partir de 1980, alguns economistas passaram a desenvolver modelos que demonstravam a possibilidade de existirem incentivos para uma empresa utilizar um monopólio em um mercado primário para fins de controlar mercados secundários, de modo a prejudicar o bem-estar dos consumidores - contrariando, de tal modo, o teorema de impossibilidade até então defendido por Chicago (Single Profit Theorem).

Um artigo de Michael Whinston demonstrou a possibilidade de se alavancar lucros monopolistas em um mercado secundário (i) caso o mercado vinculado estivesse sujeito a economias de escala, e (ii) a alavancagem induzisse à saída ou impedisse a entrada de novos competidores no mercado em questão, resultando, a partir daí, em um monopólio assegurado no mercado secundário ${ }^{255}$.

Não é nosso objetivo nos aprofundar, neste trabalho, no estudo da aplicação da Teoria dos Jogos na análise antitruste, e muito menos, defender um uso consequencialista de tais modelos. Porém, conquanto tais modelos levantem dificuldades de demonstração empírica, e - portanto - pouco tenham auxiliado, ao menos até aqui, para se identificar

\footnotetext{
253 "This discussion is too brief to consider all critiques from inside the model. Rather, it focuses on two prominent weaknesses in the neo-classical market efficiency model that render the model too naive to be the exclusive tool of antitrust policymakers: (1) an excessive reliance on static concepts of the market in empirical situations where only dynamic concepts will explain behavior or results; and (2) a failure to appreciate fully the extent and welfare consequences of strategic behavior. The second weakness is in large part a consequence of the first". (HovenKAMP, Herbert J., "Antitrust Policy After Chicago", University of Iowa Legal Studies Research Paper, 09-21, Maio/2009 - disponível em http://ssrn.com/abstract=1396788)

${ }^{254}$ KLEIN, Benjamin and Lerner, Andres V., "Introduction: The Economics Revolution in Antitrust Law". In "Economics of Antitrust Law", v. 1. p. ix-xliv, Cheltenham, Northampton: Edward Elgar Publishing, 2008

${ }^{255}$ LiANOS, Ioannis e DREYFuss, Rochelle, "New Challenges in the Intersection of Intellectual Property Rights With Competition Law - A View from Europe and the United States, CLES Working Paper Series, Abril, 2013.
} 
acordos colusivos na prática ${ }^{256}$, a sua principal contribuição para o debate é argumentativa, por afastar a presunção de inofensividade adotada pela Escola de Chicago quanto a algumas práticas.

Logo, levantam-se questionamentos quanto à legalidade per si de algumas práticas unilaterais consideradas benignas por aquela escola, sem, com isso, significar um retorno ao paradigma de ilegalidade per $\mathrm{si}^{257}$.

A influência da Nova Economia Institucional também foi importante para o desenvolvimento de uma posição que não recaísse nos extremos de Harvard e Chicago. A Nova Economia institucional, por exemplo, defendeu que o Antitruste deveria ter uma atitude mais benigna em relação à integração vertical, pois tais acordos poderiam resultar em aumento da oferta e redução de preços, maximizando o bem-estar dos consumidores. Porém, ao contrário de Chicago, a Nova Economia Institucional não defendeu a legalidade per si, mas sim, o exame do racional econômico por trás dos vários tipos de contratos ${ }^{258}$.

Todas essas críticas e revisões ao pensamento de Chicago recomendam, a nosso ver, que os órgãos reguladores da concorrência se voltem para um escrutínio mais apurado das evidências, a fim de investigar os efeitos de cada prática sobre a concorrência. Não há dúvidas de que o emprego da ciência econômica possa contribuir neste estudo da realidade - porém, deve-se evitar recair em determinismos, ou no formalismo de uma Teoria da Decisão totalmente clivada da realidade, para fins de validar condutas com base em premissas estabelecidas totalmente $a$ priori.

Em resposta, alguns autores tentarão reafirmar os pressupostos da Escola de Chicago, baseando-se - principalmente - na teoria dos Custos do Erro, desenvolvida pelo Juiz EASTERBROOK, bem como em abordagens evolucionárias, baseadas - sobretudo - em releituras de JOSEPH ALOIS SCHUMPETER.

O mote dessas teorias, autodenominadas de Neo-Chicago, é de que os custos de se proibir equivocadamente práticas eficientes seriam superiores aos custos de perpetuar

\footnotetext{
${ }^{256}$ KLEIN, Benjamin and LERNER, Andres V., "Introduction: The Economics Revolution in Antitrust Law". In "Economics of Antitrust Law”, v. 1. p. ix-xliv, Cheltenham, Northampton: Edward Elgar Publishing, 2008 257 "Both literatures emphasize efficiency as the ultimate objective of antitrust and reject most pre-Chicago per se illegality rules concerning unilateral practices. Yet where the Chicago School tended to advocate per se legality, post-Chicago thinking enthuses over rule of reason analyses. The post-Chicago literature has shown that, under some circumstances, otherwise benign unilateral practices may reduce social welfare. But the findings turn on assumptions that are hard to test with available data". (EVANS, David S. and PADILLA, A. Jorge, in "Designing Antitrust Rules for Assessing Unilateral Practices: A Neo-Chicago Approach", The University of Chicago Law Review, Vol. 72, n. 1, Symposium: Antitrust, Winter, 2005, pgs. 73-98)

${ }^{258}$ HovenKAMP, Herbert J., "Harvard, Chicago, and Transaction Cost Economics in Antitrust Analysis", University of Iowa Legal Studies Research Paper, Number 10-35, December, 2010
} 
monopólios - que estariam sempre ameaçados pela destruição criativa, ao menos conforme a releitura que esta linha de pensamento fará de SCHUMPETER.

Além disso, ao punir erroneamente condutas pró-competitivas, a política antitruste estaria criando um desestímulo para as empresas buscarem uma posição dominante no mercado - fator que, segundo SCHUMPETER, seria o principal propulsor da inovação tecnológica ${ }^{259}$.

Tendo por pano de fundo o quadro de desenvolvimentos teóricos descritos nas linhas anteriores, o roteiro de estudos que se desenvolverá neste Capítulo 3 terá os seguintes objetivos:

(i) Revisitar a literatura que discute a validade das premissas neo-Chicago, de que haveria uma relação proporcional entre concentração econômica e inovação tecnológica (SCHUMPETER), bem como examinar o impacto de tais ideias para a análise antitruste, com o surgimento de novas ferramentas analíticas (mercados de tecnologia e inovação, eficiência dinâmica);

(ii) Abordar as características inerentes à chamada Nova Economia, bem como os novos desafios apresentados para a análise antitruste envolvendo direitos de Propriedade Intelectual, sobretudo, no que se refere às barreiras à entrada;

(iii) Relacionar - sem nenhuma pretensão de esgotar o tema - os principais pontos de encontro entre a Propriedade Intelectual e o Antitruste na atualidade, quanto às condutas (licenciamentos verticais e horizontais e abuso de posição dominante) e estruturas envolvendo direitos de Propriedade Intelectual;

\footnotetext{
259 "If an anticompetitive business practice is mistakenly permitted, the resulting monopoly profits attract competition and new entrants, at least in the long run. We are not suggesting that competition cures all anticompetitive ills - only that the forces of competition, and creative destruction, provide some limitation on the magnitude and duration of monopoly profits. The monopoly or near-monopoly positions of firms such as General Motors (automobiles), IBM (computers), RCA (television sets), Kodak (photgraphic film), Xerox (photocopiers), U.S. Steel (finished steel), and Harley-Davidson (motorcycles) were not ephemeral but not permanent either. By contrast, market forces play little corrective role for procompetitive business practices deemed anticompetitive (...) Moreover, by restraining legitimate acts, antitrust laws reduce the value of being legitimate market leader - the goal that drives innovation". (Evans, David S.; PADILLA, A. Jorge, in "Designing Antitrust Rules for Assessing Unilateral Practices: A Neo-Chicago Approach", The University of Chicago Law Review, Vol. 72, n. 1, Symposium: Antitrust, Winter, 2005, pgs. 73-98). Semelhante raciocínio parece ter sido acolhido pela Suprema Corte dos Estados Unidos no seguinte pronunciamento: "'The mere possession of monopoly power, and the concomitant charging of monopoly prices, is not only unlawful; it is an important element of the free-market system. The opportunity to charge monopoly prices at least for a short period - is what attracts "business acumen" in the first place; it induces risk taking that produces innovation and economic growth. To safeguard the incentive to innovate, the possession of monopoly power will not be found unlawful unless it is acompanied by an element of anticompetitive conduct" (US 398, 407, 2004, apud, (Evans, David S.; PADILLA, A. Jorge, in "Designing Antitrust Rules for Assessing Unilateral Practices: A Neo-Chicago Approach", The University of Chicago Law Review, Vol. 72, n. 1, Symposium: Antitrust, Winter, 2005, pgs. 73-98)
} 


\subsection{A Crescente ImportânCia da InOVaÇÃo TeCnOlógiCa PaRA o Debate AtuAL SOBRE PropriedAde INTELECTUAL E CONCORRÊNCIA}

Nas considerações tecidas acima, fizemos uma breve descrição sobre como a inovação tecnológica passou a ocupar um papel de destaque no debate do antitruste, graças à releitura que os autores Neo-Chicago farão de SCHUMPETER para fins de sustentar a sua tese de que a não intervenção antitruste se justificaria sempre que fossem incertos os impactos sobre a inovação tecnológica (Teoria dos Custos do Erro).

No que se refere ao debate sobre Propriedade Intelectual, de certa forma, a inovação foi, desde cedo, invocada como uma das finalidades da proteção conferida aos inventores. Esta estratégia retórica sempre interessou aos defensores do regime da Propriedade Intelectual, pois significa defender o sistema a partir de uma (pretensa) perspectiva de interesse público e social, e não mais a partir de interesses estritamente individuais (vide o grande embate sobre Propriedade Intelectual que tomou lugar no Século XIX, conforme descrevemos no Capítulo inicial).

A partir da década de 1980, no entanto, esta ideia ganha importância central, na medida em que os economistas passam a rediscutir as teses de SCHUMPETER. A razão pela qual um retorno dos economistas a SCHUMPETER ocorre nesta época é incerta, mas pode estar relacionada com as crises econômicas então enfrentadas pelos Estados Unidos e pela Inglaterra, em contraste com o sucesso econômico do Japão, sucesso este que estava relacionado à inovação tecnológica, com o desenvolvimento de indústrias de alta tecnologia. SCHUMPETER, por sinal, lecionara no Japão, gozando de grande prestígio entre os economistas japoneses - inclusive, aqueles que compunham as equipes responsáveis pela elaboração de políticas governamentais.

Outra razão para um retorno à SCHUMPETER é o ressurgimento do interesse intelectual nos três pilares de seu pensamento: empreendedorismo, inovação e desenvolvimento econômico. Além disso, havia, desde a década anterior, uma forte crítica aos modelos estáticos neoclássicos ${ }^{260}$.

O debate internacional sobre a Propriedade Intelectual, portanto, também é influenciado por este "ressurgimento" de SCHUMPETER, conforme se pode inferir pela linguagem utilizada pelo artigo $7^{\circ}$ do Acordo sobre Aspectos dos Direitos de Propriedade

\footnotetext{
${ }^{260}$ McCRAW, Thomas K., "Schumpeter Ascending", in The American Scholar, Vol. 60, No. 3 (Summer 1991), pgs. 371-392, Published by: The Phi Beta Kappa Society
} 
Intelectual Relacionados ao Comércio (TRIPS) ${ }^{261}$, da Organização Mundial do Comércio, que estabelece, com uma das finalidades da Propriedade Intelectual, "a promoção da inovação tecnológica e da transferência e difusão da tecnologia, de forma conducente com o bem estar social e econômico".

Importante mencionar que houve também uma visão crítica quanto à pressuposta relação positiva entre Propriedade Intelectual e inovação por parte de alguns dos economistas que participaram mais ativamente das discussões envolvendo o TRIPS.

Destaca-se, por exemplo, Joseph E. STIGLiTz, que atuou como membro do Conselho Econômico do Presidente Clinton de 1993 a 1997 e como chief economist e senior vice president do Banco Mundial, de 1997 a 2000, tendo sido uma das vozes contrárias aos parâmetros internacionais estabelecidos pelo TRIPS.

JosePh STIGLiTz tornou-se crítico tanto da premissa de que "quanto mais forte fossem os direitos de Propriedade Intelectual, mais estímulo haveria para a inovação”, quanto da tese de que o custos derivados do "monopólio" conferido pelas patentes (leia-se: perdas em eficiência estática) seriam relativamente baixos em comparação com os ganhos em eficiência dinâmica proporcionados por tal "monopólio" - teses estas derivadas de SCHUMPETER. A leitura do trecho abaixo dá uma boa conta de tais críticas, além de escancarar o jogo de interesses econômicos que estava por trás das negociações do TRIPS:

"One of the important results of my work, developed in a number of my papers, was that the
invisible hand often seemed invisible because it was not there. This led me to a certain degree
of skepticism about the standard perspectives on intellectual property. When I was at the
Council of Economic Advisors we opposed the Traded-Related Aspects of Intellectual Property
Rights Agreement (TRIPS), part of the Uruguay Round of trade negotiations. Interestingly, so
did the Office of Science and Technology Policy. We were not alone in our opposition; indeed,
it was a view held by many, if not most, of the people who understood the issues. These views
stood in contrast to the views most of the people who had some special interest on this issue,
particularly from the pharmaceutical and entertainment industries, who argued that the
stronger the intellectual property rights the better. When I went to the World Bank, I continued
to be involved in the issue. We had concluded that what separates developed and developing
countries is not just the disparity, the gap, in resources, but also the disparity in knowledge,
and closing that gap in knowledge is an essential part of successful development. We had
become concerned that TRIPS might make access to knowledge more difficult-and thus make

\section{${ }^{261}$ TRIPS - Artigo 7. Objetivos:}

"A proteção e a aplicação de normas de proteção dos direitos de propriedade intelectual devem contribuir para a promoção da inovação tecnológica e para a transferência e difusão de tecnologia, em benefício mútuo de produtores e usuários de conhecimento tecnológico e de uma forma conducente ao bem-estar social e econômico e a um equilíbrio entre direitos e obrigações". 
closing the knowledge gap, and development more generally, more difficult. We also worried about the effects of TRIPS on access to life-saving medicines; TRIPS attempted (successfully) to restrict access to generic medicines, putting these drugs out of the financial reach of most in the developing countries. The World Bank has an annual report called the World Development Report, which highlights a key development issue every year. During the first year I was at the World Bank, .we focused on the problems of knowledge for development. That year's report argued that TRIPS imposed an unbalanced intellectual property regime ${ }^{262}$.

E, ainda segundo Stiglitz, os custos de um sistema de Propriedade Intelectual distorcido poderiam, na verdade, ser superiores a outras formas de monopolização, bloqueando o processo de inovação, ao contrário do que induz a redação do TRIPS:

"If we do not design this legal framework properly, however, it may actually impede innovation. That is where I will eventually take this argument. Before getting there, though, I want to point out that the social cost of the distortion of the patent system is particularly high. (By contrast, Schumpeter suggested that it would be lower than for other forms of monopolization.)" 263

Tendo em vista que, como demonstrado, o debate em ambas as esferas analisadas neste trabalho (antitruste e Propriedade Intelectual) passa a acompanhar SCHUMPETER, é importante deter-se um pouco mais nesse autor, a fim de melhor ter em conta os argumentos baseados em suas ideias.

\subsubsection{JOSEPH ALOIS SCHUMPETER}

JOSEPH AlOIS SCHUMPETER foi um teórico austríaco que estudou com EUGEN VON BÖHM-BAWERK e CARL MENGER - este último, um dos autores que, ao lado de WILLIAM JEVONS e LÉON WALRAS, contribuiram para um maior refinamento técnico da teoria econômica clássica, ao introduzirem, na ciência econômica, o conceito de utilidade marginal $^{264}$.

Nascido em Triesch, na Áustria, em 1883 (mesmo ano de nascimento de JOHN MAYNARD KEYNES) e tendo vivido a efervescente atmosfera da capital do império austrohúngaro do início do Século XX, ScHUMPETER gradua-se em Direito em Viena, em 1906.

\footnotetext{
${ }^{262}$ STiglitz, Joseph E., "Economic Foundations of Intellectual Property Rights", Duke Law Journal, Vol. 57, No. 6 (Apr., 2008), pgs. 1693-1724, Published by: Duke University School of Law.

${ }^{263}$ STIGLITZ, Joseph E., "Economic Foundations of Intellectual Property Rights", Duke Law Journal, Vol. 57, No. 6 (Apr., 2008), pgs. 1693-1724, Published by: Duke University School of Law.

${ }^{264}$ MCCRAW, Thomas K., "Schumpeter Ascending", in The American Scholar, Vol. 60, No. 3 (Summer 1991), pgs. 371-392, Published by: The Phi Beta Kappa Society
} 
Na universidade, cursou a disciplina da Economia, tendo como contemporâneos LUDWIG VON MISES, que se vincula à terceira geração da chamada Escola Austríaca de Economia, bem como vários jovens marxistas notáveis, como RUDOLF HILFERDING e EMIL LEDERER $^{265}$.

SCHUMPETER editou seu primeiro livro, um longo tratado sobre teoria econômica, em 1908, quando ele tinha somente vinte e cinco anos de idade. Seu propósito em escrevêlo era apresentar um quadro de trabalho mais rigoroso à economia alemã.

Àquela época, no rescaldo do notório Methodenstreit, protagonizado pelo historicista Gustav Schmoller de um lado e pelo teórico CARL Menger do outro, a academia alemã permanecia relativamente hostil à teoria ${ }^{266}$.

No livro, SCHUMPETER também prenunciou outro preconceito vitalício: uma repugnância a aplicar prematuramente a teoria para elaboração de políticas econômicas. Ao mesmo tempo, ele aceitou o ferramental neoclássico e hipóteses, tais como a análise estática, competição perfeita e tendência constante ao equilíbrio. Esses traços básicos do sistema neoclássico, postulados por WALRAS, todavia, não sobreviveriam intactos nos futuros escritos de SCHUMPETER ${ }^{267}$. Dois meses antes de sua morte, em novembro de 1949, ele publicou um trabalho argumentando em prol do método histórico na análise dos ciclos de negócios ${ }^{268}$.

Esse contraste pode levar a uma errônea ideia de evolução no pensamento do autor, de um pensamento original pautado na ciência matemática, para um período de maturidade acadêmica, em que teria se curvado à importância do dado histórico no estudo dos fenômenos econômicos. Essa ideia é de fato equivocada, pois SCHUMPETER jamais abandonou o apego à teoria e à ciência matemática, nem tampouco ignorou a importância de se voltar para o dado histórico ${ }^{269}$.

De acordo com suas próprias palavras, quanto à metodologia, SCHUMPETER trabalhou para "a combination of historical, statistical and theoretical analysis, and their

\footnotetext{
${ }^{265}$ MCCRAW, Thomas K., "Schumpeter Ascending", in The American Scholar, Vol. 60, No. 3 (Summer 1991), pgs. 371-392, Published by: The Phi Beta Kappa Society

${ }^{266}$ MCCRAW, Thomas K., "Schumpeter Ascending", in The American Scholar, Vol. 60, No. 3 (Summer 1991), pgs. 371-392, Published by: The Phi Beta Kappa Society

${ }^{267}$ MCCRAW, Thomas K., "Schumpeter Ascending", in The American Scholar, Vol. 60, No. 3 (Summer 1991), pgs. 371-392, Published by: The Phi Beta Kappa Society

268 "The Historical Approach to the Analysis of Business Cycles", Universities-National Bureau Conference on Business Cycle Research, November, 25-27, 1949. MACHLUP, Fritz, "Schumpeter's Economic Methodology", The Review of Economics and Statistics, Vol. 33, no 2 (May, 1951), pgs. 145-151

${ }^{269}$ MACHLUP, Fritz, "Schumpeter's Economic Methodology", The Review of Economics and Statistics, Vol. 33, no 2 (May, 1951), pgs. 145-151
} 
mutual peaceful penetration" 270 , defendendo que "there is no contradiction between the historical and the abstract approaches, and that the only difference was in their interest for different problems ${ }^{271}$ ",

Tal ecletismo de SCHUMPETER torna difícil enquadrar este economista em qualquer uma das escolas de pensamento econômico que suas ideias tangenciam - neoclássica, austríaca, ou histórica.

De fato, pode-se observar que até mesmo a visão marxista do capitalismo como um processo dinâmico profundamente influenciou SCHUMPETER - o que pode se explicar devido aos vários diálogos travados com colegas marxistas. Efetivamente, SCHUMPETER, possui afinidades com as linhas de pensamento citadas, mas sua obra não se limitou a elas $^{272}$.

Metodologicamente eclético, o pensamento de SCHUMPETER era rigoroso ao insistir em três princípios cardeais. Ele se referia à economia como uma ciência, mas ao tipo da física do que ao das ciências sociais, mas também defendeu que toda boa economia deveria incluir teoria, história e estatística, assim como também trabalhava incansavelmente em favor da econometria.

Suas próprias publicações mais precoces tomavam uma abordagem matemática e ele posteriormente ajudou a organizar a Sociedade de Econometria e serviu como seu presidente. Em uma contradição típica dentro de sua natureza, contudo, ele próprio não era um matemático de primeira linha, como revelariam seu amigo RAGNAR FRISCH e um de seus alunos mais famosos, PAUL SAMUELSON ${ }^{273}$.

\footnotetext{
${ }^{270}$ SCHUMPETER, Joseph, "Business Cycles: A Theoretical Historical and Statistical Analysis of the Capitalist Process", New York Toronto London : McGraw-Hill Book Company, 1939

${ }^{271}$ SCHUMPETER, Joseph, "Das Wesen and Hauptinhalt der theorestichen Nationalökonomie", Leipzig, 1908, p. 7, apud MACHLUP, Fritz, "Schumpeter's Economic Methodology", The Review of Economics and Statistics, Vol. 33, no 2 (May, 1951), pgs. 145-151

${ }^{272}$ McCRAW, um dos biógrafos de SCHUMPETER, ilustra tal ecletismo do autor, que era visto por seus alunos como uma de suas maiores qualidades como professor: "Ele via algo útil em praticamente todas as abordagens, e por sua vez, era respeitado por economistas para além do espectro doutrinário. Um de seus mais calorosos admiradores era Paul Sweezy, um jovem marxista que o auxiliou no curso de graduação em teoria. Como muitos economistas, Sweezy achou de todo surpreendente que,em seus cursos, Schumpeter tenha omitido qualquer referência ao seu próprio trabalho. o invés disso, ele bancava o advogado do diabo. Como escreveu Sweezy, ele tinha "todas as mais raras qualidades em um professor - ele nunca mostrou qualquer inclinação a julgar estudantes ou colegas com base em quanto eles concordavam com ele". Keynesianos (que eram a maioria substancial após 1936) e Marxistas (frequentemente, em minoria de um, pelo menos enquanto estive em Cambridge) eram igualmente bem vindos em seu ciclo. Ele não se importava com o que nós pensávamos, contanto que pensássemos".("Schumpeter Ascending", in The American Scholar, Vol. 60, No. 3 (Summer 1991), pgs. 371-392, Published by: The Phi Beta Kappa Society - tradução livre)

${ }^{273}$ McCRAW, Thomas K., "Schumpeter Ascending", in The American Scholar, Vol. 60, No. 3 (Summer 1991), pgs. 371-392, Published by: The Phi Beta Kappa Society
} 
À época de sua chegada à Harvard, em 1932, SCHUMPETER era já reconhecido como economista consagrado, tendo tido uma experiência curta (e fracassada) como Ministro de Estado, e, após isso, lecionado na Alemanha e no Japão - países que o acolheram após um período de ruína financeira e ostracismo. No Japão, como já dito, foi aclamado nacionalmente, tendo as suas ideias influenciado fortemente a elaboração de políticas econômicas naquele país ${ }^{274}$.

Em Harvard, polarizou com KEYNES, ao defender pontos de vista antagônicos sobre a explicação das crises cíclicas do capitalismo e do crescimento econômico - problemas estes que evidenciavam as insuficiências da teoria econômica neoclássica então dominante.

A teoria neoclássica, basicamente, defende a existência de um equilíbrio estático, abalável apenas por curtos períodos, devido à superprodução de determinados insumos, sendo que o crescimento econômico ocorreria apenas graças a fatores exógenos ao sistema $^{275}$.

Como consequência, a teoria do equilíbrio estático praticamente não se ateve à inovação. A rigor, a única prova da eficiência de mercados competitivos foi fornecida pelo modelo de ARROw-DEBREu e tal modelo toma como premissa que a tecnologia é fixa ${ }^{276}$.

Alguns autores que precederam SCHUMPETER - como MARShall, ARTHUR CeCIL PIGOU e H.L MOORE, a quem SCHUMPETER expressamente refere - já haviam apontado as insuficiências do modelo estático neoclássico - sem, no entanto, abandonar seus marcos teóricos ${ }^{277}$.

${ }^{274}$ McCRAW, Thomas K., "Schumpeter Ascending", in The American Scholar, Vol. 60, No. 3 (Summer 1991), pgs. 371-392, Published by: The Phi Beta Kappa Society

${ }^{275}$ MCCRAW, Thomas K., "Schumpeter Ascending", in The American Scholar, Vol. 60, No. 3 (Summer 1991), pgs. 371-392, Published by: The Phi Beta Kappa Society

${ }^{276}$ STIGLITZ, Joseph E. Economic Foundations of Intellectual Property Rights, Duke Law Journal, Vol. 57, No. 6 (Apr., 2008), pgs. 1693-1724, Published by: Duke University School of Law.

277 "Marshall, na realidade, protesta repetidamente contra as limitações do aparato estático - cf. especialmente em carta sua ao prof. John E. Clark. Ora, se fosse verdade que raciocinar por meio dele está "demasiadamente distante da vida para ser útil", então, a maior parte da análise dos Princípios seria inútil, como seria a maior parte de toda ciência exata. Isto porque a análise marshalliana apoia-se tanto nas hipóteses da estática quanto na estrutura do prof. Clark. Mas isto não é verdade. Não há nada de indevidamente abstrato em considerar um a um os fenômenos que agem no funcionamento da vida econômica sob determinadas condições. Ao contrário, significa dar a estes problemas o tratamento que eles requerem. E o próprio Marshall contribuiu substancialmente para a perfeição deste tratamento ao criar instrumentos tão preciosos como seu excedente do consumidor e sua quase renda. Além disso, ele fez uso de hipóteses de estática tanto na sua teoria de distribuição como nos fundamentos dos seus catallactics; de fato, em ponto decisivo, tratando de detalhes que exigem rigor de análise, ele limitou seus argumentos aos custos crescentes. Finalmente, ele próprio insistiu na irreversibilidade e nas dificuldades peculiares de uma curva de oferta negativa e, ao fazê-lo, chega muito perto de dizer quase o mesmo que foi dito anteriormente. A lealdade para com a tradição, a aversão a parecer demasiado "teórico" - à qual ele atentava significativamente - e aquela sua tendência, que em outros aspectos devemos tanto, de resumir os problemas da vida prática podem justificar o fato de ele não ter sido conclusivo, e, por isso, só posso concordar com o Sr. Keynes em considerar como a parte menos satisfatória de sua análise, devidamente conduzida pelo prof. 
Tendo se valido da ideia de inovação como elemento endógeno de transformação econômica $^{278}$, e, ainda, tendo como antecedente a eficiência dinâmica já presente em autores identificados com a Escola Austríaca de Economia ${ }^{279}$, SCHUMPETER descreverá o capitalismo como um processo dinâmico, no qual as estruturas endógenas do sistema são destruídas de tempos em tempos, por meio do desaparecimento de commodities, processos e mercados e sua substituição por novos, por meio da inovação.

Sraffa. Isto acarreta uma série de consequências, mas, fundamentalmente, o que dissemos nada mais é do que o desenvolvimento de uma tendência oculta por outras coisas, mas ainda presente nos Princípios. Podemos acrescentar o peso da autoridade do prof. Pigou, porque no artigo citado em nota anterior ele exclui da função de custo, por motivos de "coerência lógica", o conjunto destes fenômenos que nós mesmos nos propomos a excluir, pela mesma razão. Na verdade, ele até rejeita o que chamamos de lei fundamental dos custos. Mas o faz apoiado apenas na hipótese técnica de que é "impossível construir-se uma função de custos" baseada nas mudanças dos valores relativos dos fatores de produção, possíveis de ocorrer em consequência das mudanças na escala de produção de uma indústria. Por outro lado, ele não rejeita inteiramente as economias externas. Mas o que ele conserva delas são meramente "variações nos custos agregados associados a variações na escala de produção e decorrentes destas" (op. cit., p. 189); e se inserirmos, como devemos, a palavra "automaticamente” nesta frase, serão encontrados poucos casos, se houver, que correspondam àquele critério, como foi apontado pelo prof. Young (Quarterly Journal of Economics, p. 678, Aug. 1913). Naturalmente, a expansão e o aperfeiçoamento estão intimamente ligados na vida real. Mas, como tentaremos explicar no texto, a causa principal é a que vai do aperfeiçoamento à expansão, e não pode ser de forma alguma adequadamente tratada pela análise estática. Se for correto, a posição do prof. Pigou poderá ser vista como bem próxima àquela assumida no texto, caso o leitor leve em conta o fato de que as economias, antes de se tornarem externas, devem geralmente ser internas em alguma firma ou firmas da mesma ou de alguma outra indústria.Não pretendo, além disso, com o que disse, levantar objeções às tentativas de determinar estatisticamente as funções de custo. Pelo contrário, sou um humilde admirador do trabalho pioneiro feito pelo prof. H. L. Moore e seus seguidores, apesar de pedir licença para dizer que falar de "equilíbrios em movimento" pode ser enganoso ante o fato de que o que realmente acontece é uma destruição dos equilíbrios no significado comumente aceito". (SCHUMPETER, Joseph A., "A Instabilidade do Capitalismo", Clássicos de Literatura Econômica - Textos Selecionados de Macroeconomia,

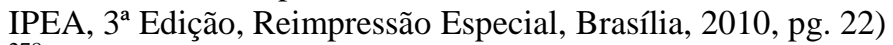

${ }^{278}$ Embora tenha omitido uma referência explícita a Marx nas primeiras edições de sua obra mais famosa "Teoria do Desenvolvimento Econômico" ("Theorie der wirtschaftlichen Entwicklung", Original em Alemão de 1912, posteriormente revisada em 1926 e sua versão em inglês, de 1934, "Theory of Economic Development"), Schumpeter veio a corrigir tal omissão no prefácio da versão japonesa de 1937 , reconhecendo a importância da influência de Marx para a ideia da inovação como elemento endógeno de transformação econômica: "It was not clear to me at the outset what to the reader will be obvious at once, namely, that [my] ideas and [my] aim are exactly the same as the Idea and the aim which underlie the economic teaching of KARL MARX. In fact, what distinguishes him from the economists of his own time and those who preceded him, was precisely a vision of economic evolution as a distinct process generated by the economic system itself" (Tradução para o Inglês do Prefácio da Edição Japonesa de "Teoria do Desenvolvimento Econômico, 1937, apud, ScHERER, F.M., "On Schumpeter”, Palestra na Harvard Kennedy School of Government, dispoonível em http://youtu.be/-ZvBjd1003M). Para FrEDERIC M. SCHERER, no entanto, a omissão de Schumpeter foi proposital, pois ele havia originalmente escrito em meio ao Império Austro-Húngaro, um ambiente politicamente ultra consdervador. Suas teorias não teriam credibilidade se fossem associadas a MARX. Ainda segundo SCHERER, mesmo nos Estados Unidos das primeiras décadas do Século XX havia resistência quanto às ideias marxistas, o que mudaria radicalmente por volta da década de 1940, quando o relativo sucesso da União Soviética atraiu o interesse acadêmico nas teorias marxistas. Não por acaso, segundo SCHERER, SCHUMPETER dedicou grande atenção às ideias de Marx em "Capitalism, Socialism and Democracy" (1942).

${ }^{279}$ DE Soto, Jesús Huerta, "The Essence of the Austrian School and the Concept of Dynamic Efficiency", REBS Review of Economy, Volume 4, Issue 1, pgs. 15-32, 2011, ISSN - 1843-763x 
A esta destruição criativa, deflagrada pela inovação, se seguiriam ciclos de imitação, difusão e equilíbrio momentâneo, interrompido novamente por novos ciclos de inovação $^{280}$.

A inovação, em SCHUMPETER, é, portanto, vista ao mesmo tempo como verdadeira essência do sistema e causa maior de sua instabilidade intrínseca ${ }^{281}$.

SCHUMPETER criticará a visão de curto prazo de KEYNES e a suposta ausência, neste autor, de uma teoria completa para o processo capitalista, atribuindo à inovação, e aos empreendedores incumbidos de sua introdução, um papel central na transformação endógena das estruturas do capitalismo. Também se mostrará um forte crítico da política do New Deal e da ferrenha repressão política da época contra os grandes negócios ${ }^{282}$.

SCHUMPETER defendeu que as grandes empresas (i.e., monopólios) seriam mais aptas a produzir inovação, por poderem, mais facilmente, suportar os enormes riscos da atividade inventiva. Uma preocupação excessiva com os monopólios não seria justificada, na visão de SCHUMPETER, uma vez que sempre existiria pressão competitiva sobre o mercado, porque a posição do monopolista estaria constantemente ameaçada pela possibilidade de destruição do próprio mercado pela inovação. Por outro lado, ao menos na perspectiva histórica do autor, os Estados Unidos não haviam conhecido um monopólio econômico excessivamente duradouro até então, para que fosse considerado nocivo ${ }^{283}$.

No que se refere particularmente ao tema da relação entre a concorrência e a inovação e o papel da proteção da Propriedade Intelectual, as idéias de ScHUMPETER serão o ponto de partida para um intenso debate econômico, no qual se pretendeu, inclusive, testar empiricamente a hipótese Schumpeteriana de que mercados mais concentrados seriam mais tendentes a produzir inovação.

\subsubsection{A Dicotomia Schumpeter X Arrow: Monopólios são mais Propensos a ProduZIr InOVAÇão?}

ARROw, mais de duas décadas após o último livro de SCHUMPETER publicado em vida (1942), retomará e rejeitará a hipótese de que mercados concentrados seriam mais propensos a produzir inovação.

\footnotetext{
${ }^{280}$ SCHUMPETER, Joseph, "Capitalism, Socialism and Democracy”, London: Allen Unwin,1943.

${ }^{281}$ SCHUMPETER, Joseph, Capitalism, Socialism and Democracy, London: Allen Unwin, 1943.

${ }^{282}$ STIGLITZ, Joseph E., "Economic Foundations of Intellectual Property Rights", Duke Law Journal, Vol. 57, No. 6 (Apr., 2008), pgs. 1693-1724, Published by: Duke University School of Law.

${ }^{283}$ SCHUMPETER, Joseph, Capitalism, Socialism and Democracy, London: Allen Unwin, 1943
} 
ARROW divergirá dessa ideia, ao sustentar que, em certo nível, na eventualidade de haver barreiras à entrada - como, por exemplo, a Propriedade Intelectual - o incentivo marginal do monopolista para investimento em inovações passaria a ser decrescente, razão pela qual o processo de inovação deveria ser confiado a empresas de menor porte ${ }^{284}$.

Além disso, segundo Arrow, as atividades de pesquisa - sobretudo pesquisas de base, as quais considerou como chave para o processo de inovação - deveriam ser financiadas pelo governo, ou por outras instituições não sujeitas aos incentivos de perdas $e$ ganhos do mercado ${ }^{285}$.

O debate em torno da influência da organização industrial sobre a inovação e o papel da regulação antitruste, tendo como ponto de partida o contraponto entre as ideias de SCHUMPETER e ARROw, produzirá uma extensa literatura que se dedicou a discutir a hipótese de que os monopolistas teriam um maior incentivo à inovação.

Com base em uma analogia com o darwinismo, que não havia sido expressamente reconhecida por SCHUMPETER ${ }^{286}$, GEORGE STIGLER, por exemplo, defenderá que as forças de seleção natural justificariam a manutenção do poder das firmas dominantes, uma vez que tal dominância seria o resultado de um superior desempenho tecnológico e $\operatorname{administrativo~}^{287}$.

O estruturalismo Cepalino latino-americano possui certas convergências com as teses Schumpeterianas, como o reconhecimento da importância do processo de mudança

\footnotetext{
284 "Kenneth Arrow observed that, with patent protection, the incentive to invest in research and development is less under monopoly than under competitive conditions, which would suggest that monopolistic firms would be slower than competitors in developing new products or processes, ceteris paribus". (GILBERT, J. Richard, and Newberry, David. M.G., "Preemptive Patenting and the Persistance of Monopoly", The American Economic Review, Vol. 72, n 3, Jun, 1982, pg. 514-526).

${ }^{285}$ ARROW, Kenneth, "Economic Welfare and the Allocation of Resources for Invention", in "The Rate and Direction of Inventive Activity: Economic and Social Factors", Universities-National Bureau, UMI, ISBN: 087014-304-2, 1962, pg. 609-626.

286 "Há muito a economia vem flertando com as idéias de evolução e seleção natural, com o darwinismo e com a biologia evolucionária, mas até recentemente sem maiores compromissos. Os exemplos clássicos são Marshall, Veblen e, posteriormente, Hayek, de forma explícita, e Schumpeter, de forma implicita, ainda que talvez potencialmente mais fértil. Após 1950, uma incursão famosa mais ainda pouco sistemática foi o debate iniciado por Alchian (1950) e corroborado por Friedman (1953), e mais tarde por Becker (1962). Nesses casos, a introdução de elementos evolucionários, na tentativa de deslocar a crítica ao suposto comportamento maximizador de lucros da firma neoclássica do nível individualmente observável para níveis agregados, é ainda pautada por simples analogia com a seleção natural, e os argumentos permanecem no plano da análise econômica tradicional". (PossAS, Mario Luiz, "Economia Evolucionária NeoSchumpeteriana: Elementos para uma integração micro-macrodinâmica", in Estudos Avançados, vol. 22, $\mathrm{n}^{\circ}$ 63, p. 281-305)

287 apud GILBERT, J. Richard, and NewBerry, David. M.G., "Preemptive Patenting and the Persistance of Monopoly", The American Economic Review, Vol. 72, nº 3, Jun, 1982, pg. 514-526
} 
tecnológica e seus efeitos sobre a estrutura econômica. Para CELSO FuRTADO, porém, a espinha dorsal deste processo não estaria na inovação, e sim, na acumulação de capital $^{288}$.

Embora a perspectiva de CELSO FURTADO seja predominantemente macroeconômica - ao passo que a análise antitruste, foco de nosso trabalho, parte, em geral, de uma perspectiva microeconômica - é importante, para os fins deste trabalho, a crítica de que o processo de mudança tecnológica seria conduzido, majoritariamente, pela busca por acumulação e que o progresso técnico assim alcançado tenderia a gerar desigualdades sociais. FURTADO defende que a superação do subdesenvolvimento se dá pela internalização dos centros de decisão econômica, e deve ser conduzida por valores outros que não a mera lógica de acumulação, por meio do planejamento estatal com vistas a resguardar o mercado interno e o interesse nacional.

Esta linha de raciocínio, embora convergindo em parte com as teses de SCHUMPETER, se aproxima de ARROw, para quem a atividade de Pesquisa e Desenvolvimento deve ser impulsionada e conduzida pelo Estado (refutada, portanto, a tese schumpeteriana de que a mera concentração econômica geraria a transformação econômica pela inovação).

OLIVER WILLIANSON, por outro lado, seguindo uma abordagem pautada nos custos de transação, defenderá que as imperfeições de mercado contribuiriam para a persistência de monopólios e que, contrario senso, na ausência de falhas de mercado, a concorrência eliminaria as empresas dominantes ${ }^{289}$.

Segundo PARTha DASGUPTA e JosePh STIGLiTZ, a crença de que a concorrência em Pesquisa e Desenvolvimento se tornaria substituta da concorrência no mercado de produtos, ou que, em última instância, ensejaria a concorrência no mercado de produtos é de se suspeitar, pois há condições sob as quais os monopólios podem persistir, mesmo sem outras barreiras à entrada, que não somente aquelas representadas pelo sistema de patentes $^{290}$.

RICHARD GILBERT e DAVID NEWBERRY, ao seu turno, construirão um modelo que considerará a interação estratégia entre agentes, para analisar os incentivos criados por

\footnotetext{
${ }^{288}$ FURTADO, Celso, "Desenvolvimento e Subdesenvolvimento", Rio de Janeiro, Fundo de Cultura, 1961, pg. 272.

${ }^{289}$ apud GILBERT, J. Richard, and Newberry, David. M.G., "Preemptive Patenting and the Persistance of Monopoly", The American Economic Review, Vol. 72, n 3, Jun, 1982, pg. 514-526

${ }^{290}$ DASGUPTA, Partha and STIGLITZ, Joseph, "Uncertainty, Industrial Structure and the Speed of R\&D”, 11 Bell Journal of Economics, 1, 27, 1980.
} 
instituições, como o direito de patentes, para que empresas com poder monopolista mantenham sua posição dominante ${ }^{291}$.

Este modelo, em resumo, descreverá o recurso às patentes como uma forma de barrar a entrada de novos competidores no mercado. Segundo os autores, os monopolistas lançariam mão desse recurso sempre que os custos de antecipar a patente, ou os custos com $\mathrm{P} \& \mathrm{D}$, fossem inferiores às perdas em lucros que seriam causadas pelo ingresso de novos competidores no mercado ${ }^{292}$.

A existência de programas de $\mathrm{P} \& \mathrm{D}$ e até mesmo o depósito de patentes, contudo, não implica, necessariamente, a implementação da inovação, com o emprego da ideia protegida na produção, mas pode representar apenas um bloqueio à entrada de novos competidores - mesmo em um mercado sem falhas.

Segundo os autores, o monopolista poderá decidir por efetivamente introduzir a inovação, porém, tomará tal decisão com base em outras circunstâncias do mercado. Ainda, os efeitos indesejáveis do uso de patentes sem intuito de produção (sleeping patents) seriam difíceis de evitar, pelas dificuldades de identificar esta prática, bem como em razão da existência de alternativas aos monopolistas para manterem sua posição dominante $^{293}$.

Conforme observa FrederiC M. SCHERER, de um modo geral, a relação entre tamanho e insumos/produção em inovação é, em média, vagamente proporcional. Empresas relativamente pequenas e fora do mercado, contudo, aparentemente, originariam uma fração desproporcional das inovações mais radicais.

Uma descoberta paralela é que parece haver uma relação em forma de um "U" invertido entre a atividade em P\&D e o nível de concentração econômica. A relação entre taxas de $\mathrm{P} \& \mathrm{D} / \mathrm{vendas}$ aumentaria com a concentração em níveis modestos, especialmente em indústrias cuja base de conhecimento avança de forma lenta. A relação atingiria um pico ao nível de concentração de quatro firmas no mercado, entre 50\% e 60\%. A partir daí, um padrão decrescente se apresenta.

SCHERER concorda que tais estatísticas se enfraquecem ou anulam totalmente quando levadas em conta as diferenças entre as indústrias quanto às oportunidades

\footnotetext{
291 Gilbert, J. Richard, and Newberry, David. M.G., "Preemptive Patenting and the Persistance of Monopoly", The American Economic Review, Vol. 72, n 3, Jun, 1982, pg. 514-526

292 Gilbert, J. Richard, and Newberry, David. M.G., "Preemptive Patenting and the Persistance of Monopoly", The American Economic Review, Vol. 72, n 3, Jun, 1982, pg. 514-526

${ }^{293}$ Gilbert, J. Richard, and NewberRY, David. M.G., "Preemptive Patenting and the Persistance of Monopoly", The American Economic Review, Vol. 72, n 3, Jun, 1982, pg. 514-526
} 
tecnológicas e possibilidades de se apropriar dos benefícios da inovação. Tais dados, porém, sugerem que as condições de oferta e demanda são mais importantes que a estrutura de mercado como determinantes do vigor tecnológico ${ }^{294}$.

RICHARD GILBERT conclui que a literatura empírica não apoia a conclusão de que grandes empresas promovem inovação por possuírem altos fluxos de caixa, economias de escala (acima de certa faixa) ou por permitirem a diversificação de risco - contrariando, portanto, o argumento de SCHUMPETER de que o monopólio poderia gerar inovação por supostamente possuir uma plataforma mais estável para $\mathrm{P} \& \mathrm{D}^{295}$.

Por outro lado, nem a teoria nem as evidências empíricas suportariam uma conclusão forte de que a concorrência é um estímulo eficaz à inovação. Há poucas evidências de que existiria um nível ótimo de concorrência para estimular os investimentos em P\&D. Além disso, os estudos empíricos teriam falhado em provar uma relação entre concentração de mercado e investimentos em $\mathrm{P} \& \mathrm{D}$, quando são levadas em conta diferenças de características entre as indústrias, como oportunidades tecnológicas e o nível de proteção existente quanto à apropriação dos lucros decorrentes da inovação.

GILBERT sugere que a pesquisa em indústrias específicas poderia conduzir a resultados mais conclusivos. Logo, os estudos empíricos até aqui realizados não validam a tese de SCHUMPETER de uma forma geral $^{296}$.

Para HovenKAMP, SCHUMPETER estava correto ao afirmar que os ganhos de longo prazo pela inovação superariam os ganhos resultantes de uma intervenção governamental com a finalidade de tornar a economia mais competitiva, de acordo com os tradicionais critérios de preço e oferta. No entanto, o autor reconhece que o problema de se mensurar as perdas resultantes de restringir uma inovação seria equivalente ao problema de se mensurar, de antemão, os ganhos que a inovação teria produzido caso tivesse sido introduzida. Na maior parte dos casos, um julgamento ex ante seria praticamente impossível, e, em todos os casos, altamente especulativo ${ }^{297}$.

\footnotetext{
${ }^{294}$ SCHERER, F.M. "Does Antitrust Compromise Technological Efficiency? A Conversation with F.M. Scherer”, Eastern Economic Journal, Volume XV, Nº1, January-March, 1989.

${ }^{295}$ GILBERT, Richard, "Looking for Mr. Schumpeter: Where Are We in the Competition-Innovation Debate?", the National Bureau of Economic Research, Vol. 6 "Innovation Policy and the Economy", Jaffe, Adam B., Lerner, Josh and Stern, Scott (editors)., the MIT Press, August, 2006.

${ }^{296}$ GILBERT, Richard, "Looking for Mr. Schumpeter: Where Are We in the Competition-Innovation Debate?", the National Bureau of Economic Research, Vol. 6 "Innovation Policy and the Economy", Jaffe, Adam B., Lerner, Josh and Stern, Scott (editors)., the MIT Press, August, 2006.

${ }^{297}$ HovenKAMP, Herbert J. "Schumpeterian Competition and Antitrust", University of Iowa Legal Studies Research Paper, Number 08-43, October, 2008.
} 
Mesmo com tais limitações, HovenKAMP afasta a conclusão de que o antitruste nada poderia fazer quanto ao problema da inovação. Em certos casos, seria necessário considerar consequências de curto prazo para a concorrência e ignorar as possibilidades de inovação que se mostrassem muito remotas. Em outros casos, deve-se considerar qual é o resultado mais provável: a inovação ou sua restrição. A probabilidade de que uma conduta venha a reforçar a inovação deve servir para enfraquecer ou, talvez, até mesmo tornar prejudicada, a preocupação levantada pelo antitruste. Em contraste, a probabilidade de uma prática restringir a inovação mereceria ser olhada com cautela ainda maior ${ }^{298}$.

Michael Katz e Howard ShElansKi, por sua vez, defendem que, em mercados de alta tecnologia, o conceito de concorrência no mercado (i.e., concorrência por preços) é, efetivamente, substituído pela concorrência de agentes pelo mercado, por meio da inovação tecnológica. Em tais mercados, sujeitos a rápido progresso tecnológico, o que haveria seria uma sucessão de monopólios, nos moldes preconizados por SCHUMPETER ${ }^{299}$.

STIGLITZ, no entanto, critica a premissa de SCHUMPETER quanto à temporariedade dos monopólios. Para ele, uma vez estabelecidos, os monopólios poderiam ser perpetuados, havendo, inclusive, um incentivo econômico para que isso viesse a ocorrer especialmente, em mercados em que há barreiras à entrada, como externalidades de rede (network externalities) e custos de mudança (swtiching costs).

Essa seria a razão para casos como o da Microsoft, em que o poder de monopólio persistiu mesmo após afastadas as práticas abusivas ${ }^{300}$.

STIGLITZ conclui que os incentivos para inovação de um monopolista não apenas são inferiores, como, também, podem aumentar os custos de seus rivais, desencorajando a inovação e aumentando ainda mais seus lucros.

\footnotetext{
${ }^{298}$ HovENKAMP, Herbert J. "Schumpeterian Competition and Antitrust", University of Iowa Legal Studies Research Paper, Number 08-43, October, 2008.

299 "In some markets subjetct to strong technological progress, this process may play itself out repeatedly. That is, competition may take the form of a succession of "temporary monopolists" who displace one another through innovation. At any one time, there is little or no head-to-head price competition.But there is significant innovation competition over time. This pattern of competition is often referred to Schumpeterian rivalry, after Joseph Schumpeter, who asserted that it is a central feature of the modern economy". (KATZ, Michael L., SHELANSKI, Howard A., "Meger Policy and Innovation: Must Enforcement Change to Account For Technological Change?", National NBureau of Economic Research, Working Paper 1070 http://www.nber.org/papers/w10710)

300 "Some of my earlier research, however, pointed out that SCHUMPETER was wrong about the temporary nature of monopoly. Monopoly power, once established, can easily be perpetuated. Not only is it possible to perpetuate monopoly power, in fact, there is an incentive to do so. This is particularly evident in the case of network externalities and in situations where there are important switching costs, such as those that arise from learning. That is one of the reasons why Microsoft is so difficult to deal with. The monopoly power persists even after the bad practices which enabled it to create that power have been terminated". (STIGLITZ, Joseph E. "Economic Foundations of Intellectual Property Rights", Duke Law Journal, Vol. 57, No. 6, Apr., 2008, pgs. 1693-1724, Published by: Duke University School of Law).
} 
Desse modo, ao contrário do que supôs SCHUMPETER, o poder de monopólio mesmo aquele obtido por meio de um direito de Propriedade Intelectual - pode desencorajar a inovação, ao invés de incentivá-la ${ }^{301}$.

Ao ler os clássicos, é preciso compreender cada autor dentro de sua época. Ao defender que os monopólios não seriam duradouros, é preciso considerar que SCHUMPETER partiu de uma perspectiva histórica limitada. Levando-se em conta o seu apego aos dados históricos e à estatística é de se cogitar se, diante das pesquisas empíricas até aqui realizadas, SCHUMPETER atenuaria ou até mesmo reconsideraria algumas de suas conclusões.

Por outro lado, é inegável a contribuição deste clássico economista no que se refere à importância da inovação tecnológica para o desenvolvimento econômico. Além disso, os conceitos de eficiência dinâmica e de mercados de inovação desenvolvidos a partir de suas ideias têm sido utilizados como ferramentas analíticas do antitruste, como veremos.

\subsubsection{EficiênCIA Dinâmica E Mercados de TeCnOlogia E InOvaÇão}

Atualmente, as diretivas para licenciamento de Propriedade Intelectual emitidas pelo Departament of Justice e pela Federal Trade Comission reconhecem que uma determinada conduta ou estrutura podem afetar o preço ou o nível de oferta em três tipos de mercado ${ }^{302}$ : o mercado de bens e serviços existentes, o mercado tecnológico, consistente de propriedade intelectual passível de ser licenciada e de suas substitutas próximas e os mercados de inovação, consistentes de pesquisa e desenvolvimento dirigidos, particularmente, a produtos e processos novos e aprimorados e de seus substitutos próximos (tomorrow's products) ${ }^{303}$.

\footnotetext{
301 “(...) Not only do monopolists have a diminshed incentive for engaging in research themselves, but monopolists can also increase their profit by discouraging innovation by rivals and raising rivals' costs. It was, in my judgement, corretly argued that Microsoft did exactly this. In fact, one of the charges brought against Microsoft in on state was not only that Microsoft's behaviour raised prices, but that it actually also slowed down innovation. That argument was also an important part of the European Union's case against Microsoft. In particular, as Microsoft repeatedly demonstrated its abillity to leverage its monopoly power in $P C$ operating systems maintained through IPR) into other arenas (by, for instance, squashing rival innovators like Netscape), it discouraged innovation further. Innovators knew that if they produced a product of sufficient import to attract Microsoft's attention, they would lose the battle with this giant". (STIGLITZ, Joseph E. Economic Foundations of Intellectual Property Rights, Duke Law Journal, Vol. 57, No. 6, Apr., 2008, pgs. 1693-1724, Published by: Duke University School of Law).

${ }^{302}$ A distinção entre estes três mercados foi primeiro observada por WILLIAM F. BAXTER. "The Definition and Measurement of Market Power in Industries Characterized by Rapidly Developing and Changing Technolgies", 1984, 53 Antitrust Law Jorunal 717

${ }^{303}$ US DOJ and FTC Guidelines on the licensing of IP rights, (n 220) Section 3.2
} 
Os conceitos de Mercados de Tecnologia e de Inovação servem como ferramentas analíticas para evitar alterações de preço ou no nível de oferta de bens e de serviços ${ }^{304}$.

De acordo com as diretivas das autoridades reguladoras norte-americanas, mercados de tecnologia consistem de direitos de propriedade intelectual a serem licenciados, bem como de tecnologias ou bens que são substitutos próximos, de modo a limitar o exercício do poder de mercado (leia-se: poder no mercado referente àquela tecnologia passível de ser licenciada).

O conceito é aplicado quando direitos de Propriedade Intelectual são comercializados separadamente dos produtos nos quais eles são usados - isto é, a tecnologia é o próprio insumo, que é integrado tanto em um produto como em um processo produtivo. É o caso, por exemplo, de uma empresa no mercado a jusante que não é verticalmente integrada para a produção e comercialização de produtos no mercado a montante ${ }^{305}$.

O conceito também é referido no bloco de isenções da União Europeia ao Regulamento de Acordos de Transferência de Tecnologia e suas diretivas ${ }^{306}$.

Uma vez delineado o mercado de tecnologia relevante, tanto a Comissão Europeia como as Agências norte-americanas aplicam o teste SSNIP - Small but Significant and Non-transitory Increase in Price. Este teste visa identificar o menor grupo de tecnologias e bens sobre os quais um suposto monopolista exerce provável poder de mercado, por meio da imposição de um pequeno, mas significativo e não-transitório, aumento de "preço" (isto é, aumento de royalties) da ordem de 5-10\%.

$\mathrm{O}$ conceito de mercados de inovação permite às autoridades reguladoras da concorrência analisar os efeitos de uma prática anticompetitiva sobre esforços de pesquisa e desenvolvimento e, finalmente, futuros mercados de produtos.

GILBERT e SUNSHINE criaram um processo de cinco passos para identificar mercados de inovação: (i) deve-se identificar quais as atividades em P\&D de firmas que estejam em processo que possam se sobrepor; (ii) deve-se localizar eventuais fontes alternativas de P\&D; (iii) deve-se avaliar a concorrência real e potencial a partir de

\footnotetext{
${ }^{304}$ LiANOS, Ioannis \& DREYFuss, Rochelle C., "New Challenges in the Intersection of Intellectual Property Rights with Competition Law - A View from Europe and the United States", CLES Working Paper Series, $4 / 2013$

${ }^{305}$ LiANOS, Ioannis \& DREYFuss, Rochelle C., "New Challenges in the Intersection of Intellectual Property Rights with Competition Law - A View from Europe and the United States", CLES Working Paper Series, $4 / 2013$

${ }^{306}$ Guidelines on the application of Article 81 of the EC Treaty to technology transfer agreements (n 106) §§ $19-25$
} 
produtos no mercado a jusante que poderiam remover os incentivos para um hipotético monopolista em P\&D aumentar o preço ou reduzir a oferta; (iv) deve-se analisar efeitos competitivos potenciais sobre o investimento em $P \& D$ que poderiam resultar do aumento de concentração provocado pela conduta; (v) finalmente, deve-se analisar quaisquer possíveis eficiências resultantes da conduta, com potencial de aumentar o nível de oferta e reduzir o preço no mercado de inovação em análise, com a finalidade de determinar se tais eficiências seriam suficientes para contrabalancear eventuais efeitos anticoncorrenciais ${ }^{307}$.

O conceito, no entanto, foi objeto de críticas, primeiramente, porque a P\&D seria apenas um insumo à produção de bens e serviços, ao passo que a análise do direito de concorrência deveria se centrar no real fornecimento de futuros bens e serviços. Além disso, alega-se que as fontes de $\mathrm{P} \& \mathrm{D}$ podem ser de difícil identificação, na medida em que a inovação pode se originar a partir de lugares inesperados.

Finalmente, a teoria econômica não forneceria suporte empírico para a premissa de que uma diminuição no número de empresas envolvidas em $\mathrm{P} \& \mathrm{D}$ afetaria negativamente a inovação (relação entre estrutura de mercado e inovação), na medida em que a eliminação de gastos redundantes, a redução de custos e a possibilidade de a empresa capturar por completo os resultados do programa de $\mathrm{P} \& \mathrm{D}$ poderiam acelerar o processo de inovação, principalmente levando-se em conta a hipótese Schumpeteriana ${ }^{308}$.

Reconhecendo que acordos de licença podem afetar o desenvolvimento de bens ainda não existentes, as diretivas do Departament of Justice e da Federal Trade Comission reconhecem que tal impacto deverá ser analisado tanto como um efeito anticoncorrencial específico no mercado relevante de bens ou tecnologia como um efeito anticoncorrencial em um mercado específico de inovação ${ }^{309}$.

O conceito somente será usado quando a capacidade de realizar pesquisa e desenvolvimento no mercado relevante puder ser associada com ativos específicos ou características peculiares das empresas.

\footnotetext{
${ }^{307}$ GILBERT and Sunshine, "Innovation Markets and Competition Analysis: EU Competition Law and US Antitrust Law” (Edward Elgar 2006).

${ }^{308}$ LIANOS, Ioannis \& DREYFUSS, Rochelle C., "New Challenges in the Intersection of Intellectual Property Rights with Competition Law - A View from Europe and the United States", CLES Working Paper Series, $4 / 2013$

${ }^{309}$ US DOJ and FTC Guidelines on licensing rights (n 220), Section 3.2.3
} 
As autoridades levarão em conta os dados de mercado ou evidências de compradores e demais participantes do mercado sobre a importância concorrencial dos players no mercado de inovação ${ }^{310}$.

As diretivas europeias, por outro lado, conferem maior ênfase ao conceito de mercados de tecnologia do que ao de mercados de inovação.

A Comissão reconhece que os acordos de licença podem afetar mercados de inovação, mas, ao analisar tais efeitos, costuma limitar-se ao exame do impacto do acordo na concorrência quanto às tecnologias e produtos já existentes. Apenas em um número limitado de casos é que a Comissão considera útil ou necessário definir os mercados de inovação, o que ocorre, por exemplo, em casos em que se entende que um determinado acordo é realmente capaz de afetar a criação de novos produtos e é possível identificar, já em um estágio muito precoce, polos de pesquisa e desenvolvimento - casos estes em que o objeto da análise recai sobre se, com o acordo, restará um número suficiente de polos de pesquisa e desenvolvimento, a fim que a concorrência em inovação seja preservada ${ }^{311}$.

O próprio CADE já se utilizou do conceito de mercados de inovação, ao analisar o ato de concentração envolvendo a Monsanto do Brasil Ltda. e a Syngenta Seeds Ltda ${ }^{312}$.

$\mathrm{Na}$ oportunidade, o órgão analisou contrato de licenciamento de tecnologia celebrado entre ambas as empresas, mais especificamente, uma cláusula de exclusividade dos resultados de melhoramentos ou de evoluções sobre o ativo licenciado (conhecimento tecnológico). O CADE concluiu que a cláusula em questão teria efeito anticoncorrencial não no mercado relevante dos produtos (milho e outros), mas, sim, no mercado de inovação, pois a Syngenta estaria impossibilitada de se aproveitar dos resultados da

\footnotetext{
${ }^{310}$ LIANOS, Ioannis \& DREYFUSS, Rochelle C., "New Challenges in the Intersection of Intellectual Property Rights with Competition Law - A View from Europe and the United States", CLES Working Paper Series, $4 / 2013$

${ }^{311}$ LiANOS, Ioannis \& DREYFuss, Rochelle C., "New Challenges in the Intersection of Intellectual Property Rights with Competition Law - A View from Europe and the United States", CLES Working Paper Series, $4 / 2013$

${ }^{312}$ AC 08012.000311/2007-26. Veja-se o seguinte trecho do voto do Conselheiro Abraham Sicsú: "As análises tradicionais de concentração focam na participação de mercado e na habilidade de uma companhia manipular preços, o que resulta em modelo estático de competição. O mercado de biotecnologia não gera produtos homogêneos., já que é indústria dinâmica caracterizada por altos investimentos em $P \& D$ na tentativa de diferenciar e melhorar os produtos. As análises antitruste devem focar-se então no conceito de mercados de inovação (innovation markets), o qual foi desenvolvido para lidar com questões antitruste focadas em $P \& D$, na qual a definição de produto não era aplicável. A discussão antitruste se desloca da capacidade de as empresas manipularem o preço para o incentivo do monopolista hipotético de retardar o andamento de pesquisa e desenvolvimento e assim deixar de difundir o avanço tecnológico".
} 
inovação, colocando a Monsanto em posição de única detentora dos melhoramentos do produto $^{313}$.

\subsubsection{Análise Dinâmica no Contexto de Controle de Atos de} CONCENTRAÇÃo HORIZONTAIS

Por uma clara influência das teses Schumpeterianas, o antitruste também passa a incorporar eficiências dinâmicas no controle de fusões. Eficiência dinâmica depende da existência de incentivos e capacidade de aumentar a produtividade e investir em inovação ao longo do tempo, o que, no longo prazo, poderá produzir bens melhores e mais baratos, ou novos produtos que garantam aos consumidores um grau de satisfação maior do que as escolhas disponíveis anteriormente.

Eficiência Dinâmica também é referida como a capacidade de uma empresa, indústria ou economia de explorar seu potencial para, inovar desenvolver novas tecnologias e, assim, expandir sua fronteira produtiva ${ }^{314}$.

No antitruste americano há uma maior flexibilidade para se reconhecer eficiências compensatórias, ao passo que no Direito Europeu - historicamente - tal possibilidade sempre foi muito mais restrita, o que - no entanto - vem se modificando na última década devido ao já abordado More Economic Approach. De acordo com as diretivas europeias, as alegações de eficiência devem ser "substanciais", "verificáveis", "precisas" e "convincentes", e devem ser quantificadas quando houver "razoável possibilidade" para $\operatorname{tanto}^{315}$.

Além disso, tem-se a exigência de prova de que os ganhos em eficiência serão repassados aos consumidores, cuja posição não pode jamais se tornar pior do que a que existia no momento anterior à fusão. Some-se, ainda, a exigência de causalidade, ou seja, as eficiências devem advir da fusão e não de outros fatores, o que levanta também a

\footnotetext{
${ }^{313}$ BRANCHER, Paulo, "Direito da Concorrência e Propriedade Intelectual - Da Inovação Tecnológica ao Abuso de Poder", Editora Singular, São Paulo, 2010, pg. 87

${ }_{314}$ ANDREJ Fatur, "EU Competition Law and the Information and Communication Technology Network Industries" (Hart Publishing 2012). Sobre eficiência dinâmica ver também: DE SOTO, Jesús Huerta, "The Theory of Dynamic Efficiency" (Routledge 2009).

${ }^{315}$ Guidelines on the Assessment of Horizontal Mergers under the Council Regulation on the Control of Concentration between Undertakings (EC) [2004] OJ C31/03, §§º 79-88
} 
questão sobre a existência de alternativas menos restritivas à concorrência que sejam capazes de alcançar o mesmo ganho em eficiência dinâmica ${ }^{316}$.

Vale ressaltar que o ônus da prova recai sobre os réus, havendo dificuldade considerável de se demonstrar tais requisitos na prática - sobretudo, quando os ganhos em eficiência serão criados pelo esforço adicional em inovação, cujos efeitos, em maior parte, somente se verificarão no futuro ${ }^{317}$.

É de se observar que nem as diretivas europeias sobre Transferência de Tecnologia nem as diretivas das autoridades norte-americanas sobre licenciamento de Propriedade Intelectual fornecem parâmetros sobre como o trade-off entre eficiências estáticas e dinâmicas deverá ser feito na prática.

Essa análise é complicada, pois, segundo NATHAN RoSENBERG:

“os aperfeiçoamentos tecnológicos não penetram a estrutura econômica somente pela entrada principal, como quando assumem a forma extremamente visível de grandes saltos tecnológicos patenteáveis, mas também utilizam inúmeras entradas menos visíveis nos fundos e pelos lados, onde sua chegada é discreta, não anunciada, não observada, e não celebrada.

A mensuração - e mesmo a percepção do retorno econômico da inovação tecnológica tem sido obscurecida pelas dificuldades envolvidas na completa identificação do crescimento de produtividade associado a uma dada inovação. Um aspecto crítico dessas dificuldades parece ser a prevalência, nas economias industrializadas modernas, de um tipo especial de economia externa. Especificamente muitos dos benefícios do aumento de produtividade decorrente de uma inovação são auferidos em setores de produção distintos daquele setor no qual foi realizada a inovação. Em vista disso, uma completa contabilização dos benefícios da inovação precisa incluir um exame das relações intersetoriais. Isso se deve ao fato de que o desenvolvimento industrial sob uma tecnologia dinâmica leva a padrões especialização inteiramente novos, por empresa e por setor produtivo, de modo que torna impossível compartimentalizar as consequências da inovação tecnológica ${ }^{318, .}$

\footnotetext{
${ }^{316}$ EU Commission's Guidelines on the application of Article 81 of the EC Treaty [now Article 101 TFEU] to technology transfer agreements

${ }^{317}$ Sobre isso, ver FACKELMANN, Christian R, "Dynamic Efficiency Considerations in EC Merger Control. An Intractable Subject or a Promising Chance for Innovation?', Oxford Centre for Competition Law and Policy, Working Paper No. L-09/06, pgs. 23-32. Para FACKELMANN, "a quantificação de eficiências dinâmicas aparece além das possibilidades da análise econômica, restando sem aplicabilidade prática" (tradução livre). Mesmo que a análise das eficiências dinâmicas seja puramente qualitativa, as diretivas europeias exigem que as empresas forneçam prova de um "impacto positivo claramente identificável sobre os consumidores, e não um impacto positivo meramente marginal”, elevando - assim - os parâmetros de prova para as partes. LIANOS, Ioannis \& DREYFUSS, Rochelle C., "New Challenges in the Intersection of Intellectual Property Rights with Competition Law - A View from Europe and the United States", CLES Working Paper Series, 4/2013 (tradução livre)

${ }^{318}$ RosenberG, Nathan, "Por dentro da Caixa-Preta - Tecnologia e Economia”, Trad. José Emílio Maiorino. Editora da Unicamp, 2006, p. 97.
} 
Em vista de tais dificuldades, as diretivas adotam uma abordagem baseada em premissas gerais, presumindo a existência de eficiências dinâmicas se o acordo de licença se enquadrar em um dos dois safe harbours do regulamento (indicadores estruturais, tais como market shares ou o número disponível de tecnologias).

Nos Estados Unidos, a versão mais recente das diretivas sobre fusões horizontais inclui uma seção sobre inovação e variação de produtos, a qual incorpora a concorrência dinâmica na análise de efeitos anticoncorrenciais. Há o reconhecimento de que " $a$ concorrência estimula as empresas a inovar" e que as autoridades deverão intervir se "houver probabilidade de que uma fusão venha a reduzir os esforços de uma empresa em inovação abaixo do nível que se verificaria na ausência da fusão ${ }^{319}$."

Os efeitos sobre a inovação podem tomar formas diversas, tais como um incentivo reduzido para continuar o desenvolvimento de um produto existente ou para iniciar o desenvolvimento de novos produtos. A respeito das eficiências dinâmicas, as diretivas observam que "ao avaliar os efeitos de uma fusão sobre a inovação, as agências consideram a capacidade da firma resultante da fusão de conduzir pesquisa $e$ desenvolvimento de forma mais efetiva”, particularmente, se isso puder estimular a inovação sem afetar o preço no curto prazo $^{320}$.

Por outro lado, também é reconhecido que "as agências deverão considerar a capacidade de uma firma em fusão de se apropriar de uma fração maior dos benefícios resultantes de suas inovações”, incluindo licenciamento e condições de Propriedade Intelectual que "afetem a capacidade de uma empresa de se apropriar dos benefícios de sua inovação ${ }^{321, "}$.

Embora as diretivas confiram maior peso à análise de curto prazo é também ressalvado que "economias em custos de pesquisa e desenvolvimento podem não ser passíveis de serem conhecidas, mesmo quando substanciais, porque elas são difíceis de se verificar ou podem ser, na verdade, o resultado de reduções anticompetitivas nas atividades em inovação ${ }^{322, "}$.

\begin{tabular}{|c|c|c|c|c|c|c|c|c|c|c|}
\hline 319 & US & DOJ & $\&$ & FTC & Horizontal & Merger & Guidelines & (2010), & disponível & em \\
\hline \multicolumn{11}{|c|}{ <http://www.ftc.gov/os/2010/08/100819hmg.pdf> Section 6.4. (tradução livre) } \\
\hline 320 & US & DOJ & $\&$ & FTC & Horizontal & Merger & Guidelines & $(2010)$ & disponível & em \\
\hline \multicolumn{11}{|c|}{ <http://www.ftc.gov/os/2010/08/100819hmg.pdf> Section 6.4. (tradução livre) } \\
\hline 321 & US & DOJ & $\&$ & FTC & Horizontal & Merger & Guidelines & (2010), & disponível & er \\
\hline \multicolumn{11}{|c|}{ <http://www.ftc.gov/os/2010/08/100819hmg.pdf> Section 6.4. (tradução livre) } \\
\hline 322 & US & DOJ & $\&$ & FTC & Horizontal & Merger & Guidelines & (2010), & disponível & em \\
\hline
\end{tabular}


KATZ e SHELANSKI recomendam que as agências desenvolvam guidelines para fazer inferências da potencial concorrência no mercado analisado com base em evidências de inovações em curso. Além disso, recomendam os autores que as agências desenvolvam expertise que permita investigações caso a caso, baseadas em fatos, para avaliar os efeitos em bem-estar nos casos em que a inovação esteja em jogo. Com isso, afirmam que as agências devem reconhecer que a inovação depende mais de investigações de fatos concretos específicos para um determinado caso e menos de presunções sistemáticas comumente aplicadas nas análises ${ }^{323}$.

No Brasil, a análise de eficiências vem ganhando importância na avaliação dos atos de concentração nos últimos anos. O Sistema Brasileiro de Defesa da Concorrência, entretanto, tem sido conservador na aceitação de argumentos baseados em ganhos de eficiência, ficando o debate restrito às eficiências estáticas, produtivas e alocativas. Não há, até o momento, precedentes que enfrentaram, explicitamente, alegações de eficiências dinâmicas $^{324}$.

A própria Lei, contudo, reconhece expressamente a possibilidade de seu conhecimento para fins de, excepcionalmente, justificar atos de concentração (vide art. 88 da Lei 12.529/2011, $\S 6^{\circ}$, inciso I, alíneas $b$ e $c^{325}$.

Note-se, porém, que o direito concorrencial brasileiro exige que a restrição imposta à concorrência seja aquela "estritamente necessária" para atingir tais eficiências $\left(\S 6^{\circ}\right)$ - ou seja, tem-se uma exigência de causalidade. Além disso, há necessidade de se provar o repasse, aos consumidores, de parte relevante dos ganhos em eficiência dinâmica alcançados. Logo, o direito brasileiro desloca a análise para as evidências no caso concreto, afastada uma primazia, a priori, da eficiência dinâmica sobre a eficiência estática (concorrência de preço e nível de oferta), em sacrifício do interesse dos consumidores.

\footnotetext{
323 Apud GEOFFroY, Ricardo Corrêa, "Eficiências Econômicas em Atos de Concentração: Rumo à Incorporação das Eficiências Dinâmicas", pg. 109, V Prêmio SEAE, 2010

${ }^{324}$ GEOFFROY, Ricardo Corrêa, "Eficiências Econômicas em Atos de Concentração: Rumo à Incorporação das Eficiências Dinâmicas", pg. 109, V Prêmio SEAE, 2010

${ }^{325}$ Lei n' 12.529/2011:

"Art. 88. (...)

$\$ 5^{\circ}$ - Serão proibidos atos de concentração que impliquem eliminação da concorrência em parte substancial do mercado relevante, que possam criar ou reforçar uma posição dominante ou que possam resultar na dominação de mercado relevante de bens ou serviços, ressalvado o disposto no $\$ 6^{\circ}$ deste artigo.

$\S 6^{\circ}$ - Os atos a que se refere o $\$ 5^{\circ}$ deste artigo poderão ser autorizados, desde que sejam observados os limites estritamente necessários para atingir os seguintes objetivos:

I-Cumulada ou alternativamente:

d) Aumentar a produtividade ou a competitividade;

e) Melhorar a qualidade de bens ou serviços; ou

f) Propiciar a eficiência e o desenvolvimento tecnológico ou econômico; $e$

II - Sejam repassados aos consumidores parte relevante dos benefícios decorrentes" (destaques acrescidos).
} 


\subsection{CARACTERísticas da Nova ECONOMia E BARREIRAS À ENTRAda}

Para abordar algumas características da Nova Economia que são especialmente problemáticas quanto à aplicação do aparato do antitruste - que foi arquitetado sob um paradigma econômico totalmente diverso - há que se ter em mente algumas transformações sofridas no regime da Propriedade Intelectual e que acompanham tais transformações na economia.

Primeiramente, como já descrito ao final do Capítulo 1, há uma expansão dos direitos de Propriedade Intelectual, que passa a abarcar bens intelectuais para além dos tradicionais campos da expressão artística e da aplicação no campo industrial estrito como, por exemplo, programas de computador e proteções sui generis, como as cultivares, circuitos integrados, entre outros ${ }^{326}$.

De um modo geral, essa expansão da Propriedade Intelectual para novas áreas novas tecnologias - produz o efeito de aumentar o escopo da proteção, pelo fato simples de que os direitos passam a ter por finalidade última proteger a tecnologia, não mais necessariamente incorporada na forma de um bem tangível - ao contrário do que ocorria sob o paradigma econômico industrial anterior à revolução tecnológica ${ }^{327}$.

Esse fator impacta diretamente alguns tipos de limitação à proteção que apenas faziam sentido sob o paradigma industrial anterior, como - por exemplo - a Doutrina da Exaustão de Direitos. Como estudado no Capítulo 2, nos Estados Unidos, desenvolveu-se a doutrina da primeira venda, em que os direitos de Propriedade Intelectual se exaurem com a venda do bem tangível - ou seja, uma vez transferida a propriedade sobre o bem físico (digamos, um livro), o detentor do Direito de Propriedade Intelectual não pode mais invocar a Propriedade Intelectual para interferir ou restringir o uso daquele bem tangível, impedir sua venda, etc.

Os bens intangíveis passam a ser a própria mercadoria objeto de comercialização no mercado, não mais necessariamente sendo transformados em bens tangíveis, mas explorados como ferramentas de pesquisa - tal como ocorre no setor de biotecnologia. Em tais mercados de tecnologia, o objeto da proteção é sujeito a restrições contratuais cada vez mais estritas e a controles quantitativos, não havendo mais como se invocar, como antes, a chamada Teoria da Exaustão para impedir tais restrições ao comércio.

\footnotetext{
${ }^{326}$ ULLRICH, Hanns, "Expansionist Intellectual Property Protection and Reductionist Competition Rules: A TRIPS Perspective”. EUI Working Paper LAW no 2004/3

${ }^{327}$ ULLRICH, Hanns, "Expansionist Intellectual Property Protection and Reductionist Competition Rules: A TRIPS Perspective”, EUI Working Paper LAW nº 2004/3
} 
Por conseguinte, os eventuais efeitos de rede podem ser mais facilmente internalizados em benefício dos detentores da Propriedade Intelectual ${ }^{328}$.

Por um lado, na ausência de bens tangíveis sujeitos às regras de apropriação e consumo que geralmente refletem o valor de mercado de uma determinada tecnologia, os proprietários da tecnologia tentarão capturar totalmente o valor dos produtos do mercado da informação, controlando quantidades ou propósitos de uso, seja por meio dos próprios direitos exclusivos, seja por meio de estipulações contratuais ${ }^{329}$.

Tem-se, ainda, como outra importante consequência econômica, que o surgimento de mercados de tecnologia não necessariamente incorporada em bens tangíveis faz com que os detentores da Propriedade Intelectual possam capturar lucros a partir da aplicação daquela tecnologia em vários setores da economia. Em outras palavras, os proprietários podem privatizar todas as qualidades multifuncionais do conhecimento, as quais estariam disponíveis ao público caso distribuídas sob a forma de bens tangíveis ${ }^{330}$. As consequências para o Antitruste passam, então, a ser objeto de discussão.

Nos Estados Unidos, uma comissão foi criada em 2002 para fins de avaliar a necessidade de modernização da legislação antitruste (Antitrust Modernization Comission - $A M C$ ), sendo uma das questões-chave analisadas se a legislação antitruste estaria apta a levar em conta apropriadamente a nova realidade do processo competitivo, presente no que se convencionou chamar de Nova Economia - definida como aquela marcada por mercados em que a inovação, a propriedade intelectual e a mudança tecnológica assumem papel central ${ }^{331}$.

A Comissão concluiu que não havia necessidade de revisar a legislação vigente, considerando-a flexível para balizar as análises de concorrência envolvendo tais mercados. Entretanto, a Comissão ressaltou que as autoridades deveriam estar, ao mesmo tempo, sensíveis às necessidades das empresas de inovar e obter escala para poderem competir nos mercados doméstico e global, e, também, à proteção dos interesses dos consumidores.

A Comissão fez, ainda, uma série de recomendações, dentre elas, a de que as agências examinassem cuidadosamente a dinâmica de todos os mercados que

\footnotetext{
${ }^{328}$ ULLRICH, Hanns, "Expansionist Intellectual Property Protection and Reductionist Competition Rules: A TRIPS Perspective”. EUI Working Paper LAW nº 2004/3

${ }^{329}$ ULLRICH, Hanns, "Expansionist Intellectual Property Protection and Reductionist Competition Rules: A TRIPS Perspective”. EUI Working Paper LAW no 2004/3

${ }^{330}$ UlLRICH, Hanns, "Expansionist Intellectual Property Protection and Reductionist Competition Rules: A TRIPS Perspective". EUI Working Paper LAW no 2004/3

331 Apud GEOFFroY, Ricardo Corrêa, "Eficiências Econômicas em Atos de Concentração: Rumo à Incorporação das Eficiências Dinâmicas”, pg. 109, V Prêmio SEAE, 2010
} 
experimentam processos de concentração, principalmente aqueles que envolvem elevado dinamismo tecnológico. Dessa maneira, deveriam considerar atenciosamente os incentivos e obstáculos com os quais se deparam as empresas que visam desenvolver novas tecnologias.

Além disso, recomendou-se que as agências dedicassem a devida atenção às características particulares desses mercados, que incluem: (i) taxas de velocidade da inovação elevadas; (ii) custos médios de produção decrescentes; (iii) requerimentos de capital relativamente modestos; (iv) entradas e saídas rápidas e frequentes no mercado; (v) economias de escala pelo lado da demanda; (vi) custos de mudança (switching costs); e (vii) vantagens de liderança.

A Comissão também recomendou que as agências conferissem peso substancial às provas de que uma concentração aumentaria a eficiência, bem como que conferissem maior crédito às eficiências de custo fixo (como gastos com $\mathrm{P} \& \mathrm{D}$ ), sobretudo em indústrias dinâmicas impulsionadas pela inovação, nas quais os custos marginais são baixos em relação aos preços.

Em tais setores de alta tecnologia, o simples fato de uma empresa praticar seu preço acima do custo marginal não implica, necessariamente, que ela possui poder de mercado, o que contraria a análise convencional.

Particularmente em indústrias inovadoras, tais como aquelas em que os ativos de propriedade intelectual são essenciais, as empresas podem ter elevados custos fixos em $\mathrm{P} \& \mathrm{D}$ e custos marginais de produção relativamente baixos. Assim, as agências devem contabilizar o valor dos ganhos de eficiência de custo fixo na avaliação dos prováveis efeitos concorrenciais das concentrações ocorridas em tais indústrias.

É necessário ter em conta - por sinal - que, neste novo contexto econômico, em que houve desenvolvimento e disseminação das tecnologias digitais e da internet, há uma série de novas possibilidades de regulação que não passam necessariamente pelo Direito.

As consequências deste fenômeno para a sociedade e para o Direito foram abordadas pelo neoconstitucionalista norte-americano LARRY LESSIG - cujo modelo jussociológico das quatro fontes de regulação tornou-se de leitura obrigatória para melhor compreensão dos novos conflitos suscitados por essas importantes transformações.

Para o referido autor, seriam quatro as diferentes fontes de regulação da conduta humana: o Direito, as normas sociais, o mercado e a arquitetura, esferas estas que se interpenetrariam e se influenciriam mutuamente. 
No que tange à questão tecnológica, de interesse imediato para o presente trabalho, tem-se que a própria arquitetura do software - o seu código-fonte e interfaces - permite que exista uma regulação indireta ${ }^{332}$.

Ao tornar um sistema fechado à interoperabilidade, pode-se, potencialmente, criar obstáculos à entrada de novos concorrentes no mercado. Foi esta estratégia que, em larga medida, foi empregada pela Microsoft quanto ao sistema operacional Windows ${ }^{333}$.

Outra barreira à entrada que parece ocorrer mais frequentemente em setores de alta tecnologia envolve os efeitos de rede (network effects). Tais efeitos de rede, também conhecidos como externalidades positivas de rede, surgem quando o valor de uma rede cresce com o número de seus usuários ${ }^{334}$.

Uma empresa, por ser a pioneira em determinado mercado (first mover), torna-se ou ameaça tornar-se a única fornecedora de certos produtos ou serviços em razão do valor da compatibilidade ou da interoperabilidade. Consumidores tendem a permanecer fiéis à rede já estabelecida, por conta dos custos ocultos (sunk costs) - as vezes referidos como efeitos de lock-in.

\footnotetext{
332 "And finally, there is a constraint that will sound much like 'nature', but which I will call 'architeture'. I mean by 'architeture' the world as I find it, understanding that as I find it, much of this world has been made. That I cannot see through wallsis a constraint on my ability to snoop. That I cannot read your mind is a constraint on my ability to know whether you are telling me the truth. That it takes 24 hours to drive to the closes abortion clinic is a constraint on a woman's ability to have an abortion. That there is a highway or train tracks separating this neighborhood from that is a constraint on citizens to integrate. These features of the world - whether made, or found - restrict and enable in a way that directs or affects behavior. They are features of this world's architeture, and they, in this sense, regulate". (LESSIG, Lawrence, "The New Chicago School, The Journal of Legal Studies, Vol. 27, No. S2, June 1998, pg. 663) “(...) and analog for architecture regulates behavior in cyberspace - code. The software and hardware that make cyberspace what it is constitute a set of constraints on how you can behave. The substance of these constraints may vary, but they are experienced as conditions on your access to cyberspace. In some places (online services such as AOL, for instance) you must enter a password before you gain access; in other places you can enter whether identified or not. In some places the transactions you engage in produce traces that link the transactions (the 'mouse droppings') back to you; in other places this link is achieved only if you want it to be. In some places you can choose to speak a language that only the recipient can hear (through encryption); in other places encryption is not an option. The code or software or architecture or protocols set these features; they are features selected by code writers; they constrain some behavior by making other behavior possible, or impossible. The code embeds certain values or makes certain values impossible. In this sense, it too is regulation, just as the architectures of real-space codes are regulations" (LESSIG, Lawrence. "Code and other Laws of Cyberspace", pg. 89, disponível em http://code-is-law.org)

333 "even if a technically superior operating system to Microsoft Windows were to emerge, a significant impediment to development would be the difficulty in getting other software makers to write software applications for it, and no one wants to do that for a program that is used only by a few thousand of people". (HovenKAMP, Herbert, "Federal Antitrust Policy: the law of competition and its practice", Second Edition, St. Paul, West Pub. Co, 1999, pg 527-528)

${ }^{334}$ PITOFSKY, Robert, "Challenges of the New Economy: Issues at the Intersection of Antitrust and Intellectual Property", Antitrust Law Journal, 913, 2000-2001.
} 
Além disso, fornecedores de produtos complementares moldarão tais produtos à rede estabelecida e terão resistência em elaborar produtos para eventuais novos entrantes. Neste caso, a hegemonia de rede, por si só, torna-se uma notável barreira à entrada ${ }^{335}$.

Essa situação é exacerbada no caso de estabelecimento de redes, em que os detentores de patentes possuem incentivos para se envolver em práticas predatórias, visando controlar o padrão da rede. Fazendo isso, eles não apenas recuperarão seus investimentos como também capturarão todo o valor da rede.

De fato, o valor de uma rede aumenta na medida em que mais empresas se tornam participantes. Logo, o detentor da patente poderá se apoderar de valor que foi gerado por outros participantes da rede. Entretanto, a Propriedade Intelectual, em tese, deve ter por objetivo compensar o esforço inventivo e não conferir um lucro abusivo ${ }^{336}$.

No que se refere à Nova Economia, tais barreiras podem, de fato, ser significativas, a ponto de propagar indefinidamente os monopólios. Os sistemas desenhados para estimular e proteger a inovação - patentes e direitos autorais - podem e frequentemente são usados para proteger um mercado contra a entrada por novos concorrentes ${ }^{337}$.

No campo específico da Propriedade Intelectual, DANIEL RUBINFELD e RoBERT MANESS sublinharam que os detentores de direitos exclusivos podem usar seu portfólio de Propriedade Intelectual de forma estratégica, de modo a aumentar os custos de seus concorrentes, por meio de patentes de validade questionável, ou depósito de uma miríade de pedidos de patente cujas alegações, por vezes, contém variações mínimas da tecnologia já existente (é o chamado patent thicket) ${ }^{338}$.

Essa estratégia coloca os concorrentes na difícil escolha entre três alternativas: uma lide judicial (com todos os seus custos inerentes), licenciamento da patente com pagamento de royalties ou, finalmente, desenhar seus produtos em torno da patente.

Todas as alternativas incrementarão custos, reduzirão seus incentivos para inovar e facilitarão práticas colusivas e, na maior parte dos casos, o resultado será um acordo nocivo à concorrência, ou um esquema de licenciamento cruzado.

\footnotetext{
335 PITOFSKY, Robert, "Challenges of the New Economy: Issues at the Intersection of Antitrust and Intellectual Property", Antitrust L.J. 913, 2000-2001.

${ }^{336}$ LiANOS, Ioannis e DREYFUSS, Rochelle, "New Challenges in the Intersection of Intellectual Property Rights With Competition Law - A View from Europe and the United States", CLES Working Paper Series, Abril, 2013.

337 PITOFSKY, Robert, "Challenges of the New Economy: Issues at the Intersection of Antitrust and Intellectual Property”, Antitrust L.J. 913, 2000-2001.

${ }^{338}$ RUBINFELD, Daniel L. and MANESS, Robert, "The Strategic Use of Patents: Implications for Antitrust", Lévêque and Shelanski (eds) (n 129) 85.
} 
Os detentores de patente também podem condicionar o licenciamento de uma tecnologia à aquisição de um pacote de licenças aos concorrentes, ainda que estes não necessitem de todos os itens do pacote, o que terá o efeito de limitar o seu poder de escolha, bem como de reduzir os incentivos para a inovação, restringindo a concorrência no mercado de produtos finais ${ }^{339}$.

Dennis CARlton e JefFrey Perloff descreveram um modelo em que uma empresa opera no mercado primário e em um mercado secundário, de um bem complementar $^{340}$. No modelo, por força de uma patente, a empresa tem, no primeiro momento, uma posição dominante no mercado primário. Contudo, em um momento seguinte, o monopolista enfrenta o risco de entrada de um produtor alternativo no mercado primário.

Neste modelo, embora o produtor alternativo tenha um produto complementar de superior qualidade, seu produto primário é de qualidade equivalente apenas no segundo momento.

Nessas circunstâncias, segundo o modelo, a estratégia do produtor alternativo será utilizar os lucros obtidos no mercado complementar para cobrir os custos fixos de usa entrada no mercado primário. Em contrapartida, o monopolista poderá contra-atacar, aumentando os custos de entrada de seus concorrentes no mercado complementar. Logo, a entrada do produtor alternativo no mercado primário seria bloqueada.

Esse modelo sugere que, em certas circunstâncias, detentores de patente terão interesse em retardar o processo de inovação dinâmica, o que poderia tornar o seu próprio padrão tecnológico obsoleto ${ }^{341}$.

Por outro lado, indústrias de alta tecnologia não diferem das convencionais no sentido de que o reconhecimento da marca, reputação e confiabilidade podem criar vantagens praticamente insuperáveis. Finalmente, práticas anticoncorrenciais ilegais, tais como preços discriminatórios, cláusulas excludentes, ou táticas de intimidação que podem

\footnotetext{
${ }^{339}$ LiANOS, Ioannis e DREYFuSS, Rochelle, "New Challenges in the Intersection of Intellectual Property Rights With Competition Law - A View from Europe and the United States, CLES Working Paper Series, Abril, 2013.

${ }^{340}$ LiAnOS, Ioannis e DREYFuss, Rochelle, "New Challenges in the Intersection of Intellectual Property Rights With Competition Law - A View from Europe and the United States, CLES Working Paper Series, Abril, 2013.

${ }^{341}$ LiANOS, Ioannis e DREYFuss, Rochelle, "New Challenges in the Intersection of Intellectual Property Rights With Competition Law - A View from Europe and the United States, CLES Working Paper Series, Abril, 2013.
} 
ser implementadas por grandes empresas podem, por si só, impedir a entrada por concorrentes mais eficientes $^{342}$.

A análise antitruste deve, portanto, ater-se a tais características inerentes à chamada Nova Economia, pois, do contrário, não se mostrará eficaz.

\subsubsection{Deve-se Aplicar uma teoria da Decisão na Análise de Condutas com POTENCIAL IMPACTO SOBRE A INOVAÇÃo TECNOLÓGICA?}

Baseados em uma releitura de SCHUMPETER, alguns teóricos, por vezes, autodenominados de Neo-Chicago defendem o argumento de que os setores de alta tecnologia seriam tão dinâmicos que cartéis e monopólios teriam vida curta. Eles seriam afastados de forma mais breve e eficiente pelas próprias forças de mercado, tais como uma nova entrada, do que pela ação de um "bando de burocratas". Além disso, a regulamentação governamental teria uma probabilidade maior de cometer erros, com efeitos mais negativos e duradouros do que as próprias falhas de mercado ${ }^{343}$.

Tal linha de pensamento defende que o legislador deveria produzir regras que minimizassem os custos esperados de erros na análise antitruste, bem como tornassem a aplicação do antitruste mais previsível para as empresas ${ }^{344}$.

Em nome da previsibilidade e da segurança jurídica, tal linha de pensamento defende a incorporação de uma Teoria da Decisão pelo antitruste ${ }^{345}$.

A Teoria da Decisão preconizada por estes autores seria aplicada em dois estágios. O primeiro estágio consistiria em utilizar-se da teoria econômica e das evidências do caso para "analisar o custo e probabilidade de erros decorrentes de condenar-se práticas fomentadoras do bem estar ou de ratificar práticas que venham a prejudicá-lo”.

\footnotetext{
${ }^{342}$ PITOFSKY, Robert, "Challenges of the New Economy: Issues at the Intersection of Antitrust and Intellectual Property", Antitrust L.J. 913, 2000-2001.

${ }^{343}$ EASTERBROOK, Frank H., "The Limits of Antitrust, 63, Tex. L. Rev. 1, 15, 184): "The economic system corrects monopoly more readily than it corrects judicial errors. There is no automatic way to expunge mistaken decisions of the Supreme Court. A practice once condemned is likely to stay condemned, no matter its benefits."

${ }^{344}$ Evans , David S.; Padilla, A. Jorge, "Designing Antitrust Rules for Assessing Unilateral, Practices: A Neo-Chicago Approach", The University of Chicago Law Review, Vol. 72, n. 1, Symposium: Antitrust, Winter, 2005, pgs. 73-98

${ }^{345}$ LiANOS, Ioannis e DREYFuss, Rochelle, "New Challenges in the Intersection of Intellectual Property Rights With Competition Law - A View from Europe and the United States", CLES Working Paper Series, Abril, 2013.
} 
O segundo estágio implicaria "selecionar, de um leque de padrões variando de legalidade per si para ilegalidade per si, incluindo a rule of reason, a regra jurídica que minimizasse os custos esperados da intervenção, levando em conta a possibilidade de erro jurídico”.

ROBERT Pitofsky, no entanto, discorda da generalização da Teoria da Decisão baseada nos custos de eventuais erros judiciais, porque este raciocínio subestimaria os custos da manutenção de monopólios duradouros, mesmo nos setores de alta tecnologia, bem como não levaria em conta fatores peculiares de cada mercado, como as barreiras a entrada ${ }^{346}$.

Efetivamente, barreiras à entrada, tais como as existentes nos setores de alta tecnologia, podem garantir vantagens por décadas, não sendo possível presumir que as forças de mercado, ou a superação tecnológica, fatalmente dissiparão tais vantagens em um prazo razoável - ao contrário do que leva a crer a Teoria da Decisão defendida pela linha Neo-Chicago descrita no início deste tópico ${ }^{347}$.

De fato, levando-se em conta a factualidade da competição schumpeteriana (concorrência de superação tecnológica) e as características inerentes aos mercados de alta tecnologia, contestamos a aplicação de uma Teoria da Decisão baseada nos custos do erro de uma intervenção estatal.

A tentativa da Teoria dos Custos do Erro é fazer com que as decisões judiciais estejam adstritas a um determinado método, que, sob a roupagem de uma abordagem pretensamente evolucionista/schumpeteriana, nada mais faz do que estabelecer - na prática - um formalismo jurídico, totalmente clivado da realidade.

Este raciocínio, em última instância, baseia-se em uma generalização forçada ${ }^{348}$, que - por sinal - não se justifica à luz dos dados empíricos, uma vez que, como vimos, jamais os estudos empíricos validaram tal relação positiva entre concentração de mercado e inovação presumida por SCHUMPETER - ao menos não a ponto de validar uma regra aplicável a todo e qualquer mercado. Assim, a premissa de que os custos do impacto negativo de uma intervenção estatal sobre inovação seriam maiores do que a não intervenção está baseada em uma fórmula claramente parcial (pois são igualmente desconhecidos os custos sociais da propagação de monopólios).

\footnotetext{
${ }^{346}$ PITOFSKY, Robert, "Challenges of the New Economy: Issues at the Intersection of Antitrust and Intellectual Property", Antitrust L.J. 913, 2000-2001.

${ }^{347}$ PITOFSKY, Robert, "Challenges of the New Economy: Issues at the Intersection of Antitrust and Intellectual Property", Antitrust L.J. 913, 2000-2001.

${ }^{348}$ LIANOS, Ioannis e DREYFuss, Rochelle, "New Challenges in the Intersection of Intellectual Property Rights With Competition Law - A View from Europe and the United States", CLES Working Paper Series, Abril, 2013.
} 
Trata-se, portanto, de raciocínio calcado em um nítido formalismo e que tem o efeito prático de conceder verdadeiros "cheques em branco" para que as autoridades antitruste possam validar, sumariamente, atos que, em tese, poderiam representar ofensas à concorrência $^{349}$.

O uso que defendemos da economia na análise de potenciais efeitos anticoncorrenciais é um uso pleno - considerando as diversas abordagens possíveis, e sem se restringir a uma determinada teoria/fórmula que não leve em conta os aspectos dinâmicos, como o comportamento estratégico, bem como outros componentes empíricos $^{350}$.

Nossa posição, assim, aproxima-se daquela defendida por JANUSZ ORDOVER, que conceitua a existência de dois mercados diferentes: o mercado upstream, composto por ideias, informações e conhecimento, e o mercado downstream, representado efetivamente por produtos e serviços. Tais mercados estariam conectados - na argumentação de ORDOVER - temporal e intertemporalmente, "no sentido de que eventos econômicos (como a intensidade de competição) que ocorrem no mercado upstream têm um impacto prospectivo na competição e na eficiência alocativa no mercado downstream”.

Assim, sugere o autor que a análise dos efeitos dessas práticas e instituições se dê na forma de uma regra da razão estruturada, que analisaria participações de mercado, níveis de concentração e barreiras à entrada em ambos os níveis dessa cadeia vertical temporal.

Nesse contexto, são necessárias análises pormenorizadas dos diferentes setores da indústria, seus respectivos processos competitivos dinâmicos e a forma como tais processos se estruturam ao longo da referida cadeia vertical temporal, que permitem encaixar adequadamente uma específica manifestação contratual, tomando-a de maneira menos alienada, como parte de uma totalidade ordenada, e não manifestação particularizada e arbitrária em um mundo sem hierarquia, poderes ou derivações do passado $^{351}$.

De tal modo, como já afirmamos anteriormente, a análise antitruste deve deslocarse de presunções generalizantes da benignidade de determinadas condutas -

\footnotetext{
${ }^{349}$ ANDRADE, José Maria Arruda de "Economização do Direito Concorrencial e Positivismo Jurídico - Entre Teoria da Decisão e Teoria das Provas, São Paulo, 2012, pg. 176 (Tese de Livre-Docência)

${ }^{350}$ ANDRADE, José Maria Arruda de "Economização do Direito Concorrencial e Positivismo Jurídico - Entre Teoria da Decisão e Teoria das Provas, São Paulo, 2012, pg. 176 (Tese de Livre-Docência)

${ }^{351}$ ORDOVER, J.A. "Economic Foundations and Considerations in Protecting Industrial and Intellectual Property" (1984), 53(3) Antitrust Law Journal 503
} 
principalmente, quando ausente qualquer previsão legal expressa nesse sentido - devendo a análise centrar-se no exame criterioso das evidências de efeitos competitivos e anticompetitivos de cada conduta no caso concreto (Teoria da Prova).

\subsection{Ilustrações dos Encontros entre Propriedade InTElectual E AnTitruste}

Nesta seção, pretende-se apresentar um quadro organizado de situações frequentemente encontradas na jurisprudência nacional e estrangeira, em que a aquisição ou utilização de direitos de Propriedade Intelectual ${ }^{352}$ pode levantar problemas concorrenciais, bem com ensejar a tutela do direito concorrencial. A maior parte desses exemplos já foi objeto de comentários anteriores, quando analisamos a jurisprudência americana e europeia.

Embora seja virtualmente impossível esgotar o tema, dadas a dinâmica e peculiaridades específicas de cada mercado - possivelmente, cada uma das hipóteses demandaria uma análise monográfica - o que se propõe é organizar um quadro geral, permitindo-se ao leitor uma melhor compreensão dos principais focos de preocupação e de seu possível enquadramento no direito brasileiro.

É de se ressaltar que nenhuma das hipóteses relacionadas se apresentará, na prática, como aparecem nos manuais, uma vez que os agentes econômicos procuram manipular os negócios jurídicos, com intuito de, indiretamente, obter posição dominante ou dela abusar.

\subsubsection{Fusões E AQuisiÇões de Ativos InTELECTUAIS}

Uma determinada empresa ou grupo poderá adquirir, de terceiros, a totalidade ou um número substancial de patentes em um determinado mercado, o que poderá ocorrer formalmente por uma operação societária, ou pelo licenciamento exclusivo dos direitos ambos com o efeito prático de dominar um mercado e erguer barreiras significativas à entrada de novos concorrentes ${ }^{353}$.

\footnotetext{
352 Notadamente, patentes, modelos de utilidade, desenho industrial, programas de computador, marcas, circuitos integrados e cultivares (conforme escopo definido ao final do Capítulo 1

353 "The acquisition of patents can raise substantial antitrust questions under Section 2 in circumstances where all (or the majority of) the patents in a given field are acquired from third parties, or under Section 7 of the Clayton Act, in the case of the acquisition of individual patents where the effect of the acquisition "may be substantially to lessen competition. Under some circumstances, a licensing arrangement may be viewed as an acquisition of assets under the United States antitrust laws. Such transactions may be subject to challenge under Section 7, which precludes an acquisition of "the whole or any part of the assets of another," the effect
} 
Em tais casos, as tensões entre Propriedade Intelectual e Direito da Concorrência são menos complexas, pois não se trata de interferência do antitruste no exercício de direito de um titular, mas sim, de concentração de ativos sob o poder de um agente econômico ou grupo. Os direitos de Propriedade Intelectual, neste contexto, se apresentam como apenas mais uma das espécies de ativos a serem considerados em tais operações.

No Brasil, a jurisprudência do CADE já determinou o licenciamento exclusivo de direitos de Propriedade Intelectual em operações desta natureza, quando os direitos de Propriedade Intelectual se mostravam de importância estratégica fundamental para dominação de um mercado, ou quando significavam barreiras à entrada ${ }^{354}$.

A Lei $n^{\circ} 12.529 / 2011$, consagrando este entendimento, incluiu, expressamente, a previsão de que o licenciamento compulsório de direitos de Propriedade Intelectual pode ser

of which "may be substantially to lessen competition, or to tend to create a monopoly." In addition, an acquisition of assets that meets certain requirements may also be subject to the "report and wait" requirements of the Hart-Scott-Rodino Antitrust Improvements Act of 1976 ("HSR Act"), which requires a potential acquirer to notify the FTC and DOJ (and wait for a certain time period) prior to consummating a proposed transaction”. (WEINSCHEL, Alan J., "Antitrust Pitfals in Licensing”, in PLI Intellectual Property Antitrust, 2001, pg 783)

354 “A natureza da concorrência no mercado de creme dental - por diferenciação de produto - tem na marca a sua principal arma. A concorrência intermarcas, por meio da construção de reputação e laços de lealdade com o consumidor é a forma predominante assumida pela concorrência nesse mercado. De todo o exposto ao longo do voto, conclui-se que é o controle simultâneo das duas marcas mais importantes do mercado, em particular da marca dominante KOLYNOS, a barreira à entrada significativa e, por conseguinte, a fonte do poder de mercado agora detido pela adquirente. Assim, é sobre o controle de marcas que deve se concentrar a decisão deste Conselho. (...) Diante do exposto, é a suspensão voluntária do uso da marca KOLYNOS e suas extensões, inclusive do material de embalagem, promoção e propaganda associado, para o fabricação $e$ comercialização de creme dental dirigidas ao mercado interno pelo período de quatro anos é a medida que considero justa para garantir que a operação não elimine a concorrência nem crie poder de mercado de tal envergadura que, por meio de seu comportamento estratégico, desencoraje a entrada de novos concorrentes e a autonomia decisória dos atuais participantes do mercado, além de eliminar substancialmente a dinâmica concorrencial do mercado.

(...) Sensível, contudo, às implicações desse trade-off e à possibilidade de fricções no abastecimento no curto prazo, é que defini um atenuante à decisão de suspensão tout cort. Tal atenuante é o licenciamento, exclusivo e por curto prazo, da marca KOLYNOS, para a formação de marcas duplas, com um esquema de gradual desaparecimento (fading out) da marca fiadora, até seu retorno à titular. Esse esquema de licenciamento exclusivo, caso adotado, vigorará durante o período de suspensão de uso da marca pela titular. O contrato de licenciamento exclusivo deverá, incluir, nos dois primeiros anos, a critério do licenciado, encomendas, assistência técnica e operacional e todos os serviços de suporte necessários à produção e entrega do produto, de modo a reduzir os custos de entrada de novo concorrente.

$O$ esquema de marca-dupla com fading out implica que todo material de embalagem, propaganda $e$ promoção apresente como logotipo principal a marca que esta sendo introduzida no mercado e a marca KOLYNOS como co-marca ou marca de fabricante. Esta marca terá espaço progressivamente reduzido no material mencionado, até o seu desaparecimento,que coincidirá com o final da suspensão do uso da marca KOLYNOS pelo seu titular. Os termos em que esse esquema de marca-dupla com fading out será executado constará, obrigatoriamente, do contrato de licenciamento a ser apresentado ao CADE. Essa solução permite à empresa explorar a marca indiretamente durante o período de suspensão. Assim, de barreira, a marca torna-se veículo de introdução da marca nova no mercado, funcionando como uma espécie de "fiador" no momento inicial”. (Ato de Concentração 27/94) 
utilizado como remédio para fins de aprovação de atos que impliquem a restrição significativa da concorrência ${ }^{355}$.

Entretanto, é de se ressaltar, mais uma vez, que a análise antitruste - ex post e ex ante - deve ir além das formas societárias utilizadas, uma vez o efeito de concentração econômica pode ser obtido tanto por meio de concentração empresarial formal (via fusão, aquisição de controle ou fundação de novas sociedades em conjunto), quanto por meio de arranjos contratuais específicos - principalmente, no caso de concentração vertical, que pode ser obtida por meio de contratos exclusivos de distribuição, fornecimento ou mesmo transferência de direitos variados de propriedade industrial) ${ }^{356}$.

Essa é a figura do controle empresarial ab extra, a que já aludira FABIO KONDER COMPARATO, por meio da qual uma nova estrutura econômica, sem nenhuma correspondência jurídica com as formas utilizadas, pode ser implementada ${ }^{357}$. Voltaremos a esse conceito em comentários posteriores.

O direito brasileiro regulamenta o direito de licenciar os direitos de propriedade intelectual (Lei 9.279, art. 61 e seguintes), bem como o direito de licenciamento de uso, comercialização e transferência de tecnologia referente aos programas de computador (art. $9^{\circ}$ e seguintes da Lei 9.609/98).

\footnotetext{
${ }^{355}$ Lei 12.529/2011:
}

"Art. 61. No julgamento do pedido de aprovação do ato de concentração econômica, o Tribunal poderá aprová-lo integralmente, rejeitá-lo ou aprová-lo parcialmente, caso em que determinará as restrições que deverão ser observadas como condição para a validade e eficácia do ato.

$\S 10$ O Tribunal determinará as restrições cabiveis no sentido de mitigar os eventuais efeitos nocivos do ato de concentração sobre os mercados relevantes afetados.

$\S 2 o$ As restrições mencionadas no $\$ 10$ deste artigo incluem:

I - a venda de ativos ou de um conjunto de ativos que constitua uma atividade empresarial;

II - a cisão de sociedade;

III - a alienação de controle societário;

IV - a separação contábil ou jurídica de atividades;

$V$ - o licenciamento compulsório de direitos de propriedade intelectual; $e$

VI - qualquer outro ato ou providência necessários para a eliminação dos efeitos nocivos à ordem econômica.

$\S 3$ o Julgado o processo no mérito, o ato não poderá ser novamente apresentado nem revisto no âmbito do Poder Executivo". (destaques acrescidos)

${ }^{356}$ Nesse sentido, vide o Voto do ex-Conselheiro Marcos Paulo Veríssimo no Julgamento do Ato de Concentração $\mathrm{n}^{\circ}$ 08012.002870/2012-38: "É óbvio, por um lado, que esse resultado (a concentração econômica) independe de fórmulas jurídicas específicas, podendo ser obtido tanto por concentração empresarial formal' (via fusão, aquisição de controle ou fundação de novas sociedades em conjunto) quanto por meio de arranjos contratuais específicos (especialmente no caso da concentração vertical, que pode ser obtida por meio de contratos exclusivos de distribuição, fornecimento ou mesmo transferência de direitos variados de propriedade industrial). A inexistência de uma linha divisória clara e substantiva entre as estruturas empresariais formais $e$ as estruturas contratuais é, por sinal, correntemente conhecida $e$ reconhecida, no mínimo, desde o famoso "the Nature of the Firm", de Ronald Coase, publicado em 1937".

${ }^{357}$ Comparato, Fábio Konder, "Grupo societário fundado em controle contratual e abuso de poder do controlador", In Direito Empresarial, p. 270-91. São Paulo: Saraiva, 1995. 
Do ponto de vista da Teoria dos Custos de Transação, uma empresa terá incentivos para licenciar sua tecnologia sempre que os custos de produção interna da tecnologia forem superiores aos de licenciamento.

A empresa pode não dispor do parque industrial necessário para desenvolver o produto patenteado, ou não dispor dos canais de distribuição para disseminação da tecnologia. Além disso, em certa medida, o licenciamento implica um reconhecimento de titularidade por parte do licenciado, o que aumenta a segurança jurídica das relações, prevenindo a possibilidade de que o licenciado venha a capitalizar sobre investimento alheio.

Nestes casos, ao menos em situações normais (isso é, desconsiderando-se a existência de cláusulas que, explícita ou implicitamente, impliquem uma associação entre agentes), a relação será vertical, pois envolverá o licenciamento de tecnologia entre partes que pertencem a fases distintas da cadeia produtiva (i.e., a tecnologia fornecida pelo licenciante é um insumo da produção dos bens comercializados pelo licenciado). Nestes casos, haverá possibilidade de os acordos se mostrarem pró-competitivos, pois poderão fomentar a concorrência de produtos que veiculem uma nova tecnologia em um mercado relevante, entre licenciados.

Via de regra, os incentivos para licenciamento de tecnologia serão tanto maiores quanto maior for a confiabilidade da proteção conferida aos direitos de Propriedade Intelectual envolvidos ${ }^{358}$. Isso ocorre porque, em casos de tecnologias com nível de proteção fraca em relação à Propriedade Intelectual, haverá sempre a possibilidade de o licenciado de se aproveitar do conhecimento adquirido para desenvolver uma tecnologia equivalente, tornando o licenciamento menos interessante.

Os incentivos para licenciar a tecnologia, neste cenário, serão inferiores aos de produzir internamente a tecnologia, bem como aos incentivos para outras formas associativas de transferência de tecnologia entre empresas (por exemplo, a formação de joint ventures), nas quais o controle da informação compartilhada é mais restrito.

Em teoria, haverá incentivos para o licenciamento entre concorrentes (horizontal) em que as preocupações quanto à concorrência são mais óbvias - na medida em que a proteção aos direitos de Propriedade Intelectual é mais fraca. Isso porque, em tais casos, as empresas têm incentivos maiores para concorrência de imitação, o que, por sua vez, aumentaria os incentivos para acordos de licenciamento cruzados, na medida em que tais

358 ORDOVER, J.A.,"A Patent System for both Diffusion and Exclusion", Journal of Economic Perspectives, 5, Pgs. 43-60 
acordos permitem acesso a tecnologias alheias, sem que se precise incorrer em custos com engenharia reversa ${ }^{359}$. Ao aumentar a segurança jurídica, as joint ventures podem fomentar a Pesquisa e Desenvolvimento de novos produtos, que não seriam lançados no mercado dado o receio mútuo entre os agentes de que os investimentos em determinado produto sejam capitalizados pelos concorrentes.

Em um e outro caso, quer se trate de uma relação horizontal ou vertical, os contratos de licenciamento podem se mostrar pró-competitivos, como também levantar preocupações em relação ao antitruste.

\subsubsection{Contratos envolvendo a Propriedade Intelectual - Cláusulas Problemáticas}

No que se refere aos contratos de licenciamento de Propriedade Intelectual, as principais cláusulas problemáticas são as seguintes:

a) Fixação de Preços de Revenda: Em se tratando de uma relação vertical, uma das cláusulas consideradas abusivas é a tentativa de fixação de preços (mínimos, máximos ou fixos) de revenda dos produtos produzidos com a patente, do sublicenciamento da própria patente (royalties) ou de produtos fabricados com insumos fabricados de acordo com a patente, ou, ainda, por meio de máquinas e equipamentos patenteados.

A preocupação quanto à fixação de preços é que ela pode eliminar a concorrência em mercados de distribuição, entre os licenciados (concorrência interbrand), bem como fomentar a colusão.

Nos Estados Unidos, perdurou durante muito tempo a regra de ilegalidade per se de acordos de fixação de preços mínimos, enquanto tentativas de fixar preços máximos eram analisadas sob a rule of reason. Atualmente, ambas as possibilidades são examinadas sob a rule of reason. Na Europa, contudo, a fixação de preços mínimos não é ilícita per si, porém, estará sujeita à análise de acordo com o art. 81 do Tratado. Por outro lado, a fixação de preços máximos e a mera sugestão de preço são isentas, desde este expediente não estabeleça pressão indireta para a fixação de preços mínimos ${ }^{360}$.

\footnotetext{
359 AnAnd, Bharat N; Khanna, Tarun, "The Structure of Licensing Contracts”. The Journal of Industrial Economics, vol. 48, n. 1, March/2000, pgs. 103-135

${ }^{360}$ Forgioni, Paula A. "Direito Concorrencial e Restrições Verticais", São Paulo, Editora Revista dos Tribunais, 2007, pgs. 201 e seguintes.
} 
No Brasil, nos termos da Lei $n^{\circ} 12.529 / 2011$, essa conduta pode caracterizar as infrações previstas no art. $36, \S 3^{\circ}$, incisos II e IX, desde que configurado que a ação tenha o objetivo ou o potencial de causar um dos efeitos anticompetitivos previstos nos vários incisos do caput $^{361}$. Assim, conforme PAULA ForgiOnI, "no contexto brasileiro, o fato de termos imposição ou sugestão não é determinante para decisão sobre a licitude ou ilicitude da prática, que dependerá do impacto concorrencial gerado. Assim, em face da nossa lei, antes de aderirmos a cômodas fórmulas preestabelecidas, é preciso ponderar vários fatores: pode econômico dos agentes, estrutura dos mercados, sistema de distribuição normalmente adotado pela concorrência, etc. ${ }^{362, "}$.

b) Exclusividade: A imposição de cláusulas de exclusividade por empresas que detenham posição dominante pode importar em elevação de barreiras à entrada e exclusão de concorrentes, por meio do aumento significativo de seus custos. Isso efetivamente ocorrerá se, por meio de cláusulas de exclusividade, os concorrentes tiverem bloqueado seu acesso aos melhores fornecedores, relegando os demais aos concorrentes, ou, então, se um número tão grande de fornecedores for cooptado de modo que os concorrentes não serão capazes de atingir economias de escala ${ }^{363}$.

Além disso, a depender das circunstâncias do mercado, é possível que a cláusula de exclusividade crie desincentivos para o licenciado desenvolver sua própria tecnologia ou adquirir tecnologias concorrentes - ainda quando aprimoradas em relação à tecnologia do licenciante.

No que tange ao licenciamento de Propriedade Intelectual, as autoridades antitruste nos Estados Unidos reconhecem alguns efeitos pró-competitivos da cláusula de

\section{${ }^{361}$ Lei 12.529/2011:}

"Art. 36. Constituem infração da ordem econômica, independentemente de culpa, os atos sob qualquer forma manifestados, que tenham por objeto ou possam produzir os seguintes efeitos, ainda que não sejam alcançados:

I - limitar, falsear ou de qualquer forma prejudicar a livre concorrência ou a livre iniciativa;

II - dominar mercado relevante de bens ou serviços;

III - aumentar arbitrariamente os lucros; e

IV - exercer de forma abusiva posição dominante. (...)

§ 30 As seguintes condutas, além de outras, na medida em que configurem hipótese prevista no caput deste artigo e seus incisos, caracterizam infração da ordem econômica:

II - promover, obter ou influenciar a adoção de conduta comercial uniforme ou concertada entre concorrentes;

IX - impor, no comércio de bens ou serviços, a distribuidores, varejistas e representantes preços de revenda, descontos, condições de pagamento, quantidades mínimas ou máximas, margem de lucro ou quaisquer outras condições de comercialização relativos a negócios destes com terceiros";

${ }^{362}$ Forgioni, Paula A. "Contrato de Distribuição. São Paulo. Editora Revista dos Tribunais, 2005, pg. 184.

${ }^{363}$ HovenKamp, H., Janis, M, Lemley, M, "IP and Antitrust, Vol. 1, New York, Aspen Publishers, 2006, pgs. 21-114 e 21-115. 
exclusividade, pois, por meio de tal cláusula, o licenciante poderá criar incentivos ao licenciado para desenvolvimento e introdução de uma tecnologia no mercado ${ }^{364}$. A recomendação, portanto, é para que tais cláusulas sejam examinadas à luz da rule of reason, devendo ser levados em conta, na análise, os potenciais efeitos benéficos.

Na Europa, há presunção de que as cláusulas de exclusividade são pro-competitivas se as partes detiverem market share inferior a 30\%, ficando os demais casos sujeitos à análise individual de acordo com o art. 81 do Acordo. Há um entendimento semelhante ao norteamericano, no sentido de levar em conta os potenciais efeitos pró-competitivos (i.e., estímulos para o aprimoramento e introdução de uma nova tecnologia).

Vale ressaltar que a cláusula de exclusividade pode não estar presente ostensivamente em um acordo, mas produzirá os mesmos efeitos se for estruturada de modo a aumentar, significativamente, os custos do licenciado quanto ao uso de tecnologias concorrentes ${ }^{365}$. Tal poderá ocorrer, por exemplo, pela concessão de incentivos positivos aos licenciados, como descontos, bônus, participação sobre royalties, entre outras técnicas semelhantes. No Capítulo seguinte, analisaremos, em detalhe, um caso analisado pelo CADE em que a exclusividade se processava de tal forma transversa.

No Direito brasileiro, o uso de cláusulas de exclusividade pode se enquadrar em qualquer uma das condutas previstas no art. $36, \S 3^{\circ}$, incisos III, IV ou V - deste que haja objetivo ou potencial de produzir os efeitos previstos no caput $^{366}$.

\footnotetext{
364 "Such restraints may anticompetitively foreclose access to, or increase competitors'costs of obtaining important inputs, or facilitate coordination to raise price and reduce output, but they also may have procompetitive effects. For example, a licensing agreement that prevents the licensee from dealing in other technologies may encourage the licensee to develop and market the licensed technology or specialized applications of that technology". (Antitrust Guidelines for the Licensing of Intellectual Property", DOJ/FTC).

${ }^{365}$ Antitrust Guidelines for the Licensing of Intellectual Property", DOJ/FTC.

${ }^{366}$ Lei 12.529/2011:

“Art. 36. Constituem infração da ordem econômica, independentemente de culpa, os atos sob qualquer forma manifestados, que tenham por objeto ou possam produzir os seguintes efeitos, ainda que não sejam alcançados:

I - limitar, falsear ou de qualquer forma prejudicar a livre concorrência ou a livre iniciativa;

II - dominar mercado relevante de bens ou serviços;

III - aumentar arbitrariamente os lucros; $e$

$I V$ - exercer de forma abusiva posição dominante.

(...)

$\S 30$ As seguintes condutas, além de outras, na medida em que configurem hipótese prevista no caput deste artigo e seus incisos, caracterizam infração da ordem econômica:

(...)

III - limitar ou impedir o acesso de novas empresas ao mercado;

IV - criar dificuldades à constituição, ao funcionamento ou ao desenvolvimento de empresa concorrente ou de fornecedor, adquirente ou financiador de bens ou serviços";

$V$ - impedir o acesso de concorrente às fontes de insumo, matérias-primas, equipamentos ou tecnologia, bem como aos canais de distribuição"
} 
c) Retrolicenciamento (Grantback): A cláusula de grantback inserida nos contratos de licenciamento (sejam eles horizontais ou verticais) estabelece o direito do licenciante de ser retrolicenciado em relação a quaisquer melhorias a serem desenvolvidas pelo licenciado com a autorização para uso e manipulação da tecnologia .Assim, ao obter uma patente nova, o licenciado se obriga a retrolicenciá-la ao licenciante, de modo a transferir ao primeiro todo o conhecimento obtido e desenvolvido, que gerou melhoria e nova tecnologia a ser protegida ${ }^{367}$.

A cláusula de grant-back é, basicamente, um mecanismo que protege o licenciante, impedindo que o licenciamento fomente a concorrência em seu próprio mercado, por meio de melhorias eventualmente introduzidas pelo licenciado. Por permitir uma maior segurança jurídica ao licenciante, a cláusula estimula a disseminação de tecnologia, bem como permite o compartilhamento de riscos em investimentos em inovação. Por tais razões, as autoridades americanas não consideram a cláusula como ilícita per $\mathrm{si}^{368}$. A cláusula acaba sendo uma antecipação de um eventual licenciamento cruzado e, por isso, por vezes aparece no contexto de um patent pool (que analisaremos adiante).

A jurisprudência americana tem considerado algumas circunstâncias para decidir se uma cláusula de grant back representa ou não problemas concorrenciais, como: (i) se o retrolicenciamento é exclusivo ou não exclusivo; (ii) se, em caso de licenciamento não exclusivo, o licenciado pode ter direito a utilizar as melhorias alcançadas; (iii) se a cláusula grant-back veda, permite ou requer que o licenciado conceda sublicenciamento das melhorias (iv) se a cláusula se limita ao escopo das patentes licenciadas ou se estende a outras inovações, não relacionadas à patente; (v) a duração da cláusula; (vi) se há previsão de royalties pelo retrolicenciamento; (vii) se alguma das partes detém poder de mercado; (viii) se as partes concorrem entre si; e (ix) potenciais efeitos negativos sobre os incentivos para Pesquisa e Desenvolvimento ${ }^{369}$.

Caso o retrolicenciamento for exclusivo e não houver previsão de royalties, por exemplo, haverá um claro desincentivo ao licenciado de introduzir melhorias, o que, na prática, poderá acarretar a manutenção da tecnologia dominante, retardando a inovação tecnológica.

\footnotetext{
${ }^{367}$ BRANCHER, Paulo, "Direito da Concorrência e Propriedade Intelectual - Da Inovação Tecnológica ao Abuso de Poder”, Editora Singular, São Paulo, 2011,pg. 143.

${ }^{368}$ Antitrust Guidelines for the Licensing of Intellectual Property", DOJ/FTC.

${ }^{369}$ GILBERT, Richard J. e SHAPIRO, Carl, "Converging Doctrines? U.S. and EU antitrust policy for the licensing of Intellectual Property”. ABA Antitrust Magazine, v. 19, Fall, 2004.
} 
$\mathrm{Na}$ Europa, tais cláusulas tendem a ser consideradas pró-competitivas na medida em que sejam recíprocas e que permitam ao licenciado se utilizar de suas próprias melhorias, ou licenciá-las para terceiros ${ }^{370}$.

De acordo com o Direito Brasileiro, tal conduta será ilícita na medida em que utilizada como expediente para alcançar ou preservar uma posição dominante do licenciante no mercado (art. 36, II, da Lei 12.529/2011).

d) Venda Casada (Tying Arrangement): No Capítulo 2, já abordamos ostensivamente a importância desta figura no desenvolvimento da jurisprudência americana envolvendo a Propriedade Intelectual e o Antitruste. Consiste em se vincular o licenciamento de um direito de Propriedade Intelectual à aquisição de bens ou serviços, ou a um pacote de licenças (bundling/package licensing).

Para caracterização de uma venda casada, a jurisprudência do CADE exige, além da existência de produtos diferenciados (isto é, produtos para os quais haja uma demanda, um mercado relevante) e de elemento de coerção, a existência de poder de mercado quanto ao produto primário ou quanto ao produto secundário ${ }^{371}$.

O CADE caminha de forma semelhante a outras jurisdições, com a diferença importante de que, nos Estados Unidos e na Europa ${ }^{372}$, a existência de poder no mercado secundário, por si só, não basta para caracterizar a venda casada, sendo necessária a comprovação de poder no mercado primário. No Direito Brasileiro, a tipicidade da conduta está prevista no art. 36, $\S 3^{\circ}$, XVIII, da Lei 12.529/2011.

\footnotetext{
370 "The Comission has followed its view in Davidson that feed and grantbacks provisions do not infringe Article 81(1), provided that they are reciprocal and enable the licensee to use its own improvements, or licensed others to use them". (KORAH, Valentine, "Intellectual Property Rights and the EC Competition Rules. Oxford: Hart Publishing, 2006, pg. 41)

${ }^{371}$ Nesse sentido, é o voto do Conselheiro Ricardo Machado Ruiz, na averiguação preliminar $\mathrm{n}^{\circ}$ 08700.005025/2007-07 (Aceco Produtos para Escritório e Informática Ltda.), pg. 12, julgado pelo CADE em 23.06.2010: “(...) a venda casada demanda a análise de alguns requisitos para sua caracterização: a) a existência de dois produtos e/ou serviços separados; b) a existência de algum elemento de coerção; c) a existência de posição dominante no mercado principal ou condicionado; d) caracterização de efeitos anticompetitivos, seja no mercado secundário/condicionado ou seja no mercado principal" Além disso, "deve haver a configuração de conduta sem qualquer racionalidade ou eficiência econômica".

${ }^{372}$ O Guia Antitruste para Licenciamento de Propriedade Intelectual norte-americano, expedido em 1995, tende a condenar uma venda casada se preenchidos três requisitos (i) existência de poder de mercado do ofertante no mercado do produto principal; (ii) existência de efeitos anticompetitivos no mercado do produto ou serviço secundário; e (iii) insuficiência de eficiências que superem os efeitos anticompetitivos do arranjo. A Comissão Europeia adota um teste mais completo: (i) existência de dois produtos ou serviços separados (ii) existência de posição dominante do ofertante no mercado do produto principal; (iii) inexistência de possibilidade de escolha de compra do produto subordinado sem o produto vinculado; (iv) ocorrência de fechamento de mercado; e (v) inexistência de justificativas objetivas para a prática. (CORvo RIBAS, Guilherme Favaro, "Direito Antitruste e Propriedade Intelectual - uma abordagem sob a ótica das vendas casadas", Editora Singular, São Paulo, 2011, pg. 72)
} 


\subsubsection{Licenciamento Cruzado (Patent Pools) e Padronização:}

Ao invés de se empenhar na corrida tecnológica e obter patentes para proteger seus inventos, as empresas podem adotar um comportamento cooperativo, por meio de estratégias baseadas em licenciamento cruzado de patentes, ou a transferência de todas as patentes para uma sociedade formada para esta finalidade.

Embora tais estratégias de cooperação não sejam ilícitas em si, abre-se a possibilidade de que venham a se tornar anticoncorrenciais, devendo-se - então - atentar para seus efeitos e consequências ${ }^{373}$.

Um exemplo típico desta ação concentrada são os chamados patent pools, que consistem em acordos celebrados entre detentores de patentes, a fim de compartilhar tecnologias entre si, passando esse portfólio de patentes a ser licenciado como um único pacote para terceiros ${ }^{374}$.

De acordo com o Departamento de Patentes e Marcas dos Estados Unidos (United States Patent and Trademark Office), um pool é formado por dois ou mais titulares de patentes que licenciam suas patentes entre si ou para uma entidade administrativa especificamente criada para esse propósito $^{375}$. Frequentemente, pools de patentes são formados por várias tecnologias patenteadas necessárias para produzir um produto padronizado $^{376}$.

Os pools de patentes, em verdade, têm desempenhado um papel importante na indústria desde 1856, quando foi criado o primeiro pool, formado pelas tecnologias que

\footnotetext{
373 "Las empresas titulares de patentes, en un sector económico determinado, pueden competir entre sí a nivel de la obtención y utilización de tecnologías, y a tal fin pueden patentar y ejercer derechos exclusivos respecto de los inventos que obtengan. En tal contexto, las patentes operan como un bien empleado en las estrategias competitivas de sus titulares. Pero en lugar de adoptar tal posición competitiva, las empresas de un sector pueden optar por pactuar concertadamente respecto de su tecnología, y particularmente de la patentada, mediante instrumentos tales como licencias recíprocas o la cesión de todas las patentes a uma sociedad formada a tal fin. Si bien esas estrategias cooperativas no son necesariamente ilicitas, crean la posibilidad de ser ilícitamente anticompetitivas, para lo cual deberán evaluarse sus efectos y consecuencia" (DE LAS CuEVAS, Cabanellas, "Derecho de Patentes de invención", Buenos Aires, Heliasta, S.R.L., 2004)

${ }^{374}$ Quint, Daniel, "The New Palgrave Dictionary of Economics. Online Edition, edited by Steven N. Durlauf and Lawrence E. Blume, 2008". Disponível em http://www.dictionaryofeconomics.com/article?id=pde2008_P000371.

375 USPTO. "Patent Pools: A Solution to the Problem of Access in Biotechnology Patents?" 2000. Disponível em: http://www.ftc.gov/opp/intellect/020417lawrencemsung2.pdf.

${ }^{376}$ FreITAS DA SILVA, Denise, "Pools de Patentes: Impactos no Interesse Público e Interface com Problemas de Qualidade do Sistema de Patentes", Universidade Federal do Rio de Janeiro, Instituto de Economia, 2012 (Tese de Doutoramento)
} 
compunham a máquina de costura. Nos Estados Unidos, o número de pools foi reduzido no período pós Segunda Guerra Mundial, em vista do então cenário hostil do antitruste ${ }^{377}$.

Os pools retomaram sua força ao final da década de 1990, graças à crença de que tal arranjo seria tão ou mais importante na Nova Economia do que havia sido para os setores tradicionais. Inovações em hardware, software ou biotecnologia frequentemente foram construídas sobre inovações detidas por um número múltiplo de proprietários ${ }^{378}$.

Efetivamente, os pools podem ser benéficos, pois, ao concentrar tecnologias complementares, todos os potenciais interessados em obter a licença da tecnologia protegida pelo pool poderão negociar diretamente com o administrador do pool, ao invés de individualmente com cada detentor do "emaranhado" de patentes que compõem o pool (ao que SHAPIRO denominou de patent thickets ${ }^{379}$ ). Por consequência, é afastado o problema de "empilhamento" de royalties (royalties stacking) - i.e., custos de royalties múltiplos para cada tecnologia envolvida, ficando o licenciamento sujeito a um único royalty.

Com isso, os custos de pesquisa, pelo interessado, de cada uma das patentes que formam o pool são drasticamente reduzidos, assim como os riscos de eventual litígio. Todos esses fatores combinados contribuem para a redução dos custos de transação no licenciamento de tecnologias, com impacto positivo sobre a inovação tecnológica considerando-se que toda inovação é, também, o resultado de lavor sobre o conhecimento alheio $^{380}$.

Há, efetivamente, um consenso entre economistas e agentes políticos de que os patent pools podem ser pró-competitivos, fomentando a inovação e trazendo benefícios aos consumidores, desde que eles estejam limitados a patentes que são complementares, ou não concorrentes $^{381}$. Preocupações surgem, porém, quando os pools envolvem empresas que são concorrentes reais ou potenciais (i.e., acordos horizontais) ${ }^{382}$.

\footnotetext{
${ }^{377}$ LERNER, Josh e TIROLE, Jean, "Efficient Patent Pools", National Bureau of Economic Research, Working Paper 9175, Cambridge, September/2002, disponível em http://www.nber.org/papers/w9175

${ }^{378}$ LERnER, Josh e TIROLE, Jean, "Efficient Patent Pools", National Bureau of Economic Research, Working Paper 9175, Cambridge, September/2002, disponível em http://www.nber.org/papers/w9175

${ }^{379}$ SHAPIRO, Carl - "Navigating the Patent Thicket: Cross Licenses, Patent Pools, and Standard Setting, Univesity of California at Berkeley"

${ }^{380}$ HovenKAMP, Herbert e BOHANNAN, Cristina in "Creation without Restraint - Promoting Liberty and Rivalry in Innovation", Oxford University Press, pg. 11

${ }^{381}$ LERnER, Josh e TIROLE, Jean, "Efficient Patent Pools", National Bureau of Economic Research, Working Paper 9175, Cambridge, September/2002, disponível em http://www.nber.org/papers/w9175

${ }_{382}$ "As the IP Guidelines state, the antitrust agencies regard patent pooling arrangements as "often procompetitive" because these arrangements can promote the dissemination of technology. Possible procompetitive effects result from: 1) clearing blocking positions; 2) avoiding costly infringement litigation; $3)$ integrating complementary technologies; and 4) reducing transaction costs. Concerns arise, however,
} 
O consenso quanto a tais princípios gerais não afasta as dificuldades práticas de se identificar pools que são anticompetitivos. As principais dificuldades de prevenir os efeitos anticoncorrenciais dos pools derivam do fato de que, no mundo real, é muito difícil distinguir patentes complementares daquelas que são concorrentes ${ }^{383}$. Além disso, os pools podem ser utilizados para proteger patentes fracas ou mesmo inválidas ${ }^{384}$, bem como propiciar a venda casada de patentes não-essenciais ${ }^{385}$.

Logo, os pools podem, efetivamente, ocultar uma estratégia colusiva, visando suprimir a concorrência, tanto no mercado relevante como nos mercados relacionados, podendo servir como uma forma de dividir as vendas, coordenar preços e viabilizar a formação de $\operatorname{cartel}^{386}$.

Os riscos são intensificados quando o pool se forma no contexto de estabelecimento de um padrão, pois alguns dos participantes no processo de estabelecimento de um padrão possuem interesses especiais, porque, em geral, são também titulares de patentes que estão relacionadas ao padrão. Há, portanto, o claro incentivo para que estes agentes conduzam as especificações do padrão de modo a incluir suas patentes ${ }^{387}$.

São também problemáticas as já mencionadas cláusulas de grant back, que abarcam a previsão de que, em caso de futuras inovações, estas serão objeto de licenciamento sem custos para os demais membros do pool, o que acarretaria um desestímulo à inovação ${ }^{388}$.

when a pooling arrangement harms competition among entities that are actual or potential competitors". (GILBERT , Richard J., "Antitrust for Patent Pools:A Century of Policy Evolution", 2004 Stanford Technology Law Review, 3, http://stlr.stanford.edu/STLR/Articles/04_STLR_3)

${ }^{383}$ LERNER, Josh e TIROLE, Jean, "Efficient Patent Pools", National Bureau of Economic Research, Working Paper 9175, Cambridge, September/2002, disponível em http://www.nber.org/papers/w9175

${ }^{384}$ CARLSON, Steven C., "Patent Pools and the Antitrust Dilemma". Yale Journal on Regulation, v. 16, pgs. 359-373, 1999

${ }^{385}$ Junghoon, Kim, “Technical Standard-Setting, Patent Pooling, and Competition Policy", Institute of Intellectual Property Bulletin, 2004, pg. 208. "A essencialidade das patentes pode ser definida (i) tecnicamente, quando, por exemplo, "qualquer interessado teria que necessariamente violá-las para conseguir implementar o padrão; ou (ii) comercialmente, quando, na prática, são necessárias para implementação dos padrões essenciais, porque não existem substitutos economicamente viáveis”. (Vide Ato de Concentração no 08012.008810/2009-23, Relator: Conselheiro Carlos Emmanuel Joppert Ragazzo)

${ }^{386}$ PRIEST, George, "Cartels and Patent License Arrangements", Journal of Law and Economics, v. 20, n.2, p. 309-77, 1977.

387 CRANE, Daniel A.. "Patent Pools, RAND Commitments, and the Problematics of Price Discrimination", Cardozo Legal Studies Working Paper No. 232, 2008. Disponível em: http://ssrn.com/abstract=1120071. Acesso em: 4 mar. 2012.

${ }^{388}$ Lerner, Josh e TIROLE, Jean. "Public Policy toward Patent Pools". NBER Chapters In: JAFFe, Adam B., LERnER, Josh e STERn, Scott (Ed.) Innovation Policy and the Economy, v.8, p. 157-186, University of Chicago Press, 2008. Disponível em: http://www.nber.org/chapters/c5304.pdf. HoVENKAMP, Herbert, JANIS, Mark; e LEMLEY, Mark. "Anticompetitive Settlement of Intellectual Property Disputes". California: Boalt Working Papers in Public Law, Boalt Hall, UC Berkeley, 2003. Disponível em: http://escholarship.org/uc/item/6v9359nt. 
Pela legislação brasileira, os pools de patentes devem ser previamente submetidos ao CADE nos casos previstos nos incisos I e II do art. 88 da Lei 12.529/2011.

\subsubsection{ABUSOS NA FIXAÇÃO DE RoYalties}

A estipulação de royalties, normalmente, ou se dá com base em montante fixo único, em percentual sobre o preço da venda dos produtos que incorporam a tecnologia, ou por um valor fixo sobre cada produto vendido.

A vinculação do cálculo dos royalties a elementos sem qualquer relação com os direitos de Propriedade Intelectual, contudo, pode ocultar uma estratégia para desestimular o uso de tecnologias concorrentes, para fins de dominação de um mercado.

O caso mais famoso na jurisprudência é o Microsoft. A Microsoft estabeleceu com os fabricantes de computadores, um acordo em que os royalties de licenciamento de seu sistema operacional Windows eram calculados sobre o produto de suas vendas considerando, inclusive, os computadores que não incluíssem o Windows.

Como os fabricantes não tinham nenhum custo adicional de vender computadores com o Windows, ao passo que teriam que arcar com royalties extras para cada computador vendido com outro sistema operacional instalado, o resultado foi um bloqueio ao desenvolvimento de outros sistemas operacionais.

No Direito brasileiro, esta conduta pode se enquadrar em qualquer uma das condutas previstas no art. $36, \S 3^{\circ}$, incisos III, IV ou V - deste que haja objetivo ou potencial de produzir os efeitos previstos no caput.

\subsubsection{NEGATIVA DE LICENCIAR}

Na jurisprudência norte-americana e europeia, muito se discutiu sobre a aplicação da doutrina das essential facilities - objeto de comentários no Capítulo 2 - no que se refere ao estabelecimento, em alguns casos, de um pretenso dever de licenciar ${ }^{389}$.

A Suprema Corte criou uma regra de legalidade per si de recusas a licenciar, mesmo nos casos em que a recusa teria o efeito de influenciar um outro mercado, que não aquele relacionado ao direito de Propriedade Intelectual em análise. Após isso, a Suprema

${ }^{389}$ LIANOS, Ioannis e DREYFUSS, Rochelle, "New Challenges in the Intersection of Intellectual Property Rights With Competition Law - A View from Europe and the United States", CLES Working Paper Series, Abril, 2013. 
Corte restringiu as possibilidades de que uma recusa unilateral de contratar poderia se achar em violação à Seção 2 do Sherman Act, concluindo que haveria "poucas exceções à regra de que não existe um dever de ajudar concorrentes ${ }^{390}$ ".

$\mathrm{Na}$ Europa, o caso Magill, já analisado no Capítulo 2, foi o ápice de reconhecimento de um dever de licenciar, porém, a interpretação do precedente foi restringida em julgamentos posteriores, como tratamos anteriormente ${ }^{391}$.

Em período mais recente, entretanto, a Comissão Europeia voltou a expandir o dever de fornecimento a concorrentes ${ }^{392}$.

Em sua mais recente diretiva sobre aplicação de regras de práticas abusivas de exclusão, a Comissão reconheceu que uma recusa à licença pode ser questionada se: (i) a recusa se refere a um produto ou serviço que é objetivamente necessário para competir de forma eficaz em um mercado secundário; (ii) a recusa ocasionará a eliminação da concorrência no mercado secundário, e (iii) a recusa ocasionará dano ao consumidor ${ }^{393}$.

Quanto ao requisito (iii), a Comissão enfatiza o interesse dos consumidores e indica que examinará a probabilidade de consequências negativas da recusa à licença no mercado relevante compensarem, ao longo do tempo, as consequências negativas de impor um dever de licenciar. Retardar a inovação constituiria um exemplo de dano ao consumidor. Por outro lado, o detentor da patente poderá alegar a necessidade de recuperar investimentos exigidos para o desenvolvimento deste insumo e a necessidade da empresa de gerar incentivos para investir no futuro, abstraídos os riscos de que os projetos não sejam bem sucedidos ${ }^{394}$.

\footnotetext{
${ }^{390}$ LIANOS, Ioannis; DREYFUSS, Rochelle, "New Challenges in the Intersection of Intellectual Property Rights With Competition Law - A View from Europe and the United States", CLES Working Paper Series, Abril, 2013.

${ }^{391}$ LIANOS, Ioannis; DREYFUSS, Rochelle, "New Challenges in the Intersection of Intellectual Property Rights With Competition Law - A View from Europe and the United States, CLES" Working Paper Series, Abril, 2013.

${ }^{392}$ LIANOS, Ioannis; DREYFUSS, Rochelle, "New Challenges in the Intersection of Intellectual Property Rights With Competition Law - A View from Europe and the United States", CLES Working Paper Series, Abril, 2013.

${ }^{393}$ LIANOS, Ioannis; DREYFuSs, Rochelle, "New Challenges in the Intersection of Intellectual Property Rights With Competition Law - A View from Europe and the United States", CLES Working Paper Series, Abril, 2013.

${ }^{394}$ LIANOS, Ioannis; DREYFUSS, Rochelle, "New Challenges in the Intersection of Intellectual Property Rights With Competition Law - A View from Europe and the United States", CLES Working Paper Series, Abril, 2013.
} 
Em contraste com o Direito norte-americano, na Europa, recusas de fornecer interoperabilidade são analisadas sob a categoria mais ampla de recusa ao fornecimento ${ }^{395}$.

A Comissão aplicou esta regra à recusa, pela Microsoft, de fornecer à Sun Microsystems a informação necessária para estabelecer interoperabilidade entre seus sistemas operacionais e o Windows. A Microsoft foi ordenada a divulgar a informação sobre interoperabilidade em uma forma razoável, não-discriminatória e em tempo hábil.

Embora a Comissão não tenha contemplado uma divulgação compulsória do código-fonte do Windows e a medida apenas tenha abrangido especificações de interface, ela reconheceu que "não pode ser ignorado que determinar à Microsoft a divulgação de tais especificações e permitir seu uso por terceiros restringe o exercício da propriedade intelectual $^{396, "}$.

A conduta da Microsoft não estava, necessariamente, impedindo o surgimento de um novo produto, entretanto, de acordo com a Comissão, possuiria o efeito de reduzir os incentivos de seus concorrentes para inovar (e produzir novos produtos no futuro) e, portanto, limitavam a escolha do consumidor. A Comissão afirmou que os direitos de propriedade intelectual não podiam constituir uma justificação objetiva para a recusa da Microsoft e empregou um exame de ponderação a fim de verificar se o possível impacto negativo de uma tal ordem sobre os incentivos da Microsoft para inovar poderiam ser contrabalanceados por seu impacto positivo no nível de inovação em toda a indústria (incluindo a própria Microsoft) ${ }^{397}$.

Adotando a visão de que "os esforços de pesquisa e desenvolvimento da Microsoft são estimulados por cada passo em inovação de seus concorrentes no mercado de sistemas operacionais" e que, se seus concorrentes saíssem do mercado, isso diminuiria os incentivos da Microsoft para inovar, a Comissão concluiu que os custos seriam compensados pelos benefícios no caso concreto. A Corte Europeia de Justiça confirmou a decisão da Comissão em $2007^{398}$.

\footnotetext{
${ }^{395}$ LIANOS, Ioannis; DREYFUSS, Rochelle, "New Challenges in the Intersection of Intellectual Property Rights With Competition Law - A View from Europe and the United States", CLES Working Paper Series, Abril, 2013.

${ }^{396}$ LIANOS, Ioannis; DREYFUSS, Rochelle, "New Challenges in the Intersection of Intellectual Property Rights With Competition Law - A View from Europe and the United States", CLES Working Paper Series, Abril, 2013.

${ }^{397}$ LIANOS, Ioannis; DREYFuSs, Rochelle, "New Challenges in the Intersection of Intellectual Property Rights With Competition Law - A View from Europe and the United States", CLES Working Paper Series, Abril, 2013.

${ }^{398}$ LIANOS, Ioannis; DREYFUSS, Rochelle, "New Challenges in the Intersection of Intellectual Property Rights With Competition Law - A View from Europe and the United States", CLES Working Paper Series, Abril, 2013.
} 
Verifica-se, portanto, que a jurisprudência europeia mais recente tende a reconhecer um dever de licenciar, atribuindo um grande peso aos impactos da conduta sobre a inovação, dentre outras circunstâncias, como a exclusão da concorrência em um mercado secundário.

No Brasil, as hipóteses de licenciamento compulsório previstas no art. 68 da Lei 9.279/96 incluem o exercício abusivo de patentes, ou a prática de abuso de poder econômico por meio de patentes. A atual redação da Lei 12.529/2011, no entanto, atribui ao CADE o poder de recomendar o licenciamento compulsório em caso de abuso estendendo tal possibilidade a todas as espécies de direitos de Propriedade Intelectual, como veremos em maiores detalhes no Capítulo seguinte.

A jurisprudência tradicional do CADE, no entanto, parece reservar o licenciamento compulsório, ou qualquer forma de cessão compulsória, a hipóteses muito excepcionais, devendo ficar reservado "para situações de clara dominação de mercado, exclusão ou eliminação de competidores efetivos ou potenciais através da elevação das barreiras à entrada no mercado e outras formas de lesão potencial à concorrência ${ }^{399}$ ".

\subsubsection{Outras Figuras Anticoncorrenciais Envolvendo a Propriedade INTELECTUAL: PATENT TROLLS E SHAM LITIGATION}

Muito se discute, especialmente nos Estados Unidos, sobre os patent trolls também chamados patent assertion entities ou non-practicing entities.

Trata-se de detentores de patentes cuja única atividade econômica é extrair lucro a partir de processos judiciais baseados supostas violações de suas patentes.

Nessas situações, ocorre o chamado problema de hold-up, isto é, o problema do refém.

Uma determinada empresa que já tenha realizado um investimento para produzir um determinado produto com base em uma tecnologia possui custos muito elevados para migrar para uma tecnologia alternativa.

Como essas entidades não desenvolvem e nem lançam produtos no mercado, elas não estão sujeitas à típica estratégia de contra-ataque, ou seja, a ameaça de ajuizamento de ações alegando violação recíproca de patentes.

\footnotetext{
${ }^{399}$ Voto do ex-Conselheiro Paulo Dyrceu Pinheiro no ato de Concentração 47/95.
} 
Os Patent Trolls se valem dos altos custos de litígio, os quais envolvem não apenas as custas judiciais, mas, também, as horas internas expendidas em produzir provas contra as alegações levantadas em juízo pelos Trolls. Some-se a isso a possibilidade de o autor em um processo de violação requerer a busca e apreensão dos produtos, o que é um risco muito alto para as empresas produtivas.

Por tais circunstâncias, os Patent Trolls possuem um grande poder de barganha, podendo, portanto, pressionar para que o litígio resulte em acordo, em que poderão exigir royalties em valor muito acima do razoável.

Estima-se que os Patent Trolls sejam responsáveis por um terço dos processos envolvendo violações de patentes nos Estados Unidos. Um estudo acadêmico calcula que os Trolls custariam à sociedade norte-americana aproximadamente 30 bilhões de dólares ano e que teriam representado um custo de 500 bilhões no curso das últimas duas décadas ${ }^{400}$.

Para que se tenha uma ideia do atual nível de demonização dos trolls nos Estados Unidos, basta dizer que o tema tornou-se assunto de primeira página em dois dos principais jornais no país, o New York Times e o Wall Street Journal, ambos condenando a prática oportunista e agressiva de tais entidades.

Até mesmo o presidente Barack Obama condenou os Trolls publicamente em um discurso em fevereiro de 2013, em que defendeu uma reforma do sistema de patentes.

O ativismo legislativo contra os Patent Trolls produziu quatorze projetos de lei em discussão no Congresso até o final de 2013 - além de diversas outras iniciativas no âmbito de vinte e sete estados americanos.

O principal projeto em âmbito federal - o Innovation Act - foi aprovado na comissão jurídica do Congresso e na House of Representatives em 05 de Dezembro de 2013, por expressiva votação (325-91).

O projeto eleva o nível de requisitos para conhecimento de petições iniciais em casos envolvendo violação ao direito de patentes, obrigando o autor a identificar, especifica e objetivamente, as suas alegações, fornecendo detalhes sobre os métodos ou atos objetos da acusação, bem como a informar a principal atividade econômica da entidade que alega violação e as reais partes interessadas.

${ }^{400}$ Bessen, James, "The Private and Social Costs of Patent Trolls", Boston University School of Law, Working Paper n'11-45, 2011, apud LEMLEY, Mark, "Missing the Forest for the Trolls", Columbia Law Review,Stanford Law and Economics Olin Working PaperNo. 443, May, 2013 
Além disso, o projeto determina que a prova documental deverá ser pré-constituída e que os custos de quaisquer outros meios de prova produzidos devem recair sobre o autor.

Não obstante tamanha preocupação com os Patent Trolls, MARK LEMLEY entende que os problemas a eles relacionados se devem, em última análise, a problemas do próprio sistema de patentes. LEMLEY argumenta que, embora os Patent Trolls atuem de forma oportunista, as chamadas practicing entities - ou seja, empresas que exploram patentes com intuito produtivo - também têm incorporado modelos de negócio próprios dos trolls. Em outras palavras, embora os trolls explorem as falhas do sistema de patentes, eles não são os únicos a fazê-lo.

Por outro lado, em termos práticos, traçar uma linha divisória entre o que seja uma non-practicing entity e uma practicing entity pode levantar dificuldades, o que, por sua vez, também dificultaria o tratamento do tema por meio de legislação que visasse, especialmente, os Patent Trolls.

Portanto, segundo LEMLEY, o foco da reforma do sistema de Propriedade Intelectual deveria se voltar para aquilo que seria doença em si: as falhas sistêmicas da Propriedade Intelectual, e não para o seus sintomas.

Para LEMLEY, a principal preocupação do legislador não deveria recair especificamente sobre a ação individual dos Patent Trolls, mas sim, sobre como tornar o sistema de obtenção de patentes mais transparente, confiável e estritamente destinado a proteger invenções que não sejam óbvias. Além disso, deve-se adequá-lo para que a indenização buscada em uma eventual ação seja sempre proporcional à contribuição tecnológica real trazida pela patente.

O tema dos Patent Trolls tangencia outra forma de conduta abusiva envolvendo direitos de Propriedade Intelectual, embora com ela não se confunda: é o que a doutrina norte-americana denominou de Sham Litigation, ou Vexatious Litigation na União Europeia.

O Sham Litigation consiste em um uso abusivo dos sistemas regulatório e processual com a finalidade de elevar os custos dos concorrentes, excluir a concorrência e, em última análise, prejudicar os consumidores finais ${ }^{401}$.

Essa área de interação entre a Propriedade Intelectual e a concorrência é ainda relativamente inexplorada, embora - em nossa visão - o assunto tenha maior relação com a

${ }^{401}$ LIANOS, Ioannis e DREYFUSS, Rochelle, "New Challenges in the Intersection of Intellectual Property Rights With Competition Law - A View from Europe and the United States", CLES Working Paper Series, Abril, 2013. 
esfera da proteção privada dos concorrentes, do que com a proteção da instituição concorrência, nos moldes da clássica divisão do Direito Concorrencial Alemão - que, em certa medida, também se verifica no Direito brasileiro.

Assim, sem termos a pretensão de esgotar o tema do Sham Litigation, a sua menção nessa dissertação se dá apenas un passant, pois serve para ilustrar as várias tensões entre Propriedade Intelectual e Direito Antitruste no Século XXI.

Sham Litigation ou Vexatious Litigation é um típico caso de conduta predatória não baseada em preços.

Nestes casos, a grande dificuldade enfrentada pelas cortes é estabelecer critérios para distinguir entre o legítimo exercício de direito de petição e o uso abusivo com efeitos anticoncorrenciais.

Nos Estados Unidos, por exemplo, é reconhecido, como regra, que os esforços para influenciar agentes públicos, por meio de lobby, publicidade e outros meios, são protegidas pelo Direito Fundamental de Petição, e tais manifestações não violariam o Direito Antitruste. E isso mesmo nos casos em que a motivação não for juridicamente protegida, como se dá com a tentativa de se eliminar a concorrência. Essa doutrina se denomina Nooerr-Pennington Immunity.

Entretanto, as cortes vêm admitindo algumas exceções à regra de imunidade, quando as partes se utilizam do processo, e não o seu resultado, para dissimular uma conduta anticoncorrencial.

Na Europa, Vexatious Litigation pode constituir uma forma de abuso de posição dominante, contrária ao Artigo 102 da TFEU.

O elemento chave para identificar o Sham Litigation é a ausência de interesse genuíno em receber a tutela judicial. Estabelecer o genuíno motivo do autor, portanto, tem sido a principal preocupação da jurisprudência, tanto na Europa como nos Estados Unidos.

Na prática, as cortes adotam duas abordagens diferentes para identificar o Sham Litigation, uma delas, mais restrita, define o Sham Litigation com um padrão de falta de fundamentação legal para o pedido, realizado sem nenhuma relação com seu mérito, e desenhado apenas para atrasar e amarrar o processo judicial. Outra linha centra a análise do real motivo do réu em um cálculo de custo-benefício de seu interesse econômico em ajuizar a ação.

Seguindo a primeira abordagem, a existência de finalidade predatória é demonstrata em situações de má apreciação da realidade dos fatos pelos tribunais, em razão de perjúrio, 
fraude ou suborno. Entretanto, os Tribunais também consideram como Sham Litigation ações que são manifestamente infundadas ou sem causa provável.

$\mathrm{Na}$ análise de existência de causa provável, as cortes examinam a situação existente quando a ação em questão foi ajuizada. A provável causa para instaurar uma ação civil exige não mais do que uma crença razoável de que há chances de sucesso. Esse teste exige, como primeiro passo, a prova de que o processo é objetivamente infundado, em um sentido de que nenhum litigante razoável poderia esperar alcançar êxito com base em seu mérito. Essa abordagem é passível de críticas, uma vez que uma causa poderia vir a ser considerada infundada por uma corte, mas ser acolhida por outra.

A segunda abordagem é mais ampla. O fato de uma ação não ser infundada não exclui a possibilidade de que o uso do processo possa constituir uma violação antitruste. Ao contrário, a existência de Sham Litigation é avaliada objetivamente, com foco no interesse econômico do autor na ação. O que deve contar é se o benefício buscado pelo autor suplanta os seus custos. O teste econômico para concluir pela existência do Sham Litigation seria, portanto, essencialmente um teste de conduta predatória, na medida em que se exige prova de sacrifício econômico, que não poderá ser recuperado pelo autor em um momento seguinte, mesmo no caso de que venha a lograr êxito em sua ação.

A aplicação de tal teste, porém, levanta uma série de questionamentos. Por exemplo, a informação referente aos méritos relativos das partes opostas e ao valor de recuperação podem estar no domínio privado, havendo incentivos para que tal informação seja mal representada em juízo.

Isso levanta a questão sobre qual seria o critério adequado para estabelecer a existência de Sham Litigation. Diferentemente da vasta literatura sobre preços predatórios, os economistas ainda não produziram muitos estudos sobre os incentivos existentes para Sham Litigation.

A Suprema Corte dos Estados Unidos adotou um teste bipartido, combinando as abordagens objetiva e subjetiva: (i) a ação deve ser infundada de modo que nenhum litigante poderia esperar obter êxito baseado em seu mérito; (ii) apenas uma vez que o processo é tido como objetivamente infundado, poderá a corte examinar a motivação subjetiva do litigante (sua má fé).

Assim, o motivo, por si só, não torna viável uma responsabilização por violação à Seção 2 do Sherman Act, apenas porque o direito de Propriedade Intelectual revelou-se inválido. Da mesma forma, em razão do elemento subjetivo exigido, a falta de 
fundamentação da ação não poderá, por si só, levar à conclusão de que há uma afronta ao antitruste. Logo, não bastaria demonstrar que a ação é objetivamente infundada, o autor deve conhecer ou acreditar que ela é infundada.

No Direito Europeu, a Corte Europeia de Justiça concluiu que o exercício do direito de ajuizar ações pode ser considerado abusivo apenas em circunstâncias excepcionais, a saber, (i) quando a ação não puder ser considerada como uma tentativa razoável de estabelecer os direitos da empresa em questão e somente servir para criar um constrangimento à parte contrária e (ii) a ação é parte de um plano cujo objetivo é eliminar a concorrência. O teste europeu parece ser mais voltado à intenção do autor em comparação ao teste norte-americano, embora ainda haja um elemento objetivo consistente na necessidade de demonstrar tal intento a partir da ausência de qualquer outra explicação plausível para ação, que não seja provocar embaraço à outra parte.

Esses elementos levantam uma série de obstáculos práticos, especialmente, quando se trata de indústrias específicas, em que as disputas sobre a propriedade intelectual revelam alto teor de complexidade, como acontece na indústria farmacêutica, por exemplo, o que aumenta o número de alegações aparentemente genuínas e razoáveis, prejudicando o "molde" idealizado pelo teste. Deve-se notar que uma empresa dominante, ao iniciar uma ação sob alegação de violação à Propriedade Intelectual, seria exigida a mostrar que havia expectativa de direito no início do processo, o que pode ser feito por meio de pareceres jurídicos ou documentos internos que demonstrem a percepção da empresa sobre o valor de seu ativo em disputa (Propriedade Intelectual).

O Sistema Brasileiro de Defesa da Concorrência já emitiu um pronunciamento referente a uma conduta semelheante ao Sham Litigation, em um caso em que a Siemens VDO Automotive foi acusada de mover ações judiciais para prejudicar uma concorrente do ramo de tacógrafos, a Seva Engenharia Eletrônica, mercado este que, à época em que iniciado o caso (2005), era $85 \%$ dominado pela Siemens.

A Siemens moveu duas ações - um Mandado de Segurança e uma Ação Ordinária ambas tendo sido extintas sem julgamento de mérito, por ilegitimidade ativa.

Conforme relatório do Conselheiro Fernando Furlan, a Secretaria de Defesa Econômica foi taxativa ao considerar que havia reuniões gravadas a comprovar que houve um convite à cartelização por parte da Siemens. A SDE considerou que "nenhum litigante razoável entenderia lhe caber direito líquido e certo a que a Seva cumprisse as especificações da Portaria 50/2001 (do Denatran). Ambas as ações, de idêntico 
fundamento, estariam baseadas em um direito difuso, mas a Siemens não possuiria legitimidade para defesa de tais direitos difusos".

Segundo a SDE, "a insistência em pedido já declarado improcedente e a falta de menção ao Mandado de Segurança fracassado também demonstram má-fé da representada. O intuito de prejudicar concorrente é evidenciado por (1) inclusão da Seva no polo passivo da Ação Ordinária (2) ataque a novo produto desenvolvido pela Seva e homologado por autoridades competentes e (3) deixar de combater outras empresas que não teriam atendido a exigências da Resolução (sendo que, de acordo com o parecer do Denatran, os problemas técnicos do tacógrafo da Seva são comuns a outros tacógrafos no mercado)”.

Tal decisão, embora tenha se valido de alguns argumentos desenvolvidos na jurisprudência estrangeira (notadamente, norteamericana) não permite concluir que houve uma recepção do instituto da Sham Litigation pelo Direito brasileiro. Segundo declarou o Conselheiro Furlan após o julgamento, “A sham litigation é um instituto norteamericano e tem critérios específicos que esse caso talvez não atendesse. Mas, nós, temos em nosso Direito o abuso de direito de ação, bem como o (então) inciso V do artigo 21 da Lei 8.884 ("criar dificuldades à constituição, ao funcionamento ou ao desenvolvimento de empresa concorrente ou de fornecedor adquirente ou financiador de bens ou serviços”) - conduta atualmente prevista no art. $36, \S 3^{\circ}$, IV, da Lei 12.529/2011.

De qualquer forma, este foi o primeiro precedente em que o Sistema Brasileiro de Defesa da Concorrência reconheceu a possibilidade de abuso de posição dominante por meio de ações judiciais para impedir a entrada de um concorrente no mercado.

\subsection{ASPECTOS CONCORRENCIAIS DO LICENCIAMENTO INTERNACIONAL DE TECNOLOGIA - O ACORDO TRIPS}

O aumento da competitividade dos países em desenvolvimento nos ramos industriais mais tradicionais, bem como o surgimento de novas indústrias baseadas estritamente no conhecimento, fez com que as economias dos países desenvolvidos se concentrassem cada vez mais nestes novos setores, em que suas vantagens comparativas se mostram mais fortes.

A crescente importância dos bens intelectuais para a economia dos países desenvolvidos levou a pressões internacionais para que houvesse uma harmonização de 
padrões mínimos de proteção à Propriedade Intelectual. De sua parte, os países em desenvolvimento se enxergaram em uma posição em que a aceitação de tais padrões mínimos lhes foi imposta sob pena de não terem acesso aos mercados internacionais ${ }^{402}$.

Dada a insatisfação dos países desenvolvidos com os mecanismos e foros internacionais então existentes (Convenções de Berna e de Paris e ONU), os países desenvolvidos - em especial os Estados Unidos - pressionaram para que o tema passasse a ser discutido, exclusivamente, sob uma ótica comercial, no âmbito da Organização Mundial do Comércio ${ }^{403}$.

É nesse contexto que surge o TRIPS e tais considerações são vitais para melhor interpretação de suas disposições - em especial, aquelas que representam importantes concessões e salvaguardas conseguidas pelos países em desenvolvimento ${ }^{404}$.

O tema da transferência tecnológica - como se pode imaginar - foi um dos principais focos de discussões, pois é de vital importância para os países em desenvolvimento, que são, eminentemente, importadores de tecnologia e dependem do mercado internacional para obter acesso à inovação tecnológica. Os contratos internacionais de tecnologia podem, no entanto, dar ensejo a práticas como as abordadas

402 "Among the many causes of the drive to overcome preexisting territorial limitations on intellectual property rights, two merit attention here. First, the growing capacity of manufacturers in developing countries to penetrate distant markets for traditional industrial products has forced the developed countries to rely more heavily on their comparative advantages in the production of intellectual goods than in the past. Second, the rise of knowledge-based industries radically altered the nature of competition and disrupted the equilibrium that had resulted from more traditional comparative advantages. Not only is the cost of research and development often disproportionately higher than in the past, but the resulting innovation embodied in today's high-tech products has increasingly become more vulnerable to free-riding appropriators. Market access for developing countries thus constituted a bargaining chip to be exchanged for greater protection of intellectual goods within a restructured global marketplace”.

(REICHMAN, J.H., "Universal Minimum Standards of Intellectual Property Protection under the TRIPS Component of the WTO Agreement", The International Lawyer, Summer, 1995)

403 "Duas são as razões fundamentais da inclusão do TRIPS no GATT: o interesse de completar as deficiências do sistema de proteção da propriedade intelectual da OMPI, e a necessidade de vincular, definitivamente, o tema do comércio internacional".

(BASSO, Maristela, "Os fundamentos atuais do Direito Internacional da Propriedade Intelectual", Conferência proferida no "Seminário sobre Direito Autoral", realizado pelo centro de Estudos Judiciários, nos dias 17 e 18 de março de 2003, no Centro Cultural Justiça Federal, Rio de Janeiro/RJ, Revista CEJ Brasília, no 21, pg. 1630, abr/jun 2003)

404 "The extent to which developing countries will themselves benefit from stronger patent systems - as distinct from compensatory market access - depends in part on the willingness of firms in developed countries either to increase direct investments in developing countries or to license more of their advanced technology to local firms. Moreover, familiarization with the benefits of the patent system could stimulate greater investment in domestic research and development and should encourage the private sector to develop its own intellectual property. Nevertheless, the value of a patent system to developing countries remain controversial, and single developing countries could suffer hardship because of a growing dependence on foreign patents with few countervailing benefits. In such a case, one must acknowledge the achievements of the developing-country negotiators, who have built numerous safeguards and escape hatches into the TRIPS Agreement”.(REICHMAN, J.H., "Universal Minimum Standards of Intellectual Property Protection under the TRIPS Component of the WTO Agreement", The International Lawyer, Summer, 1995) 
nos subitens anteriores, as quais podem ter por finalidade a dominação de mercados, ou a imposição de obstáculos indesejáveis à inovação tecnológica no contexto local.

Por essa razão, no período anterior ao TRIPS, alguns países em desenvolvimento costumavam adotar políticas intervencionistas sobre tais contratos.

Este era o caso política brasileira que vigorou até a década de 1980, a qual era baseada em uma intervenção unilateral estrita sobre os contratos de transferência internacional de tecnologia, ficando - à época - a cargo do INPI exercer tal controle, nos termos do Ato Normativo INPI n. 15/1975. O referido Ato permitia não apenas o controle de cláusulas contratuais consideradas abusivas, mas, também, que o INPI exercesse, em qualquer contrato, uma análise econômica da razoabilidade da importância a ser paga pelo receptor a título de royalties, bem como a determinação dos custos e benefícios que a economia brasileira poderia extrair dos acordos sujeitos à aprovação e registro.

Além disso, o INPI poderia até mesmo proibir a importação, sob argumento de que se tratava de tecnologia que o receptor estaria capacitado a desenvolver, visando - assim aperfeiçoar a capacidade tecnológica brasileira. Por fim, as cláusulas que garantiam renúncia de direitos eram consideradas nulas per $\mathrm{si}^{405}$.

Este modelo regulatório estrito foi, posteriormente, abandonado, quando, no início da década de 1990, intensificou-se um movimento de desregulamentação e liberalização econômica que culminaria com a própria adesão do Brasil ao TRIPS e a introdução da Lei de Propriedade Industrial em 1996.

O TRIPS, a seu turno, não introduz suas próprias regras no que se refere à repressão de práticas abusivas e à proteção da concorrência, mas autoriza os Estados Membros a estabelecer regras locais com esta finalidade, desde que sejam compatíveis com o Acordo.

Essa reserva em favor da soberania dos Estados Membros representou uma concessão que os países desenvolvidos fizeram em resposta à iniciativa original dos países em desenvolvimento de estabelecer um Código de Conduta quanto à Transferência de Tecnologia ${ }^{406}$.

O Art. 8.1. faculta ao Estados Membros a adoção de "medidas necessárias para proteger a saúde e a nutrição públicas e para promover o interesse público em setores de

\footnotetext{
405 TIMM, Luciano Benetti, "Contrato Internacional de Transferência de Tecnologia no Brasil: Intersecção da Propriedade Intelectual com o Direito Antitruste”, III Prêmio SEAE, Monografia em Defesa da Concorrência e Regulação Econômica, 2008.

${ }^{406}$ ULLRICH, Hanns, "Expansionist Intellectual Property Protection and Reductionist Competition Rules: A TRIPS Perspective", EUI Working Paper LAW n 2004/3"
} 
importância vital para seu desenvolvimento sócio-econômico e tecnológico, desde que as medidas sejam compatíveis com o Acordo".

O Art. 8.2 do TRIPS estabelece, como princípio básico, que algumas medidas, “desde que consistentes com a previsão deste Tratado, podem ser necessárias para evitar o abuso de direitos de Propriedade Intelectual por seus titulares ou evitar recurso a práticas que limitem de maneira injustificável o comércio ou que afetem adversamente a transferência internacional de tecnologia ${ }^{407, "}$.

O acordo confere maior especificidade a este princípio na Parte II, intitulada "Padrões Concernentes à Disponibilidade, Escopo e Uso de Direitos de Propriedade Intelectual", cuja seção 8 trata do "Controle de Práticas Anticoncorrenciais em Licenças Contratuais".

Essa seção consiste de um único artigo (40), o qual reafirma que os Estados Membros reconhecem a potencialidade de práticas ou condições de licenciamento que restrinjam a concorrência e afetem adversamente o comércio, impedindo a transferência de tecnologia, bem como autorizam os Estados Membros a introduzirem legislação para combater práticas que redundem em abuso da Propriedade Intelectual que tenha efeitos adversos sobre a concorrência no mercado relevante.

Nota-se que a redação do dispositivo leva a crer que, para ser considerada anticoncorrencial, uma determinada prática deve ser considerada, também, um abuso do exercício do direito conferido pela Propriedade Intelectual. A redação parece excluir da permissão conferida pelo TRIPS o mero exercício regular da Propriedade Intelectual. Dito de outro modo: há exigência de que a prática, cumulativamente, represente (i) um abuso à Propriedade Intelectual e (ii) um prejuízo ao comércio, à concorrência no mercado relevante ou à transferência de tecnologia.

Finalmente, o dispositivo trata de mecanismos de consulta e solução de conflitos envolvendo países membros ${ }^{408}$.

\footnotetext{
${ }^{407}$ ARTIGO 8

"Princípios

1. Os Membros, ao formular ou emendar suas leis e regulamentos, podem adotar medidas necessárias para proteger a saúde e nutrição públicas e para promover o interesse público em setores de importância vital para seu desenvolvimento sócio-econômico e tecnológico, desde que estas medidas sejam compatíveis com o disposto neste Acordo.

2. Desde que compativeis com o disposto neste Acordo, poderão ser necessárias medidas apropriadas para evitar o abuso dos direitos de propriedade intelectual por seus titulares ou para evitar o recurso a práticas que limitem de maneira injustificável o comércio ou que afetem adversamente a transferência internacional de tecnologia”.

${ }^{408}$ SEÇÃO 8: CONTROLE DE PRÁTICAS DE CONCORRÊNCIA DESLEAL EM CONTRATOS DE LICENÇAS
} 
Não há outras regras sobre Direito Concorrencial no TRIPS, com a exceção de uma previsão bastante específica, constante do art. $31, b$ e $c$, a qual está inserida em seção que trata de princípios concernentes ao segundo uso de uma tecnologia protegida, ficando os Estados Membros autorizados a impor licenças compulsórias de direitos de propriedade intelectual, a fim de afastar a recusa de licenciamento do segundo uso que - ao cabo de processo administrativo ou judicial - venha a se mostrar como anticompetitiva ou desleal 409

É importante destacar que o TRIPS confere uma autonomia relativamente ampla aos Estados Membros, tanto para definir em que consistiria um exercício abusivo da Propriedade Intelectual, como para estabelecer parâmetros para configurar o efeito

\begin{abstract}
ARTIGO 40
“1. Os Membros concordam que algumas práticas ou condições de licenciamento relativas a direitos de propriedade intelectual que restringem a concorrência podem afetar adversamente o comércio e impedir a transferência e disseminação de tecnologia.

2. Nenhuma disposição deste Acordo impedirá que os Membros especifiquem em suas legislações condições ou práticas de licenciamento que possam, em determinados casos, constituir um abuso dos direitos de propriedade intelectual que tenha efeitos adversos sobre a concorrência no mercado relevante. Conforme estabelecido acima, um Membro pode adotar, de forma compatível com as outras disposições deste Acordo, medidas apropriadas para evitar ou controlar tais práticas, que podem incluir, por exemplo, condições de cessão exclusiva, condições que impeçam impugnações da validade e pacotes de licenças coercitivas, à luz das leis e regulamentos pertinentes desse Membro".

3. Cada Membro aceitará participar de consultas quando solicitado por qualquer outro Membro que tenha motivo para acreditar que um titular de direitos de propriedade intelectual, que seja nacional ou domiciliado no Membro ao qual o pedido de consultas tenha sido dirigido, esteja adotando práticas relativas à matéria da presente Seção, em violação às leis e regulamentos do Membro que solicitou as consultas e que deseja assegurar o cumprimento dessa legislação, sem prejuízo de qualquer ação legal e da plena liberdade de uma decisão final por um ou outro Membro. O Membro ao qual tenha sido dirigida a solicitação dispensará consideração plena e receptiva às consultas com o Membro solicitante, propiciará adequada oportunidade para sua realização e cooperará mediante o fornecimento de informações não confidenciais, publicamente disponíveis, que sejam de relevância para o assunto em questão, e de outras informações de que disponha o Membro, sujeito à sua legislação interna e à conclusão de acordos

mutuamente satisfatórios relativos à salvaguarda do seu caráter confidencial pelo Membro solicitante.

4. Um Membro, cujos nacionais ou pessoas nele domiciliadas estejam sujeitas ações judiciais em outro Membro, relativas a alegada violação de leis e regulamentos desse outro Membro em matéria objeto desta Seção, terá oportunidade, caso assim o solicite, para efetuar consultas na mesmas condições previstas no parágrafo $3 ”$.
\end{abstract}

${ }^{409}$ Artigo 31

Outro Uso sem Autorização do Titular

"Quando a legislação de um Membro permite outro uso do objeto da patente sem a autorização do titular, inclusive o uso pelo Governo ou por terceiros autorizados pelo governo, as seguintes disposições serão respeitadas:(...)

b) esse uso só poderá ser permitido se o usuário proposto tiver previamente buscado obter autorização do titular, em termos e condições comerciais razoáveis, e que esses esforços não tenham sido bem sucedidos num prazo razoável. Essa condição pode ser dispensada por um Membro em caso de emergência nacional ou outras circunstâncias de extrema urgência ou em casos de uso público não-comercial. No caso de uso público não-comercial, quando o Governo ou o contratante sabe ou tem base demonstrável para saber, sem proceder a uma busca, que uma patente vigente é ou será usada pelo ou para o Governo, o titular será prontamente informado;

c) o alcance e duração desse uso será restrito ao objetivo para o qual foi autorizado, e no caso de tecnologia de semicondutores, será apenas para o uso público não-comercial ou para remediar um procedimento determinado como sendo anticompetitivo ou desleal após um processo administrativo ou judicial" 
negativo ao comércio, concorrência ou transferência tecnologia. Note-se que não há, no TRIPS, nenhuma regra geral determinando que os países membros submetam tais práticas a uma rule of reason. Aliás, ao menos ao tempo em que as tratativas para o TRIPS se desenrolaram, vários países europeus ainda adotavam diversas regras de ilegalidade per $s e^{410}$.

No passado, tanto a exceção de interesse público como as medidas para prevenir abusos, estabelecidas, respectivamente, nos artigos 8(1) e 8(2) do TRIPS poderiam justificar o recurso à licença compulsória.

Havia, no entanto, discussões consideráveis sobre o significado de abuso, sendo que alguns poucos países desenvolvidos - dentre eles os Estados Unidos - limitavam o conceito às práticas anticoncorrenciais que se aproximassem das violações antitruste. A maioria dos outros países, contudo, considerava a doutrina do abuso aplicável se o titular não produzisse o objeto da patente localmente, bem como se se recusasse a garantir o licenciamento em termos razoáveis, prejudicando - assim - o desenvolvimento industrial, ou, ainda, nos casos de desabastecimento do mercado ou imposição de preços abusivos pelos produtos patenteados.

O TRIPS incorpora o conceito mais específico de abuso à exceção de interesse público no já analisado artigo 31, que estabelece a possibilidade de licenças compulsórias em caso de recusa de licenciamento que seja considerada anticoncorrencial por decisão proferida em processo administrativo ou judicial.

Houve pressões de países desenvolvidos para que o não uso de patentes detidas por estrangeiros no mercado local não fosse considerado como suficiente para autorizar a concessão de licenças compulsórias. O TRIPS, então, passa a sujeitar todas as licenças compulsórias concedidas nos termos dos artigos 8(1) e 8(2) às mesmas condições estabelecidas pelo já analisado artigo 31.

Como consequência, para obter uma licença compulsória com base na exceção de interesse público nos termos do artigo 8(1), o artigo 31 exige que o potencial beneficiado pela licença busque, previamente, negociar com o titular para tentar obter uma licença em condições normais de mercado. Caso a licença compulsória seja, finalmente, concedida, haverá limitações para seu uso, sendo que o licenciado não poderá valer-se da licença compulsória para exportar os bens patenteados.

\footnotetext{
${ }^{410}$ ULLRICH, Hanns, "Expansionist Intellectual Property Protection and Reductionist Competition Rules: A TRIPS Perspective", EUI Working Paper Law no 2004/3"
} 
Por outro lado, nos termos do artigo 8(2), não há exigência de que se busque negociar, previamente, a licença com o titular, nem tampouco restrições à exportação, desde que uma decisão judicial ou administrativa tenha declarado a conduta do titular da patente como anticoncorrencial $^{411}$.

Outro comentário importante é que, a considerar a redação do art. 40 (1) ("os Membros concordam...”) e os exemplos citados no dispositivo - parte dos quais já foram abordados nos itens anteriores (cláusulas de exclusividade ou grant back, pacotes de licença abusivos ou venda casada), depreende-se que não haveria uma liberdade irrestrita aos Estados Membros no que se refere à matéria ali tratada (práticas abusivas em acordos de licença) - que é mais específica em relação à tratada no art. 8 (práticas abusivas envolvendo Propriedade Intelectual). Dito de outro modo, existiria um certo nível de obrigatoriedade para os Estados Membros regularem essa matéria, o que - por sinal - vai de encontro à já mencionada reinvindicação histórica dos países em desenvolvimento quanto ao controle de práticas abusivas em contratos de licença internacionais ${ }^{412}$.

Entretanto, HANS ULLRICH entende que tais regras não poderiam ser transformadas em obrigações afirmativas, mas, tão somente, representariam apenas uma reserva dos países Membros quanto ao possível exercício desmesurado do amplo regime de proteção à Propriedade Intelectual conferido pelo TRIPS, o que - politicamente - representaria uma

\footnotetext{
411 "In past, both the public-interest exception and measures to prevent abuse, respectively stipulated in articles $8(1)$ and $8(2)$ of the TRIPS Agreement, could justify resort to compulsory licensing. In the past, however, arguments about the meaning of "abuse" engendered considerable controvery. A few developed countries, notably the United States, limited the concept to anticompetitive practices bordering on antitrust violations. Most other countries - and a leading commentator - considered the doctrine of abuse applicable if a patentee fails to work the patent locally in due course of "refuses to grant licenses on reasonable terms and thereby hampers industrial development, or does not supply the national market with sufficient quantities of the patented product, or demands excessive prices for such products.

The TRIPS Agreement merges this broader concept of abuse with the public interest exception for purposes of compulsory licensing under article 31. However, considerable effort has been made to discredit the nonworking of foreign patents locally as a sufficient basis for triggering such licenses. The TRIPS Agreement then subjects all nonexclusive compulsory licenses sounding in any of the bases established by artciles $8(1)$ and $8(2)$ to the conditions of article 31.

So long as the grounds for trigggering a nonexclusive compulsory license are rooted in the broad notion of "abuse" under article 8(1), say, because of public interest considerations or beacuse the patentee refused to authorize the desired use "on reasonable commercial terms and conditions"; article 31 requires the would-be licensee to seek a negotiated license from the right holder, and failing this, to pay equitable compensation(...) In contrast, a complainant who seeks a compulsory license under article 8(2) to rectify abuse of a patent in the narrow, technical sense familiar from United States law will remain exempt from both the duty to negotiate and restrictions on export, provided that some judicial or administrative authority deems the patentee's conduct anticompetitive".

(ReIchman, J.H., "Universal Minimum Standards of Intellectual Property Protection under the TRIPS Component of the WTO Agreement", The International Lawyer, Summer, 1995)

${ }^{412}$ ULLRICH, Hanns, "Expansionist Intellectual Property Protection and Reductionist Competition Rules: A TRIPS Perspective", EUI Working Paper Law n 2004/3"
} 
espécie de concessão aos Membros, em reconhecimento à sua soberania residual no que se refere a esta área de interesse público.

$\mathrm{O}$ argumento é de que TRIPS representaria, em verdade, um sistema de troca, a partir do qual o acesso a mercados internacionais seria intercambiado contra um certo nível de perda de controle político sobre os mercados domésticos, sendo que a medida de equivalência nesta troca seria o nível de proteção conferido pelos direitos de Propriedade Intelectual.

Uma vez que o preço a ser pago é a perda de controle soberano sobre a regulação de mercados domésticos, tal preço não poderia ser expandido para além da barganha. $\mathrm{E}$ uma vez que o objeto da barganha é a própria operação do sistema doméstico de propriedade intelectual, os Membros estariam obrigados a controlar práticas restritivas apenas à medida que tais práticas representassem um prejuízo à operação do sistema doméstico de Propriedade Intelectual arquitetado nos moldes do TRIPS ${ }^{413}$.

Por outro lado, a exigência de compatibilidade com o TRIPS impõe uma regra de proporcionalidade, no sentido de que a aplicação das regras de concorrência locais não pode se converter em um pretexto para mitigar a eficácia do sistema de Propriedade Intelectual estabelecido nos termos do próprio TRIPS.

Isso implica, em primeiro lugar, que o Direito Concorrencial local deve guardar seu propósito original, o qual - por sua vez - deve se manter nos limites da proteção à concorrência, não podendo tornar ilícitos usos e formas de Propriedade Intelectual que o TRIPS busca proteger.

O exercício de direitos de Propriedade Intelectual pode ser regulado apenas na medida em que estejam em jogo potenciais efeitos anticoncorrenciais, porém, modos de exploração da Propriedade Intelectual que sejam expressamente reconhecidos pelo TRIPS não podem ser proibidos per se.

Como estudado, as regras previstas nos artigos 8(1), 8(2) e 40 do TRIPS conferem uma razoável margem aos Estados Membros para regularem a exceção de interesse público 8(1), bem como prevenir práticas abusivas envolvendo a Propriedade Intelectual 8(2) ou mais especificamente - contratos de licenciamento de tecnologia (40), quando tais práticas importarem em uma restrição indevida ao comércio, à concorrência ou à transferência de tecnologia. O TRIPS reconhece o licenciamento compulsório como um remédio possível para tais práticas, desde que observadas certas condições (artigo 31).

${ }^{413}$ ULLRICH, Hanns, "Expansionist Intellectual Property Protection and Reductionist Competition Rules: A TRIPS Perspective”, EUI Working Paper Law n 2004/3 
Note-se que o escopo de competência dos países membros abrange tanto a definição do que consistiria em uma conduta abusiva, como quanto às regras de concorrência em si.

Tendo em vista que tais dispositivos são importantes concessões feitas aos países membros - notadamente, os países em desenvolvimento - passa a haver uma oportunidade considerável para que o legislador doméstico se valha de tal esfera de liberdade para fins de mitigar os efeitos negativos da excessiva proteção à Propriedade Intelectual conferida pelo TRIPS no que se refere ao mercado interno.

Como veremos em maiores detalhes no Capítulo 4, o a Lei 9.279/96 contém dispositivos que tratam do exercício abusivo de patentes e do abuso de poder econômico por meio da patente, estabelecendo a licença compulsória como sanção.

A Lei 9.279/96, contudo, apenas reconhece a figura do uso abusivo de direitos de patentes - ficando excluídas as outras modalidades de Propriedade Intelectual.

A Lei 12.529/2011 (Lei de Defesa da Concorrência), inovando neste quadro e tratando a matéria, definitivamente, sob uma perspectiva de direito público, estendeu a hipótese de exercício abusivo de direitos para todas as modalidades de Propriedade Intelectual, o que consideramos um avanço considerável, pois melhor se aproveita do âmbito de competência reconhecido pelo TRIPS ao legislador doméstico, permitindo que o mercado interno seja melhor resguardado quanto às práticas abusivas já abordadas. 


\title{
Capítulo 4 - Dos Rumos Atuais do Debate no Direito Brasileiro: Avanços e Armadilhas
}

\begin{abstract}
“(...) "A priori” ou "em abstrato” não são bons conselheiros das políticas de defesa econômica. O "específico" e o "empírico" vão mais em linha com os objetivos do ordenamento antitruste e os valores constitucionais a que se submete. Quando se trata de alta agregação do conhecimento e capitais tecnológicos, o " $a$ priori" e o "em abstrato" são mais inapropriados ainda, pois pertencem ao passado, enquanto as tecnologias disruptivas apresentam-nos o futuro". (Conselheiro Alessandro Octaviani Luis, no Ato de Concentração n ${ }^{\circ}$ 08700.004957/2013-72)
\end{abstract}

\subsection{Introdução: A Propriedade Intelectual no Contexto Sistemático da ORDEM ECONÔMICA BRASILEIRA}

O presente Capítulo é dedicado à análise do atual estágio e dos rumos do debate no âmbito do órgão brasileiro de defesa da concorrência. Vale ressaltar que o nosso enfoque será eminentemente dogmático, pois iremos tratar do tema sob a perspectiva do direito positivo e de como tem se dado a concretização da Lei brasileira antitruste (Lei $\mathrm{n}^{\circ}$ 12.529/2011) em casos envolvendo direitos reconhecidos pela Lei de Propriedade Intelectual (Lei 9.279/96), procurando identificar movimentos recentes e compreender os caminhos a serem seguidos, bem como antecipar os possíveis perigos a serem evitados.

Considerando-se a reconhecida importância de ambos os corpos de legislação para a ordem econômica capitalista, ordem que foi expressamente incorporada pelo Estado Brasileiro, é certo que o tema tangencia questões de maior espectro, como - apenas para citar um exemplo - a Política brasileira de incentivo à inovação tecnológica. A inovação tecnológica, como cediço, é tema de central importância para o programa de superação do subdesenvolvimento, também assumido pelo Estado brasileiro, e para o fortalecimento do mercado interno.

A discussão de tais questões em toda a sua profundidade, no entanto, excederia o escopo do presente trabalho, mesmo porque ambas as esferas (Propriedade Intelectual e Antitruste) consistem em apenas dois dos elementos que compõem o vasto quadro institucional que qualquer país pode arquitetar com vistas a fomentar incentivos à inovação - como o financiamento governamental direto de Pesquisa e Desenvolvimento, programas 
educacionais, desburocratização, aspectos qualitativos do sistema de concessão de patentes, entre outros.

Mesmo sem nos debruçar sobre temas referentes ao desenho de políticas econômicas de propagação de inovação e superação do desenvolvimento, contudo, assumimos como premissa metodológica o caráter sistemático da ordem econômica brasileira. Esse ponto de partida é importante, pois permeará toda a nossa interpretação de ambos os corpos de legislação (antitruste e Propriedade Intelectual), abandonando-se a ideia de que tanto uma como outra esfera poderia ser tomada isoladamente e de forma descolada do texto constitucional ${ }^{414}$.

Por sinal, uma concepção excessivamente individualista da Propriedade Intelectual tem sido a causa maior de perplexidade da doutrina quando se discute o controle antitruste do exercício de direitos de Propriedade Intelectual - o que se verifica na medida em que a relação entre as duas esferas vem ganhando importância nas agendas do Sistema Brasileiro de Defesa da concorrência e do INPI nos últimos anos.

Tais concepções mais tradicionais e "isolacionistas" remontam à ideia da Propriedade Intelectual como monopólio - termo que é impróprio, por sua imprecisão e ambiguidade - ou ao um excessivo recurso à analogia com a propriedade tangível (problemas já discutidos amplamente no Capítulo 1).

Some-se a isso à problemática de interpretação dos direitos de Propriedade Intelectual como direitos fundamentais (art. $\left.5^{\circ}, \mathrm{XIX}, \mathrm{da} \mathrm{CF} / 88\right)^{415}$.

\footnotetext{
${ }^{414}$ De fato, quanto ao Direito de Concorrência, é bem conhecido o fenômeno de "desconstitucionalização" da praxe do direito de concorrência brasileiro, pois as decisões proferidas pelo Sistema Brasileiro de Direito da Concorrência se mostram repletas de importações do antitrust norte-americano, ao passo que continuam impermeáveis a argumentos de ordem constitucional. Tal provavelmente ocorreu devido o deslumbre inicial dos operadores deste ramo do direito quanto a todo o aparato jus-econômico produzido ao longo de anos de história de rupturas e reviravoltas no direito antitruste norte-americano, e que foi prontamente importado e aceito sem quaisquer confrontos epistemológicos ou exames de compatibilidade com a Constituição Federal - mesmo quando a CF/88 é tão explícita quanto ao conteúdo da ordem econômica brasileira, ao contrário do que ocorre com Constituição dos Estados Unidos da América (como, inclusive, tivemos a oportunidade de estudar no Capítulo 2). A respeito do fenômeno de desconstitucionalização, SCHUARTZ, Luis Fernando, ("A Desconstitucionalização do Direito de Defesa da Concorrência", disponível em http://bibliotecadigital.fgv.br/dspace/bitstream/handle/10438/1762/TpD\%20007\%20-\%20Schuartz\%20-\%

20Desconstitucionalizacao.pdf?sequence=1). Mesmo assim: "Alegar que o direito concorrencial está distante do debate e da prática constitucional brasileiros, além de problemática, não deve implicar na adesão a este ideal, seja pela própria desconsideração com a ordem econômica constitucional, seja porque a história de nosso sistema de defesa da concorrência é, ainda, recente. Se, de fato, a vinculação do direito concorrencial brasileiro à Constituição for mais teórica do que prática e estiver mais nos 'corações e mentes' dos professores e de seus adeptos do que em sua concretização, ainda assim, nos parece uma boa teoria e uma boa causa para se defender" (BERCOVICI, Gilberto e ANDRADE, José Maria Arruda de, "A Concorrência Livre na Constituição de 1988", in Filosofia e Teoria Geral do Direito, por João Maurício Adeotado e Carlos Bianca Bittar, São Paulo, Quarter Latin, pgs. 449-468).

${ }^{415}$ SAMPAIO FERRAZ JR., com propriedade, criticou tal entendimento: "Não se deve menosprezar a importância deste texto já pelo fato de ele constar de um dos incisos do artigo $5^{\circ}$ da Constituição Federal.
} 
Este quadro conduziu a uma grande dificuldade da doutrina brasileira de compreender o papel estratégico da proteção conferida à Propriedade Intelectual, principalmente, na chamada Nova Economia ${ }^{416}$.

É de se destacar que já TUlio AsCARELLI - que lecionou na Faculdade de Direito da Universidade de São Paulo, influenciando fortemente o desenvolvimento do estudo da Propriedade Intelectual no Brasil - reconhecia que a proteção conferida aos Beni imaterialli é confluente com a livre concorrência ${ }^{417}$. De fato, ao delimitar que o objeto do direito é a criação intelectual, e não o mercado, ASCARELLI já definira que a Propriedade Intelectual é direito exercido perante a clientela (isto é, perante o mercado, e não sobre $\left.\mathrm{ele}^{418}\right)$.

Trilhando a mesma linha de AsCARELLI, alguns autores nacionais dedicados ao estudo da Propriedade Intelectual, como Denis Borges Barbosa e Newton Silveira, contribuíram para superação de tal visão estática da Propriedade Intelectual, e para a compreensão de que há um fundamento concorrencial para os direitos de uso exclusivo ${ }^{419}$.

Por outro lado, é bem verdade que por este simples fato não podemos ser conduzidos ao exagero de pensar que a propriedade do inventor industrial - tout court - tenha-se transformado num dos direitos fundamentais da pessoa humana. A propriedade, pelo caput do art. $5^{\circ}$, o é. Mas na forma da disposição, o inciso XXIX tem antes o sentido de um comando constitucional ao legislador ordinário - "a lei assegurará aos autores (...)” - e não propriamente de um reconhecimento, na autoria intelectual, de um direito fundamental do autor industrial. A forma correta, na tradição constitucional, exige que direitos básicos sejam declarados, isto é, reconhecidos, e não instituídos. Ordenar que a legislação ordinária assegure é protrair a eficácia da norma e não, como exige o $\S 1^{\circ}$ do art. $5^{\circ}$, garantir-lhe aplicação imediata”.(SAMPAIO FERRAZ JR., Tércio, "Propriedade Industrial e Defesa da Concorrência", Revista da ABPI, no 8, ano II, São Paulo, 1993, pgs. 1012)

${ }^{416}$ GraU-KunTZ, Karin, "Direito de Patente e Mercados Secundários - Impressoras e Cartuchos de Tinta", Revista Eletrônica do IBPI n ${ }^{\circ}$ 5, 2012.

417 "Proprio l'abolizione di un sistema di privilegi nell'esercizio dell'attivitá e l'affermazione del principio della libera concorrenza condusse a porre il problema della liceitá del compiemento di atti destinati a terzi utilizzando determinate creazioni intellettuali, la preclusione della cui libera utilizzazione era richiesta ora dalla stessa tutela della possibilitá del consumatore di scegliere tra beni diversi, ora dall'interesse alla promozione del progresso culturale e tecnico, e cioé pur sempre da motivi confluenti nell'orientamento al quale si riporta il principio della libera concorrenza.

418 "Numa atmosfera de concorrência entre empresas, a titularidade ou uso de um dos objetos da propriedade intelectual dá exclusividade no uso de certos bens imateriais, de forma que só seus titulares possam explorar a oportunidade perante o mercado, configurada pela utilização privativa de tais bens. Assim, a exclusividade neste contexto é de caráter concorrencial” (BORGES BARBOSA, Denis, "Uma Introdução à Propriedade Intelectual”, Lumen Juris, Segunda Edição Revista e Atualizada, 2003).

419 “ASCARELLI emprega a expressão bem imaterial para indicar a criação intelectual individualizada $e$ tutelada, objeto de um direito absoluto, e não em contraposição às coisas corpóreas (p. 286). O direito absoluto sobre tais bens se assemelha ao direito de propriedade, disciplina que se opõe ao sistema de monopólios e privilégios. O esquema da propriedade se baseia na possibilidade de considerar objetivamente a criação intelectual e individualizá-la em um bem imaterial (p. 288). (...) Por isso ASCARELLI entende que, estruturalmente, os direitos de utilização exclusiva podem se enquadrar no esquema do direito de propriedade, entendido como um direito absoluto patrimonial de gozo e disposição, cujo ponto de referência é constituído por um bem externo ao sujeito (p. 293)". (SILVEIRA, Newton, "Propriedade material e concorrência", Revista dos Tribunais, São Paulo, Vol. 75, n 604, pgs-264/271, Fevereiro, 186)

“(...) nos afiliando à visão de Ascarelli descrita quanto à destacabilidade da criação de seu criador, como objeto de direito, por sua vez entendemos que a natureza das relações jurídicas atinentes a esse objeto, num 
Também foi importante a contribuição de autores dedicados ao estudo do Direito Concorrencial, que passaram a defender um fundamento eminentemente concorrencial da Propriedade Intelectual, qual seja: o de reprimir a concorrência desleal por imitação e, em contrapartida, propagar a competição por superação - que está calcada em um princípio meritório.

Conforme declarou CAliXto SAlOMÃo FILHO, “A proteção à invenção industrial serve, por outro lado, ao estímulo criativo. Impedindo o free-riding ${ }^{420}$, ou seja, o aproveitamento por parte daquele que não investiu na pesquisa dos resultados dela advindos, estimula a pesquisa e o desenvolvimento individual. Na repressão ao free-riding encontra, portanto, um fundamento eminentemente concorrencial ${ }^{\text {,421. }}$.

E, prosseguindo no autor, o reconhecimento de tal fundamento concorrencial do direito industrial, e de finalidades comuns ao Direito de Defesa da Concorrência, traz, como consequência, que a Propriedade Intelectual não pode mais ser encarada apenas como propriedade ou privilégio individual - mas sim, como um instituto de caráter publicista.

Mais do que isso, o exercício de direitos de Propriedade Intelectual passa, então, a estar sujeito ao controle do abuso de poder:

"A demonstração do fundamento concorrencial do direito industrial tem uma conseqüência importantíssima. Mesmo caracterizado como monopólio, sendo sua justificativa concorrencial (v. itens “c” e "d" infra), ele não é mais uma disciplina extravagante. Não está infenso, portanto, à aplicação do direito antitruste. Conseqüiência disto é que o direito à patente ou à marca não mais pode ser visto como uma propriedade ou privilégio de seu titular. Entendido como meio de tutelar a concorrência (no sentido institucional), assume a função principal de garantir o acesso e escolha dos consumidores. Assim, ao contrário do que normalmente se acredita, a compreensão do direito industrial dentro da lógica institucional do direito concorrencial é a única capaz de dar ao primeiro a conotação publicística de que este necessita.

Pelas suas próprias origens recentes, de inspiração concorrencial, está e deve estar o direito industrial permeado pelos princípios concorrenciais. Antes que uma justificativa para a desaplicação do direito concorrencial, o direito industrial é um caso especial de sua

contexto contemporâneo de economia de mercado, se exerce perante uma clientela”. (BORGES BARBOSA, Denis, "Do Bem Incorpóreo à Propriedade Intelectual", 2009 - disponível no portal do autor em http://www.denisbarbosa.addr.com/arquivos/novidades/teoria.pdf)

${ }^{420}$ Como demonstramos no Capítulo 1, a analogia com a Propriedade Tangível e o uso do estigma do freeriding levou a exageros nos Estados Unidos, contribuindo para uma excessiva e nociva proteção à Propriedade Intelectual. Isso não prejudica o raciocínio do autor aqui citado, desde que se interprete "freeriding" por tentativa de terceiros de capitalizar sobre o esforço inventivo alheio - o que é de fato antijurídico.

${ }^{421}$ CaliXto Salomão Filho, "Direito Industrial, Direito Concorrencial e Interesse Público", Revista de Direito Público da Economia, Belo Horizonte, ano 2, n. 7, 2.004, p. 29 e ss. 
aplicação. No direito antitruste, de inspiração mais publicista, a interseção entre ambos é amplamente reconhecida, sendo que a lei antitruste contém um dispositivo expresso e exclusivo a respeito do abuso de patentes (\$20, GWB), que deixa clara a inspiração concorrencial do direito industrial ao afirmar que ocorre abuso concorrencial quanto a utilização for além do objeto de proteção da patente ("uber den Inhalt des Schutzrechtes hinausgehen”).

É importante ter claro que, no caso do direito industrial, a proteção é uma propriedade dinâmica e não estática, i.e., trata-se de proteger o direito de utilização e não a titularidade do bem objeto da produção em si. Isso não deve nos levar, no entanto, a crer que é objetivo da norma a criação de um conjunto de regras excepcionais à concorrência. A lei de concorrência procurou deixar esta característica bem clara ao estabelecer no artigo 15 a sujeição de todos, inclusive os monopólios legais, ao direito concorrencial

(...) A compreensão concorrencial do direito industrial torna tudo mais simples. Amplia e torna pública a disciplina exatamente porque tira o foco dos requisitos para a concessão e centra-se na disciplina do abuso de direito. A patente, como qualquer situação de poder no mercado, pode gerar abusos, que devem ser coibidos. O direito industrial passa, então, a incluir nesse aspecto uma disciplina específica do abuso de poder ${ }^{422}$.

Efetivamente, em oposição à propriedade tangível, a natureza do direito de Propriedade Intelectual é mais propriamente definida como um direito negativo, na medida em que se expressa unicamente pelo poder de impedir terceiros de usar a invenção.

Ao assim fazer, a Propriedade Intelectual confere ao seu titular uma vantagem concorrencial (vantagem de custo), permitindo-lhe capitalizar sobre a invenção. Tal exegese torna a Propriedade Intelectual muito mais instrumental e dinâmica ${ }^{423}$, não se coadunando mais com a ideia de um privilégio concedido em caráter de exceção à regra de livre concorrência (mas, sim, em função e nos interesses da livre concorrência e dos consumidores).

\footnotetext{
${ }^{422}$ Em semelhante sentido, SAMPAIO FERRAZ JR.: "No jogo do mercado, o princípio da livre concorrência não admite, em tese, a exclusividade. Não se trata, porém, de uma incompatibilidade absoluta, mas apenas na medida em que a exclusividade engendra situações monopolísticas na economia de mercado livre. É exatamente esta circunstância que se choca com os princípios da livre iniciativa e da livre concorrência. E, neste ponto, os privilégios concedidos pelo direito industrial, com respaldo na Constituição, cruzam-se com os impedimentos exigidos pelas leis antitruste, igualmente respaldadas no texto constitucional" (Propriedade Industrial e Defesa da Concorrência”, Revista da ABPI, nº 8, ano II, São Paulo, 1993, pgs. 10/12).

423 "A patente, com Direito de dizer "não", é um mecanismo de mercado e que permite ao titular recuperar os custos da invenção mediante a sua incorporação (chamada de "internalização") nos preços - ainda que nem sempre as patentes gerem preços mais elevados; muitas vezes, como no exemplo do processo mais eficaz, o que a patente faz é dar ao titular uma vantagem concorrencial que lhe permite vender produtos baratos. A patente, com este conteúdo jurídico singular, portanto, é um instrumento especificamente capitalista de apropriação do conhecimento".

(CARvalho, Nuno Pires de. A estrutura dos sistemas de patentes e de marcas. Rio de Janeiro: Lumen Juris, 2009, p.4)
} 
A Propriedade Intelectual passa a ser vista, portanto, como um instrumento de atuação no mercado, ficando o seu exercício - por conseguinte - sujeito às regras do jogo deste mesmo mercado.

O mercado, como já afirmara o Ministro EROS GRAU (ADIn no 3512/DF), não é uma situação fática, mas uma construção jurídica, uma ordem no sentido de regularidade e previsibilidade de comportamentos, cujo funcionamento pressupõe a obediência, pelos agentes que nele atuam, de determinadas condutas.

A ordem econômica na Constituição de 1.988 opta, expressamente, por um sistema capitalista, atribuindo um papel primordial à livre iniciativa, porém, a livre iniciativa não exclui a intervenção estatal, pois "a ordem econômica diretiva contemplada na Constituição de 1.988 propõe a transformação do mundo do ser. O seu artigo 170 determina que a ordem econômica (mundo do ser) deva estar fundada na valorização do trabalho e na livre iniciativa e deva ter por fim assegurar a todos existência digna, conforme os ditames da justiça social, observados determinados princípios (...) Mais do que simples instrumento de governo, a nossa Constituição enuncia diretrizes, programas $e$ fins a serem realizados pelo Estado e pela sociedade. Postula um plano de ação global normativo para o Estado e para a sociedade, informado pelos preceitos veiculados pelos seus artigos $1^{o}, 3^{o}$ e 170. Os fundamentos e os fins definidos em seus artigos $1^{o}$ e $3^{o}$ são os fundamentos e os fins da sociedade brasileira”.

Diante desse quadro constitucional, torna-se difícil reconhecer a juridicidade do exercício de direitos individuais que se revele em clara tensão com os objetivos do Estado brasileiro, bem como atos que, mesmo calcados em direitos reconhecidos, se caracterizem como abuso de poder econômico reprimível nos termos do art. 173 da CF/88. Ademais, não se pode perder de vista que o próprio reconhecimento constitucional do privilégio reconhecido aos autores e inventores tem como viga mestra o progresso técnico e o desenvolvimento tecnológico do país.

Vale ressaltar que a intervenção estatal visa, antes de tudo, à preservação da própria ordem capitalista, não estando de acordo com a Constituição Federal condutas “autofágicas”, cujo efeito último é a desarticulação da própria ordem ${ }^{424}$.

424 “É necessário considerarmos, de outra banda, como anota Avelãs Nunes, que a intervenção do Estado na vida econômica consubstancia um redutor de riscos tanto para os indivíduos quanto para as empresas, identificando-se, em termos econômicos, com o princípio de segurança: "A intervenção do Estado não poderá entender-se, com efeito, como uma limitação ou um desvio imposto aos próprios objectivos das empresas (particularmente das grandes empresas), mas antes como uma diminuição de riscos e uma garantia de segurança maior na prossecução dos fins últimos da acumulação capitalista”. Vale dizer: a chamada intervenção do Estado no domínio econômico é não apenas adequada, mas indispensável à 


\subsection{QUADRO DE TRABALHO DA LEgISLAÇÃo BRASILEIRA QUANTO À INTERFACE ENTRE Propriedade Intelectual e Antitruste no Período Anterior à Lei No $^{\circ}$ $12.529 / 2011$}

A bem da verdade, no que se refere à Propriedade Intelectual, o próprio Direito Positivo brasileiro (Lei 9.279/96) já contém dispositivos tendentes a coibir o exercício abusivo de patentes, ou abuso de poder econômico por meio da patente, estabelecendo a licença compulsória como sanção ${ }^{425}$.

O problema é que a Lei 9.279/96 não indica quais são as modalidades de práticas anticoncorrenciais cuja correção poderá ser objeto de licença compulsória. Parte da doutrina enxergou no art. 21, XVI ("açambarcar ou impedir a livre exploração de direitos de propriedade industrial ou intelectual ou de tecnologia”) da antiga lei antitruste brasileira (Lei $8.884 / 94^{426}$ ) o principal exemplo de abuso reprimível por licença ${ }^{427}$.

consolidação e preservação do sistema capitalista de mercado. Não é adversa à lógica do sistema, que em verdade não a dispensa como elemento da sua própria essência. Assim é porque o mercado é uma instituição jurídica. Dizendo-o de modo mais preciso: os mercados são instituições jurídicas. A exposição de Natalino Irti é incisiva: o mercado não é uma instituição espontânea, natural - não é um locus naturalis - mas uma instituição que nasce graças a determinadas reformas institucionais, operando com fundamento em normas jurídicas que o regulam, o limitam, o conformam; é um locus artificialis. O fato é que, a deixarmos a economia de mercado desenvolver-se de acordo com as suas próprias leis, ela criaria grandes e permanentes males. "Por mais paradoxal que pareça - dizia Karl Polanyi - não eram apenas os seres humanos e os recursos naturais que tinham que ser protegidos contra os efeitos devastadores de um mercado auto-regulável, mas também a própria organização da produção capitalista” (voto do Min. Eros Grau na ADIn no 3512/DF)

${ }^{425}$ Lei 9.279/96:

"Art. 68. O titular ficará sujeito a ter a patente licenciada compulsoriamente se exercer os direitos dela decorrentes de forma abusiva, ou por meio dela praticar abuso de poder econômico, comprovado nos termos da lei, por decisão administrativa ou judicial.

$\S 1^{\circ}$ Ensejam, igualmente, licença compulsória:

I - a não exploração do objeto da patente no território brasileiro por falta de fabricação ou fabricação incompleta do produto, ou, ainda, a falta de uso integral do processo patenteado, ressalvados os casos de inviabilidade econômica, quando será admitida a importação; ou

II - a comercialização que não satisfizer às necessidades do mercado”.

${ }^{426}$ Lei 8.884/94 (revogada):

“Art. 21. As seguintes condutas, além de outras, na medida em que configurem hipótese prevista no art. 20 e seus incisos, caracterizam infração da ordem econômica:

(...)

XVI - açambarcar ou impedir a livre exploração de direitos de propriedade industrial ou intelectual ou de tecnologia”;

${ }^{427}$ Diz UlHôA COELHO, em comentários a esse dispositivo: “José Inácio Franceschini, em percuciente estudo referente ao abuso do poder econômico exercido através dos contratos de tecnologia (em Franceschini, 1985:609/620), aponta dois aspectos na questão respeitante à circulação dos bens imateriais: o estático, referente à não-utilização ou não exportação intencional, em detrimento do interesse coletivo, e o dinâmico, consistente na outorga de licença ou cessão de direito industrial em termos anticoncorrenciais. Ainda segundo a lição de Franceschini, o desuso de privilégio pode caracterizar abuso do poder econômico principalmente quando a empresa detentora de certa tecnologia e com presença proeminente no mercado em que é empregada, empenha-se em adquirir os demais privilégios exploráveis nesse mercado, alcançando status monopolístico por via oblíqua. É a hipótese de açambarque de direito industrial, mencionado pela lei. 
Por sinal, a própria Lei $8.884 / 94$ previa a possibilidade de órgão de defesa da concorrência recomendar, à autoridade competente, a concessão de licença compulsória ${ }^{428}$.

Nota-se, porém, que a licença compulsória prevista no art. 24 da antiga lei tinha a natureza jurídica de pena administrativa, que poderia ser cominada ao infrator de qualquer uma das condutas previstas no art. 21 (e não apenas em função das condutas relacionadas às próprias patentes cuja licença compulsória se estaria a obrigar). Tanto que as demais penas ali previstas incluíam medidas que não tem o menor caráter concorrencial, como por exemplo - o cancelamento de quaisquer benefícios fiscais, isenções e até mesmo parcelamentos tributários concedidos ao agente. Assim, a aplicação da referida pena não tinha o caráter de remediar problemas concorrenciais.

Não mais bastasse, as hipóteses de licença compulsória reconhecidas tanto pela antiga Lei 8.894/94 como pela Lei 9.279/96 somente contemplam o uso abusivo de patentes, excluindo outras modalidades de direitos de Propriedade Intelectual.

Com esse quadro de trabalho então conferido pela legislação brasileira, muito se discutia na doutrina sobre a possibilidade de controle, por parte da autoridade encarregada da defesa da concorrência, quanto ao exercício abusivo de direitos de Propriedade Intelectual.

\subsubsection{O Caso das Autopeças de Reposição como um Caso-Limite do Quadro de Trabalho Brasileiro quanto À Interface entre a Propriedade Intelectual e O Direito de CONCORRÊNCIA}

Um caso-limite, que pode ser considerado um marco na jurisprudência nacional, foi o pronunciamento do CADE na Averiguação Preliminar nº 08012.002673/2007-51.

O caso em questão envolve a representação da Associação Nacional dos Fabricantes de Autopeças - ANFAPE, em face das montadoras de automóveis Volksvagem, Fiat e Ford.

(...) Tanto os mecanismos estáticos como os dinâmicos de utilização anticoncorrencial de direitos industriais são puníveis como infração contra a ordem econômica pela atual legislação antitruste." (ULHOA COELHO, Fábio, Direito Antitruste Brasileiro - Comentários à Lei no 8.884/94, Ed. Saraiva, 1995)

${ }^{428}$ Lei 8.884/94 (revogada):

“Art. 24. Sem prejuízo das penas cominadas no artigo anterior, quando assim o exigir a gravidade dos fatos ou o interesse público geral, poderão ser impostas as seguintes penas, isoladas ou cumulativamente:(...)

IV - a recomendação aos órgãos públicos competentes para que:

a) seja concedida licença compulsória de patentes de titularidade do infrator"; 
O caso envolvia mercados relacionados, sendo o mercado primário o mercado de veículos, e o mercado secundário o fornecimento de peças de reposição.

Os autores da representação sustentaram que as montadoras de automóveis estariam impondo a Propriedade Intelectual (desenho industrial) sobre as autopeças de reposição, com o suposto fim de impedir a autuação de fabricantes independentes de autopeças no $\operatorname{mercado}^{429}$.

Os autores (ANFAPE) sustentaram violação aos incisos I ("limitar, falsear ou de qualquer forma prejudicar a livre concorrência ou a livre iniciativa"), II ("dominar mercado relevante de bens e serviços"), e IV ("exercer de forma abusiva posição dominante") do art. 20, bem como aos incisos IV ("impedir o acesso de novas empresas no mercado") e V ("criar dificuldades à constituição, funcionamento ou ao desenvolvimento de empresa concorrente ou de fornecedor, adquirente ou financiador de bens ou serviços $)^{430,}$.

A Secretaria de Defesa Econômica e o ProCADE haviam opinado pelo arquivamento do processo, tendo os autores interposto Recurso de Ofício, com parecer favorável do Ministério Público Federal ${ }^{431}$.

O CADE, no entanto, conferiu, por unanimidade, provimento ao Recurso de Ofício, para fins de determinar à SDE que instaurasse processo administrativo visando apurar as

\footnotetext{
${ }^{429} \mathrm{O}$ caso, portanto, tem desenho semelhante à situação já enfrentada várias vezes pelas cortes estrangeiras, algumas delas já objetos de comentários no Capítulo 2 (vide, por exemplo, caso Magill, julgado pela Comissão Europeia, e caso Kodak, julgado pela Suprema Corte americana. O primeiro caso se referia aos mercados relacionados de emissoras de TV e guias de programação, enquanto o segundo se referia aos mercados de fotocopiadoras e serviços acessórios).

${ }^{430}$ Lei n $\mathbf{0}^{\mathbf{8}}$ 8.884/94:

"Art. 20. Constituem infração da ordem econômica, independentemente de culpa, os atos sob qualquer forma manifestados, que tenham por objeto ou possam produzir os seguintes efeitos, ainda que não sejam alcançados: (Revogado pela Lei $n^{\circ} 12.529$, de 2011).

I - limitar, falsear ou de qualquer forma prejudicar a livre concorrência ou a livre iniciativa;

II - dominar mercado relevante de bens ou serviços; (...)

IV - exercer de forma abusiva posição dominante".

"Art. 21. As seguintes condutas, além de outras, na medida em que configurem hipótese prevista no art. 20 e seus incisos, caracterizam infração da ordem econômica; (Revogado pela Lei no 12.529, de 2011).(...)

$I V$ - limitar ou impedir o acesso de novas empresas ao mercado;

$V$ - criar dificuldades à constituição, ao funcionamento ou ao desenvolvimento de empresa concorrente ou de fornecedor, adquirente ou financiador de bens ou serviços";

${ }^{431}$ No caso, para concluir pelo arquivamento, é importante observar que a SDE baseou-se no entendimento das autoridades americanas que, a partir da década de 1970, passaram a entender que uma patente, quando existissem alternativas tecnológicas, não importaria em poder econômico (tratamos dessa "virada" de entendimento no Capítulo 2). Assim, na situação da doutrina econômica corrente presume-se que uma patente não importe em violação dos parâmetros concorrenciais cabendo àquele que reclama provar o abuso (caso Illinois Tools, de 2006) -http://denisbarbosa.addr.com/entrevista.pdf
} 
infrações cogitadas, a fim de apurar possível violação, pelas Representadas, aos arts. 20, I, II e IV, e 21, IV e V, da Lei 8.884/94, no setor de autopeças de reposição.

Veja-se as principais conclusões alcançadas pelo voto proferido pelo relator, Conselheiro Carlos Emmanuel Joppert Ragazzo:

(i) Embora o direito de propriedade industrial e o direito de concorrência sejam, em regra, complementares, na medida em que prezam por diferenciação, competitividade e inovações, em prol da coletividade, o exercício de um direito de propriedade industrial, por vezes, pode revelar-se ilegítimo e configurar um ilícito anticoncorrencial, passível de intervenção da autoridade antitruste;

(ii) a conduta anticompetitiva pode decorrer tanto de fraudes ou abusos no procedimento de registro do direito de propriedade industrial quando de abusos no exercício do direito em si. A mera obtenção dos registros de desenho industrial pelas Representadas, ainda que tenha obedecido ao procedimento da Lei de Propriedade Industrial, com o aval do INPI, não afasta, por si só, a possibilidade de que tais registros sejam exercidos de modo abusivo, na medida em que se desvirtuem dos fins sócio-econômicos que amparam o direito;

(iii) a exclusividade conferida às Representadas pelos registros de desenho industrial das autopeças em questão, que impede a concorrência por parte de Fabricantes Independentes de Peças Automotivas - FIAPs, garante às montadoras um monopólio na reposição dos produtos, monopólio esse no qual os consumidores estão presos, em razão de um efeito de lock-in;

(iv) a concorrência no mercado primário de venda de veículos não é suficiente para garantir preços, opções e condições de venda competitivas no mercado secundário de reposição de peças, uma vez que, no momento da compra do veículo, assimetrias de informação e escolhas enviesadamente otimistas fazem com que o consumidor não considere como fator relevante de decisão as condições do mercado de reposição, ao menos no que se refere às peças objeto de discussão;

(v) a conjugação desses fatores permite que as Representadas exerçam seu poder de monopólio no mercado de reposição das autopeças em questão de forma severa, com potenciais danos significativos à concorrência e aos consumidores, na forma de maiores preços, menos opções e piores condições de venda, efeitos esses que seriam muito provavelmente evitados ou atenuados caso fosse permitida a concorrência dos FIAPs;

(vi) Por outro lado, a exclusividade das Representadas diante dos FIAPs não parece se justificar: a) pela necessidade de recuperar investimentos em P\&D sobre as peças objeto do processo, já que tais custos aparentam ser baixos, são mais do que recuperados no momento da venda do veículo e, mesmo diante de uma abertura do mercado aos FIAPs, os lucros das montadoras no mercado de reposição permaneceriam significativos; b) pela necessidade de se manter incentivos à inovação, pois, além de haver plena recuperação dos gastos de $\mathrm{P} \& \mathrm{D}, \mathrm{o}$ lançamento de novos produtos nesse setor está voltado ao mercado primário de venda de 
veículos, e não ao mercado secundário de peças de reposição; $(. . .)^{432}$ (e) pela necessidade de se evitar práticas de "cream skimming", já que não há evidências de que a manutenção de estoques de autopeças pelas Representadas gere custos extras em relação aos FIAPs, nem que não seja lucrativa;

(vii) Tais conclusões levam a crer que a imposição dos registros de desenho industrial em questão diante dos FIAPs, por parte das Representadas, impedindo a concorrência desses agentes, tem o condão de gerar danos significativos à concorrência, danos esses não justificados por objetivos de inovação, de recuperação de investimentos, de apropriação, de manutenção de competitividade ou outros, provocando, assim, um resultado líquido negativo sobre o bem-estar da economia e dos consumidores;

(viii) Na medida em que produz tal resultado negativo, a imposição dos registros de desenho industrial das Representadas diante dos FIAPs revela-se: a) um exercício abusivo do direito de propriedade industrial em questão, na medida em que se desvirtua dos fins sócio-econômicos estabelecidos pela própria norma constitucional que ampara esse direito, que tem por objetivo "o interesse social e o desenvolvimento tecnológico do País" (art. $5^{\circ}$, XXIX); b) juridicamente desproporcional, pois compromete severamente o direito à livre concorrência, o direito dos consumidores e a repressão ao abuso de poder econômico, sem contrapartidas em termos de benefícios visados pelos direitos de propriedade intelectual; e c) uma potencial infração à Lei $n^{\circ} 8.884 / 94$, pois consubstancia abuso de posição dominante com o fim de impedir ou dificultar a atuação de concorrentes, com potenciais efeitos danosos à ordem econômica.

(ix) Tal conduta é passível de intervenção por parte do CADE que é a autoridade competente para constatar e punir abusos de poder econômico, ainda que decorrentes de direitos de propriedade industrial e, mais especificamente, de registros de desenho industrial, já que, além de o CADE estar legalmente compelido a tanto, não há imunidade antitruste para desenhos industriais e o INPI não é competente para empreender tal exame;

(X) Em se reconhecendo o ilícito antitruste, independentemente de medidas judiciais e legislativas eventualmente cabíveis, a providência adequada e necessária por parte do CADE para eliminar os efeitos nocivos à ordem econômica seria, além da multa cabível, determinar às Representadas a não imposição, aos FIAPs, dos registros de desenho industrial em questão, nos termos dos arts. 23 e 24, V, da Lei de Defesa da Concorrência. A imposição dos registros a outras montadoras fabricantes de veículos pode ser mantida, não se fazendo o licenciamento compulsório dos registros de desenho industrial;

(xi) Não se verifica indícios relevantes de conduta de preços abusivos ou "sham litigation". A prática a ser apurada e eventualmente punida é a do abuso de posição dominante com o fim de

\footnotetext{
${ }^{432}$ Omitimos, aqui, argumentos das Representadas que pouco ou nada contribuem para o debate sobre Propriedade Intelectual e o Antitruste, como a necessidade de se assegurar padrões mínimos de segurança para as peças de reposição, bem como de se evitar a comercialização de peças falsificadas "como se fossem genuínas". A decisão do Conselheiro Ragazzo entendeu - e com ela concordamos - que não é papel da autoridade de defesa da concorrência fiscalizar os parâmetros de segurança exigidos pela legislação para peças automotivas, nem tampouco reprimir atos de confusão que estariam no campo da proteção (privada) conferida contra a concorrência desleal, mas não no campo do abuso de poder econômico ou de posição dominante.
} 
impedir ou dificultar a atuação de concorrentes (arts. 20, inciso I, II e IV, e 21, incisos IV e V, da Lei $n^{\circ}$ 8.884/94)".

A decisão, embora não tenha colocado um fim à lide - apenas tendo reconhecido, em tese, a possibilidade de ocorrência de condutas abusivas - causou grandes discussões na doutrina, ao acenar, pela primeira vez de forma tão contundente, pela possibilidade de o CADE intervir no exercício de direitos de Propriedade Intelectual.

Este caso, por se tratar - a nosso ver - de um caso limite merece algum aprofundamento, por refletir bem os problemas teóricos e legislativos levantados por discussões envolvendo a Propriedade Intelectual e o Antitruste. O caso servirá, também, de pano de fundo para os comentários que faremos sobre modificações importantes no quadro de trabalho da legislação brasileira para abordar a questão da interface entre Propriedade Intelectual e o antitruste, anteriormente descrito.

Antes de prosseguir na análise do caso, contudo, é importante estabelecer algumas premissas metodológicas.

\subsubsection{Alguns Comentários Importantes Sobre Metodologia E}

\section{Epistemologia - Papel da Economia nas Discussões envolvendo Direito da ConcorrênCia. Algumas Armadilhas a SEREm Evitadas}

Em outro lugar, afirmamos ${ }^{433}$ que, do ponto de vista metodológico, optamos por um positivismo exclusivo - o que, ao contrário de um senso comum equivocado, não implica, em absoluto, em afastar-se a importância dos princípios no Direito ${ }^{434}$.

Por positivismo exclusivo, queremos referir a um necessário teste de pedigree, pelo qual, em razão do Princípio do Estado Democrático de Direito, todas as decisões administrativas e judiciais devem conter fundamento último no texto legal. Refutamos, assim, concepções jusnaturalistas, ou pretensos "princípios" - ou "meta-princípios", "meta-valores" ("super-normas") ${ }^{435}$ - que não sejam expressamente reconhecidos em nosso ordenamento jurídico.

\footnotetext{
${ }^{433}$ BRITO JUNIOR, Jorge Luiz de, "PIS/COFINS, Conceito de Insumos e a Questão dos "Insumos dos Insumos" - Proposta de Interpretação Teleológica e Uso de Argumento Econômico - Estudo de Caso do Setor Sucroalcooleiro", in Revista de Direito Tributário Atual, no 30, Dialética, São Paulo, 2014, pg. 208.

${ }^{434}$ DimOULIS, Dimitri e LunARDI, Soraya Gasparetto, - "O Positivismo Jurídico Diante da Principiologia", in “Teoria do Direito Neoconstitucional - Superação ou Reconstrução do Positivismo Jurídico?” - Coord;: Dimoulis, Dimitri, Oto DuARTE, Écio, Editora Método, São Paulo, 2008, pg. 179.

435 “(...) os positivistas não consideram que os princípios são superiores em relação aos demais elementos normativos, em razão de sua fundamentalidade e importância axiológica. Tal pensamento que apresenta os princípios como "supernormas" carece de fundamento jurídico, pelo menos no Brasil, onde não há previsão
} 
O uso que fazemos da Economia neste trabalho é, claramente, argumentativo ${ }^{436}$, pois o fundamento último de toda e qualquer interpretação proposta deve se encontrar na lei. Interpretar, entretanto, é um ato de construção, e não de declaração de sentidos préconcebidos do texto normativo ${ }^{437}$.

Outro esclarecimento importante é que não nos valeremos de uma concepção essencialista dos textos normativos ou da própria ciência econômica ${ }^{438}$. Esse ponto é realmente crucial, pois a existência de um mainstream na ciência econômica não indica que ela seja monolítica, e - tampouco - que o mero recurso a argumentos advindos de uma

de hierarquização dos dispositivos constitucionais com base em sua fundamentalidade, "abertura" ou importância. Por essa razão, a opção interpretativa que privilegia os princípios em relação às regras (concretas) não possui embasamento no sistema vigente para resolver antinomias entre normas". (DIMOULIS, Dimitri e LUNARDI, Soraya Gasparetto, Idem, pg. 190).

436 "Atualmente, muitos autores questionam a divisão e a hierarquia entre os elementos da hermenêtica, algo que não fora defendido sequer por Savigny. Nos dizeres de Hassemer e Eros Grau, trata-se da inexistência da tal metaregra que oriente a aplicação para todos os casos práticos de qual deveria ser o critério hermenêutico a predominar. Além desse ponto, o próprio aspecto teleológico começa a ser revisto, já que se trata de um dos mais difíceis de se utilizar com rigor, em virtude de sempre ser possivel alegar uma razão do texto normativo, como lembrado por Tércio Ferraz Jr, que cita, ainda, o art. $5^{o}$ da Lei de Introdução às Normas do Direito Brasileiro (antiga Lei de Introdução ao Codigo Civil - LICC). Nessa releitura, alguns autores, sem levar com rigor a separação entre elementos e a sua hierarquização, defendem que ao argumento teleológico estaria presente nos demais, seja nas considerações gramaticais, nas históricas e sistemáticas. Esse tipo de leitura é útil para se analisar as constituições nacionais como a do Brasil, repleta de dispositivos extremamente analíticos e, por outro lado, de normas do tipo que prescrevem objetivos. A partir dessas formulações, é possível pensar na teleologia da ordem econômica brasileira e reconhecer a política econômica positiva e vinculante, apesar de todos os percalços para sua aplicação. Esse tipo de argumentação não deve ser confundido com a perspectiva consequencialista, que seria propor um objetivo à frente e acima dos demais. Em primeiro lugar, pois muitos dos consequencialismos hodiernos têm como metarregra ou sobrevalor algo não positivado (é o caso do law and economics clássico, ao defender a eficiência econômica como crescimento econômico) ou moralismos universais e procedimentais, que buscam reforços em discursos ou sobreprincípios gerais (algo como a proporcionalidade em um de seus testes, o de adequação entre fins e meios). No caso da pesquisa teleológica, ao menos naquela aqui defendida, há apreço pelo texto positivado (ainda que se procure o afastamento de perspectivas essencialistas, de que o conteúdo já estaria contido nos textos ) e respeito pelo sistemático; a teoria predileta não busca substituir o texto posto, ainda que sua concretização demande sempre decisões jurídicas constitutivas. Daí a conclusão de que se deve evitar um consequencialismo jurídico, mormente com base em ideologias e construtos teóricos não positivados. Se qualquer finalidade ou decisão for boa o suficiente, que o processo democrático reconheça tal fato e que o concretize, por meio do processo legislativo. (...) Será mediante esse uso cada vez mais técnico, transparente (inclusive quanto ao alcance preditivo limitado) $e$ cada vez mais divulgado quanto a seus pressupostos, que a microeconomia contribuirá para o fortalecimento do positivismo jurídico e para a segurança jurídica, e não ao contrário, para a sua insegurança" (ARRUDA DE ANDRADE, José Maria, in "Economização do Direito Concorrencial e Positivismo Jurídico: entre Teoria da Decisão e das Provas" - Tese de Livre Docência - FDUSP, 2012, São Paulo, Pg. 175).

${ }^{437}$ Tal como defende MÜLLER, Friedrich (in "Teoria Estruturante do Direito", $2^{\mathrm{a}}$ Edição Revista, Atualizada e Ampliada, Revista dos Tribunais, São Paulo, 2009). No Brasil, Paulo de Barros Carvalho sempre advogou essa visão em suas importantes contribuições ao estudo do Direito Tributário (vide, recentemente, BARROS CARvalho, Paulo de "Breves Considerações Sobre a Função Descritiva da Ciência do Direito Tributário" Consultor Jurídico, $1^{\circ}$ de Outubro de 2013).

${ }^{438}$ ARRUDA DE ANDRADE, José Maria, in "Interpretação da Norma Tributária, São Paulo: MP Editora, 2006, e, novamente, em sua Tese de Livre Docência (pg. 129). 
ciência exata venha a conferir à determinada interpretação uma pretensa pecha de "neutralidade", ou o status de "infalibilidade" e certeza de suas predições.

A economia é uma linguagem e, desse modo, um argumento econômico pode conter - e, via de regra, contém - por trás de si, um viés ideológico.

Não nos filiamos, assim, à chamada Escola de Chicago de Law and Economics - de RICHARD POSNER e ROBERT BORK - que foi quem primeiro defendeu a aplicação de argumentos econômicos para fundamentação de decisões judiciais.

O movimento do Law and Economics, que ganhou grande força - inclusive política - nos Estados Unidos, a partir da década de 1970, parte, em geral, de pressupostos diferentes dos nossos, pois a referida escola se vale de um consequencialismo forte ${ }^{439}$, que - segundo defendem os adeptos dessa escola - deveria vincular a interpretação do Juiz (Teoria Normativa).

Dito de outra forma: o Juiz estaria obrigado a sempre buscar a interpretação importasse em maximização da eficiência econômica. Essa pauta, por sinal, estava claramente comprometida com os ideais do Partido Republicano nos Estados Unidos.

Não é nosso objetivo descrever, de forma detalhada, as características e variadas vertentes dessa escola de pensamento jurídico, mas apenas ter em conta as suas características mais marcantes: o consequencialismo forte, bem como a elevação da eficiência econômica ao grau de "meta-valor", ou "meta-princípio" - o que rejeitamos, dada a nossa premissa de apego ao texto legal como fundamento último de decisões.

Vale ressaltar a ampla influência do law and economics, inclusive, no Brasil, onde, em período recente, importantes trabalhos acadêmicos têm se dedicado à importação dos pressupostos desta escola de pensamento e sua extensão à realidade brasileira - o que desperta algumas preocupações quanto a um necessário e salutar embate epistemológico (leia-se: verificação de aplicabilidade de tais pressupostos ao ordenamento jurídico brasileiro - sobretudo, considerando-se a sistematicidade da ordem econômica brasileira, bem como a realidade econômica e social do país) ${ }^{440}$.

Tendo em conta esses esclarecimentos de ordem metodológica, e, apesar de nossas advertências em relação a um abuso de argumentos econômicos - que pode levar a reducionismos perigosos (vide, por exemplo, crítica que fizemos no Capítulo anterior,

\footnotetext{
${ }^{439}$ ARRUDA DE ANDRADE, José Maria, Idem.

${ }^{440}$ CARvalho, Cristiano, in "Teoria da Decisão Tributária" (Tese de Livre Docência FDUSP), São Paulo, 2010.
} 
quanto à Teoria dos Custos do Erro) - prosseguimos com nossa análise dos argumentos em jogo no caso envolvendo as peças de reposição.

\subsubsection{O Caso das PeÇas de Reposição como Marco divisório na}

\section{JURISPRUdÊNCIA BRASILEIRA E DE IMPORTANTES MODIFICAÇÕES INTRODUZIDAS NO ORDENAMENTO JURÍDICO (LEI No 12.529/2011)}

Estabelecidas nossas premissas metodológicas, um primeiro comentário importante sobre o caso é que, à semelhança do que ocorreu em julgamento importante no âmbito da Comissão Europeia, envolvendo mercados relacionados (Caso Magill, analisado no Capítulo 2), a proteção conferida à Propriedade Intelectual no caso do desenho industrial de peças de reposição era falha - e isso, mesmo abstraindo-se a questão concorrencial.

É que, como bem apontara NEWTON SILVEIRA, em parecer apresentado no caso ${ }^{441}$, a proteção ao desenho industrial jamais deveria ter sido reconhecida, em primeiro lugar, às peças de reposição, pois ausente um dos requisitos essenciais da proteção, qual seja: a existência de traço distintivo ${ }^{442}$.

Efetivamente, há pouco ou nada em uma peça, individualmente considerada, que permita a distinção, por parte dos consumidores, entre produtos diferentes. Apenas o todo (isto é, o automóvel) é que se torna distinto pelo conjunto de suas formas e linhas.

Como bem observou o Conselheiro Ragazzo em sua decisão, os próprios investimentos das montadoras em pesquisa e desenvolvimento em design são - certamente

\footnotetext{
${ }^{441}$ SILVEIRA, Newton, Parecer publicado na Revista Eletrônica do INBPI (REVEL), www.ibpibrasil.org, acesso em 24.10.2012

${ }^{442}$ Lei no 9.279/1996:

"Art. 95. Considera-se desenho industrial a forma plástica ornamental de um objeto ou o conjunto ornamental de linhas e cores que possa ser aplicado a um produto, proporcionando resultado visual novo e original na sua configuração externa e que possa servir de tipo de fabricação industrial".

"Art. 96. O desenho industrial é considerado novo quando não compreendido no estado da técnica.

$\S 1^{\circ} \mathrm{O}$ estado da técnica é constituído por tudo aquilo tornado acessível ao público antes da data de depósito do pedido, no Brasil ou no exterior, por uso ou qualquer outro meio, ressalvado o disposto no $\S 3^{\circ}$ deste artigo e no art. 99.

$\S 2^{\circ}$ Para aferição unicamente da novidade, o conteúdo completo de pedido de patente ou de registro depositado no Brasil, e ainda não publicado, será considerado como incluído no estado da técnica a partir da data de depósito, ou da prioridade reivindicada, desde que venha a ser publicado, mesmo que subseqüentemente.

$\S 3^{\circ}$ Não será considerado como incluído no estado da técnica o desenho industrial cuja divulgação tenha ocorrido durante os 180 (cento e oitenta) dias que precederem a data do depósito ou a da prioridade reivindicada, se promovida nas situações previstas nos incisos I a III do art. 12".

"Art. 97. O desenho industrial é considerado original quando dele resulte uma configuração visual distintiva, em relação a outros objetos anteriores.

Parágrafo único. $O$ resultado visual original poderá ser decorrente da combinação de elementos conhecidos". (destaques acrescidos)
} 
- direcionados a torná-las competitivas no mercado primário de automóveis e não ao mercado secundário de peças de reposição.

Esse vício, porém, se encontra no próprio âmbito da Propriedade Intelectual e, como sabido, a competência do órgão brasileiro de defesa da concorrência não compreende a revisão de tais distorções encontradas no sistema brasileiro de concessão de patentes.

Embora essa constatação, de certa forma, extrapole o tema de nosso trabalho, entendemos importante iniciar a análise do caso com essa ponderação, pois, dada a desejada necessidade de coerência e previsibilidade das decisões judiciais e administrativas, as conclusões do julgamento poderiam levar a extremos (v.g., concluir que o escopo da Propriedade Intelectual somente se estenderia ao mercado primário, e não ao secundário, e isso como regra a ser aplicada em todas as situações em que o mesmo problema fosse levantado). Sendo assim, a primeira ponderação é se tal salto seria possível a partir da análise de caso que, de partida, contém uma aberração (equivocada proteção conferida ao desenho industrial).

Dissemos isso porque alguns autores parecem advogar a posição de que, como regra, independentemente de falhas na concessão do direito de Propriedade Intelectual, o antitruste sempre seria chamado a intervir quando a Propriedade Intelectual estivesse a bloquear a concorrência qualitativa em um mercado ${ }^{443}$, o que - não obstante o respeito que temos pela importante contribuição que têm dedicado ao estudo do tema e da Propriedade Intelectual - parece-nos uma conclusão um pouco extremada.

Como reconhecemos ao longo de todo o trabalho, firmes desde a orientação de ASCARELLI, passando por outras autoridades no estudo do tema no Brasil, a Propriedade Intelectual não tem por objeto conferir exclusividade sobre mercados, mas sim, sob um determinado meio, que também não se confunde com o produto físico em si (uma ideia

\footnotetext{
${ }^{443}$ Essa parece ser a posição de GRAU-KUNTZ, autora que tem realizado importantes contribuições para o estudo da Propriedade Intelectual, bem como para sua compreensão dinâmica: "A garantia da vantagem contra a concorrência de imitação, que como demonstrei na primeira parte deste trabalho está imediata e necessariamente voltada a fomentar a concorrência de superação inovadora, se esgotaria nesta hipótese em si mesma, sem cumprir com o fim que se justifica a intervenção legislativa no estado natural das informações. Mesmo que o título de patente seja formalmente válido, isto é, partindo do pressuposto que não haja discussão sobre a correção da concessão da garantia da vantagem concorrencial pelo órgão competente, o seu exercício de forma a bloquear os caminhos de superação inovadora está em desconformidade com seus limites intrínsecos e caracteriza um abuso, como acima denominei este tipo de prática. Por outro lado o querer fazer legítimo o exercício da vantagem concorrencial no mercado secundário nestas condições implica, como já destaquei, em certeza de retorno de investimento, um fato que poderia descrever como o indicativo máximo de que a vantagem concorrencial contida no direito de patente não está a funcionar com devia, posto ela apenas oferecer "possibilidades de retorno de investimento", e nada mais do que isto". (GRAU-KUNTZ, Karin, "Direito de Patente e Mercados Secundários - Impressoras e Cartuchos de Tinta", Revista Eletrônica do IBPI n 05, 2012)
} 
inventiva e com aplicação na indústria, no caso de uma patente, apenas para citar um exemplo).

Entretanto, pode ocorrer de a Propriedade Intelectual acabar acarretando o efeito prático de criar, em termos fáticos, uma reserva de mercado, o que se dá, principalmente, em invenções de altíssimo valor agregado, com é comum em setores de alta tecnologia.

É natural que, com o atual grau de avanço tecnológico, a maioria das invenções se revista de melhorias daquilo que já existe, mas não se pode afastar a possibilidade de invenções que realmente impliquem em ruptura de padrão tecnológico. Nesses casos, a corrida pelas patentes, realmente, se caracterizará como aquele tipo em que o "vencedor leva tudo" (winner takes all).

Logo, em tais casos, a Propriedade Intelectual, mais do que uma vantagem significativa, terá o efeito prático de excluir a concorrência, temporariamente, em um mercado (sem que com isso se queira dizer que o objetivo da Propriedade Intelectual é conferir um monopólio). Nestes casos, poderia se afirmar que o exercício da Propriedade Intelectual seria contrário ao antitruste? Entendemos que não.

Poderia se argumentar que, nos casos em que a corrida tecnológica for do tipo winner takes all, a concorrência de inovação, pelo menos, não estará excluída - o que, por sinal, nem sempre é verdade: no que se refere à concorrência de inovação por melhorias naquele determinado produto, nem sempre, haverá oportunidades para tais melhorias. Mas podemos aceitar o argumento de que sempre haverá, em última análise, a possibilidade de destruição criativa, no sentido schumpeteriano de um determinado mercado sendo completamente substituído pela criação de “novos produtos, processos, etc.”.

Porém, voltando-se ao caso das peças de reposição, vemos que este é um argumento que não basta para solucionar o problema. Veja-se que, a despeito da vantagem concorrencial extrema (talvez, exagerada) pleiteada pelas montadoras quanto ao desenho industrial das peças, a pressão sobre essas empresas para a inovação não estará excluída totalmente.

Pelo contrário, é provável que as empresas continuem a investir milhões em design, embora seja também verdade que os consumidores no mercado secundário não poderão usufruir de tais investimentos. Por outro lado, do ponto de vista dos fabricantes independentes de peças, até onde pudermos considerar como uma inovação a fabricação de peças de acordo com um desenho já idealizado pelas montadoras, será difícil defender a 
posição das fabricantes de autopeças com base na necessidade de se conferir estímulos à inovação.

Nada do que vimos acima justificaria uma regra forte de que sempre que os direitos de Propriedade Intelectual vierem a excluir a concorrência em um mercado, tal circunstância demandaria a intervenção do antitruste.

É importante observar que, abstraída a falha na concessão do direito de desenho industrial já comentada, as montadoras, ao processarem as fabricantes independentes de autopeças, agiram nos limites do direito de desenho industrial, ao menos formalmente considerado, de “(...) impedir terceiro, sem o seu consentimento, de produzir, usar, colocar à venda, vender ou importar ${ }^{444, "}$.

Não há, a princípio, nenhuma limitação que faça com que o "direito de impedir terceiro de produzir" seja exercível somente no mercado primário, mas não no secundário. Entendemos que uma tal limitação importante sobre o direito de Propriedade Intelectual não poderia decorrer de uma proibição implícita do sistema, mas sim, estar prevista de forma expressa no ordenamento, de modo a permitir aos agentes realizar cálculos de previsibilidade.

Um trecho particular do voto do Conselheiro Ragazzo nos chama a atenção em especial: “(...) em se reconhecendo o ilícito antitruste, independentemente de medidas judiciais e legislativas eventualmente cabíveis (...)" - de fato, nos preocupa a questão do

\footnotetext{
${ }^{444}$ Lei no 9.279/96:

“Art. 109. A propriedade do desenho industrial adquire-se pelo registro validamente concedido.

Parágrafo único. Aplicam-se ao registro do desenho industrial, no que couber, as disposições do art. 42 e dos incisos I, II e IV do art. 43.

"Art. 42. A patente confere ao seu titular o direito de impedir terceiro, sem o seu consentimento, de produzir, usar, colocar à venda, vender ou importar com estes propósitos:

I - produto objeto de patente;

II - processo ou produto obtido diretamente por processo patenteado.

$\S 1^{\circ}$ Ao titular da patente é assegurado ainda o direito de impedir que terceiros contribuam para que outros pratiquem os atos referidos neste artigo.

$\$ 2^{\circ}$ Ocorrerá violação de direito da patente de processo, a que se refere o inciso II, quando o possuidor ou proprietário não comprovar, mediante determinação judicial específica, que o seu produto foi obtido por processo de fabricação diverso daquele protegido pela patente”.

"Art. 43. O disposto no artigo anterior não se aplica:

I - aos atos praticados por terceiros não autorizados, em caráter privado e sem finalidade comercial, desde que não acarretem prejuízo ao interesse econômico do titular da patente;

II - aos atos praticados por terceiros não autorizados, com finalidade experimental, relacionados a estudos ou pesquisas científicas ou tecnológicas; (...)

IV - a produto fabricado de acordo com patente de processo ou de produto que tiver sido colocado no mercado interno diretamente pelo titular da patente ou com seu consentimento".
} 
ativismo do CADE em questões que pertençam à esfera da política legislativa, dadas as premissas metodológicas que assumimos acima ${ }^{445}$.

Como já dito anteriormente, não excluímos a importância dos princípios no direito, mas é conhecida a problemática de afastamento de regras em benefício de princípios, pois as regras contém uma solução para um conflito concreto, ao passo em que os princípios, conquanto também versem sobre solução de conflitos, não o fazem de forma específica.

No caso das marcas, é interessante observar que a Lei 9.279/96 expressamente previu uma solução para o conflito de natureza semelhante, ao estabelecer que a proteção de marcas não afeta o mercado secundário de fabricantes de acessórios, desde que não haja concorrência desleal (atos de confusão) ${ }^{446}$.

Por razões que são difíceis de cogitar, o legislador não incluiu a mesma previsão no que se refere ao desenho industrial e às demais espécies de Propriedade Intelectual.

A questão, de fato, pode ser vista sob duas perspectivas possíveis: política econômica e direito positivo. Do ponto de vista da política econômica, temos razões de sobra para acreditar que a dominação de mercados secundários por meio de direitos de Propriedade Intelectual é nociva, bem como que eventual regra que condenasse a extensão da proteção da Propriedade Intelectual aos mercados secundários teria fundamento na teoria econômica.

Como já foi objeto de comentários no Capítulo 3, a tese do single profit theorem, da Escola de Chicago, foi superada no plano teórico, com o surgimento de modelos dinâmicos que reconhecem que, sob determinadas circunstâncias, há incentivos para uma empresa estender seu poder de mercado aos mercados relacionados.

\footnotetext{
${ }^{445}$ O próprio DENIS BoRges BARBOSA, que suportou ativamente a posição das Fabricantes Individuais de Autopeças, parece conceder que a questão, na verdade, pediria alteração legislativa: "Em um grande número de países, as leis de desenho industrial foram alteradas para explicitar o que resulta desta reflexão. Como no caso de marcas, a extensão do poder de mercado resultante de uma marca não pode ir além do mercado para o qual a exclusividade é concedida. O futuro é a discussão no poder judiciário com base não no abuso de poder econômico, mas no abuso do direito de desenho industrial. Os fundamentos são os que já expus. $O$ futuro também é a ação junto ao Poder Legislativo para especificar na lei ordinária o mesmo que está expresso em leis dos países desenvolvidos de economia de mercado: que o desenho industrial, quando existe o problema de reposição de peças must-match, não proíbe o fabricante e revendedor de auto-peças de fabricar livremente" (http://denisbarbosa.addr.com/entrevista.pdf)

${ }_{446}$ Lei 9.279/96:

"Art. 132. O titular da marca não poderá:

I - impedir que comerciantes ou distribuidores utilizem sinais distintivos que lhes são próprios, juntamente com a marca do produto, na sua promoção e comercialização;

II - impedir que fabricantes de acessórios utilizem a marca para indicar a destinação do produto, desde que obedecidas as práticas leais de concorrência";
} 
Além disso, uma tal regra estaria mais em linha com a ordem econômica constitucional, na medida em que mercados menos verticalizados tendem a produzir mais empregos $^{447}$.

Porém, do ponto de vista do direito positivo - como já dissemos antes - não temos como suportar uma pretensa regra de que sempre que um direito de Propriedade Intelectual importar a interdição da concorrência em um mercado - seja ele primário ou secundário se estará diante de uma violação antitruste. Tal, em nossa opinião, implicaria uma restrição muito importante do sistema de Propriedade Intelectual, para que os agentes pudessem simplesmente deduzi-la.

Outro ponto de preocupação, no que se refere ao pronunciamento do CADE em questão, é o seguinte trecho da argumentação utilizada no voto-condutor: "Tais conclusões levam a crer que a imposição dos registros de desenho industrial em questão diante dos FIAPs, por parte das Representadas, impedindo a concorrência desses agentes, tem o condão de gerar danos significativos à concorrência, danos esses não justificados por objetivos de inovação, de recuperação de investimentos, de apropriação, de manutenção de competitividade ou outros, provocando, assim, um resultado líquido negativo sobre o bem-estar da economia e dos consumidores".

Em nossa opinião, não poderia o CADE se empenhar em cálculos de impactos positivos e negativos da Propriedade Intelectual sobre o bem-estar no caso concreto, porque, mais uma vez, esta é uma tarefa que caberia ao legislador, atentando para os princípios que regem a ordem econômica constitucional.

Vimos, ao longo de todo o trabalho, que os custos sociais e econômicos (leia-se, perdas em eficiência) da Propriedade Intelectual são consideráveis e todo Estado defrontase com tais custos antes de estabelecer um sistema de Propriedade Intelectual.

Se o Estado opta por instituir tal sistema é um sinal de que está disposto a suportar tais custos e não caberia a um órgão de regulação da concorrência corrigir tais efeitos quando eles se mostrarem negativos. Se esse raciocínio for consagrado, haverá uma grande insegurança jurídica para o sistema da Propriedade Intelectual.

\footnotetext{
${ }^{447}$ Tal foi, inclusive, reconhecido pelo texto da Exposição de Motivos da Medida Provisória no $135 / 03$, que originou a Lei $\mathrm{n}^{\circ}$ 10.833/03 (Regime não Cumulativo da COFINS). O referido texto estabelece como um dos objetivos do regime da não-cumulatividade conferir um estímulo à eficiência econômica, bem como afastar uma verticalização artificial de empresas: "O principal objetivo das medidas ora propostas é o de estimular a eficiência econômica, gerando condições para um crescimento mais acelerado da economia brasileira nos próximos anos. Neste sentido, a instituição da Cofins não-cumulativa visa corrigir distorções relevantes decorrentes da cobrança cumulativa do tributo, como por exemplo a indução a uma verticalização artificial das empresas, em detrimento da distribuição da produção por um número maior de empresas mais eficientes - em particular empresas de pequeno e médio porte, que usualmente são mais intensivas em mão de obra".
} 
Até o momento, o objeto de nossas críticas foi quanto à instituição de uma pretensa regra não positivada, de que a Propriedade Intelectual nunca poderá significar exclusão da concorrência no mercado, mesmo quando esta exclusão for decorrente, unicamente, do reconhecimento da proteção conferida à Propriedade Intelectual - e não de comportamento estratégico e de outras circunstâncias de mercado.

Também refutamos a noção de que o CADE possa realizar cálculos de benefícios e prejuízos, em bem-estar, do sistema da Propriedade Intelectual, a fim de confirmar ou não a proteção. Ambas as conclusões dependeriam de fundamento no direito positivo, o que como vimos - não existe. A propagação de decisões que não tenham fundamento direto no Direito Positivo e a conversão do órgão de defesa da concorrência em órgão produtor de política econômica são, para nós, armadilhas a serem evitadas.

Por outro lado, consideramos o reconhecimento, pelo CADE, de que não há imunidade da Propriedade Intelectual quanto ao antitruste, como um avanço importante na jurisprudência e que foi, de certo modo, acompanhado pelo legislador.

A Lei $n^{\circ}$ 12.529/2011 introduziu importantes modificações no quadro de trabalho anteriormente descrito, principalmente, no que se refere ao reconhecimento explícito de que "exercer ou explorar abusivamente direitos de propriedade industrial, intelectual, tecnologia ou marca” constitui uma infração à ordem econômica (art. 36, $\mathrm{XIX}^{448}$ ).

Observa-se, ainda, que, ao versar sobre as penas, o art. 38 incluiu dispositivo que prevê que a autoridade de defesa da concorrência poderá recomendar, ao órgão competente, que seja concedida licença compulsória de direito de propriedade intelectual (o que inclui todas as espécies, e não apenas as patentes), desde que a infração estiver relacionada ao uso desse direito $(\operatorname{art} .38, \mathrm{IV}, a)^{449}$. Logo, a pena em questão passa a ser

\footnotetext{
${ }^{448}$ Lei 12.529/2011:

"Art. 36. Constituem infração da ordem econômica, independentemente de culpa, os atos sob qualquer forma manifestados, que tenham por objeto ou possam produzir os seguintes efeitos, ainda que não sejam alcançados:

$\S 10$ A conquista de mercado resultante de processo natural fundado na maior eficiência de agente econômico em relação a seus competidores não caracteriza o ilícito previsto no inciso II do caput deste artigo. (...)

II - dominar mercado relevante de bens ou serviços;

(...)

XIX - exercer ou explorar abusivamente direitos de propriedade industrial, intelectual, tecnologia ou marca”.

449 “Art. 38. Sem prejuízo das penas cominadas no art. 37 desta Lei, quando assim exigir a gravidade dos fatos ou o interesse público geral, poderão ser impostas as seguintes penas, isolada ou cumulativamente:

(...)

IV - a recomendação aos órgãos públicos competentes para que:

a) seja concedida licença compulsória de direito de propriedade intelectual de titularidade do infrator, quando a infração estiver relacionada ao uso desse direito;"
} 
específica, funcionando como uma solução para os efeitos anticoncorrenciais da conduta em conexão com o direito de Propriedade Intelectual.

Finalmente, o art. 61 passa a prever, expressamente, que, na análise de atos de concentração, poderá o órgão de defesa da concorrência determinar, como restrição, o licenciamento compulsório de direitos de Propriedade Intelectual com a finalidade de mitigar os efeitos restritivos à concorrência (art. $\left.61, \S 2^{\circ}, \mathrm{V}^{450}\right)$.

Estas modificações instituem um quadro de trabalho muito mais amplo para o tratamento do tema referente à interface entre a Propriedade Intelectual e a concorrência, refletindo uma compreensão mais dinâmica do direito de uso exclusivo, conforme já prenunciava a doutrina.

\subsubsection{A Questão do Poder nOS MERCAdos SECUNDÁRIOS}

Contudo, voltando ao paradigma do caso das peças de reposição, em nossa opinião, o atual quadro de trabalho da legislação ainda não seria suficiente para que se pudesse validar uma pretensa regra de que, sempre que o exercício da Propriedade Intelectual excluir a concorrência qualitativa em um mercado (primário ou secundário), isso clamaria por uma intervenção antitruste.

Um dos argumentos que foi levantado por parte da doutrina é o de que as montadoras estariam se valendo da ausência de concorrência no mercado secundário para repassar o preço do produto primário para o mercado secundário, de modo que as montadoras estariam competindo no mercado secundário disfarçadamente.

Isso porque, no momento da decisão de compra pelo bem primário (no caso, o automóvel), o consumidor contaria com um leque de alternativas atrativas, porque só seria capaz de ver preços baixos e, consequentemente, boas oportunidades de compra.

$\mathrm{O}$ custo real do produto, no entanto, somente viria à tona quando, no mercado secundário, a "máscara cai”. O consumidor, assim, estaria, segundo a autora, levando "gato

\footnotetext{
450 “Art. 61. No julgamento do pedido de aprovação do ato de concentração econômica, o Tribunal poderá aprová-lo integralmente, rejeitá-lo ou aprová-lo parcialmente, caso em que determinará as restrições que deverão ser observadas como condição para a validade e eficácia do ato.

§ 1 o O Tribunal determinará as restrições cabíveis no sentido de mitigar os eventuais efeitos nocivos do ato de concentração sobre os mercados relevantes afetados.

$\S 20$ As restrições mencionadas no $\$ 10$ deste artigo incluem:

(...)

$V$ - o licenciamento compulsório de direitos de propriedade intelectual; $e$ ”.
} 
por lebre", pagando relativamente pouco pelo bem primário, mas só podendo tirar pleno proveito do produto pagando muito pelas peças de reposição no mercado secundário ${ }^{451}$.

Logo, o consumidor, atraído pelas ofertas no mercado primário, se veria sem opções no mercado secundário de peças de reposição, dada a limitação à concorrência imposta pela proteção ao desenho industrial (efeitos de lock-in). Por outro lado, os custos de mudança do consumidor no mercado primário (switching costs) seriam muito elevados, fazendo com que o consumidor fique enclausurado.

Alguns autores ${ }^{452}$ chegaram a interpretar que tal estratégia utilizada pelas montadoras se subsumiria à infração então prevista no art. 21, XXIII, da Lei 8.884/94, ou seja, "subordinar a venda de um bem à aquisição de outro ou à utilização de um serviço, ou subordinar a prestação de um serviço à utilização de outro ou à aquisição de um bem $^{453}$ - conduta conhecida como venda casada no âmbito de direito do consumidor, e com paralelos na jurisprudência americana sobre tying arrangements (vide Capítulo 2).

Apesar de engenhosa, esta interpretação também não é isenta de problemas. Para fins de caracterização de uma venda casada, a jurisprudência do CADE exige, além da existência de produtos diferenciados e de elemento de coerção, a existência de poder de mercado quanto ao produto primário ou quanto ao produto secundário ${ }^{454}$.

\footnotetext{
${ }^{451}$ Estes, mutatis mutandis são os argumentos apresentados por GRAU-KUNTZ em relação aos mercados de impressoras e cartuchos de tinta ("Direito de Patente e Mercados Secundários - Impressoras e Cartuchos de Tinta”, Revista Eletrônica do IBPI no 5, 2012).

452 "Se o titular do desenho industrial registrado exercer o seu direito de exclusividade sobre bem protegido, pelas regras atuais da propriedade intelectual, exercerá monopólio, a um só tempo, no mercado primário e sobre o mercado secundário, pois (sic), retirará a possibilidade de concorrência também neste mercado (o de peças de reposição). $O$ abuso da posição dominante está caracterizado pela prática de venda casada diferida no tempo, isto é, o consumidor ao adquirir o bem principal estará fadado a comprar, em futuro não distante, as peças destinadas à reparação ou manutenção desse bem. O consumidor de um bem complexo caro e durável não tem condições de, no momento da compra, aferir o grau de gasto com a substituição de partes daquele bem". (CAMELIER, Alberto, "Desenho Industrial: Abuso de Direito e Reflexo na Concorrência do Mercado de Reposição", Tese de Doutoramento, FADUSP, 2012). Sobre uma abordagem baseada nas vendas casadas, ver também o estudo de CORVO RIBAS, Guilherme Favaro, "Direito Antitruste e Propriedade Intelectual - uma abordagem sob a ótica das vendas casadas”, Editora Singular, São Paulo, 2011.

${ }^{453}$ Lei 8.884/94:

"Art. 21. As seguintes condutas, além de outras, na medida em que configurem hipótese prevista no art. 20 e seus incisos, caracterizam infração da ordem econômica;

XXIII - subordinar a venda de um bem à aquisição de outro ou à utilização de um serviço, ou subordinar a prestação de um serviço à utilização de outro ou à aquisição de um bem”;

454 Nesse sentido, é o voto do Conselheiro Ricardo Machado Ruiz, na averiguação preliminar $\mathrm{n}^{\circ}$ 08700.005025/2007-07 (Aceco Produtos para Escritório e Informática Ltda.), pg. 12, julgado pelo CADE em 23.06.2010: “(...) a venda casada demanda a análise de alguns requisitos para sua caracterização: a) a existência de dois produtos e/ou serviços separados; b) a existência de algum elemento de coerção; c) a existência de posição dominante no mercado principal ou condicionado; d) caracterização de efeitos anticompetitivos, seja no mercado secundário/condicionado ou seja no mercado principal" Além disso, "deve haver a configuração de conduta sem qualquer racionalidade ou eficiência econômica”.
} 
O CADE caminha de forma semelhante a outras jurisdições, com a diferença importante de que, nos Estados Unidos e na Europa ${ }^{455}$, a existência de poder no mercado secundário, por si só, não basta para caracterizar a venda casada, sendo necessária a comprovação de poder no mercado primário.

É bem verdade que, em importante precedente (caso Kodak, 1992 - em que se julgou a venda casada de fotocopiadoras e acessórios e serviços no mercado de reposição), a Suprema Corte americana aceitou a alegação de que apenas o poder no mercado secundário seria o suficiente, em situações em que os consumidores se tornam dependentes do mesmo fornecedor no mercado do produto ou serviço vinculado (efeitos de lock in), mas tal decisão sofreu críticas de vários setores, tendo sido restringida a sua aplicação em precedentes seguintes.

A principal crítica da doutrina norte-americana foi quanto a uma confusão conceitual entre poder de uma empresa sobre o próprio preço e poder sobre o mercado, poder este que é o objeto próprio do antitruste - o qual exige que a empresa tenha, efetivamente, poder de estabelecer os preços de mercado ${ }^{456}$.

No caso das peças de reposição, por exemplo, a comprovação de poder de mercado no mercado de reposição (aftermarket) não é algo tão simples quanto pode parecer. É que, ainda que a concorrência esteja excluída no mercado secundário, a pressão competitiva no mercado primário pode, em tese, irradiar efeitos indiretos sobre o mercado secundário. Em outras palavras, as montadoras podem ate exigir, no mercado secundário, preços superiores aos que seriam praticados caso existissem concorrentes no mercado secundário, mas é bem provável que o poder das montadoras não seja suficiente para livremente fixar os preços de mercado ou restringir a oferta a seu bel-prazer.

\footnotetext{
${ }^{455}$ O Guia Antitruste para Licenciamento de Propriedade Intelectual norte-americano, expedido em 1995, tende a condenar uma venda casada se preenchidos três requisitos (i) existência de poder de mercado do ofertante no mercado do produto principal; (ii) existência de efeitos anticompetitivos no mercado do produto ou serviço secundário; e (iii) insuficiência de eficiências que superem os efeitos anticompetitivos do arranjo. A Comissão Europeia adota um teste mais completo: (i) existência de dois produtos ou serviços separados (ii) existência de posição dominante do ofertante no mercado do produto principal; (iii) inexistência de possibilidade de escolha de compra do produto subordinado sem o produto vinculado; (iv) ocorrência de fechamento de mercado; e (v) inexistência de justificativas objetivas para a prática. (CORVo RIBAS, Guilherme Favaro, "Direito Antitruste e Propriedade Intelectual - uma abordagem sob a ótica das vendas casadas", Editora Singular, São Paulo, 2011, pg. 72)

456 “(...) the Court's opinion in Kodak has been widely criticized for confusing the issue of a single's firm's power over its own price and the proper concept of antitrust market power, which requires the firm to have the power to control market prices. (...) the former concept can exist in competitive markets where sellers sell differentiated products but individually have no power over the market price. Thus, it is not appropriate to equate power over one's own product's price, which occurs frequently within competitive industries with differentiated products, with the ability to affect the market price, which is the proper concern for antitrust policy". (KoBAYASHI, Bruce H. "Spilled Ink or Economic Porgress? The Antitrust Bulletin, v. 53, n. 1, p. 533, pg. 26, Spring 2008).
} 
Isso porque, caso assim agissem, as montadoras encontrariam uma séria dificuldade de fidelizar consumidores que, a despeito dos problemas de assimetria da informação em uma primeira compra, seriam orientados pela experiência negativa de "altos custos de reposição" quando tivessem que, futuramente, optar pela compra de um novo automóvel $^{457}$.

É evidente que as montadoras continuam tendo uma vantagem, podendo extrair lucros superiores aos que se verificariam em condições de concorrência no mercado secundário, mas este poder encontra limites, ao menos em tese, graças aos efeitos irradiados pela concorrência no mercado primário. Importante destacar que esta análise pode ser modificada a depender das circunstâncias do caso concreto.

Uma posição semelhante foi defendida pelo Conselheiro Arthur Sanchez Badin, do CADE, na Averiguação Preliminar no 08012.003009/2006-49 (23/06/2010). Neste processo, se investigou a venda casada de softwares e suporte técnico ${ }^{458}$.

Em conclusão, apesar da ausência de concorrentes no mercado secundário, as montadoras não possuem total poder sobre os preços, ou sobre a oferta, do mercado. Sob este prisma, torna-se muito tênue a linha entre aquilo que seria o aproveitamento natural de um privilégio legal atribuído pelo sistema da Propriedade Intelectual (aqui, novamente, estamos abstraindo as falhas na concessão da proteção no caso em exame), de um abuso de poder econômico.

Para não perder de vista a nossa linha de raciocínio, até o momento, atacamos os argumentos levantados em favor de uma pretensa regra de que sempre haveria necessidade de intervenção antitruste em casos em que a Propriedade Intelectual excluir a concorrência em um mercado relevante (seja ele primário ou secundário).

Isso significa que o CADE nada poderia fazer no caso das peças de reposição? A nossa resposta é negativa, conforme passaremos a tratar no próximo tópico.

\footnotetext{
${ }^{457}$ No caso Kodak, o voto vencido do Juiz Scalia entendeu que tal poder de mercado meramente "indiciário" não constitui um problema do antitruste. Para o Juiz, a correção deste problema caberia ao direito contratual e das obrigações. No caso Kodak, não haveria poder de Mercado em razão da concorrência vigorosa no mercado primário, de fotocopiadoras. (ANDERSEN, William R., "Kodak and Aftermarket Tying Analysis: Some comparative thoughts", Pacific Rim Law \& Policy Journal, v. 4, n. 1, pg. 289, 1995).

458 "Discordando da decisão da Suprema Corte, entendo que tanto o caso por ela analisado como o em tela representam exemplos de falha de mercado por assimetria de informação, mas não propriamente um problema antitruste (quando muito, tratar-se-ia de um problema de defesa do consumidor, a ser analisado em outra seara)".
} 


\subsubsection{Meios Ilícitos de Conquista de Poder de Mercado ou Posição Dominante, POR MEIO de EXercício (ABUSIVo) DA Propriedade INTEleCTUAL}

No caso em questão, há indícios de que houve, sim, aquisição de posição dominante por meios ilícitos. Efetivamente, é o meio de obtenção de determinada posição no mercado que caracterizará a infração à ordem econômica, conforme reconhece o art. $36, \S 1^{\circ}$, da Lei $12.529 / 2011^{459}$.

Ao contrário do que se poderia supor, este meio não é apenas o desenho industrial. Se o direito de Propriedade Intelectual fosse o único meio pelo qual se adquiriu a posição dominante no mercado, haveria um contrassenso em se defender a ocorrência de violação antitruste - pois o sistema da Propriedade Intelectual estaria a assegurar uma vantagem ao agente ao mesmo tempo em que impedindo o seu uso (convém frisar, não se está a referir a nenhuma garantia de monopólio).

Mas o fato é que, no caso em referência, as montadoras, aparentemente, se utilizaram, por décadas, de uma tática de tolerância quanto à atuação das fornecedoras de peças de reposição.

Efetivamente, como registra o estudo de AlBERTO CAMELIER sobre o mercado de peças de reposição," desde os anos 60 do século passado, automóveis com cinco anos ou mais não contavam com reposição de peças originais. Esse fato gerou a criação de empresas ocupadas exclusivamente em suprir tais peças de reposição, notadamente, calotas, para-choques, lanternas, vidros, etc. Essas indústrias se firmaram no mercado e labutaram - sem nenhuma oposição ou queixa das montadoras - por dezenas de anos. Durante décadas, essas empresas trabalharam na legalidade. Por que agora estão ilegais? O que mudou? Como fica a racionalidade jurídica, isto é, a expectativa ou o

\footnotetext{
${ }^{459}$ Lei 12.529/2011:

"Art. 36. Constituem infração da ordem econômica, independentemente de culpa, os atos sob qualquer forma manifestados, que tenham por objeto ou possam produzir os seguintes efeitos, ainda que não sejam alcançados:

$\S 10$ A conquista de mercado resultante de processo natural fundado na maior eficiência de agente econômico em relação a seus competidores não caracteriza o ilícito previsto no inciso II do caput deste artigo. (...)

II - dominar mercado relevante de bens ou serviços;

(...)

XIX - exercer ou explorar abusivamente direitos de propriedade industrial, intelectual, tecnologia ou marca".
} 
cálculo ${ }^{460}$ gerado por uma parte em razão do comportamento reiterado da outra, alterado ex abrupto ${ }^{461}$."

Verifica-se que as montadoras, em verdade, se valeram de um expediente de deslealdade, pois permitiram que as fornecedoras de autopeças desbravassem o mercado secundário, para, somente então invocar a proteção do desenho industrial. Agindo desse modo, essas empresas puderam alcançar uma posição dominante, eliminando o risco do negócio, que é inerente ao sistema capitalista. Mais do que isso, capitalizaram sobre investimentos e riscos suportados por terceiros.

Note-se que esta conduta se caracteriza independentemente de qualquer direito de Propriedade Intelectual, mas o uso do desenho industrial, no contexto desta estratégia empregada, confere uma aparência de legalidade e legitimidade à conduta - que, em si repita-se - já era anticoncorrencial. É esse uso da forma da Propriedade Intelectual, quando, na verdade, o que se pretendia era convalidar e consolidar uma conduta anticoncorrencial, ao invés de proteger a originalidade do desenho, que deve ser considerado um meio ilícito, abusivo ${ }^{462}$. O desenho industrial assim usado representa a imposição de barreiras à entrada de novos concorrentes, fazendo com que a posição dominante alcançada ilicitamente se propague no tempo.

E, no caso, a ilicitude não está restrita ao campo da tutela privada conferida à concorrência, pois, as montadoras combinaram uma estratégia anticoncorrencial com o uso abusivo da Propriedade Intelectual, resultando em exclusão de concorrentes e tentativa de dominar mercado relevante (de peças de reposição). Ficam assim caracterizadas - por este prisma - as infrações previstas nos incisos II e IV do art. 20 da então vigente Lei 8.884/94, que - vale lembrar - não exigem que o resultado "dominação de mercados" seja alcançado.

\footnotetext{
460 “A calculabilidade juridical assume, assim, uma dimensão toda própria: apanágio da racionalidade juridical, significa a possibilidade de cálculo do resultado. O direito é racional porque garante o processo e não o resultado a ser obtido, mesmo porque a "álea normal" é inerentre aos negócios. Ou seja, o direito é estruturado com o propósito de possibilitar o cálculo do resultado (Weber), viabilizando, inclusive, a previsão do comportamento do outro, segundo os parâmetros por ele colocados (Irti)". (FORGIONI, Paula, "A Interpretação dos negócios empresariais no novo Código Civil Brasileiro", Revista de Direito Mercantil, Industrial, Econômico e Financeiro no 130 - abril -junho de 2003, pg. 14)

${ }^{461}$ CAMELIER, Alberto, "Desenho Industrial: Abuso de Direito e Reflexo na Concorrência do Mercado de Reposição", Tese de Doutoramento, FADUSP, 2012.

${ }^{462}$ Nas palavras de BORGES BARBOSA, "Em particular, o Direito não aceita que um titular de direito induza alguém - pela falsa tolerância - a abrir e ampliar um mercado, para, só então, entrar na área aberta pelo terceiro, parasitando o trabalho e os esforços de quem investiu. A propriedade intelectual vai tanto quanto o parasitismo do concorrente, quanto contra o do próprio titular. Isso acontece quando, através de uma aparente tolerância, o que se constrói é uma verdadeira armadilha". (http://denisbarbosa.addr.com/entrevista.pdf)
} 
Nosso enfoque não está em tensão com o Direito Positivo, pois a conclusão independe de reconhecimento de um suposto instituto de renúncia tácita aos direitos de Propriedade Intelectual, ou da incidência do instituto da caducidade. Ambos os institutos possuem formas procedimentais próprias, que não foram observadas no caso.

É importante destacar que, ainda que perfeitamente válidos formalmente os direitos de propriedade intelectual, a conduta anticoncorrencial se caracteriza em momento lógico anterior à invocação da proteção.

As montadoras poderiam, de forma lícita, ter invocado o desenho industrial no mercado secundário para restringir a produção, comercialização e importação, o que - em termos práticos - acarretaria uma restrição temporária da concorrência naquele mercado (novamente, não estamos defendendo que o objetivo da Propriedade Intelectual seja gerar um tal monopólio, mas o surgimento deste efeito, circunstancialmente, não pode ser considerado, per si, como contrário ao antitruste).

O que as montadoras não poderiam ter feito é alcançar a posição dominante não por meio do exercício regular de restrição à produção, comercialização e importação, e, tampouco, com base em eficiência própria, mas por eficiência alheia. Também não poderiam as montadoras, uma vez obtida tal posição dominante, usar o direito de Propriedade Intelectual para capitalizar sobre investimentos alheios, criando um escudo legal para uma posição que foi alcançada de forma anticoncorrencial.

Essa mesma posição foi defendida por E. BAGLEY e GAVIN CLAKSON ${ }^{463}$ :

"Our proposal dictates that intellectual property owners should be entitled ab initio to exclude other firms from developing ancillary markets within the scope of the original intellectual property grant, via unilateral refusal to license the intellectual property. If, however, the other firms are not excluded and ancillary markets, develop and provide a product of service that is separately demanded by consumers, then, after a sufficient period of time, adverse possession would preclude the original intellectual property owners from excluding other firms from the ancillary markets as they pertain to existing products".

A proteção da Propriedade Intelectual não pode servir para convalidar, confirmar, a dominação de mercado alcançada por meio de esforço alheio.

${ }^{463}$ BAGLEY, Constance E.; ClAKSON, Gavin, "Adverse Possession for Intellectual Property: adapting an ancient concept to resolve conflicts between antitrust and intellectual property laws in the information age", Harvard Journal of Law \& Technology, v. 16, p. 327-393, Spring 2003. 
4.2.6. Conclusão Parcial: Uma Tentativa de Conceituação das figuras do Abuso de Direitos de Propriedade Intelectual, Dominação de Mercados e Abuso de Posição dominante, Considerando o novo Quadro de Trabalho

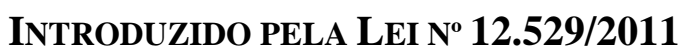

Como já referido, a Lei $n^{\circ}$ 9.279/96 já previa as figuras do exercício abusivo dos direitos de patente, bem como o abuso de poder econômico por meio de patentes. A Lei 12.529/2011, por sua vez, estendeu a hipótese de exercício abusivo de direitos para todas bas modalidades de Propriedade Intelectual.

Em nossa opinião, a hipótese de exercício abusivo prevista no art. 36 da Lei $n^{\circ}$ 12.529/2011 praticamente se sobrepõe àquela prevista no art. 68 da Lei $n^{\circ}$ 9.279/96, pois tudo o que é previsto, quanto às patentes, no art. 68 da Lei 9.279/96 também está contido no art. 36 da Lei ${ }^{\circ}$ 12.529/2011.

Porém, há duas exceções importantes.

A primeira exceção é e que a Lei 9.279/96 configura, em regra, o não exercício do direito de patentes como um abuso (art. 68, $\S 1^{\circ}$, I). Esta regra não se estende automaticamente às demais modalidades de Propriedade Intelectual, a menos que as circunstâncias do caso concreto indiquem que o não exercício foi utilizado como meio para prática do abuso.

A segunda exceção é quanto à “comercialização que não satisfaz às necessidades de mercado" (art. 68, $\S 1^{\circ}$, II). Deve-se entender aqui uma restrição da oferta ${ }^{464}$ que - por si só - já poderia caracterizar, em tese, um exercício abusivo de poder dominante, nos termos do art. 36, IV, §2º da Lei $\mathrm{n}^{\circ}$ 12.529/2011. Porém, é importante destacar que, ao contrário do art. 36 da Lei $n^{\circ}$ 12.529/2011, o art. 68 da Lei 9.279/96 (de aplicação restrita às patentes), permite a licença compulsória mesmo sem a caracterização de abuso. Ou seja, a mera verificação de não atendimento às necessidades de mercado já é circunstância suficiente e eficaz para a concessão de licença compulsória - o que poderá decorrer de uma mera limitação na capacidade produtiva, sem qualquer conduta abusiva.

Verifica-se que as condutas previstas nos vários incisos do $\S 3^{\circ}$ do art. 36 apenas se configurarão como infração à ordem econômica quando tiverem por objeto ou forem

\footnotetext{
${ }^{464}$ Di Blasi , Gabriel; Garcia, Mario Soerensen e Mendes, Paulo Parente M., "A Propriedade Industrial - O Sistema de Marcas, Patentes e Desenhos Industriais Analisado a partir da Lei n 9.279, de 14 de maio de 1996", Rio de Janeiro, Editora Forense, 2002.
} 
potencialmente capazes de produzir os efeitos previstos nos incisos do caput do art. 36 da Lei ${ }^{\circ} 12.529 / 2011$.

Logo, o "exercício abusivo" previsto no inciso XIX deve ser interpretado como uma conduta meio para a consecução de um dos fins previstos em cada um dos incisos do caput do art. 36 - não sendo exigida a concretização do resultado, no entanto.

Assim, há os seguintes requisitos para caracterização da conduta "exercício abusivo de direitos de Propriedade Intelectual”, quais sejam:

(i) Deve haver um exercício abuso de tais direitos (inciso XIX do art. 36);

(ii) O exercício abusivo deve caracterizar ou ser potencialmente capaz de (a) limitar falsear ou prejudicar a livre concorrência; (b) dominar mercado relevante de bens ou serviços; (c) aumentar arbitrariamente os lucros; e (d) exercer de forma abusiva posição dominante (incisos do art. 36, caput).

(iii) A obtenção de posição dominante (dominação de mercado) será presumida quando uma empresa ou grupo for capaz de unilateral ou coordenadamente alterar as condições de mercado (v.g., preço ou oferta) ou grupo de empresas controlar $20 \%$ de mercado relevante (podendo o CADE alterar este percentual de acordo com as características do mercado) ou quando um agente

(iv) A posição dominante não pode estar fundada em processo natural fundado na maior eficiência do agente econômico (art.36. $\left.\S 1^{\circ}\right)$

De tais dispositivos, bem como das ponderações e lições que extraímos do caso das peças de reposição, alcançamos as seguintes conclusões:

1) A restrição à livre concorrência, bem como a dominação de mercado primário ou secundário (incluindo o exercício abusivo desta posição dominante) que forem alcançadas por meio de um direito de Propriedade Intelectual não podem, por si só, ser caracterizadas como ilícitas - o que, tampouco, afasta tal possibilidade ${ }^{465}$. É necessário, contudo, que haja um elemento de exercício abusivo, que não pode ser presumido, mesmo quando caracterizado o resultado (i.e., mesmo quando restringida a concorrência ou alcançada a posição dominante);

2) Para que o elemento "exercício abusivo" seja caracterizado, deve-se centrar a análise, em um primeiro momento, nos limites do direito reconhecido pela Propriedade

\footnotetext{
465 "No tocante aos casos em que o direito de PI é a causa eficiente de uma lesão ou risco de lesão à concorrência, a literatura aponta o princípio de que o uso regular de um direito exclusivo não pressupõe restrição ilícita na concorrência, mas igualmente não exclui a possibilidade de efeitos anticompetitivos". (BArbosA, Denis Borges, “A Criação de um Ambiente Competitivo no Campo da Propriedade Intelectual - o caso sul americano, 2005 - disponível no portal do autor em: http://www.denisbarbosa.addr.com/arquivos/)
} 
Intelectual. Se o detentor da Propriedade Intelectual agiu nos limites de seu direito de impedir a produção, comercialização ou importação por terceiros, tal não pode ser compreendido como circunstância suficiente para caracterizar o abuso.

3) Porém, é necessária total atenção para as circunstâncias do caso. Se a conduta do detentor do direito de Propriedade Intelectual não apenas induz a uma violação, como também importa um rompimento de expectativas razoáveis e aproveitamento indevido de esforços de terceiros, já estamos fora do campo do exercício regular de direito e dentro do âmbito do "exercício abusivo"- pois a Propriedade Intelectual não serve para convalidar, legitimar, uma tal conduta oportunista e anticoncorrencial ${ }^{466}$. O Direito Civil brasileiro reconhece a ilicitude do ato de agrente que o exerce em excesso aos limites impostos pelo seu fim econômico ou social, pela boa-fé e pelos bons costumes $^{467}$;

4) Não se exige que a conduta abusiva seja eficaz no alcance dos objetivos (v.g., obtenção de posição dominante), bastando que ela tenha por objeto, ou que possa produzir tais efeitos. A mera tentativa de excluir concorrentes por meio do exercício abusivo já deve ser considerada suficiente para caracterizar o ilícito;

5) Por outro lado, embora a posição dominante ou poder econômico alcançados por meio dos direitos de Propriedade Intelectual não possam ser considerados como ilícitos per se, o exercício desta posição não pode se dar de forma abusiva, ficando sujeito a limites. O art. 68 da Lei 9.279/96 já prevê a figura do "abuso de poder econômico por meio de patentes”, que incidirá caso o detentor da patente não a utilize ou não atenda as exigências de mercado (mecanismo importante para coibir abusos em setores de interesse público geral, como medicamentos). A Lei 12.529/2011, por outro lado, confirma a possibilidade de o CADE recomendar ao órgão competente o licenciamento compulsório em tais casos (art. 38, IV, a), o que não está restrito às patentes;

\footnotetext{
${ }^{466} \mathrm{O}$ raciocínio aqui é semelhante à doutrina do unclean hands desenvolvida na jurisprudência americana, conforme vimos no Capítulo 2 (Motion Salt Co vs. G.S. Suppiger Co., 1942). Porém, há que se ter claras algumas diferenças importantes: a doutrina da unclean hands estava em conexão com a patent misuse, que era aplicada como uma possível defesa contra alegação de violação de patentes, em um litígio de direito privado. Como o direito brasileiro agora reconhece a possibilidade de violação antitruste por meio do exercício abusivo de Direitos de Propriedade Intelectual, o âmbito de aplicação do raciocínio aqui exposto é mais amplo, podendo se dar no controle ex ante e ex post exercido pela autoridade brasileira de defesa da concorrência.

${ }^{467}$ Código Civil:

"Art. 187. Também comete ato ilícito o titular de um direito que, ao exercê-lo, excede manifestamente os limites impostos pelo seu fim econômico ou social, pela boa-fé ou pelos bons costumes”.
} 
6) Outros exemplos de abuso de posição dominante envolvendo a Propriedade Intelectual seriam tentativas de bloquear ou retardar o desenvolvimento de novos produtos ou processos produtivos (concorrência de superação);

7) Um parêntesis para lembrar que, antes que se possa cogitar de abuso de posição dominante, esta posição deve estar caracterizada;

8) Nos termos da lei, a posição dominante será presumida quando uma empresa ou grupo for capaz de unilateral ou coordenadamente alterar as condições de mercado (Poder de Mercado). Aqui, deve se tomar cuidado para não confundir poder sobre o próprio preço com o efetivo poder sobre o mercado - circunstância que não se caracteriza, necessariamente, quando uma empresa puder fixar preços acima de seus custos marginais (teoria neoclássica, que, contudo, é insuficiente para descrever as características da Nova Economia);

9) Deve-se analisar se a Empresa, realmente, pode, livremente, controlar os preços de mercado e restringir a oferta, sem quaisquer pressões competitivas. Também se presumirá a posição dominante quando ficar caracterizado o controle sobre uma fatia significativa do mercado $(20 \%$, nos termos da lei, ou outro percentual estabelecido pelo CADE).

\subsection{Controle Antitruste sobre Contratos de Fornecimento/Licenciamento de TeCnOlogia - OUtras Armadilhas}

No Capítulo 3, fizemos uma crítica a uma determinada vertente de Teoria da Decisão, denominada Teoria dos Custos do Erro, que, basicamente, confere um "cheque em branco" para validação de condutas e estruturas sempre que um potencial impacto negativo sobre a inovação estiver em jogo.

Ainda que esta Teoria não tenha sido expressamente recepcionada pelo direito antitruste brasileiro, tampouco se tendo notícia de citações a esta teoria em decisões do Sistema Brasileiro de Defesa da Concorrência, um raciocínio similar tem impregnado decisões envolvendo a aprovação de acordos de licenciamento de tecnologia (considerados como Atos de Concentração para fins do antitruste, conforme já explanado no Capítulo 3).

Este raciocínio tendeu à aprovação sumária de acordos quando satisfeitas algumas condições que, de acordo com a teoria econômica, tornariam os acordos competitivos. 
A armadilha está no fato de se considerar, em nome da previsibilidade e da economia, uma teoria econômica em abstrato, em atentar para as peculiaridades contratuais e para a interação de cada uma das cláusulas sobre cada mercado, considerado em suas características e sem levar em conta o componente estratégico.

Esta postura é passível de críticas, por importar em um formalismo jurídicoeconômico descolado da realidade e - por vezes - do texto legal.

Um exemplo do que estamos a abordar é o Parecer $n^{\circ} 171$ da SuperintendênciaGeral do CADE:

"Pelo exposto, entende-se que licenciamentos não-exclusivos de uso de tecnologia, desde que também não carreguem consigo acordos de não-concorrência, transferência de ativos, organização comum ou vínculos societários de qualquer natureza, ou qualquer medida que implique em alteração dos centros decisórios ou restrição concorrencial, não são de notificação obrigatória ao CADE nos termos da Lei $n^{\circ}$ 12.529/2011" (Parecer $n^{\circ} 171$ da Superintendência-Geral)

Esta conclusão da SG, diga-se, apenas ecoa julgamentos reiterados do CADE, que aprovaram sumariamente, contratos de fornecimento em casos em que não havia cláusula de exclusividade, bem como acordos de não concorrência, ou que implicassem em modificações societárias com impacto sobre os centros decisórios e restrição concorrencial, e - ainda - cujo prazo e volume não apontassem para uma restrição importante da concorrência.

Nesse sentido, veja-se o pronunciamento do Conselheiro Arthur Badin, então presidente do CADE:

"O levantamento da posição do CADE a respeito de contatos de fornecimento demonstrou que:

- a grande maioria dos casos notificados envolvendo tais contratos são conhecidos e aprovados sem restrições, após trâmite pelo procedimento sumário;

- os poucos casos em que se entendeu pela aprovação com restrições, esta se deu tão somente em razão da inserção de cláusula de exclusividade no contrato ;

- nas oportunidades em que instado a abordar a questão da necessidade em tese, de notificação dessas operações, o CADE optou por manter seu posicionamento usual e determinar sempre o conhecimento.

Parece-me bem vinda a oportunidade para que o CADE supere a resistência e a cautela excessiva no exame de contratos de fornecimento, de forma a sedimentar algo há tanto sinalizado aos administrados.

A análise dos casos acima demonstra que os contratos de fornecimento que (i) não impliquem transferência de direitos sobre ativos concorrencialmente relevantes (b) não contenham cláusulas de exclusividade ou equivalentes de qualquer natureza capazes de restringir o 
direito de decisão sobre ativos (produtos e serviços), (c) tenham prazo de vigência inferior a cinco anos (consideradas eventuais prorrogações), (d) contemplem a possibilidade de rescisão imediata e sem ônus à parte requerente (e) não representem a negociação de um volume de produtos superior ao percentual estabelecido no art. 54, $\$ 3^{\circ}$, da Lei $n^{\circ} 8.884 / 94$, prescindem de notificação da SBDC por não serem capazes de limitar ou prejudicar a livre concorrência ou deles resultar a dominação de bens e serviços”.

Posteriormente, no Ato de Concentração 08012.005472/2010-10, o CADE resumiu ainda mais a regra: não havendo exclusividade ou compromisso de não concorrência, a submissão não seria obrigatória.

Verifica-se, assim, que a jurisprudência do CADE acabou por construir uma espécie de isenção antitruste para tais tipos de acordo - isenção esta que não possui nenhuma previsão legal.

Além disso, esta técnica menospreza o poder de manipulação dos agentes econômicos, pois, na medida em que - nas palavras do pronunciamento acima transcrito o órgão de concorrência sinaliza tais regras aos jurisdicionados, passa a existir um claro estímulo para que as operações sejam modeladas de modo a se amoldar, ao menos no seu aspecto estético, exterior, à hipótese de isenção. Assim, ainda que as exigências no campo da forma jurídica visível tenham sido atendidas, no campo fático, uma nova estrutura econômica, sem nenhuma correspondência com a forma, pode ter sido arquitetada. É fenômeno ao qual COMPARATO denominou "Controle Empresarial ab extra ${ }^{468 \text { ". }}$

Uma posição mais crítica - e, a nosso ver exemplar - foi exposta no voto do Conselheiro Alessandro OCtAVIANi, nos autos do Ato de Concentração $\mathrm{n}^{\circ}$ 08700.004957/2013-72.

No caso em referência, cuidou-se de um contrato de licenciamento da tecnologia de soja transgênica Intacta RR2 PRO, pela licenciante Monsanto para a licenciada Bayer, que desenvolveria diferentes cultivares, a partir de seu banco de germoplasma, nos quais inserirá aquela tecnologia. Tais cultivares, resultantes do somatório da tecnologia da Monsanto com as características desenvolvidas pela Bayer, poderiam ser exploradas

\footnotetext{
468 “(...) '(O) poder de controle de uma empresa sobre a outra - elemento essencial do grupo de subordinação - consiste no direito de decidir, em última instância, a atividade empresarial de outrem. Normalmente, ele se funda na participação societária de capital, permitindo que o controlador se manifeste na assembleia geral ou reunião de sócios da empresa controlada. Mas pode também suceder que essa dominação empresarial exerça, ab extra, sem participação de capital de uma empresa em outra e sem que o representante da empresa dominante tenha assento em algum órgão administrativo da empresa subordinada. É o fenômeno do chamado controle externo. (...) além desses tipos de contratos nominados (...) também admite-se que qualquer outro contrato possa gerar a situação de dependência - controle, característica do grupo de subordinação. Os exemplos dados são o financiamento bancário e o contrato de financiamento".

(COMPARATO, Fábio Konder, "Grupo societário fundado em controle contratual e abuso de poder do controlador”, In "Direito Empresarial”, p. 270-91. São Paulo: Saraiva, 1995)
} 
comercialmente diretamente pela Bayer, por meio de multiplicação e distribuição, ou repassadas a terceiros multiplicadores, para a produção em massa das sementes. Essas sementes, por sua vez, seriam comercializadas aos sojicultores para o plantio.

O Conselheiro AlESSANDRO OCTAVIANI houve por avocar a decisão em caso em que a Superintendência-Geral opinara pela dispensa de notificação ao CADE.

O voto do Conselheiro OCTAVIANI fez uma análise detalhada da cadeia produtiva da soja transgênica, bem como do aparato jurídico institucional sobre o qual a Monsanto articulou seu modelo de negócios no Brasil: Lei de Propriedade Intelectual (Lei 9.279/1996), Lei de Cultivares (Lei 9.456/1997) e a Lei de Biossegurança (Lei $11.105 / 2005)$.

No caso da Lei de Cultivares (Lei 9.456/1997), um dispositivo específico afastou a violação à proteção no caso de o agricultor reservar e plantar sementes para uso próprio em seu estabelecimento ou no estabelecimento de terceiros ${ }^{469}$. Esse dispositivo importou em um obstáculo a ser superado, o que fez com que a Monsanto tivesse que criar uma estratégia diferenciada de cobrança de royalties no Brasil, dada a dificuldade de fiscalizar cada um dos agricultores.

Essa estratégia envolveu a disseminação da tecnologia por meio de contratos de licenciamento, ficando a licenciada (Bayer) responsável pelo desenvolvimento das cultivares e venda das sementes certificadas aos agricultores.

Em um primeiro momento, a Monsanto deixaria de receber royalties no licenciamento da tecnologia. A remuneração da Monsanto - desenvolvedora de tecnologia - no mercado de soja dependeria do sucesso na combinação de sua tecnologia Intacta RR2 PRO com as características genéticas presentes no banco de germoplasma das licenciadas (Bayer) - desenvolvedoras de cultivares - de forma a que se produzissem sementes comercialmente viáveis e para que pudesse receber royalties do agricultor, quando este plantar a semente ou quando vender o grão.

Em uma primeira análise, a licenciante (Monsanto) dependeria mais do banco de germoplasma da licenciada (Bayer) para obter sucesso no mercado de sementes, mas a recíproca não seria verdadeira.

\footnotetext{
${ }^{469}$ Lei no 9.456/1997:

“Art. 10. Não fere o direito de propriedade sobre a cultivar protegida aquele que:

I - reserva e planta sementes para uso próprio, em seu estabelecimento ou em estabelecimento de terceiros cuja posse detenha; (...)”
} 
Porém, apesar de os obtentores de cultivar não dependerem de uma tecnologia transgênica para produzir um cultivar viável - dado que seu trabalho é o de combinação de características genéticas contidas em um banco de germoplasma, de forma a obter um cultivar adaptado às condições edafoclimáticas de determinado lugar - a depender da demanda dos agricultores, a obtenção de cultivar com determinada característica transgênica pode ser comercialmente necessária.

Ocorre que as duas únicas tecnologias de soja geneticamente modificadas disponíveis no mercado brasileiro são detidas pela Monsanto (Propriedade Intelectual) - ou seja, esta empresa é dominante no mercado de fornecimento da tecnologia.

No caso dos royalties devidos pelo uso, pelos agricultores, da soja com a tecnologia da licenciante (Propriedade Intelectual), ainda que os agricultores detenham em seu poder as sementes produzidas naturalmente para replantio, haveria, em tese, uma nova incidência de royalties. Por outro lado, os royalties pelo uso do cultivar (de propriedade da licenciada, Bayer) são devidos apenas uma única vez, no momento da venda da semente certificada. Essa situação, em tese, poderia acarretar uma maior margem de lucro para licenciante/desenvolvedora de tecnologia (Monsanto) em comparação com a licenciada/desenvolvedora de cultivar (Bayer).

Para corrigir esse descompasso, tornando mais interessante do ponto de vista comercial a implementação da sua tecnologia pelas licenciadas, a Monsanto usualmente estabelece uma cláusula de compartilhamento de valor em seus contratos de licenciamento de tecnologia. Tais cláusulas, basicamente, determinam que a licenciada (no caso, a Bayer) teria uma participação nos lucros (royalties) recebidos pela Monsanto.

Além disso, essa cláusula cria o interesse da Bayer de contribuir para que os sojicultores paguem o royalty devido à Monsanto já na compra da semente.

Nas palavras do Conselheiro OCTAVIANI, tal cláusula:

“(...) cria o interesse da Bayer de contribuir para que os sojicultores paguem o royalty devido à Monsanto já na compra da semente, alinhando-se com esse mesmo interesse comercial específico da Monsanto, que não está diretamente ligado ao licenciamento da tecnologia Intacta em particular, e sim, ligado à atuação da Monsanto como desenvolvedora de tecnologias transgênicas como um todo, assim, estrutura-se uma lógica do individual ao total, pela qual a licenciada começa a tornar-se agente difusor da licenciadora. Não estão mais separados; passam a estar conectados. E essa conexão é programada para a auto expansão. Da capacidade de dizer não, para a manufatura do terreno onde muitos quererão obter o sim”. 
Além disso, a cláusula em questão, alinhada a outras previsões, reforçavam que, na verdade, se estava diante de um verdadeiro contrato associativo ${ }^{470}$ entre as duas empresas para além do mero licenciamento de tecnologia:

“Em outras palavras, essa cláusula cria o interesse da Bayer de contribuir para que os sojicultores paguem o royalty devido à Monsanto já na compra da semente, alinhando-se com esse mesmo interesse comercial específico da Monsanto, que não está diretamente ligado ao licenciamento da tecnologia Intacta em particular, e sim, ligado à atuação da Monsanto como desenvolvedora de tecnologias transgênicas como um todo, assim, estrutura-se uma lógica do individual ao total, pela qual a licenciada começa a tornar-se agente difusor da licenciadora. Não estão mais separados; passam a estar conectados. E essa conexão é programada para a auto expansão. Da capacidade de dizer não, para a manufatura do terreno onde muitos quererão obter o sim.

A mesma lógica rege o mecanismo do "Incentivo Aumentado", explicitado pela Cláusula 4.5. (CONFIDENCIAL). Em resumo, o Incentivo Aumentado garante um "prêmio" à Bayer englobando todo seu portfólio no mercado da soja. Novamente temos aqui o alinhamento de interesses comerciais e posições estratégicas entre licenciante e licenciada, resultando, inclusive, na troca de informações concorrencialmente sensíveis entre ambos, chegando ao ponto de instrusão que expressamente estipula apresentação de relatórios de vendas, por áreas geográficas passíveis de serem solicitadas pela Monsanto “a qualquer momento”

Outro mecanismo importante para entender o relacionamento entre licenciante e licenciada por força do presente contrato é o chamado "Royalty Mínimo": (CONFIDENCIAL) Como se vê, Royalty Mínimo é a importância financeira devida pela Bayer à Monsanto, a partir de determinado marco temporal, todas as vezes em que os acres de Soja Intacta produzida nos campos sob a responsabilidade da Bayer sejam menores do que o percentual estipulado (CONFIDENCIAL). Com isso, a Bayer pagaria essa compensação ou “indenização”, caso não implemente a tecnologia ora licenciada em sua produção de forma satisfatória. (...)

\footnotetext{
${ }^{470}$ Vide as importantes considerações da Conselheira ANA FRAZÃo no julgamento dos Atos de Concentração $\mathrm{n}^{\mathrm{o}} 08012.002870 / 2012-38,08012.006706 / 2012-08, \mathrm{n}^{\mathrm{o}} 08012.003898 / 2012-34$ e no $08012.003937 / 2012-01$ : “(...) o que distingue os contratos associativos dos demais contratos não é a existência ou não de cooperação, mas sim o grau de zelo e o tipo desta. Enquanto nos contratos comutativos a cooperação é um dever lateral, já que as prestações das partes são naturalmente distintas e contrapostas, nos contratos associativos a cooperação corresponde à própria prestação ou aos deveres principais assumidos pelas partes. Isso acontece porque os contratos comutativos ou de troca partem da premissa de que as necessidades das partes são diferentes. Já nos contratos associativos ou plurilaterais as necessidades das partes são as mesmas ou muito próximas, motivo pelo qual são reunidas em torn do fim comum que, por sua vez, impõe o paralelismo do comportamento das partes". Também destacam-se as ponderações do então CONSElHeiro Marcos Paulo Veríssimo, no Julgamento do Ato de Concentração no 08012.002870/201238 já apontara: "É óbvio, por um lado, que esse resultado (a concentração econômica) independe de fórmulas jurídicas específicas, podendo ser obtido tanto por concentração empresarial formal' (via fusão, aquisição de controle ou fundação de novas sociedades em conjunto) quanto por meio de arranjos contratuais específicos (especialmente no caso da concentração vertical, que pode ser obtida por meio de contratos exclusivos de distribuição, fornecimento ou mesmo transferência de direitos variados de propriedade industrial). A inexistência de uma linha divisória clara e substantiva entre as estruturas empresariais formais e as estruturas contratuais é, por sinal, correntemente conhecida e reconhecida, no mínimo, desde o famoso "the Nature of the Firm”, de Ronald Coase, publicado em 1937”.
} 
Além disso, a cláusula 4.4.1. exclui do cálculo dessa área produzida os acres contendo o evento RRI (sem quaisquer outros eventos ou características transgênicas), o que alinha a prática comercial da Bayer com interesses estratégicos da Monsanto, vez que desincentiva o uso da única outra tecnologia transgência disponível para soja atualmente, a RR1, também inventada pela Monsanto, mas com a patente expirada desde 2010.

Temos, ainda, a previsão de isenção desse "royalty” mínimo (CONFIDENCIAL) (Cláusula 4.4.7). Ou seja, isenta-se a Bayer do pagamento do royalty mínimo enquanto a tecnologia ora licenciada (Intacta RR2 PRO) não tiver significativa penetração no mercado brasileiro. Com isso, temos novamente a inclusão da Bayer na política comercial global da Monsanto, por força do licenciamento de tecnologia, o que reforça o alinhamento de interesses empresariais, resultando em evidentes implicações concorrenciais, a serem ulteriormente enfrentadas".

E, conclui o Conselheiro OCTAVIANI: “Aqui, a modulação contratual mais uma vez faz ser portada, com uma tecnologia, um comportamento econômico de parceria estratégica, em tudo distante da caricatural, e abstrata e inofensiva imagem de "meros contratos de transferência de tecnologia sem exclusividade”.

Além disso, o contrato em questão continha várias outras cláusulas que reforçavam o interesse comum das partes em manter um relacionamento estratégico de longo prazo, ficando a licenciada obrigada a submeter seus planos estratégicos globais à prévia aprovação da licenciante:

"Deve se abandonar, portanto, a figura do "mero" contrato de licenciamento de tecnologia como negócio jurídico acima ou fora da cadeia produtiva em que se insere, por meio do qual o licenciante simplesmente autorizaria a utilização de sua tecnologia, sem qualquer envolvimento no processo produtivo, esperando passivamente pelo recebimento dos "royalties". Tal ingênua caricatura não condiz com a realidade e sublima questões concorrenciais de extrema importância. Como dito anteriormente, o "a priori" e o "em abstrato" não são bons conselheiros das políticas de defesa da concorrência”.

As características do contrato levaram o Conselheiro a decidir pelo conhecimento da operação, não apenas por se enquadrar como um contrato associativo, nos termos do art. 90, IV, da Lei $\mathrm{n}^{\circ}$ 12.529/2011, mas por importar em aquisição de controle indireto, nos termos do inciso II do artigo 90 da Lei 12.529/2011. O mercado relevante definido foi o mercado de fornecimento de tecnologia de soja transgênica no território nacional, em que se verificou a presença da tecnologia da Monsanto em 99,21\% das cultivares registradas.

Adicionalmente, foram consideradas as elevadas barreiras à entrada nesse mercado, por se tratar de indústria de capital intensivo e que, por outro lado, depende da confiança do agricultor. Os próprios direitos de Propriedade Intelectual constituem barreiras à entrada no mercado em questão. 
Logo, o mercado de sementes transgênicas está altamente concentrado, ao passo em que o mercado de sementes convencionais é mais competitivo. Por essa razão, a Monsanto tenderia a consolidar o seguimento de transgênicos, pois nesse mercado a firma poderia auferir lucros acima dos níveis obtidos em mercado competitivo. A aplicação prática de tal estratégia poderia ser uma redução da oferta de sementes convencionais - mercado no qual a Monsanto também atua, por meio de sua subsidiária Monsoy.

Os efeitos da aquisição de controle da Bayer pela Monsanto sobre a concorrência seriam sentidos em uma elevação das barreiras à entrada de competidores no mercado de fornecimento de tecnologia transgênica, pois, graças ao acordo de "compartilhamento de valor", qualquer empresa que ingressasse neste mercado não poderia entrar em acordo com a Bayer e obter acesso ao seu banco de germoplasma. Ou seja, para concorrer com a Monsanto, a empresa concorrente teria que "cobrir" os incentivos oferecidos pela rival.

Aliás, a própria Bayer possui uma tecnologia transgênica patenteada e aprovada pelos órgãos regulatórios (tecnologia Liberty Link), mas, com o acordo de “compartilhamento de valor", não haverá incentivos para a introdução desta nova tecnologia no mercado brasileiro. Some-se a isso a cláusula que estabelece licenciamento futuro de tecnologias sequer disponibilizadas no mercado - o que representa um bloqueio à inovação tecnológica/eficiência dinâmica.

Em resumo, foram determinadas uma série de restrições quanto às cláusulas que estabeleciam o "acordo de compartilhamento de valor", bem como o compartilhamento de informações entre as duas empresas para fins de coleta dos royalties. Finalmente, foi determinada a exclusão de todas as cláusulas que possibilitem o exercício de influência externa da Monsanto sobre a Bayer.

Conforme concluiu o Conselheiro:

“as referidas cláusulas, tal como redigidas, não obrigam a exclusividade, mas induzem-na (ou, melhor dizendo, a "aconselham com veemência”), incrementando os custos de troca da tecnologia Intacta por outras tecnologias eventualmente disponíveis para a Bayer e, consequentemente, elevando as barreiras à entrada de novos concorrentes no mercado de tecnologias transgênicas para soja, de forma que os prejuízos à concorrência superam em muito as eficiências produzidas pela instituição do compartilhamento de valor e de incentivos entre licenciantes e licenciadas nesse mercado. Aqui, ter-se-ia a consagração de um modelo "desindutor" da inovação e da concorrência, justamente o inverso da melhor hermenêutica para as relações entre direito da concorrência e direito da propriedade industrial, ainda mais sob a égide da Constituição de 1988, propaladora de uma Ordem Econômica vertida à “produção de produtores de conhecimento". 
A decisão do CADE no caso examinado torna claras as insuficiências e as armadilhas do formalismo jurídico, que - defendemos - devem ser evitadas. Em nossa opinião, a decisão identificou, precisamente, o ponto em que a posição dominante, obtida legal e legitimamente por meio de direitos de Propriedade Intelectual se perverte em abuso, bloqueando os caminhos da inovação e desarticulando a ordem econômica.

É precisamente este tipo de análise, atenta à realidade, orientada por um uso pleno da teoria econômica - não restrito às armadilhas de uma Teoria da Decisão formalista coerente com os princípios da ordem econômica brasileira e com reverência ao direito positivo, que pretendemos defender na abordagem de questões envolvendo a Propriedade Intelectual e o antitruste. 


\section{CONCLUSÕES}

Diferentemente do que se observou nos Estados Unidos, em que a abordagem das Cortes sobre a interface entre a Propriedade Intelectual e o antitruste sofreu diversas rupturas ao longo da história, variando as interpretações de acordo com as teorias econômicas que prevaleciam em cada período, e de acordo com as agendas partidárias dos partidos dominantes - tal como estudado detalhadamente no Capítulo 2 - o Brasil possui uma ordem econômica com caráter sistemático e conteúdo constitucional bem definidos. $\mathrm{O}$ Direito de Concorrência e a Propriedade Intelectual não podem ser interpretados de forma descolada dos princípios expressamente positivados em tal ordem.

Diante de tal caráter sistemático da ordem econômica e considerando a relativa esfera de liberdade conferida pelo TRIPS - por meio de importantes concessões obtidas pelos países em desenvolvimento nos artigos 8(1), 8(2) e 40 - o legislador pátrio possui uma oportunidade valiosa para regular estas matérias, de modo a concretizar os princípios e metas expressamente assumidos pela ordem econômica pátria - notadamente, impedir práticas contratuais restritivas que tenham por efeito potencial a dominação de mercados com consequências nocivas para o alcance de uma maior autonomia tecnológica.

Atentando para os marcos da esfera de liberdade conferida pelo TRIPS, o legislador brasileiro, com a edição da nova lei de defesa da Concorrência (Lei 12.529/2011), expandiu consideravelmente o quadro de trabalho nacional para tratar de questões relacionadas à interface entre a Propriedade Intelectual e a Concorrência.

Tais modificações consagram a superação de uma noção excessivamente individualista e estática da Propriedade Intelectual em benefício de uma visão mais funcional e que leva em conta o papel econômico representado por tais direitos - o que se deve, em grande parte, graças às importantes contribuições de autores no cenário nacional, já desde Ascarelli, passando por autores como NeWton Silveira, Denis Borges Barbosa, CAliXto SAlomão Filho e, mais recentemente, Karin GraU-KuntZ.

Em verdade, a Lei n ${ }^{\circ}$ 9.279/96 (Lei de Propriedade Industrial) já previa, nos moldes do art. 8(1) do TRIPS, as figuras do exercício abusivo dos direitos de patente, bem como o abuso de poder econômico por meio de patentes.

A Lei 12.529/2011, entretanto, estendeu a hipótese de exercício abusivo de direitos para todas as modalidades de Propriedade Intelectual, bem como estabeleceu remédios específicos para afastar os efeitos negativos de tais práticas no mercado relevante, ao passo 
que a lei anterior apenas estabelecia a recomendação de concessão de licenças compulsórias como forma de sanção administrativa genérica (sem nenhuma consideração sobre os efeitos da conduta no mercado relevante, diga-se).

$\mathrm{Na}$ interpretação dos dispositivos em questão, deve-se sempre ter em mente a crise atravessada sistema da Propriedade Intelectual, em vista de sua insuficiência para lidar com novas realidades trazidas por fenômenos como a revolução tecnológica e a Nova Economia, os quais suscitaram vários movimentos de crítica jus-filosófica à Propriedade Intelectual na virada do século XXI nos Estados Unidos - destacando-se movimentos como o Open Source, o Software livre ou Copyleft de Richard Stallman e outras propostas teóricas mais abrangentes e ambiciosas, por parte de autores como LESSIG, BENKLER, BOYLE, SAMUELSON, LEMLEY, entre outros.

Tais trabalhos contribuíram grandemente para isolar as discussões sobre o sistema da Propriedade Intelectual dos estigmas e preconceitos amplamente disseminados por grupos de interesse, recolocando a discussão sobre a consistência e limites de tais argumentos em termos jurídicos, econômicos e morais. Em uma linha semelhante ao que defendem os últimos autores citados, entendemos que argumentos de ordem econômica mais comuns em questões envolvendo o antitruste - devem ser sempre isolados de concepções generalizantes e submetidos a um escrutínio atento dos fatos. Um exemplo disso é a crítica que fizemos no final do Capítulo 1 ao estigma do free riding como critério para embasar decisões judiciais e administrativas.

Também em razão disso, em termos metodológicos, tal como exposto detalhadamente no Capitulo 4, defendemos uma hermenêutica destes dispositivos que afaste decisões que não estejam fundamentadas no direito positivo, sem que isso implique aceitar concepções essencialistas dos textos legais, ou afastar a importância dos princípios no Direito - principalmente, a já reconhecida importância dos princípios da ordem econômica sistemática prevista na Constituição Federal brasileira.

Neste contexto, o uso da ciência econômica que defendemos em casos envolvendo Propriedade Intelectual e concorrência é um uso meramente argumentativo, uma vez que os fundamentos últimos da decisão devem estar sempre calcados no direito positivo, e não em uma determinada teoria econômica escolhida pelo livre convencimento das autoridades competentes.

Estas considerações são importantes, pois, no que se refere ao antitruste, é já bem conhecido o fenômeno da desconstitucionalização que combatemos - o que se deve, em 
grande parte, à importação de construtos jus-econômicos extraídos das autoridades de defesa da concorrência estrangeiras, notadamente, estadunidenses.

No que se refere especificamente à questão da interface entre Propriedade Intelectual e o direito antitruste, a experiência brasileira é bastante recente, mas alguns casos-limite (v.g., o caso do mercado secundário de peças de reposição, estudado no Capítulo 4) levaram parte da doutrina a advogar a extensão de entendimentos que foram alcançados por cortes estrangeiras, a despeito dos limites semânticos impostos pelo quadro de trabalho do direito positivo brasileiro não necessariamente contemplarem as mesmas conclusões. Isso se deve, essencialmente, a uma insatisfação de parcela da doutrina com o quadro de trabalho então apresentado pelas Leis 9.279/96 e pela então Lei Brasileira de Defesa da Concorrência (Lei 8.884/94).

A despeito das importantes contribuições destes autores para o desenvolvimento do tema, entendemos que tais soluções devem ser sempre contempladas por modificação legislativa, respeitando-se o processo democrático, e não pela via de decisões judiciais aderentes a pronunciamentos emitidos por autoridades estrangeiras.

Por outro lado, algumas ferramentas analíticas desenvolvidas por cortes estrangeiras para lidar com os fenômenos típicos da Nova Economia já vêm sendo aplicadas pelos órgãos brasileiros de defesa da concorrência - como, por exemplo, os conceitos de Mercados de Inovação e Tecnologia, que são, sem sombra de dúvidas, mais adequados para representar a realidade atual, em que a tecnologia não necessariamente corporificada em bens tangíveis passa a ser objeto do mercado. Nesses casos, a contribuição da experiência estrangeira é bem vinda, pois se trata apenas de métodos para definição do mercado relevante a ser considerado em análises antitruste, estando o emprego de tais ferramentas restrito ao direito positivo.

Tendo por base as premissas metodológicas assumidas em nosso trabalho, dos dispositivos constantes das Leis 9.279 e 12.529 extraímos as seguintes conclusões:

1) A restrição à livre concorrência, bem como a dominação de mercado - seja ele primário ou secundário - que forem alcançadas por meio de um direito de Propriedade Intelectual não podem, por si só, ser caracterizadas como ilícitas - mas a Propriedade Intelectual também não afasta a possibilidade de ilicitude da conduta ${ }^{471}$. É necessário,

\footnotetext{
471 "No tocante aos casos em que o direito de PI é a causa eficiente de uma lesão ou risco de lesão à concorrência, a literatura aponta o princípio de que o uso regular de um direito exclusivo não pressupõe restrição ilícita na concorrência, mas igualmente não exclui a possibilidade de efeitos anticompetitivos". (BArbosA, Denis Borges, “A Criação de um Ambiente Competitivo no Campo da Propriedade Intelectual - o caso sul americano, 2005 - disponível no portal do autor em: http://www.denisbarbosa.addr.com/arquivos/)
} 
para tanto, que haja um elemento de exercício abusivo, que não pode ser presumido, mesmo quando caracterizado o resultado (i.e., mesmo quando restringida a concorrência ou alcançada a posição dominante);

2) Para que o elemento "exercício abusivo" seja caracterizado, deve-se centrar a análise, em um primeiro momento, nos limites do direito reconhecido pela Propriedade Intelectual. Se o detentor da Propriedade Intelectual agiu nos limites de seu direito de impedir a produção, comercialização ou importação por terceiros, tal não pode ser compreendido como circunstância suficiente para caracterizar o abuso.

3) Porém, é necessária total atenção para as circunstâncias do caso. Se a conduta do detentor do direito de Propriedade Intelectual não apenas induz a uma violação, como também importa um rompimento de expectativas razoáveis e aproveitamento indevido de esforços de terceiros, já estamos fora do campo do exercício regular de direito e dentro do âmbito do "exercício abusivo"- pois a Propriedade Intelectual não serve para convalidar, legitimar, uma tal conduta oportunista e anticoncorrencial. O Direito Civil brasileiro, por sinal, reconhece a ilicitude do ato de agente que o exerce um direito com excesso aos limites impostos pelo seu fim econômico ou social, pela boa-fé e pelos bons costumes (art. 187 do Código Civil);

4) Não se exige que a conduta abusiva seja eficaz no alcance dos objetivos (v.g., obtenção de posição dominante), bastando que ela tenha por objeto, ou que possa produzir tais efeitos. A mera tentativa de excluir concorrentes por meio do exercício abusivo já deve ser considerada suficiente para caracterizar o ilícito;

5) Por outro lado, embora a posição dominante ou poder econômico alcançados por meio dos direitos de Propriedade Intelectual não possam ser considerados como ilícitos per se, o exercício desta posição não pode se dar de forma abusiva, ficando sujeito a limites. O art. 68 da Lei 9.279/96 já prevê a figura do "abuso de poder econômico por meio de patentes”, que incidirá caso o detentor da patente não a utilize ou deixe de atender às exigências de mercado (mecanismo importante para coibir abusos em setores de interesse público geral, como medicamentos - nos moldes permitidos pelo artigo 8.1. do TRIPS). A Lei 12.529/2011, por outro lado, confirma a possibilidade de o CADE recomendar ao órgão competente o licenciamento compulsório em tais casos (art. 38, IV, a), o que não está restrito às patentes;

6) Outro exemplo de possível abuso de posição dominante envolvendo a Propriedade Intelectual seriam tentativas de bloquear ou retardar o desenvolvimento de novos 
produtos ou processos produtivos (concorrência de superação), por meio de arranjos contratuais;

7) Antes que se possa cogitar de abuso de posição dominante, esta posição deve estar caracterizada. Nos termos da lei, a posição dominante será presumida quando uma empresa ou grupo for capaz de unilateral ou coordenadamente alterar as condições de mercado (Poder de Mercado).

8) Aqui, deve se tomar cuidado para não confundir poder sobre o próprio preço com o efetivo poder sobre o mercado - circunstância que não se caracteriza, necessariamente, quando uma empresa puder fixar preços acima de seus custos marginais (teoria neoclássica, que, contudo, é insuficiente para descrever as características da Nova Economia);

9) Deve-se analisar se a Empresa, realmente, pode, livremente, controlar os preços de mercado e restringir a oferta, sem quaisquer pressões competitivas. Também se presumirá a posição dominante quando ficar caracterizado o controle sobre uma fatia significativa do mercado $(20 \%$, nos termos da lei, ou outro percentual estabelecido pelo CADE).

Quanto ao controle de estruturas, no Brasil, a análise de eficiências vem ganhando importância na avaliação dos atos de concentração nos últimos anos. Entretanto, o Sistema Brasileiro de Defesa da Concorrência tem sido conservador na aceitação de argumentos baseados em ganhos de eficiência, ficando o debate restrito às eficiências estáticas, produtivas e alocativas. Não há, até o momento, precedentes que enfrentaram, explicitamente, alegações de eficiências dinâmicas - cuja importância é crescente em outras jurisdições, devido à influência das teses Schumpeterianas.

A própria Lei brasileira reconhece expressamente a possibilidade de seu conhecimento para fins de, excepcionalmente, justificar atos de concentração (vide art. 88 da Lei 12.529/2011, $\S 6^{\circ}$, inciso I, alíneas $b$ e $c^{472}$.

\footnotetext{
${ }^{472}$ Lei no 12.529/2011:

"Art. 88. (...)

$\$ 5^{\circ}$ - Serão proibidos atos de concentração que impliquem eliminação da concorrência em parte substancial do mercado relevante, que possam criar ou reforçar uma posição dominante ou que possam resultar na dominação de mercado relevante de bens ou serviços, ressalvado o disposto no $\$ 6^{\circ}$ deste artigo.

$\S 6^{\circ}$ - Os atos a que se refere o $\$ 5^{\circ}$ deste artigo poderão ser autorizados, desde que sejam observados os limites estritamente necessários para atingir os seguintes objetivos:

I- Cumulada ou alternativamente:

g) Aumentar a produtividade ou a competitividade;

h) Melhorar a qualidade de bens ou serviços; ou

i) Propiciar a eficiência e o desenvolvimento tecnológico ou econômico; e

II - Sejam repassados aos consumidores parte relevante dos benefícios decorrentes” (destaques acrescidos)
} 
Note-se, porém, que o direito concorrencial brasileiro exige que a restrição imposta à concorrência seja aquela estritamente necessária para atingir tais eficiências $\left(\$ 6^{\circ}\right)-$ ou seja, tem-se a exigência de causalidade. Além disso, há necessidade de se provar o repasse, aos consumidores, de parte relevante dos ganhos em eficiência dinâmica alcançados.

Logo, o direito brasileiro desloca a análise para as evidências no caso concreto afastada uma primazia, a priori, da eficiência dinâmica sobre a eficiência estática (concorrência de preço e nível de oferta), em sacrifício do interesse dos consumidores diferentemente do que se observa em outras jurisdições, como na União Europeia, em que as Cortes chegaram ao ponto de relativizar direitos de Propriedade Intelectual quando estiverem em jogo possíveis efeitos nocivos à inovação tecnológica (vide, por exemplo, o Caso Microsoft).

Finalmente, quanto ao controle antitruste exercido sobre os contratos de transferência de tecnologia, refutamos qualquer tentativa de estabelecer uma Teoria da Decisão formalista, tendente a instituir regras não positivadas de legalidade per si, que se traduzam em verdadeiros "cheques em branco" para aprovação de atos que, em sua substância, poderiam dissimular verdadeiras tentativas de controlar mercados, sob pretexto de que os custos de tolerar atos de concentração podem ser inferiores aos custos de uma intervenção antitruste equivocada, quando estiverem em jogo potenciais efeitos nocivos à inovação tecnológica (Tese Neo-Chicago). Além de não estarem positivadas, tais regras se baseiam em consequencialismos que, raramente, são aceitos pela teoria econômica mais atualizada.

Ao invés disso, defendemos que tais contratos sejam sujeitos a uma regra da razão estruturada, em que as autoridades antitruste desempenhem análises pormenorizadas dos diferentes setores da indústria, seus respectivos processos competitivos dinâmicos, tomando as cláusulas contratuais de maneira menos descolada da realidade e mais atenta aos fatos e ao direito positivo. 


\section{BIBLIOGRAFIA}

Aghion, Philippe; Bloom, Nick; Blundell, Richard; Rachel, Griffith; Peter, Howit, "Competition and Innovation an Inverted-U Relationship", The Quarterly Journal of Economics, May 2005

AnAND, Bharat N; KHAnNA, Tarun, "The Structure of Licensing Contracts", The Journal of Industrial Economics, vol. 48, n. 1, March/2000, pgs. 103-135

Andrew, B. Abel; MAnKIw, Gregory N.; Summers, Lawrence H. e ZeCKHAUSER, Richard, "Assessing Dynamic Efficiency: Theory and Evidence", Review of Economic Studies, $1989,56,1-20$

ANDREJ Fatur, "EU Competition Law and the Information and Communication Technology Network Industries”, Hart Publishing, 2012

ARrow, Kenneth "Economic Welfare and the Allocation of Resources", In The Rate and Direction of Inventive Activity: Economic and Social Factors, Princeton University Press, 1962, pg. 609, disponível em: http://www.nber.org/chapters/c2144.pdf

Arruda DE ANdrade, José Maria, "Economização do Direito Concorrencial”, São Paulo, Quartier Latin, 2014 "Economização do Direito Concorrencial e

Positivismo Jurídico: entre Teoria da Decisão e das Provas”, São Paulo, FDUSP, 2012 (Tese de Livre Docência)

“Interpretação da Norma Tributária”, São Paulo,

MP Editora, 2006

“A Constituição Brasileira e as Considerações

Teleológicas na Hermenêutica Constitucional”, In: Cláudio Pereira de Souza Neto; Daniel 
Sarmento; Gustavo Binenbojm (Org.), Vinte Anos da Constituição Federal de 1988, Rio de Janeiro, Lumen Juris, 2009, pgs. 323/340

"Hermenêutica da Ordem Econômica e

Constitucional e o Aspecto Constitutivo da Concretização Constitucional”, Revista Fórum de Direito Financeiro e Econômico, v. 1, pgs. 249/268, 2012

“Entre Princípios e Regras. Entre Progressos Iniciais e Fanatismo", In: José Augusto Fontoura Costa, José Maria Arruda de Andrade, Alexandra Mery Hansen Matsuo (Org.). Direito Teoria e Experiência. Homenagem a Eros

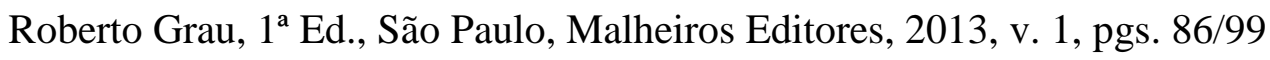

Ascarelli, Túlio, In: “Teoria Della Concorrenza e Dei Beni Immateriali - Istituizioni Di Diritto Industriale”, Terza Edizione, Milano, Dott. A. Giufré Editore, 1960

ASCEnSÃo, José Oliveira, "Direito da Internet e da Sociedade da Informação", Rio de Janeiro, Editora Forense, 2002

Avelãs Nunes, J. Antônio, "Uma Introdução à Economia Política”, São Paulo, Editora Quartier Latin, 2007

Bagley, Constance E., Clakson, Gavin, “Adverse Possession for Intellectual Property: adapting an ancient concept to resolve conflicts between antitrust and intellectual property laws in the information age", Harvard Journal of Law \& Technology, v. 16, p. 327-393, Spring 2003

BAKER, Jonathan B., "Beyond Schumpeter vs. Arrow: How Antitrust Fosters Innovation", June 2007, Washington College of Law, disponível em http://ssrn.com/abstract=962261

BARbosA, Dênis Borges, "Do Bem Incorpóreo à Propriedade Intelectual", 2009, disponível no portal do autor em: http://www.denisbarbosa.addr.com/arquivos/novidades/teoria.pdf 
http://denisbarbosa.addr.com/entrevista.pdf

"Nota sobre a aplicação das Essential Facilities à Propriedade Intelectual", 2005, disponível no portal do autor em http://www.denisbarbosa.addr.com/arquivos/200/concorrencia/essential.doc

“Jurisprudência do CADE sobre PI”, 2005, disponível no portal do autor em http://www.denisbarbosa.addr.com/picade.doc

"A Criação de um Ambiente Competitivo e o Caso Sul-

Americano", 2005 , disponível em http://www.iprsonline.org/unctadictsd/docs/Barbosa\%20FINAL\%20formatado.pdf

"Nota sobre a Propriedade Intelectual e a legislação, a prática e a jurisprudência brasileira em matéria de abuso de direitos e abuso de poder econômico", 2005, disponível no portal do autor em: http://www.denisbarbosa.addr.com/abuso\%20brasil.doc

"Uma Introdução à Propriedade Intelectual", Rio de Janeiro, Lumen Juris, Segunda Edição Revista e Atualizada, 2003, disponível no portal do autor em http://www.denisbarbosa.addr.com/arquivos/livros/umaintro2.pdf

“A Doutrina da Concorrência", 2002, disponível no portal do autor em http://www.denisbarbosa.addr.com/11.doc

"Cláusulas Restritivas nos Contratos de Tecnologia" 1981, disponível no portal do autor em http://www.denisbarbosa.addr.com/169.rtf

“A Lei Antitruste e a Propriedade Industrial”, 1980, disponível no portal do autor em: http://www.denisbarbosa.addr.com/paginas/200/concorrencia.html 
BARbOSA, Cláudio R., in "Introdução à Propriedade intelectual como informação", 1" Edição, São Paulo, Editora Campus, 2009

Barros Carvalho, Paulo de, "Breves Considerações Sobre a Função Descritiva da Ciência do Direito Tributário", Consultor Jurídico, 1 de Outubro de 2013

BAsso, Maristela; Polido, Fabrício Bertini Pasquot, Editorial, "Special Issue: International Intellectual Property Law and the Creative Industries", Intelectual Journal of Intellectual Property Management (Print), v. 4, pg. 01-05, 2010

Basso, Maristela; SAlomão FILho, Calixto; Polido, Fabrício Bertini Pasquot, "Propriedade Intelectual e preços diferenciados de medicamentos essenciais: políticas de saúde pública para países em desenvolvimento”, Revista de Direito Público, São Paulo, v. 3, n. 11, pgs. 63-97, 2005

BAsso, Maristela, "Análise dos Direitos de Propriedade Intelectual sob a Perspectiva do Direito Antitruste: especial referência às marcas", Revista do IBRAC, v. 16, pgs. $75 / 100,2009$

"Prazo de Patentes - Aplicabilidade do Artigo 40, parágrafo único da Lei n. 9279/1996”, Revista da ABPI, v. 10, pgs. 25-33, 2009

"A tutela constitucional da propriedade intelectual na carta de 1988: Avanço Indiscutível”, Revista de Informação Legislativa, v.1, pgs. 39-48, 2008

"Propriedade Intelectual: combustível para o desenvolvimento brasileiro" (entrevista), Revista do Tribunal Regional Federal 1. Região, v.2, pgs. 11-16, 2006

"Os fundamentos atuais do Direito Internacional da Propriedade Intelectual", Conferência proferida no Seminário sobre Direito Autoral, realizado pelo centro de Estudos Judiciários, nos dias 17 e 18 de março de 2003, no Centro Cultural Justiça Federal, Rio de Janeiro/RJ, Revista CEJ Brasília, no 21, pg. 16-30, abr/jun 2003 
BAXTER, William F. "The Definition and Measurement of Market Power in Industries Characterized by Rapidly Developing and Changing Technolgies", 1984, 53 Antitrust Law Jorunal 717

BEIER, Friedrich Karl, "The Significance of the Patent System for Technical, Economic and Social Progress", disponível em $\underline{\text { http://beck- }}$ online.beck.de/default.aspx?printmanager=print\&VPATH=b

BELKNAP, Michael R., "The Supreme Court under Earl Warren, 1953-1969”, University of South Carolina Press, April, 2005, pgs. 13-14

Benkler, Yochai, "The Wealth on Networks - How Social Production Transforms Markets and Freedom”, Yale University Press, New Haven and London, 2006

Bentham, Jeremy, "Observations on Parts of the Declaration of Rights as Proposed by Citizen Sieyes", The Works of Jeremy Bentham, Vol. 2 (Judicial Procedure, Anarchical Fallacies, works on Taxation) [1843] $\quad-\quad$ disponível em http://oll.libertyfund.org/titles/bentham-the-works-of-jeremy-bentham-vol2?q=decried\#Bentham_0872-02_6404

BercovicI, Gilberto; Andrade, José Maria Arruda de, "A Concorrência Livre na Constituição de 1988”, In: Filosofia e Teoria Geral do Direito, por João Maurício Adeotado e Carlos Bianca Bittar, São Paulo, Quarter Latin, 2011, pgs. 449/468

Bercovici, Gilberto; Octaviani, Alessandro, "Direito e Subdesenvolvimento: O Desafio Furtadiano, In: Rosa Freire d'Aguiar (Org.), Celso Furtado e Dimensão Cultural do Desenvolvimento, $1^{\text {a }}$ Ed., Rio de Janeiro, E-Papers, Centro Internacional Celso Furtado, 2013, pgs. $49 / 67$

BercovicI, Gilberto; MAssoneto, L.F., "A Constituição Dirigente Invertida: A Blindagem da Constituição Financeira e a Agonia da Constituição Econômica”, In: Jacinto Nelson de Miranda Coutinho; José Luis Bolzan de Morais; Lenio Luiz Streck (Org.), A 
Constitucionalização do Direito: Fundamentos Teóricos e Aplicações Específicas, Rio de Janeiro, Lumen Juris, 2007, pgs. 167/175

BercovicI, Gilberto, "Constituição e Estado de Exceção Permanente: Atualidade de Weimar”, $1^{\text {a }}$ edição, Rio de Janeiro, Azougue Editorial, 2004, pg. 276

Bohannan, Christina; HovenkamP, Herbert J., "Creation Without Restraint: Promoting Liberty and Rivalry in Innovation", Oxford University Press, December 2011; U Iowa Legal Studies Research Paper. Available at SSRN: http://ssrn.com/abstract=2125277

BRANCHER, Paulo, "Direito da Concorrência e Propriedade Intelectual - Da Inovação Tecnológica ao Abuso de Poder”, Editora Singular, São Paulo, 2010, pg. 87

Brant, Leonardo Nemer Caldeira; Lage, D.A.; Cremasco, S.S.; Basso, Maristela, "Interface entre Propriedade Intelectual e Direito Antitruste: Análise dos efeitos da Importação Paralela no Brasil”, In: Leonardo Nemer Caldeira Brant; Délber Andrade Lage; Suzana Santi Cremasco (Org.), Direito Internacional Contemporâneo, $1^{\text {a }}$ Edição, Curitiba, Juruá, 2011, pgs. 597/617

BrandeIS, Louis D., “Other People's Money and How the Bankers Use It”, New York, Frederick A. Stokes Company Publishers, 1913

BRITO JUnIOR, Jorge Luiz de, "PIS/COFINS, Conceito de Insumos e a Questão dos "Insumos dos Insumos" - Proposta de Interpretação Teleológica e Uso de Argumento Econômico - Estudo de Caso do Setor Sucroalcooleiro", in Revista de Direito Tributário Atual, no 30, Dialética, São Paulo, 2014, pg. 208.

BurChFIEL, Kenneth J, "Revising the 'Original' Patent Clause: Pseudohistory in Constitutional Construction”, Vol. 2, Spring Issue, 1989

CAMEliER, Alberto, "Desenho Industrial: Abuso de Direito e Reflexo na Concorrência do Mercado de Reposição", Tese de Doutoramento, FADUSP, 2012 
CARlson, Steven C., "Patent Pools and the Antitrust Dilemma", Yale Journal on Regulation, v. 16, pgs. 359-373, 1999

Carvalho, Cristiano, “Teoria da Decisão Tributária”, São Paulo, 2010 (Tese de Livre Docência FDUSP)

Carvalho, Nuno Pires de, "A estrutura dos sistemas de patentes e de marcas", Rio de Janeiro: Lumen Juris, 2009

CElli Júnior, Humberto; BAsso, Maristela; Amaral, J. Alberto; “A Teoria do "Patent Linkage" e a "Contributory Infringement Doctrine" no Direito de Propriedade Industrial Brasileiro e no Direito Comparado", In: Umberto Celli Junior; Maristela Basso; Alberto Amaral Junior (Org.), Arbitragem e Comércio Internacional - Estudos em Homenagem a Luiz Olavo Baptista, $1^{\text {a }}$ Ed., São Paulo, Quartier Latin, 2013, v. 1, pgs. 211/245

Chang, Ha-Joo, "Maus Samaritanos - O Mito do Livre-Comércio - A história secreta do capitalismo", Rio de Janeiro, Elsevier, 2009

"Kicking Away the Ladder - An Unofficial History of Capitalism, Especially in Britain and the United States”, Challenge, 2002, Vol. 45, Issues 5, pgs. 63/97

CoAse, Ronald H. "The Nature of the Firm", Economica, New Series, Vol. 4, No. 16, 1937, pgs. 386-405

"The Problem of Social Cost", Journal of Law and Economics, Vol. 3, The University of Chicago Press, 1960

Comparato, Fábio Konder, "Grupo societário fundado em controle contratual e abuso de poder do controlador”, In: Direito Empresarial, p. 270-91. São Paulo: Saraiva, 1995.

CORvo RIBAS, Guilherme Favaro, "Direito Antitruste e Propriedade Intelectual - uma abordagem sob a ótica das vendas casadas”, São Paulo, Editora Singular, 2011 
Crane, Daniel A., "Patent Pools, RAND Commitments, and the Problematic of Price Discrimination”, Cardozo Legal Studies Working Paper No. 232, 2008. Disponível em: http://ssrn.com/abstract=1120071. Acesso em: 4 mar. 2012.

"Chicago, Post-Chicago and Neo-Chicago". Review of How Chicago Overshot the Mark: The Effect of Conservative Economic Analysis on U.S. Antitrust, by R. Pitofsky, editor, U. Chi. L., Rev. 76, n 4, 2009: 1911-33

DAsGuPTA, Partha; Stiglitz, Joseph, "Uncertainty, Industrial Structure and the Speed of R\&D”, 11 Bell Journal of Economics, 1, 27, 1980

Delvin, Alan, "Antitrust in an Era of Market Failure", Harvard Journal of Law \& Public Policy, v. 33, 2011

DE LAS Cuevas, Cabanellas, "Derecho de Patentes de invención", Buenos Aires, Heliasta, S.R.L., 2004

DE Soto, Jesús Huerta, “The Essence of the Austrian School and the Concept of Dynamic Efficiency”, REBS Review of Economy, Volume 4, Issue 1, pp. 15-32, 2011

Dimoulis, Dimitri; LunARDI, Soraya Gasparetto, - "O Positivismo Jurídico Diante da Principiologia", In: Teoria do Direito Neoconstitucional - Superação ou Reconstrução do Positivismo Jurídico? - Dimitri Dimoulis; Écio Oto Duarte (Cord.), São Paulo, Editora Método, 2008, pg. 179.

Di Blasi , Gabriel; Garcia, Mario Soerensen e Mendes , Paulo Parente M., "A Propriedade Industrial - O Sistema de Marcas, Patentes e Desenhos Industriais Analisado a partir da Lei n 9.279, de 14 de maio de 1996”, Rio de Janeiro, Editora Forense, 2002.

DREXL, Josef, "Is there a 'more economic approach' to intellectual property and competition law?", In: Research Handbook on Intellectual Property and Competition Law, Edgard Elgar Publishing Limited, UK, 2008 
DutTon, H.I, "The Patent System and Inventive Activity during the Industrial Revolution”, Manchester University Press, 1984

DwORKIN, Ronald M. "Is Wealth a Value?", The Journal of Legal Studies, Vol. 9, No. 2, Change in the Common Law: Legal and Economic Perspectives, Mar, 1980, pgs. 191/226 "Why Efficiency? - A Response to Professors Calabresi and Posner", Hofstra Law Review, Vol. 8, Iss.3, Article 5, 1979-1980

EISFELD. Jens, "Sobre a Oposição entre o Pensamento Jusnaturalista e Histórico na primeira metade do Século XIX, exemplificada na Propriedade Intelectual”, In: Revista Eletrônica do IBPI, Ano II, nº 4, 2011

EASTERBROOK, Frank H., "The Limits of Antitrust”, 63, Texas Law Review, 1, 15, 1984

European COMISSION, "Guidelines on the application of Article 81 of the EC Treaty to technology transfer agreements" (n 106) §§ 19-25

"Guidelines on the Assessment of Horizontal Mergers under the Council Regulation on the Control of Concentration between Undertakings" (EC) [2004] OJ C31/03, $\S \S^{\circ} \mathrm{s} 79-88$

Evans, David S.; Padilla, A. Jorge, "Designing Antitrust Rules for Assessing Unilateral Practices: A Neo-Chicago Approach”, The University of Chicago Law Review, Vol. 72, n. 1, Symposium: Antitrust, Winter, 2005, pp. 73-98

Evans, David; Layne-Farrar, Anne - "Software Patents and Open Source: The Battle Over Intelelctual Property Rights, Virginia Journal of Law \& Technology”, Vol. 9, nº 10, Summer, 2004

FAgundeS, Jorge; Pondé, João Luiz - "Barreiras à Entrada e Defesa da Concorrência: Notas Introdutórias", Texto para Discussão $\mathrm{n}^{\mathbf{0}}$ 1, Cadernos de Estudo, Universidade Cândido Mendes, 1998 
FackelmanN, Christian R, "Dynamic Efficiency Considerations in EC Merger Control. An Intractable Subject or a Promising Chance for Innovation?", Oxford Centre for Competition Law and Policy, Working Paper No. L-09/06, 2006, pp. 23-32

Ferraz JR, Tércio Sampaio, "Propriedade Industrial e Defesa da Concorrência", Revista da ABPI, nº 8, ano II, São Paulo, 1993, pgs. 10/12

FISHER, Willian, In: "Theories of Intellectual Property", New Essays in the Legal and Political Theory of Property, Cambridge University Press, 2001, disponível em http://www.law.harvard.edu/faculty/tfisher/iptheory.html

FIANI, Ronaldo, "Uma Avaliação Crítica da Teoria de Rent Seeking", Seminário de Pesquisa IE/UFRJ, Rio de Janeiro, 2003

FIKENTSCHER, Wolfgang, "Intellectual Property and Competition - Human Economic Universals or Cultural Specificities? A Fareweel to Neoclassics", IIC-International Review of intellectual property and competition law, 38(2), 2007, pgs. 137/165

Forgioni, Paula A., "Os Fundamentos do Antitruste”, 7a edição, São Paulo, Revista dos Tribunais, 2014, v.1

“A evolução do direito comercial brasileiro. Da mercancia ao mercado", $2^{a}$ ed., São Paulo, Revista dos Tribunais, 2012

“A Teoria Geral dos Contratos Empresariais", 2a edição, São Paulo, Revista dos Tribunais, 2012

“Contrato de Distribuição", 2ª edição, São Paulo. Editora Revista dos Tribunais, 2008, v. 1

“Direito Concorrencial e Restrições Verticais", 1ª edição, São Paulo, Editora Revista dos Tribunais, 2007 
"Tullio Ascarelli, a teoria geral do Direito e os contratos de distribuição, Revista Magister Direito Empresarial, Concorrencial e do Consumidor, São Paulo, v. 02, pgs. 11/35, 2005

FRANCESCHELLI, Remo, “Trattato di Diritto Industriale" Parte Generale, volume primo, Milano, Dott. A. Giuffré Editore, 1961, p. 381.

Freitas da Silva, Denise, "Pools de Patentes: Impactos no Interesse Público e Interface com Problemas de Qualidade do Sistema de Patentes", Universidade Federal do Rio de Janeiro, Instituto de Economia, 2012 (Tese de Doutoramento)

Gama Cerqueira, "Tratado da Propriedade Industrial”, Vol. 1, 2ª Ed. Rev. e Atual., Revista dos Tribunais, 1946, pg. 103

Gama Cerqueira, Hugo E. da Gama, "A Economia Evolucionista: Um Capítulo Sistêmico da Teoria Econômica", Belo Horizonte, UFMG/Cedeplar, 2000, disponível em http://web.cedeplar.ufmg.br/cedeplar/site/pesquisas/td/TD\%20150.pdf)

GEOFFroy, Ricardo Corrêa, "Eficiências Econômicas em Atos de Concentração: Rumo à Incorporação de Eficiências Dinâmicas", Monografia premiada com o $2^{\circ}$ lugar no V Prêmio SEAE, 2010

GERBER, David J., "Law and Competition in Twentieth Century Europe - Protecting Prometheus", Oxford University Press, 1998

“Global Competition - Law, Markets, and Globalization”, Oxford University Press, 2010

GILBERT, Richard, "Looking for Mr. Schumpeter: Where Are We in the CompetitionInnovation Debate?", Innovation Policy and the Economy, Vol. 6, The MIT Press, 2006 
“Antitrust for Patent Pools:A Century of Policy Evolution", Stanford Technology Law Review, 3, 2004, disponível em: http://stlr.stanford.edu/STLR/Articles/04_STLR_3

Gilbert, J. Richard; Newberry, David. M.G., "Preemptive Patenting and the Persistance of Monopoly", The American Economic Review, Vol. 72, nº 3, Jun, 1982, pg. 514-526

GILBERT, Richard J.; SHAPIRO, Carl, "Converging Doctrines? U.S. and EU antitrust policy for the licensing of Intellectual Property”. ABA Antitrust Magazine, v. 19, Fall, 2004.

GiL-Moltó, Maria J., "Economic Aspects of the Microsoft Case: Networks, Interoperability and Competition", University of Leicester, Department of Economics, Working Paper No. 08/39, November, 2008

Giocoli, Nicola, "Competition vs. Property Rights: American Antitrust Law, the Freiburg School and the early years of European Competition Policy", Munich Personal RePEc Archive, Paper No. 33807, 2011, http://mpra.ub.uni-muenchen.de/33807

Godin, Benoît, The Knowledge Economy: Fritz Machlup's Construction of a Synthetic Concept", Project on the History and Sociology of S\&T Statistics, Working Paper No. 37, 2008, Disponível em http://www.csiic.ca/PDF/Godin_37.pdf

GraU, Eros Roberto; Forgioni, Paula A., "O Estado, a empresa e o contrato”, 1 a edição, São Paulo, Malheiros, 2005, v.1

GRAU, Eros Roberto , “A Ordem Econômica na Constituição de 1988”, 14ª Edição, Revista e Atualizada, São Paulo, Malheiros, 2010

"O Direito Posto e o Direito Pressuposto", 7ª edição, São Paulo,

Malheiros Editores, 2008, v.1

Grau-Kuntz, Karin, "Estudo - Direito de Patente e Mercados Secundários -Impressoras e Cartuchos de Tinta", Revista do IBPI n 05, 2012 
"A interface da propriedade intelectual com o direito antitruste", publicado na plataforma do IBPI - Instituto Brasileiro de Propriedade Intelectual (www.ibibrasil.org), (exposição apresentada na Faculdade de Direito da Universidade de São Paulo em 22 de agosto de 2011 - Organização IBPI e Departamento de Direito Comercial da Faculdade de Direito da Universidade de São Paulo)

“Jusnaturalismo e Propriedade Intelectual”, Revista da Associação Brasileira de Propriedade Intelectual - ABPI, n 100, Maio/Junho 2009

"Algumas Considerações sobre a Crise do Direito de Autor", Revista Eletrônica da ABPI (REVEL), disponível em http://www.ibpibrasil.org/media/29f2bc789bf9ae9bffff82bcac14421f.pdf, 02.07.2012

"Sobre a Interpretação do Artigo 5, XXIX, da Constituição brasileira”, Revista Eletrônica da ABPI (REVEL), disponível em http://www.ibpibrasil.org/media/29f2bc789bf9ae9bffff82bcac14421f.pdf, acesso em 02.07.2012

Hans-JoAChIM, Dahms, "Neue Sachlichkeit in the Architecture and Philosophy of the 1920's", In: MiNAR, Edgard, "Heidegger, Wittgenstein and Skepticism", The Harvard Review of Philosophy, IX, 2001, disponível em: http://www.harvardphilosophy.com/issues/2001/Minar.pdf

HAYEK, Friedrich A., "Individualism and Economic Order", The University of Chicago Press, 1948

"The Use of Knowledge in Society", American Economic Review, XXXV, No. 4, 1945, pg 519-530 
HeINEMANN, Ullrich, MESTMÄCKER, Immenga, "EU Wettbewerbsrecht 5. Auflage 2012 Die Anwendung der Wettbewerbsregeln auf die Verwertung von Schutzrechten und sonst geschützten Kenntnissen"

Heller, Heller; EISENBERG, Rebecca S., "Can Patents Deter Innovation? The Anticommons in Biomedical Research”, Science, 1, Vol. 280, no. 5364, May 1998, pgs. 698-701

HoPE, Janet, "Biobazaar: The Open Source Revolution and Biotechnology", USA-UK, Harvard University Press, 2008

HovenKamp, Herbert J., "Innovation And Competition Policy: Cases and Materials an Open Source Casebook", University of Iowa - College of Law, 2013

“Competition for Innovation", Iowa Legal Studies Research Paper

No. 13-26, October, 2012 "Harvard, Chicago, and Transaction Cost Economics in Antitrust Analysis”, University of Iowa Legal Studies Research Paper, Number 10-35, December, 2010

"Antitrust Policy After Chicago", University of Iowa Legal Studies Research Paper, 09-21, May, 2009 - disponível em http://ssrn.com/abstract=1396788.

"The Neal Report and the Crisis in Antitrust" - University of Iowa Legal Studies Research Paper, Number 09-09, March, 2009

"United States Competition Policy in Crisis: 1890-1955", Minessota Law Review, Vol. 94, pg. 311, University of Iowa Legal Studies Research Paper No. 08-32, 2009 
"Schumpeterian Competition and Antitrust", University of Iowa Legal Studies Research Paper, Number 08-43, October, 2008.

"The Antitrust Enterprise: Principle and Execution -Cambridge, Massachusetts; Harvard University Press, 2008, pgs. 20-22

"IP and Antitrust Policy: A Brief Historical Overview", University of Iowa Legal Studies, Research Paper Nº5-31, December, 2005 "Federal Antitrust Policy: the law of competition and its practice", Second Edition, St. Paul, West Pub. Co, 1999, pg 527-528 "The Political Economy of Substantive Due Process", 40 Stanford Law Review 379, 1988

HovenKamP, H.; Janis, M; Lemley, M, "IP and Antitrust", Vol. 1, New York, Aspen Publishers, 2006, pgs. 21-114 e 21-115.

"Anticompetitive Settlement of Intellectual Property Disputes”. California: Boalt Working Papers in Public Law, Boalt Hall, UC Berkeley, 2003, disponível em: http://escholarship.org/uc/item/6v9359nt.

HugHES, Justin, “The Philosophy of Intellectual Property”, Georgetown Law Journal, December, 1988

Junghoon, Kim, “Technical Standard-Setting, Patent Pooling, and Competition Policy", Institute of Intellectual Property Bulletin, 2004, pg. 208

KATZ, Michael L.; ShElAnski, Howard A., "Meger Policy and Innovation: Must Enforcement Change to Account For Technological Change?", National Bureau of Economic Research, Working Paper 1070, 2004, disponível em: http://www.nber.org/papers/w10710 
KeYNES, J.M., “The General Theory Of Employment, Interest and Money”, Create Space Independent Publishing Platform, 2011

"The End of Laissez-Faire", In: Essays in Pesuasion - CWJMK, Londres, Macnillan, v. IX, cap. IV-2, 1972, p. 272-94.

KLEIN, Benjamin; LERNER, Andres V., "Introduction: The Economics Revolution in Antitrust Law". In: Economics of Antitrust Law, v. 1. p. ix-xliv, Cheltenham, Northampton: Edward Elgar Publishing, 2008

Kobayashi, Bruce H. "Spilled Ink or Economic Porgress?", The Antitrust Bulletin, v. 53, n. 1 , p. $5-33$, pg. 26 , Spring 2008

KORAH, Valentine, "Intellectual Property Rights and the EC Competition Rules". Oxford: Hart Publishing, 2006

"The Interface Between Intellectual Property and Antitrust: The European experience”, Antitrust Law Journal, Vol. 69, n³ 3, 2002,, pp. 801-839

Kubrusly, Cláudia Tosin, "Direito antitruste e propriedade intelectual: análise concorrencial dos acordos de licença e da recusa de licenciar" (Dissertação de Mestrado FADUSP, 2008)

LEÃO, Milton Lucídio Barcellos, "Limites e Possibilidade Hermenêuticas do Princípio da Igualdade no Direito de Patentes Brasileiro" (Tese de Doutorado, Pontífica Universidade Católica do Rio Grande do Sul, Porto Alegre, 2010)

LEMLEY, Mark, "Missing de Forest for the Trolls", Columbia Law Review,Stanford Law and Economics Olin Working PaperNo. 443, May, 2013

"A New Balance Between IP and Antitrust", Southwestern Journal of Law and Trade in the Americas, Vol. 13, pg. 237, 2007, Standford Law and Economics Olin Working Paper No. 340 
"Property, Intellectual Property, and Free Riding", in Texas Law Review, vol. 83, 2004-2005, pg. 1031-1075, disponível em: http://ssrn.com/abstract=582602

"Ten Things to do About Patent Holdup of Standards (and one not to)",

Boston College Law Review, Vol. 48, Boston College Law Review, Vol. 48: 149, 2007

LEMOS, Ronaldo, "Direito, Tecnologia e Cultura", Editora FGV, 2005, disponível em: http://virtualbib.fgv.br/dspace/handle/10438/2190

Lerner, Josh; TIRole, Jean, "Public Policy toward Patent Pools". NBER Chapters In: JafFe, Adam B., Lerner, Josh e Stern, Scott (Ed.), "Innovation Policy and the Economy", v.8, p. 157-186, University of Chicago Press, 2008. Disponível em: http://www.nber.org/chapters/c5304.pdf.

"Efficient Patent Pools", National Bureau of Economic Research, Working Paper 9175, Cambridge, September/2002, disponível em http://www.nber.org/papers/w9175

LESSIG, Lawrence, “The New Chicago School”, The Journal of Legal Studies, Vol. 27, No. S2, June 1998

"Code and other Laws of Cyberspace", disponível em http://code-islaw.org

LiAnOS, Ioannis e DREYFuss, Rochele C., "New Challenges in the Intersection of Intellectual Property Rights with Competition Law”, CLES Working Paper Series - Faculty of Laws, UCL, 4/2013

LiTAN, Robert E., "Antitrust and the New Economy", University of Pittsburgh, Law Review, v. 62, n. 3, Spring 2001 
MACLEOD, Christine, "Patents and Industrialization: An Historical Overview of the British Case, 1624-1907”, Department of History, University of Bristol, UK, June, 2010)

MachluP, Fritz; Penrose, Edith. "The patent controversy in the nineteenth century", The Journal of Economic History. Vol. X. n. I. 1950.pp. 1-29

"An Economic Review of the Patent System", Study of the Subcommitee on Patents, Trademarks, and Copyrights of the Comittee on the Judiciary United States Senate, Eighty-Fifth Congress, Second Session - Pursuant Senate Resolution 236 - Study No 15, Washington, Government Printing Office, 1958

“The Political Economic of Monopoly", Baltimore,

The Johns Hopkins Press, 1952

"Die Wirtschaftlichen Grundlagen des

Patentrechts", 1. Tei, GRUR, Aus1 1961, 373

"Schumpeter's Economic Methodology", The

Review of Economics and Statistics, Vol. 33, No. 2 (May, 1951), pp. 145-151, Published by: The MIT Press

MCCRAw, Thomas, "Schumpeter Ascending", in The American Scholar, Vol. 60, No. 3 Summer, 1991, pp. 371-392, Published by: The Phi Beta Kappa Society

"Louis D.Brandeis Reappraised", The American Scholar, Vol. 54, n 4, Autumn 1985, pp. 525-536

“Prophets of Regulation”, Harvard University Press, 1984

MAnN, Ronald J., "Do Patents Facilitate Financing in the Software Industry?", Texas law review, Vol. 83, n. ${ }^{\circ}$ 4, 2005 
Marshall, Alfred, "Princípios de Economia: Tratado Introdutório", Trad. Rômulo de Almeida e Ottolny Strauch, São Paulo, Abril Cultura, 1982

MARQUES, Remédio, "Propriedade Intelectual e interesse público", Boletim da Faculdade de Direito de Coimbra, Coimbra, n. LXXIX, p. 348, 2003

MizuKAMI, Nicoletti Pedro, "Função Social da Propriedade Intelectual: Compartilhamento de Arquivos e Direitos Autorais na CF/88", Dissertação de Mestrado, Pontifica Universidade Católica, São Paulo, 2007

MonTI, Mario, "EU Competition Policy After May 2004”, Fordham Annual Conference on International Antitrust Law and Policy, New York, 24 October, 2003, Discurso/03/489

MÜLlER-ARMACK, Alfred, "The Social Market Economy as An Economic and Social Order", Review of Social Economy, Vol. 36, No. 3, Continuing Perspectives on the Nature of Social Economics, December, 1978, pgs. 325-331

MüLLER, Friedrich, “Teoria Estruturante do Direito”, 2a Edição Revista, Atualizada e Ampliada, São Paulo, Revista dos Tribunais, 2009

Newberg, Joshua A.; Tom, Willard K "Antitrust and Intellectual Property - From Separate Spheres to One Unified Field”, Antitrust Law Journal, nº 66, 1997, pg. 169

OCtAVIANI, Alessandro; BerCovici, Gilberto, "Direito e Subdesenvolvimento: o desafio furtadiano", In: Rosa Freire Aguiar (Org.), Celso Furtado e a dimensão cultural do desenvolvimento, $1^{\text {a }}$ edição, 2013, v. 1, pgs. 49/68

OCTAVIANI, Alessandro, "Recursos Genéticos e Desenvolvimento: Os Desafios Furtadiano e Gramsciano, $1^{\text {a }}$ ed., São Paulo, Saraiva, 2013, v.1

"O CADE e a hermenêutica realista: grupo econômico para fins de direito concorrencial, participação minoritária, gestão compartilhada e fundos de 
investimento (homenagem a Fábio Konder Comparato)", A Nova Lei do CADE: o $1^{\circ}$ ano na visão das autoridades, $1^{\text {a }}$ edição, 2013, pgs. 29/76

“O Campo Biodiversidade/Biotecnologia: Os Recursos

Genéticos como Epicentro", Revista Internacional de Direito e Cidadania, v. 4, pgs. 195 218,2011

"Biotechnology in Brazil: Promoting Open Innovation". In:

Lea Shaver (Org.), Acess to Knowledge in Brazil: New Research on Intellectual Property, Innovation and Development, New Haven, Yale Law School, 2008, v., p. 127-161

"Recursos Genéticos: Biopiratas Chutando A Escada". Pontes entre o Comércio e Desenvolvimento Sustentável, São Paulo, p. 12 - 13, 01 jul. 2005.

OCDE - Roundtables 2004 - http://www.oecd.org/daf/competition/abuse/34306055.pdf

OMPI - Relatório Anual (2011) - disponível em: http://www.wipo.int/ipstats/en/statistics/country_profile/countries/br.html

Ordover, J.A. "Economic Foundations and Considerations in Protecting Industrial and Intellectual Property”, 1984, 53(3) Antitrust Law Journal 503

“A Patent System for both Diffusion and Exclusion”, Journal of Economic Perspectives, 5, 1991

PAUlAnI, “Acumulação e Rentismo: resgatando a teoria da renda de Karl Marx para pensar o capitalismo", Paper, Rio de Janeiro, ANPEC, 2012

Pitofsky, R., "How Chicago Overshot the Mark: The Effect of Conservative Economic Analysis on U.S. Antitrust", University of Chicago Law Review 76, n 4, 2009

"Challenges of the New Economy: Issues at the Intersection of Antitrust and Intellectual Property", Antitrust Law Journal, 913, 2000-2001 
PIVA DE ANDRADE, Gustavo, "A interface entre a Propriedade Intelectual e o Direito Antitruste”, Revista da ABPI 91, Novembro/Dezembro, 2007

PoPE, James Gray, “The Thirteenth Amendment Versus the Commerce Clause: Labor and the Shaping of American Constitutional Order", 1921-1950, 102 Colum. L. Rev. 1, 14, 5455,2002

PossAs, Mario Luiz, "Economia Evolucionária Neo-Schumpeteriana: Elementos para uma integração micro-macrodinâmica”, Estudos Avançados, vol. 22, nº 63, 2008, p. 281-305

"Eficiência Seletiva: Uma Perspectiva Neo-Schumpeteriana Evolucionária sobre Questões Econômicas Normativas", Artigo apresentado em versão preliminar no Seminário "Frontiers and Trends of Development: Innovation Research and Policy", organizado pelo IE/UFRJ e CRIC/Univ. of Manchester, Rio de Janeiro, 26.09.2002

Posner, Richard A. "Economic Analysis of Law”, 4 Ed., Boston: Little-Brown, 1992

"Intellectual Property: The Law and Economics Approach", Journal of Economic Perspectives - Volume 19, Number 2, Spring, 2005

PRIEST, George, "Cartels and Patent License Arrangements", Journal of Law and Economics, v. 20, n.2, p. 309-77, 1977.

QuINT, Daniel, “The New Palgrave Dictionary of Economics”. Online Edition, edited by Steven N. Durlauf and Lawrence E. Blume, 2008, Disponível em http://www.dictionaryofeconomics.com/article?id=pde2008_P000371.

ReICHMAN, J.H., "Universal Minimum Standards of Intellectual Property Protection under the TRIPS Component of the WTO Agreement", The International Lawyer, Summer, 1995

RICARDO, David, "On the Principles of Political Economy and Taxation", $3^{\text {rd }}$ Edition, London, John Murray, 1821 
Rosenberg, Bárbara, "Patentes de Medicamentos e Comércio Internacional: Os parâmetros do TRIPS e do direito concorrencial para a outorga de licenças compulsórias”. Tese de Doutorado apresentada na Faculdade de Direito da Universidade de São Paulo, 2004

Rosenberg, Bárbara; CAscão, Luís Bernardo Coelho, "Breves Notas sobre Atos de Concentração Submetidos ao CADE”, Concentração de Empresas no Direito Antitruste Brasileiro, André Marques Gilberto; Celso Fernandes Campilongo; Juliana Girardelli Vilela, São Paulo, Singular, 2012

Rosenberg, Nathan, "Por dentro da Caixa-Preta - Tecnologia e Economia", Trad. José Emílio Maiorino, Editora da Unicamp, 2006, p. 97.

RubinfELD, Daniel L.; MANESS, Robert, "The Strategic Use of Patents: Implications for Antitrust”, Lévêque and Shelanski (eds) (n 129) 85, 2004.

SAMUELSON, Pamela, "The Strange Odyssey of Software Interfaces and Intellectual Property Law", UC Berkeley - School of Law, Public Law Research Paper No. 1.323.818, 2008, disponível em http://ssrn.com/abstract=1323818

SAITO, Leandro, "A propriedade intelectual como barreira à entrada de novos players no mercado de softwares", São Paulo, IBPI, 2012

SAlomão Filho, Calixto; Comparato, Fábio Konder, "O Poder de Controle na Sociedade Anônima”, São Paulo, Ed. Forense, 2005, v. 1

SAlomão FilHo, Calixto, “Direito Concorrencial”, São Paulo, Malheiros, 2013 “As Condutas", 1ª ed., São Paulo, Malheiros, 2003 “As Estruturas”, 2a Edição, São Paulo, Malheiros, 2002 “A Legal Theory of Economic Power", 1 ed., 2011, v.1. 
"Historie Critique des Monopolies: Une Perspective Juridique et Économique", 1. Ed., Paris, LGDJ, 2010, v.1

"Direito Industrial, Direito Concorrencial e Interesse Público",

Revista de Direito Público da Economia - RDPE, ano 2, nº 7, Belo Horizonte, Editora Fórum, pg. 30

"Razoabilidade e Legalidade do Licenciamento Compulsório do Ponto de Vista Concorrencial”, In: Direitos de Propriedade Intelectual \& Saúde Pública - O acesso universal aos medicamentos anti-retrovirais no Brasil, São Paulo, Instituto de Direito do Comércio Internacional e Desenvolvimento, 2007, pgs. 147/167

SAMPAIO Ferraz JR., Tércio, "Propriedade Industrial e Defesa da Concorrência”, Revista da ABPI, nº 8, ano II, São Paulo, 1993, pgs. 10/12

SHAPIRO, Carl, "Navigating the Patent Thicket: Cross Licenses, Patent Pools, and Standard Setting", Innovation Policy and the Economy, Vol. 1, National Bureau of Economic Research, MIT Press, 2001

SCHERER, F.M. "Does Antitrust Compromise Technological Efficiency? A Conversation with F.M. Scherer”, Eastern Economic Journal, Volume XV, №1, January-March, 1989. “On Schumpeter", Harvard Kennedy School (Palestra):

-Parte 1: http://youtu.be/dLtjWZGJLuY

-Parte 2: http://youtu.be/-ZvBjd1003M

- Parte 3: http://youtu.be/MJfDqO54hM4

- Parte 4: http://youtu.be/ga7JnUHQPJM

SchumPETER, Joseph, "The Theory of Economic Development - An Inquiry into Profits, Capital, Credit, Interest and the Business Cycle”, Harvard University Press, 1934 
"Business Cycles: A Theoretical Historical and Statistical Analysis of the Capitalist Process", New York Toronto London : McGraw-Hill Book Company, 1939

“Capitalism, Socialism and Democracy”, London: Allen Unwin,1943

"The Instability of Capitalism", The Economic Journal, v. XXXVIII,

n. 151, Sept. 1928.

“A Instabilidade do Capitalismo", Clássicos de Literatura

Econômica - Textos Selecionados de Macroeconomia, IPEA, $3^{\mathrm{a}}$ Edição, Reimpressão Especial, Brasília, 2010

Shavell, Steven e TANGuY Van Ypersele, "Rewards Versus Intellectual Property Rights", Journal of Law and Economics , vol. XLIV, October, 2001 - disponível em http://law.harvard.edu - acesso em 09.12.2014.

SchuARTZ, Luis Fernando, "A Desconstitucionalização do Direito de Defesa da Concorrência”, disponível em http://bibliotecadigital.fgv.br/dspace/bitstream/handle/10438/1762/TpD\%20007\%20\%20Schuartz\%20-\%

SILVEIRA, Newton, "Propriedade material e concorrência", Revista dos Tribunais, São Paulo, Vol. 75, nº 604, pgs-264/271, Fevereiro, 1986

Parecer publicado na Revista Eletrônica do INBPI (REVEL), www.ibpibrasil.org, acesso em 24.10.2012

"Propriedade intelectual", $3^{\text {a }}$ Ed., Ed. Barueri, Manole, 2005

"Direito de autor no desenho industrial". 1. ed. São Paulo: Revista dos Tribunais, 1982 
SMith, Adam, "Inquiry Into the Nature and Causes of the Wealth of Nations", Canaan Edition, 1940, Disponível em http://www.econlib.org/library/Smith/smWN.html "A riqueza das nações, uma investigação sobre sua natureza e suas causas" - Trad. Luiz João Baraúna, São Paulo, Abril Cultura, 1983 (Os Economistas)

Stallman, Richard, "Free Software: Freedom and Cooperation" (discurso), New York University in New York, New York on 29 May 2001

STIGLITZ, Joseph E., "Economic Foundations of Intellectual Property Rights", Duke Law Journal, Vol. 57, No. 6, Published by: Duke University School of Law, Apr., 2008, pp. 1693-1724

Stuart Mill, John, in "Principles of Political Economy", Book V, Chapter X, Of Interferences of Government Grounded on Erroneous Theories, $7^{\text {th }}$ Edition, London, Longmans, Green and Co., 1909, disponível em: http://www.econlib.org/library/Mill/mlP72.html\#V.10.25

SundER, Madhavi, "Playing With Fire”, Journal of Gender, Race \& Justice, Vol. 4, No. 1, Fall 2000, disponível em: http://papers.ssrn.com/sol3/papers.cfm?abstract_id=279318

TIMM, Luciano Benetti, "Contrato Internacional de Transferência de Tecnologia no Brasil: Intersecção da Propriedade Intelectual com o Direito Antitruste", III Prêmio SEAE, Monografia em Defesa da Concorrência e Regulação Econômica, 2008.

"Teorias Rivais sobre a Propriedade Intelectual no Brasil", Economic Analysis of Law Review, V.1, n 1, Jan-Jun, 2010

UCDAVIS Glossary, Information and Educational Technology (disponível em: http://iet.ucdavis.edu/glossary.cfm)

Ulho Coelho, Fábio, "Direito Antitruste Brasileiro - Comentários à Lei n 8.884/94”, 5 Edição, São Paulo, Saraiva, 1995 
UlLRICH, Hanns, "Expansionist Intellectual Property Protection and Reductionist Competition Rules: A TRIPS Perspective”, EUI Working Paper LAW nº 2004/3

United States of AmericA's DePartment of Justice AND FedERAL Trade COMISSION Guidelines on the licensing of IP rights, (n 220) Section 3.2

Horizontal Merger Guidelines (2010), disponível em <http://www.ftc.gov/os/2010/08/100819hmg.pdf> Section 6.4. (tradução livre)

USPTO, "Patent Pools: A Solution to the Problem of Access in Biotechnology Patents?" 2000. Disponível em: http://www.ftc.gov/opp/intellect/020417lawrencemsung2.pdf.

Webster, Nesta H., "The Cavalier de Boufflers - A Romance of the French Revolution", New York, E.P. Dutton and Company, 1916

WeInSCHEL , Alan J., “Antitrust Pitfalls in Licensing”, PLI Intellectual Property Antitrust, 2001,pg 783

WIEACKer, Frans, "História do Direito Privado Moderno", Lisboa, Calouste Gulbenkian, 1993 